Uma abordagem de desenvolvimento de linha de produtos orientada a modelos para a construção de famílias de sistemas embarcados críticos

Paulo Gabriel Gadelha Queiroz 

Data de Depósito: 20/03/2015

Assinatura:

\section{Uma abordagem de desenvolvimento de linha de produtos orientada a modelos para a construção de famílias de sistemas embarcados críticos}

\section{Paulo Gabriel Gadelha Queiroz}

Orientadora: Profa. Dra. Rosana Teresinha Vaccare Braga

Tese apresentada ao Instituto de Ciências Matemáticas e de Computação - ICMC-USP, como parte dos requisitos para obtenção do título de Doutor em Ciências - Ciências de Computação e Matemática Computacional. VERSÃO REVISADA 
Ficha catalográfica elaborada pela Biblioteca Prof. Achille Bassi e Seção Técnica de Informática, ICMC/USP, com os dados fornecidos pelo(a) autor(a)

Queiroz, Paulo Gabriel Gadelha

Q3a Uma abordagem de desenvolvimento de linha de produtos orientada a modelos para a construção de familias de sistemas embarcados críticos / Paulo Gabriel Gadelha Queiroz; orientadora Rosana Teresinha Vaccare Braga. -- São Carlos, 2015. $230 \mathrm{p}$.

Tese (Doutorado - Programa de Pós-Graduação em Ciências de Computação e Matemática Computacional) -Instituto de Ciências Matemáticas e de Computação, Universidade de São Paulo, 2015.

1. Engenharia de Software. 2. Linha de Produtos. 3. Sistemas Embarcados Críticos. I. Braga, Rosana Teresinha Vaccare, orient. II. Título. 
Dedico esta tese a todos que acompanharam e torceram pela minha jornada. 



\section{Agradecimentos}

A Deus, por me dar oportunidade, capacidade e vontade para realizar este trabalho.

A toda minha família, em especial, meus pais Amélia e Paulo, meus avós Rita e Pedro e meus irmãos Pedro, Davi, Rebeca e Daniel. Não existem palavras suficientes para expressar o quanto amo, admiro e tenho orgulho de vocês.

À Professora Dra. Rosana Teresinha Vaccare Braga, pela amizade, conselhos, conhecimento e confiança na orientação deste trabalho. Tenho certeza que, um dia, você vai ao céu sem escalas.

À Professora Dra. Renata P. M. Fortes, à Professora Dra. Rosangela Aparecida Delloso Penteado e ao Professor Dr. João Porto de Albuquerque, pelas sugestões apresentadas no exame de qualificação.

À Professora Dra. Rossana Andrade e à Professora Dra. Ellen Francine pela avaliação e pelas contribuições apresentadas.

Aos professores de graduação, de mestrado e de doutorado que contribuíram para minha formação. Em especial, à Professora Dra. Rossana Andrade, à Professora Dra. Cláudia Linhares, ao Professor Dr. Riverson Rios, ao Professor Dr. Joaquim Bento, ao Professor Dr. Creto Vidal que foram fonte de inspiração durante a minha graduação e ao Professor Dr. Paulo C. Masiero, Professor Dr. Adenilso Simão, Professora Dra. Graça Pimentel que apoiaram meu trabalho e foram importantes durante a minha pós-graduação.

Aos amigos da velha geração do LABES/USP, pelo companheirismo, pela hora do café, pelo futebol e pelos churrascos: Andrezinho, Brunão, Calvo, Cascão, Camila, Casão, Chan, Daga, Diogo, drauzinho, Digão, DJ D’, Edson, Endo, Fabis, Frotinha, japa, KLB, Lenon, Logan, Marcelo, Vânia, Maria, Nerso, Otávio, Paula Donegan, Pio, pikaxu, puiuna, Plúcio, Rafael, Rodolfo, rumus, tibum, tiozão, Vânia, Dema, Viny, RafinhaD, zé1 e zé2.

Aos amigos e companheiros da nova geração do LABES/USP, pela parceria e amizade em tão pouco dempo de convivência: cocota, brauninho, pneu, aninha, livinha, stevão, Iohito, damasceno fura olho, danyboy, dema neto, ricardão, Silverio el pedrito e zeNilton.

Aos amigos e companheiros de rep que fizeram da minha estadia em São Carlos um momento bem mais divertido, agradável e prazeroso: beirinha, kaka, calcinho, cabeção, etzinho, mada, Marcella Letícia, marquito, maycuzim, miel, mobilis, pablito, petinho, ricardim, van, tobinha, Viça, Xunim, pimposo, tim, David. Provavelmente esqueci de alguém, mas com certeza todos estão gravados em minhas melhores lembranças, ou nas fotos, em caso de aminésia alcoolica ;). 
Aos amigos de Fortaleza, por, apesar da minha ausência, ainda serem meus amigos. Em especial à turma do galerão, composta por pedro katia, borges, vinicim, louis, rubens, rubem, jaja, lemonada, neguim, dieguim e nosso eterno amigo cissu caboco. Também agradeço aos meus amigos putinhos: viny baiano, mateta, rafinha, josino, orlando, raul, rômulo e todos os GRs.

Á Marília, que me apoiou, apostou em mim e me confortou com seu companheirismo nos dois anos finais do doutorado.

Aos colegas e amigos da UFERSA, em especial aos grandes amigos jijo, danyBoy e angelicats.

Aos professores e funcionários do ICMC, pelo constante auxílio, disposição e atenção. A todas as pessoas que contribuíram de alguma forma para a realização deste trabalho. A vida, por ser linda como ela é.

A UFERSA, por me liberar nos 6 meses finais para a conclusão deste trabalho.

"Os homens perdem a saúde para juntar dinheiro, depois perdem o dinheiro para recuperar a saúde.

E por pensarem ansiosamente no futuro esquecem do presente de forma que acabam por não viver nem no presente nem no futuro.

E vivem como se nunca fossem morrer... e morrem como se nunca tivessem vivido.. 


\section{Resumo}

Sistemas embarcados críticos (SEC) correspondem aos sistemas embarcados para aplicações críticas, que são aplicações nas quais falhas podem por vidas em perigo. A crescente imersão deste tipo de sistema em nossas atividades cotidianas aumentou sua demanda, e consequentemente, a necessidade por novas técnicas de desenvolvimento que possam aumentar a produtividade dos desenvolvedores. Linha de produtos (LP) é uma técnica de reúso, na qual famílias de produtos similares são desenvolvidos em conjunto, e portanto, objetiva-se o desenvolvimento em larga escala. Com a utilização de LP, pode-se reusar requisitos e arquitetura de forma sistemática. Entretanto, o reúso no domínio de sistemas embarcados críticos ainda é visto de forma cética. Por outro lado, o domínio de SEC tem obtido avanços de desenvolvimento por meio de técnicas orientadas a modelo. A Engenharia orientada a modelos (MDE) concentra-se na importância de modelos no ciclo de vida do sistema, tornando-os parte do produto final. Assim, mantêm-se os modelos simples, e a maioria da complexidade do software passa a pertencer às transformações, que podem ser obtidas automaticamente por motores de transformação. Isso ajuda a aumentar a qualidade do produto final, bem como facilitar a futura evolução do software, que poderá ser feita mudando-se os modelos de alto nível e obtendo-se, de forma automática, o novo produto. MDE é particularmente útil no domínio de SEC, pois a partir de modelos corretos do problema, a chance de introdução de erros durante a codificação é menor se geradores de aplicações forem utilizados em vez de codificação manual. Além disso, o aumento no nível de abstração proporcionado pelo MDE permite que técnicas de validação e verificação sejam usadas desde os estágios iniciais de desenvolvimento, tais como co-design e co-simulação. Portanto, este trabalho visa defender a tese de que é possível oferecer os benefícios do desenvolvimento em larga escala para o domínio de SEC e ainda continuar se beneficiando de técnicas de MDE. Para corroborar esta tese, define-se uma abordagem de desenvolvimento de linha de produtos de sistema com uso de técnicas de engenharia orientada a modelos para o desenvolvimento de famílias de sistemas embarcados críticos. Além disso, apresenta-se um estudo de caso de marca-passo elaborado segundo as indicações da abordagem proposta que indicam a viabilidade de sua utilização.

Palavras-chaves: engenharia de linha de produtos. sistemas embarcados críticos. engenharia orientada a modelos 



\section{Abstract}

Safety-critical embedded systems (SCES) correspond to embedded systems for critical applications, i.e., applications where lives can be lost if they fail. The increasing immersion of this type of system in our daily activities increased their demand and, consequently, the need for new development techniques that can increase developers productivity. Product Line (LP) is a promising technique for reuse, in which families of similar products are developed together and, therefore, it aims at large-scale development. With the use of LP we can reuse requirements and architecture systematically. However, developers remain sceptical about reuse in the SCES domain, mainly due to problems in the past, such as the failure of the spacecraft Ariane 5. In addition, advances in development of techniques for the SEC domain have been obtained, for example through model-driven engineering (MDE) approaches. MDE focuses on the importance of models in the software life cycle, making them part of the final product. So, it keeps models simple, and most of the software complexity belongs to the transformations that can be obtained automatically by transformation engines. This helps increasing the quality of the final product, and facilitate the future development of software that can be done by changing the high level models and obtaining, automatically, the new product. MDE is particularly useful in the SCES domain because, from correct models of the problem, the chance of introducing errors during coding is smaller if generators are used in the development instead of manual coding. In addition, the increased level of abstraction provided by MDE allows the use of validation and verification techniques since the early stages of development, such as co-design and co-simulation. Therefore, this work aims to defend the thesis that it is possible to offer the benefits of large-scale development for the SCES domain and still continue to benefit from MDE techniques. In support of this thesis, we define a system product line approach using model-driven techniques for the development of safety-critical embedded families. In addition, we present a case study prepared according to the directions of approach.

Key-words: product line engineering. safety-critical systems. model-driven engineering. 



\section{Lista de ilustrações}

Figura 1 - Processo de projeto segundo a metodologia $y$-chart. . . . . . . . . . . 48

Figura 2 - Processo de avaliação de segurança, em "V" no domínio de aviação industrial. 49

Figura 3 - Desenvolvimento de software orientado a modelos. . . . . . . . . . . . 55

Figura 4 - Exemplo de relacionamento entre metamodelo e modelo. . . . . . . . . . 56

Figura 5 - Exemplo de relacionamento entre metametamodelo e metamodelo. . . . . . 60

Figura 6 - Metamodelagem em quatro níveis. . . . . . . . . . . . . . . . . 61

Figura 7 - Taxonomia dos diagramas SysML . . . . . . . . . . . . . . 62

Figura 8 - Estrutura de um nó básico no diagrama de requisitos SysML. . . . . . . . . 63

Figura 9 - Metamodelo do diagrama de requisitos SysML. . . . . . . . . . . . . . 64

Figura 10 - Arquitetura do perfil MARTE. . . . . . . . . . . . . . . . 66

Figura 11 - Utilização de um gerador de aplicações. . . . . . . . . . . . . . . . . . . 67

Figura 12 - Transformação de PIM para PSM. . . . . . . . . . . . . . . . . . . . 72

Figura 13 - Exemplo de modelo de características. . . . . . . . . . . . . . . . . . . 80

Figura 14 - Estrutura para utilização da CVL(HAUGEN; WaSOWSKI; CZARNECKI,

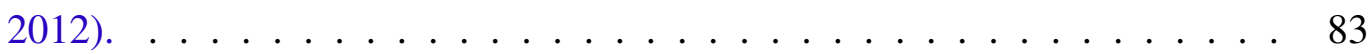

Figura 15 - Distribuição dos sistemas alvo. . . . . . . . . . . . . . . . . 97

Figura 16 - Modelos utilizados nos trabalhos encontrados. . . . . . . . . . . . . . . . . 97

Figura 17 - Gerência de variabilidades. . . . . . . . . . . . . . . . . . . . 98

Figura 18 - Sumário dos resultados. . . . . . . . . . . . . . . . . . . . . . . 99

Figura 19 - Visão geral da estrutura e das fases da abordagem ProLCES. . . . . . . . . 107

Figura 20 - Visão geral da estrutura e etapas da Engenharia de Requisitos de domínio. . 123

Figura 21 - Relação entre as atividades da etapa de elicitação de requisitos e os artefatos requeridos e providos. . . . . . . . . . . . . . . . . . 124

Figura 22 - Modelo de requisitos da linha de produtos de marcapasso em SysML. . . . . 129

Figura 23 - Estereótipos definidos para estender o diagrama de requisitos. . . . . . . . . 130

Figura 24 - Relação de artefatos requeridos e providos pela etapa de definição do escopo. 131

Figura 25 - Parte do modelo de features da linha de produtos de VANT a nível de software e hardware. . . . . . . . . . . . . . . . . . . . . . . . . . . . 134

Figura 26 - Relação de artefatos requeridos e providos pela atividade de mapeamento de variabilidades. . . . . . . . . . . . . . . . . . . . 135

Figura 27 - Exemplo de modelo base completo (LP de VANTs) . . . . . . . . . . . . . 138

Figura 28 - Exemplo de modelo CVL da linha de produtos de VANTs. . . . . . . . . . 139

Figura 29 - Artefatos requeridos e providos pela etapa de priorização de requisitos. . . . 139

Figura 30 - Exemplo de resolução de variabilidades no modelo da linha de produtos de VANTs. . . . . . . . . . . . . . . . . . . . 141 
Figura 31 - Modelo de produto de VANT, como resultado da execução da CVL com uma configuração. . . . . . . . . . . . . . . . . . . . . . . 141

Figura 32 - Relação entre os artefatos e as atividades da etapa de análise. . . . . . . . . 142

Figura 33 - Metamodelo da descrição textual de casos de uso. . . . . . . . . . . . . . . 144

Figura 34 - Uso da relação refinar para manter a rastreabilidade dos requisitos para os casos de uso. . . . . . . . . . . . . . . . . . . . . . . . . 144

Figura 35 - Metamodelo do diagrama de atividades da UML. . . . . . . . . . . . . 145

Figura 36 - Relação entre os artefatos e atividades da etapa de identificação e análise de subdomínios. . . . . . . . . . . . . . . . . . . . . . . . . . . 148

Figura 37 - Subdomínios da linha de produtos de VANTs. . . . . . . . . . . . . . 150

Figura 38 - Visão geral dos artefatos requeridos e providos pela atividade de definição do perfil. . . . . . . . . . . . . . . . . . . . 152

Figura 39 - Exemplo de utilização dos estereótipos definidos por Gomaa (2004). ... 153

Figura 40 - Parte dos estereótipos do perfil da linha de produtos de VANTs. . . . . . . . 154

Figura 41 - Visão geral das etapas principais do projeto de domínio. . . . . . . . . . . 158

Figura 42 - Artefatos requeridos e providos pela etapa de definição das diretrizes arquiteturais. . . . . . . . . . . . . . . . . . . . 161

Figura 43 - Domínio de VANTs simplificado, descrito por meio de features. . . . . . . . 163

Figura 44 - Artefatos requeridos e providos pela etapa de definição das diretrizes arquiteturais. . . . . . . . . . . . . . . . . . 166

Figura 45 - Componentes gerais de um sistema básico. . . . . . . . . . . . . . . 167

Figura 46 - Arquitetura inicial, em alto nível do VANT. . . . . . . . . . . . . . . . 173

Figura 47 - Arquitetura em alto nível do VANT com o refinamento do módulo X. . . . . 175

Figura 48 - Parte do diagrama de requisitos SysML da linha de produtos de marca-passo. 192

Figura 49 - Tipos de sistemas marca-passo e suas features. . . . . . . . . . . . . . . 192

Figura 50 - Features da linha de produtos de marca-passo . . . . . . . . . . . . . . 193

Figura 51 - Modelo de requisitos de linha de produtos. . . . . . . . . . . . . . . . . . . 194

Figura 52 - autômato temporal do marca-passo VVI. . . . . . . . . . . . . . . . . . 195

Figura 53 - Modelo do coração humano. . . . . . . . . . . . . . . . . . . 195

Figura 54 - Modelo sendo validado pela UPPAAL. . . . . . . . . . . . . . . . . 196

Figura 55 - Estereótipos do perfil de variabilidade. . . . . . . . . . . . . . . . . . 196

Figura 56 - Arquitetura em alto nível. . . . . . . . . . . . . . . . . . . . 197 


\section{Lista de tabelas}

Tabela 1 - Tipos de variabilidades e seu significado . . . . . . . . . . . . 136 



\section{Lista de abreviaturas e siglas}

ACM

ADL

AMS

API

ALP

AST

ATAM

ATL

CAD

CIM

CMMI

CVL

CWM

DCCA

DR

DSL

DSM

DTD

EA

EATAM

ED

EMF

EMP
Association for Computing Machinery

Architecture Description Language

Analog and Mixed-Signal

Application Programming Interface

Arquiteturas de linha de produtos

Abstract Syntax Tree

Architectural Trade-off Analysis Method

ATLAS Transformation Language

computer aided design

Computational Independent Model

capability maturity model integration

Common Variability Language

Common Warehouse Metamodel

Deductive Cause Consequence Analysis

Documento de Requisitos

Domain Specific Language

Domain-Specific Modeling

Document Type Definition

Engenharia de Aplicações

Extended Architecture Tradeoff Analysis Method

Engenharia de Domínio

Eclipse Modeling Framwork

Eclipse Modeling Project 
ER Engenharia de Requisitos

ESE $\quad$ Embedded System Engineering

FAST Family-Oriented Abstraction, Specification, and Translation

FDR Failures-Divergences Refinement

FHA Functional Hazard Analysis

FMEA $\quad$ Fault Trees e Failure Modes and Effects Analysis

FMECA Failure Modes, Effects, and Criticality Analysis

FPGA Field Programmable Gate Array

FTA Fault Tree Analysis

GAC Gerador de aplicações configurável

GCM Generic Component Model

GMT Generative Modeling Technologies

GRM Generic Resource Modeling

GQAM Generic Quantitative Analysis Modeling

HIL Hardware in the Loop

HLAM High-Level Application Modeling

HRM Hardware Resource Modeling

ICNT-SEC Instituto Nacional de Ciência e Tecnologia em Sistemas Embarcados Críticos

ICSEA International Conference on Software Engineering Advances

IEEE Institute of Electrical and Electronics Engineers

JET Java Emitter Template

JMI Java Metadata Interface

LP Linha de Produtos

LPS Linha de Produtos de Software

M2T Model to Text

MARTE Modeling and Analysis of Real-Time Embedded systems 


\begin{tabular}{|c|c|}
\hline MDA & Model-Driven Architecture \\
\hline MDD & Model-Driven Development \\
\hline MDE & Model-driven Engineering \\
\hline MIT & Massachusetts Institute of Technology \\
\hline MOF & Meta Object Facility \\
\hline MP & Marca-Passo \\
\hline MTS & Modal Transition System \\
\hline NFP & Non-Functional Properties \\
\hline NSCP & N-Self Checking Programming \\
\hline NVP & N-Version Programmin \\
\hline OCL & Object Constraint Language \\
\hline OMG & Object Management Group \\
\hline PAM & Performance Analysis Modeling \\
\hline $\mathrm{P} \& \mathrm{D}$ & Pesquisa e Desenvolvimento \\
\hline PD & Projeto de Domínio \\
\hline PDM & Platform Definition Model \\
\hline PIM & Platform Independent Model \\
\hline PHA & Preliminary Hazard Analysis \\
\hline PLE & Product Line Engineering \\
\hline PLP & Product Line Practice \\
\hline PLUS & Product Line UML-Based Software Engineering \\
\hline POSA & Pattern-Oriented Software Architecture \\
\hline ProLiCes & Product Line on Critical Embedded Systems \\
\hline PSM & Platform Specif Model \\
\hline PSSA & Preliminary System Safety Assessment \\
\hline PULSE & Product Line Software Engineering \\
\hline
\end{tabular}




\begin{tabular}{|c|c|}
\hline QoS & Quality of service \\
\hline QP & Questão Primária \\
\hline QS & Questão Secundária \\
\hline QVT & Query/Views/Transformations \\
\hline $\mathrm{RB}$ & Recovery Block \\
\hline RBBV & Recovery Block with Backup Voting \\
\hline $\mathrm{RCP}$ & Rapid Control Prototyping \\
\hline RS & Revisão Sistemática \\
\hline SAM & Schedulability Analysis Modeling \\
\hline SAAM & Software Architecture Analysis Method \\
\hline SANT & Sistema aéreo não tripulado) \\
\hline SAP & safety assessment process \\
\hline SBCARS & $\begin{array}{l}\text { Simpósio Brasileiro de Componentes, Arquiteturas e Reutilização de Soft- } \\
\text { ware }\end{array}$ \\
\hline SCESE & Safety-critical Embedded System Engineering \\
\hline SCES & Safety-critical Embedded System \\
\hline SE & Sistema Embarcado \\
\hline SEKE & Software Engineering \& Knowledge Engineering \\
\hline $\mathrm{SoC}$ & System-o-a-Chip \\
\hline SPLE & System Product Line Engineering \\
\hline SPT & Performance and Time Specification \\
\hline SRM & Software Resource Modeling \\
\hline SSA & System Safety Assessment \\
\hline SUT & System Under Test \\
\hline SysML & Systems Modeling Language \\
\hline TBM & Teste Baseado em Modelos \\
\hline
\end{tabular}


UAV Unmanned Aerial Vehicles

UML Unified Modeling Language

VANT Veículo Aéreo Não Tripulado

VHDL VHSIC Hardware Description Language

VP Virtual Prototypes

V\&V Validação \& Verificação

VV\&T Validação, Verificação \& Teste

XMI XML Metadata Interchange

XML eXtensible Markup Language 



\section{Sumário}

Introdução $\ldots \ldots \ldots \ldots \ldots \ldots \ldots \ldots \ldots$

I REFERENCIAIS TEÓRICOS

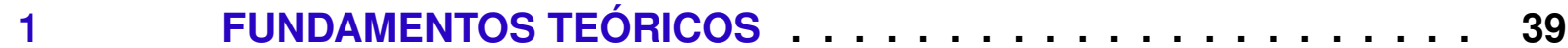

$1.1 \quad$ Considerações Iniciais . . . . . . . . . . . . . . . . . 39

1.2 Sistemas Embarcados Críticos . . . . . . . . . . . . . . . 39

1.2 .1 Definição . . . . . . . . . . . . . . . . . . . . 39

$1.2 .2 \quad$ Nomenclatura . . . . . . . . . . . . . . . . . . . . . . 43

1.2.3 Engenharia de Sistemas Críticos . . . . . . . . . . . . . . 44

1.2.3.1 Principais desafios . . . . . . . . . . . . . . . . . . . 44

1.2.3.2 Metodologias de desenvolvimento . . . . . . . . . . . . . . . . . 45

1.2.3.3 A avaliação da segurança . . . . . . . . . . . . . . . . 48

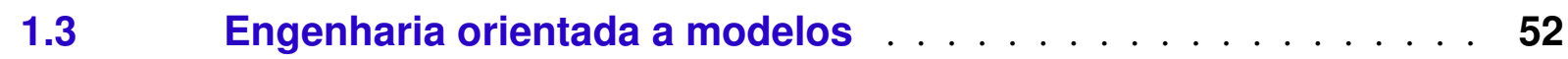

1.3.1 Metamodelagem . . . . . . . . . . . . . . . . . 59

1.3.2 Linguagens específicas de domínio . . . . . . . . . . . . . . . 60

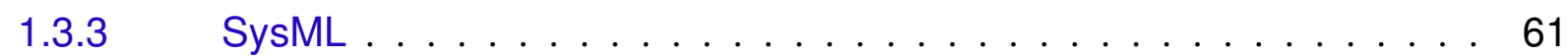

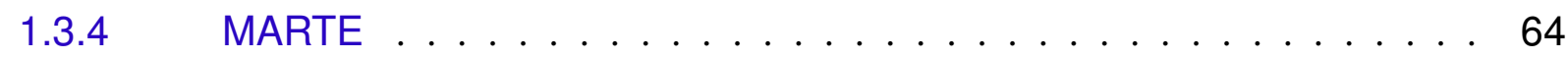

1.3.5 Geradores de Aplicações . . . . . . . . . . . . . . . . . 66

1.3.5.1 Classificação das Técnicas de Transformação . . . . . . . . . . . . . . 68

1.3.6 Model-driven Architecture . . . . . . . . . . . . . . . . . . . . 69

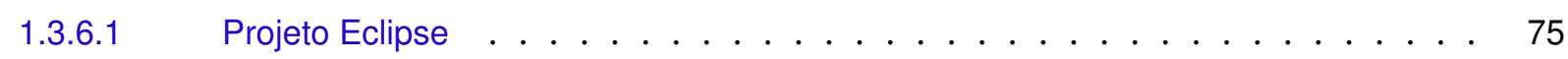

$1.4 \quad$ Engenharia de Linha de Produtos . . . . . . . . . . . . 76

1.4.1 Variabilidades em Linhas de Produtos . . . . . . . . . . . . . . 78

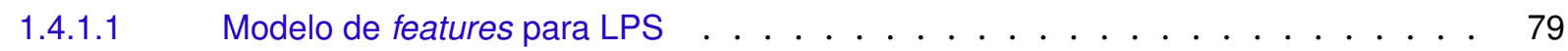

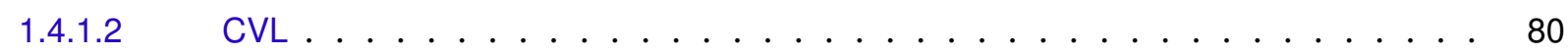

$1.5 \quad$ Considerações Finais $\ldots \ldots \ldots$. . . . . . . . . . 83

$\begin{array}{lll}\text { II } & \text { RESULTADOS } & 85\end{array}$

2 LINHA DE PRODUTOS ORIENTADA A MODELOS NO DOMÍNIO DE SISTEMAS EMBARCADOS CRÍTICOS . . . . . . . . . . 87

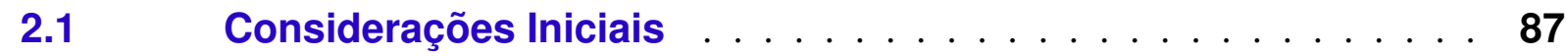

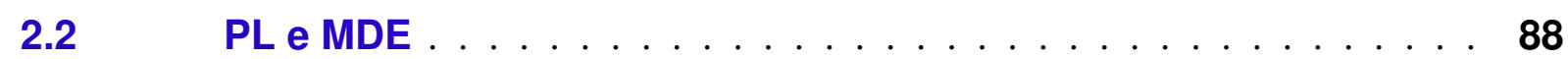

$2.3 \quad$ Revisão sistemática . . . . . . . . . . . . . . . . 89 
4.7.1 Engenharia de requisitos de domínio . . . . . . . . . . . . 119

4.7.1.1 Elicitação de requisitos . . . . . . . . . . . . . . . . 123

4.7.1.2 Definição do Escopo . . . . . . . . . . . . . . . . . . . . 130

4.7.1.3 Modelagem de domínio . . . . . . . . . . . . . 133

4.7.1.4 Priorização de requisitos . . . . . . . . . . . . . . . 137

4.7.1.5 Análise . . . . . . . . . . . . . . . . 140

4.7.1.6 Identificação e análise de sub-domínios . . . . . . . . . . . . . . 147

4.7.1.7 Definição de perfil UML para variabilidade . . . . . . . . . . . . . . 152

4.7.2 Projeto de domínio . . . . . . . . . . . . . . . . 154

4.7.2.1 Diretrizes arquiteturais . . . . . . . . . . . . . . . . 160

4.7.2.2 Padrões e táticas para definições arquiteturais . . . . . . . . . . . . . . 164

4.7.2.3 Padrões arquiteturais para sistemas críticos . . . . . . . . . . . . . . 166

4.7.2.4 Padrões arquiteturais para projeto com variabilidade . . . . . . . . . . . 170

4.7.2.5 Refinamento dos módulos . . . . . . . . . . . . . . . . . 172

4.7.3 Implementação de domínio . . . . . . . . . . . . . . . 177

$4.7 .4 \quad$ Configuração . . . . . . . . . . . . . . . . . 181

$4.8 \quad$ Engenharia de Aplicações . . . . . . . . . . . . . 183

$4.9 \quad$ Considerações Finais . . . . . . . . . . . . . . . 184

5 AVALIAÇÃo dA ABORdAGEM PROPOSTA . . . . . . . . . . . 187

$5.1 \quad$ Ferramentas utilizadas . . . . . . . . . . . 188

$5.2 \quad$ Engenharia da linha de produtos . . . . . . . . . 188 
5.2.1 Engenharia de requisitos . . . . . . . . . . . . . . . . . . 189

$5.2 .2 \quad$ Projeto de domínio . . . . . . . . . . . . . . . . . . . . . . 195

5.2.3 Implementação de domínio . . . . . . . . . . . . . . . . . . . 197

5.3 Discussão . . . . . . . . . . . . . . . . . . . . . . . 199

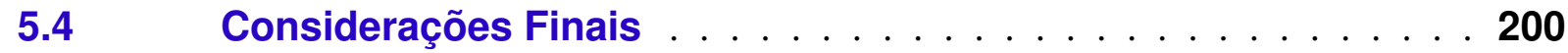

$6 \quad$ CONCLUSÕES . . . . . . . . . . . . . . . 201

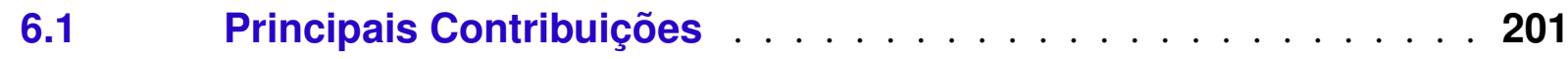

6.2 Publicações resultantes da tese . . . . . . . . . . . . . . 202

6.3 Lições aprendidas . . . . . . . . . . . . . . . . 203

6.4 Trabalhos futuros . . . . . . . . . . . . . . . . . . . 204

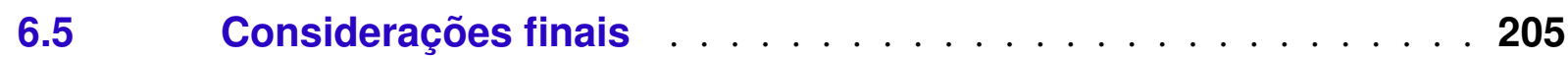

Referências . . . . . . . . . . . . . . . 207 



\section{Introdução}

As técnicas de desenvolvimento de Sistemas Embarcados (SE) atualizam-se constantemente para atender à crescente demanda gerada pela evolução do hardware, em termos do aumento do poder computacional dos processadores e da redução correspondente do seu tamanho e custo. Essa evolução gera um aumento da expectativa dos usuários por novas funcionalidades, assim como permite que elas sejam, cada vez mais, movidas para o software (BURCH; PASSERONE; SANGIOVANNI-VINCENTELLI, 2001; RA; STRØM, 2004; MULLER, 2008; SIFAKIS, 2005). Essa mudança tem o intuito de aumentar a flexibilidade dos sistemas, pois é bem mais fácil alterar algumas linhas de código em um sistema embarcado para adicionar, retirar ou alterar alguma funcionalidade, do que exigir o desenvolvimento de um hardware completamente novo para essa funcionalidade (QUEIROZ; BRAGA, 2014b).

Um sistema embarcado, ou sistema embutido, é um sistema microprocessado no qual o computador é completamente encapsulado ou dedicado ao dispositivo ou sistema que ele controla (SIFAKIS, 2005). Portanto, a Engenharia de Sistemas Embarcados (ESE, do Inglês, $\boldsymbol{E}$ mbedded $\boldsymbol{S} y$ stems $\boldsymbol{E}$ nineering) envolve aspectos inerentes ao projeto de hardware e aspectos inerentes à Engenharia de Software.

Além disso, existem Sistemas Embarcados conhecidos como Sistemas Embarcados Críticos (SCES, do inglês, Safety-Critical Embedded Systems) cujas falhas podem resultar em perdas de vida, danos significativos em propriedades ou ao meio ambiente. Os SCES são comuns em aplicações de dispositivos médicos, sistemas de controle de voo em aeronaves, armamentos, sistemas nucleares e aeronaves não tripuladas (KNIGHT, 2002). Sistemas de controle de voo, por exemplo, devem apresentar taxa de falhas tão baixa quanto uma falha séria a cada 105 ou 109 horas de operação (MOIR, 2006).

Os SCESs possuem diversos requisitos complexos, como: a rápida evolução do ambiente em que operam; confiabilidade, segurança, disponibilidade, criticidade, reatividade, autonomia, robustez e escalabilidade, de tal forma que os sistemas possam ser produzidos com custo/benefício e tempo de mercado aceitáveis (QUADRI; SADOVYKH; INDRUSIAK, 2012). Portanto, a Engenharia de Sistemas Embarcados Críticos (SCESE, do Inglês, Safety-Critical Embedded Systems Engineering) necessita de metodologias de desenvolvimento eficientes, flexíveis e que possam reduzir essa complexidade de produção.

Inicialmente, as técnicas de desenvolvimento de SCES concentravam-se na redução dos erros, e portanto, surgiram diversas técnicas com base na utilização de métodos formais, tais como: Ostroff (1992), Bowen, Bowen e Stavridou (1993), Büssow, Geisler e Klar (1998), Sifakis (2001), e, Hlavaty, Preucil e Stepan (2002). Entretanto, ainda existia a necessidade de aumentar a produtividade, reduzir custos e evitar que erros fossem adicionados durante a 
codificação. Para alcançar esses objetivos, vários autores propõem a utilização da Engenharia Orientada em Modelos (MDE - do Inglês, Model-Driven Engineering) com o objetivo de reduzir a complexidade do desenvolvimento por meio do aumento da abstração, além de possibilitar o aumento da automatização por meio de transformações entre modelos e de transformações de modelo para código (PORTER et al., 2009; HENKEL; HU; BHATTACHARYYA, 2003; KIENHUIS et al., 2002). Essas abordagens orientadas a modelos trouxeram um grande avanço em termos de produtividade e ferramentas para o domínio de SEC. Surgiram ferramentas de modelagem e geração de código, tal como o Matlab Simulink (BEUCHER, 2006), SCADE (GÜDEMANN; ORTMEIER; REIF, 2007), EMF (STEINBERG et al., 2009), sistemas operacionais de tempo-real para aplicações embarcadas e outras.

Esta tese considera MDE como um superconjunto do desenvolvimento orientado a modelos (MDD - do Ingleês, Model-Driven Development) (ATKINSON; KüHNE, 2003), e possui como um de seus princípios fundamentais a consideração dos modelos como entidades de primeira classe. Qualquer artefato de software é um modelo ou um elemento de modelo (BÉZIVIN, 2006). Além disso, MDE possui atividades que vão além das atividades de desenvolvimento e engloba outras atividades orientadas a modelo de um processo de engenharia baseado em modelos.

O desenvolvimento de SCES deve usufruir das vantagens advindas de todas as inovações tecnológicas e intelectuais que possam contribuir com sua qualidade (RUSHBY, 2001). Portanto, percebe-se ainda como necessidade, aplicar ao domínio de SEC os avanços em termos de técnicas de reúso, mais notadamente Linha de Produtos (NORTHROP et al., 2009). Uma Linha de Produtos (PL - do inglês, Product Line) é representada por produtos que, embora possuam requisitos em comum, ao mesmo tempo exibem variabilidades significativas (GRISS, 2000).

Existem LPs de diversos tipos e em diferentes domínios, desde a indústria automotiva e aeronáutica, até software para sistemas Web. Visto que a utilização de LPs visa o desenvolvimento em larga escala, redução dos custos e prazos de desenvolvimento, é natural a sua utilização em SCES para que se possa tirar proveito das partes comuns existentes tanto no software quanto no hardware desses sistemas. A Engenharia de Linhas de Produtos (PLE - do Inglês, Product Line Engineering) provou ser um paradigma adequado para o desenvolvimento de uma diversidade de aplicações de software ou Sistemas similares, a um baixo custo, em menor tempo e com alta qualidade (METZGER; POHL, 2007).

\section{Desafios do reúso em SCES}

Reúso de Software é uma questão de estudo desde o estabelecimento da Engenharia de Software como uma disciplina reconhecida (HABLI, 2009). Inicialmente, o reúso era feito de forma oportunista por meio do que se chama informalmente de "copiar e colar". Essa função permite, por exemplo, realizar cópia de trechos de código. Entretanto, esse reúso oportunista não é recomendado, pois entre outros fatores, tem o potencial de criar código duplicado desnecessariamente, o que é capaz de resultar em sistemas com baixa performance e de difícil manutenção 
(KIM et al., 2004).

Um dos primeiros trabalhos a considerar o reúso sistemático foi apresentado por McIlroy (1968), segundo o qual, "para considerar o desenvolvimento de software como uma disciplina de engenharia bem estabelecida, é necessário desenvolver bibliotecas compartilhadas de rotinas de software robustas e inteligíveis". Desde então, a pesquisa vem evoluindo na busca por novos métodos e técnicas que promovam reúso de forma sistemática. Entre essas técnicas, destacam-se as bibliotecas de software (PRIETO-DIAZ; FREEMAN, 1987), padrões (GAMMA et al., 1995), desenvolvimento baseado em componentes (KOZACZYNSKI; BOOCH, 1998; SZYPERSKI, 2002), frameworks (JOHNSON, 1997), linguagens específicas de domínio (DEURSEN; KLINT; VISSER, 2000), Linha de Produtos de Software (NORTHROP et al., 2009), entre outras.

No domínio de aplicações críticas surgiram várias questões relacionadas ao perigo do reúso. A falha de lançamento da espaçonave ARIANE 5 (DOWSON, 1997) é um dos erros mais conhecidos, resultante do reúso, da história. Essa falha originou-se do código reutilizado do ARIANE 4, que possuía aceleração inicial e trajetória diferentes do ARIANE 5.

O maior argumento contra o reúso em aplicações críticas baseia-se na observação que criticidade é um atributo de um sistema completo e é específico de contexto (HABLI, 2009). Segundo Redmill e Anderson (2000), "aparentemente trivial, ou mesmo não reconhecido, variação no projeto ou no uso entre a aplicação nova e a velha podem ter consideráveis implicações na segurança. Reúso é perigoso".

Segundo Leveson (1995), o reúso pode até reduzir a segurança, uma vez que os riscos do novo sistema podem não ter sido considerados na análise original do sistema reutilizado. Portanto, ela conclui que o reúso não é a solução para o problema de segurança.

Embora apresentem essa posição, ambos concordam sobre a importância de obter os benefícios do reúso, por meio de um aumento no planejamento, orientação e sistematização (HABLI, 2009). Diversos autores consagrados concordam que o reúso pode ser mais sistemático e confiável quando planejado desde os estágios iniciais de desenvolvimento (KANG et al., 1992; FRAKES; ISODA, 1994; MATSUMOTO, 1984; JOHNSON; HARRIS, 1991; YGLESIAS, 1993; CYBULSKI et al., 1998).

Segundo Habli (2009), os requisitos principais para reúso em aplicações críticas incluem:

- consideração explícita de premissas ambientais e operacionais;

- consideração sistemática da reutilização, a partir de fases iniciais do desenvolvimento;

- justificativa clara do projeto do sistema e do software;

- documentação clara de análise de segurança; e

- ênfase especial na rastreabilidade. 
Além desses requisitos, pode-se incluir ainda:

- utilização de um processo com ênfase em reúso;

- utilização de técnicas de validação e verificação em diversos estágios do desenvolvimento;

- aumento do grau de automatização; e

- utilização de técnicas de verificação de modelos tanto nos modelos genéricos (família de sistemas) quanto nos específicos (sistemas alvo).

A seguir, introduz-se as principais técnicas de reúso propostas nesta tese, considerando os desafios de reúso acima, no domínio de SEC.

\section{PLE A MDE}

PLE e MDE são técnicas com ênfase em reúso que visam a redução do custo de desenvolvimento de sistemas, aumento de produtividade, aumento da confiabilidade, portabilidade, interoperabilidade e outros. Além disso, essas técnicas promovem o reúso nos mais altos níveis de abstração por meio da reutilização de conhecimento, tais como requisitos e projeto.

Existem diversas abordagens de desenvolvimento de Linhas de Produtos, tais como as propostas por (WEISS; LAI, 2004; GOMAA, 2004; ATKINSON et al., 2002; KANG et al., 1998), entre outras e diversas abordagens orientadas a modelos, assim como as propostas por (MILLER; MUKERJI, 2003; CRANE; DINGEL, 2008; DORI, 2002), entre outras. Nesta tese, PLE e MDE são tratadas como técnicas complementares e não concorrentes. O desenvolvimento de Linha de Produtos pode se beneficiar das técnicas orientadas a modelos para aumentar a produtividade dos artefatos da linha, bem como permitir a geração automática de sistemas alvo (membros) a partir da linha.

As semelhanças entre essas técnicas de desenvolvimento também podem ser observadas em seus fluxos típicos de trabalho. Observa-se que os passos para o desenvolvimento com MDE são basicamente: (A) definição ou descoberta de um metamodelo existente; (B) criação de modelos usando esse metamodelo; (C) criação ou uso de regras de transformação existentes; (D) elaboração de outros gabaritos de artefatos necessários; (E) início da geração de código e implantação.

Observa-se, também, que os passos para o desenvolvimento de Linhas de Produtos são divididos em duas fases distintas, a Engenharia de Domínio (ED) e a Engenharia de Aplicações (EA). Segundo Czarnecki e Eisenecker (2000), ED é a atividade de coleta, organização e armazenamento de experiências passadas na construção de sistemas ou parte de sistemas de um domínio em particular, na forma de artefatos reutilizáveis, além de fornecer maneiras adequadas para reutilizar esses artefatos na construção de novos sistemas. A ED envolve três processos principais: Análise de Domínio; Projeto de Domínio; e, Implementação de Domínio. 
Dessa forma, observa-se que essas atividades e processos podem relacionar-se entre si da seguinte forma: a realização da Análise de Domínio está relacionada, em parte, com a realização das atividades A, B; a realização do processo de Projeto de Domínio, relaciona-se parcialmente com as atividades B; a realização da Implementação de Domínio pode se relacionar, parcialmente, com a atividade D e E; por fim, a EA relaciona-se com a atividade E.

\section{Lacunas de pesquisa em SCES}

A pesquisa em Sistemas Embarcados Críticos precisa integrar esforços em diversas áreas, tais como Algoritmos, Arquitetura de Computadores, Sistemas Distribuídos e Engenharia de Software (BUNSE; GROß; PEPER, 2007). O principal desafio é fazer com que o software acompanhe as evoluções do hardware com interoperabilidade, confiabilidade e custos acessíveis (RA; STRØM, 2004; MULLER, 2008; RAVI et al., 2004).

Conforme descrito anteriormente, algumas abordagens adotaram naturalmente o MDE como técnica para o desenvolvimento de SCES, com o objetivo de reduzir alguns dos problemas de desenvolvimento. Embora o uso dessa técnica apresente diversos benefícios para o domínio de SCES, tais como redução de erros, aumento da produtividade e redução dos custos, as evoluções trazidas ainda não são suficientes para suprir a demanda de mercado, pois SCES estão se tornando aplicações mais complexas, com requisitos que mudam constantemente, rapidamente e com demanda crescente.

Ferramentas de modelagem, como o Matlab/Simulink, permitem a especificação de sistemas em níveis mais altos de abstração, desenvolvimento de algoritmos e simulação de comportamento. Entretanto, os modelos matemáticos que essas ferramentas apoiam não cobrem o escopo de projeto necessário para o desenvolvimento de SCES (BOTTERWECK; POLZER; KOWALEWSKI, 2009) e não apoiam o gerenciamento de variabilidades. Necessita-se de metodologias e ferramentas que permitam especificações em alto nível e que cubram todo o escopo do desenvolvimento de famílias de SCES.

Por um lado, a maioria das iniciativas de MDE focam em transformações específicas para alguma etapa do desenvolvimento. Portanto, percebe-se a necessidade de uma abordagem que apoie todo o ciclo de vida do processo de desenvolvimento. Por outro lado, as abordagens que se utilizam de SPLE não tiram proveito das possibilidades de simulação das técnicas baseadas em modelos, ou ainda, não utilizam o MDE em todas as etapas do desenvolvimento.

Embora, em teoria, a SPLE tenha alcançado seu estado de maturidade, na prática, a implementação de uma abordagem de gerenciamento de variabilidades continua a ser um desafio, caso a caso, em qualquer organização (DERAKHSHANMANESH; FOX; EBERT, 2014). Para reduzir a complexidade deste empreendimento, é inevitável lidar com variabilidade de múltiplas perspectivas e gerenciá-la de forma consistente entre os artefatos, ferramentas e fluxos de trabalho.

No trabalho apresentado por Derakhshanmanesh, Fox e Ebert (2014), os autores afirmam 
que a maior lição aprendida com o desenvolvimento da Linha de Produtos de sistema de controle de deslizamento para automóveis é que a engenharia de linha de produtos de software, sozinha, não é suficiente na área de sistemas embarcados. Essa afirmação surgiu a partir da observação de que a maioria das features (KANG et al., 1998) e requisitos dos produtos são ditados ou pelo menos influenciados por decisões a nível de sistema, considerando hardware e software em conjunto. Na verdade, features puramente relacionadas a recursos que não requerem mudanças em componentes eletrônicos, são raras (DERAKHSHANMANESH; FOX; EBERT, 2014).

A tese

Dados: (i) a demanda crescente por sistemas embarcados críticos; (ii) o potencial de Linha de Produtos para apoiar o desenvolvimento em larga escala; e, (iii) o relativo sucesso de técnicas orientadas a modelo no desenvolvimento de sistemas embarcados críticos; a seguinte questão de pesquisa é levantada e norteou os trabalhos científicos conduzidos nesta tese:

É possível combinar a engenharia de linha de produtos com a engenharia orientada a modelos, em uma abordagem de desenvolvimento sistemática e viável, e obter o benefício do desenvolvimento em larga escala no domínio de sistemas embarcados críticos sem perder os benefícios já alcançados com a orientação a modelos?

A tese sendo defendida é a de que a combinação da Engenharia de Linha de Produtos com técnicas Orientadas a Modelos em um processo sistemático é viável e pode elevar os níveis de produtividade alcançados por desenvolvedores de Sistemas Embarcados Críticos sem perder os benefícios da utilização de Orientação a Modelos.

$\mathrm{Na}$ busca por esse objetivo, as seguintes questões secundárias foram definidas:

1. Quais elementos são necessários adicionar a um processo de PLE para que seja capaz de promover os objetivos do desenvolvimento em larga escala no domínio de SCES?

2. Uma abordagem que combina PLE e MDE é viável para o desenvolvimento de SCES?

3. Quais partes do processo de PLE podem beneficiar-se das técnicas do MDE identificadas?

4. Como combinar PLE e MDE em um único processo de desenvolvimento de famílias SCES?

\section{Definição do escopo da tese}

Priorizou-se a definição de uma abordagem prática, usável e completa sem ser muito extensa, pois uma cobertura demasiadamente extensa ou com foco em partes do ciclo de vida do sistema, inviabilizaria o desenvolvimento de estudos de caso completos. Essa, além de ser uma das motivações desta pesquisa, é importante para que a avaliação final, que consiste em colocar a abordagem em prática por meio de um estudo de caso, possa ser realizada. Observa-se que por um lado, se a abordagem apresentasse pontos indefinidos, ela não poderia ser utilizada 
para o desenvolvimento de estudos de caso completos. Por outro lado, se abordagem fosse muito extensa, também não seria possível completar os estudos de caso em tempo hábil e a abordagem seria de difícil adoção por parte de desenvolvedores. Para balancear essas forças, a abordagem foi definida de forma incremental e experimental, como foco na definição de atividades essenciais.

Foram definidas atividades para a construção de artefatos reutilizáveis, na fase de Engenharia de Domínio, com base nas técnicas de MDE (modelos, simuladores, geradores, etc.) de forma objetiva, assim, podem ser seguidas por desenvolvedores de sistemas. Além disso, as facilidades criadas na fase de Engenharia de Domínio simplificam sobremaneira a fase de Engenharia de aplicações.

Este trabalho não tem o objetivo de pesquisar PLE, MDE e SCES, de forma individual e em profundidade. Isso seria um trabalho extremamente complexo que excederia o tempo estipulado para uma pesquisa em nível de doutorado. Em vez disso, buscou-se combinar as técnicas já estabelecidas em um processo novo, de maneira a agregar os benefícios de ambas abordagens no domínio de SCES.

Observa-se que em relação à Engenharia Orientada a Modelos, o foco não é definir um processo completo para MDE, e sim utilizar MDE para estender um processo de Engenharia de Linha de Produtos, levando em consideração a complexidade do desenvolvimento de Sistemas Embarcados Críticos e aproveitando os benefícios, já estabelecidos, do MDE neste domínio.

Portanto, o tratamento de atividades como manutenção e evolução dos artefatos não faz parte do escopo deste trabalho. Sabe-se, também, que as ferramentas são parte essencial do MDE e, atualmente, existe uma grande quantidade de opções. Por esse motivo, este trabalho fez uso de ferramentas já existentes e livres, ao invés de construir um ambiente ou ferramentas novas ou utilizar ferramentas proprietárias.

\section{Metodologia de pesquisa}

Este trabalho iniciou-se como parte do grupo de estudos em Linha de Produtos do INCTSEC (INCT-SEC, 2008)(Instituto Nacional de Ciência e Tecnologia em Sistemas Embarcados Críticos), cujo principal objetivo é o desenvolvimento de métodos e ferramentas para o desenvolvimento de Linhas de Produtos de Sistemas Críticos. Formou-se uma parceria entre o INCT-SEC e a empresa AGX (AGX Tecnologia Ltda, 2014) para o desenvolvimento de um veículo aéreo não tripulado (VANT), chamado Tiriba, e posteriormente para transformá-lo em uma linha de produtos. A partir dos esforços de transformação do Tiriba em uma linha de produtos foram encontradas lacunas práticas, que posteriormente foram verificadas no estado da arte, por meio da condução de uma Revisão Sistemática da Literatura (SLR - do inglês, Systematic Literature Review) (KITCHENHAM, 2004). O objetivo da SLR foi obter uma visão global sobre as abordagens, métodos e metodologias atuais que combinam PLE com MDE para construir famílias de SCES. Essa revisão sistemática utilizou o processo proposto por (BIOLCHINI et al., 2007) com o uso de algumas diretrizes propostas por (KITCHENHAM, 2004). Os resultados dessa revisão 
são apresentados no Capítulo 2. Para apoiar os resultados encontrados na SLR, elaborou-se e aplicou-se um Survey (VISSER; KROSNICK; LAVRAKAS, 2000) com desenvolvedores de SCES, em especial, desenvolvedores de Veículos Aéreos não Tribpulados (UAV - do inglês Unmanned Aerial Vehicles). Os resultados do Survey também são apresentados no Capítulo 2.

A partir da definição das lacunas da área e de um estudo aprofundado sobre o desenvolvimento de sistemas críticos, engenharia orientada a modelos e engenharia de linha de produtos, começou-se a delinear uma abordagem de engenharia de linha produtos de sistemas com uso de técnicas orientada a modelos. Após iniciar o desenvolvimento de uma linha de produtos com essa abordagem, novas lacunas foram surgindo e sendo preenchidas incrementalmente. A primeira abordagem definida foi submetida para avaliação em uma conferência e incrementada a partir dos feedbacks obtidos.

Esse processo foi feito de forma iterativa, até o desenvolvimento de uma linha de produtos por meio de estudo de caso. Com essa metodologia, é possível ter indícios de que a abordagem é viável e, além disso, pode-se definir os passos necessários para que o domínio de sistemas embarcados críticos possa se beneficiar do desenvolvimento em larga escala, sem perder os benefícios adquiridos com o desenvolvimento orientado a modelos.

\section{Principais contribuições da tese}

As principais contribuições apresentadas nesta tese são:

- Uma abordagem sistemática, chamada ProLCES (do Inglês, Product Line for safetyCritical Embedded Systems) contendo atividades, com suas respectivas entradas e saídas que detalham as tarefas necessárias para a realização da engenharia de domínio com integração, de forma concreta, das técnicas orientadas a modelo no desenvolvimento de sistemas embarcados críticos;

- Definição de um processo sistemático para Engenharia de requisitos de domínio orientada a modelos e com garantia de rastreabilidade de requisitos;

- Identificação de um conjunto de padrões específicos para garantia de segurança que podem ser combinados com padrões referentes a variabilidades para guiar a definição da arquitetura da linha;

- Definição de um perfil de variabilidade para oferecer rastreabilidade entre os artefatos de requisitos e projeto, sem a necessidade de ferramentas específicas;

- um método para combinar a linguagem de modelagem SysML (Object Management Group, 2012) com a linguagem de definição de variabilidades CVL (HAUGEN; WaSOWSKI; CZARNECKI, 2012) para derivação de produtos da linha durante a Engenharia de Requisitos. 


\section{Estrutura da tese}

Neste primeiro capítulo apresentou-se o contexto, a motivação, os objetivos e o escopo da pesquisa descrita neste trabalho. $\mathrm{O}$ restante da tese está estruturado da seguinte maneira:

- no Capítulo 1, são apresentados os fundamentos teóricos: engenharia de sistemas embarcados críticos, engenharia de linha de produtos e engenharia orientada a modelos;

- no Capítulo 2, são apresentados a revisão sistemática e os resultados de um survey sobre o desenvolvimento de LP de SCES com técnicas de MDE;

- no Capítulo 3, apresenta-se uma visão geral da abordagem ProLCES;

- no Capítulo 4, apresenta-se, em detalhes, a fase de engenharia de domínio da abordagem ProLCES, com suas etapas de engenharia de requisitos de domínio, projeto de domínio e implementação de domínio, Além disso, são apresentadas as técnicas de configuração da linha de produtos e a fase de engenharia de aplicações;

- no Capítulo 5, apresenta-se uma avaliação da abordagem proposta nesta tese;

- no Capítulo 6, por fim, são apresentadas as conclusões deste trabalho. 

Parte I

Referenciais teóricos 



\section{Fundamentos teóricos}

\subsection{Considerações Iniciais}

Neste capítulo, são apresentados os fundamentos teóricos relevantes para a pesquisa apresentada nesta tese, tais como Sistemas Embarcados Críticos, Engenharia Orientada a Modelos e Engenharia de Linha de Produtos.

O capítulo está organizado da seguinte forma: na Seção 1.2, são explicados os conceitos de Sistemas Embarcados Críticos, suas principais características e técnicas usadas no seu desenvolvimento; na Seção 1.3, são apresentados os conceitos da Engenharia Orientada a Modelos, destacando seus objetivos, características, abordagens de desenvolvimento e linguagens de modelagem utilizadas neste trabalho; na Seção 1.4, são explicados os conceitos de Linha de Produtos, destacando seus objetivos, vantagens de uso, tratamento de variabilidades e uma visão geral das principais abordagens de desenvolvimento; por fim, na Seção 1.5, são apresentadas as considerações finais sobre os tópicos apresentados neste capítulo.

\subsection{Sistemas Embarcados Críticos}

Esta seção inicia-se com a definição de Sistemas Embarcados Críticos e suas principais características, seguida da nomenclatura utilizada na área. Por fim, são apresentadas as principais técnicas usadas na Engenharia de Sistemas Embarcados Críticos.

\subsubsection{Definição}

Sistemas Embarcados Críticos correspondem aos sistemas que integram software e hardware especialmente projetados para realizar um conjunto de tarefas pré-definidas (SIFAKIS, 2005), cujo principal requisito é o seu caráter crítico. Esse tipo de sistema é conhecido internacionalmente como Safety-Critical Embedded System (SCES), e para compreender sua natureza é necessário entender primeiro as palavras que o caracterizam:

- crítico, segundo o dicionário (FERREIRA et al., 1999), refere-se a difícil, grave e perigoso.

- safety é definido como "livre de condições que podem causar morte, lesões, doenças ocupacionais, danos ou perdas em equipamentos ou propriedades“ (MIL-STD-882B, 1984). 
Portanto, ao se usar essa definição absoluta tem-se que Sistemas Embarcados Críticos são Sistemas Embarcados que devem ser livres de condições de perigo, ou seja, são sistemas seguros. No contexto desta tese, traduz-se safety como segurança. Observa-se que o uso dessa definição absoluta, leva a conclusão de que qualquer sistema que apresente algum elemento de risco é inseguro. Entretanto, qualquer sistema que produz benefícios pessoais, sociais ou industriais contém um indispensável elemento de risco (LEVESON, 1986). Portanto, segurança é um conceito relativo que corresponde a uma medida do grau de liberdade de risco, em qualquer ambiente (LEVESON, 1986).

Leveson (1986) faz uma analogia usando o aparelho de barbear (em inglês, chamado de safety razor) e o palito de fósforo (em inglês, chamado de safety matches), segundo a qual esses itens não são seguros, de acordo com a definição apresentada acima, porém eles são mais seguros que suas alternativas, navalha e fósforo, respectivamente.

Diante dessa discussão, pode-se afirmar, tanto intuitivamente quanto formalmente, que os Sistemas Críticos são reconhecidos de acordo com as consequências de suas falhas. Portanto, SCES são aqueles sistemas embarcados cujas falhas podem resultar em perda de vidas, dano significativo em propriedades ou danos ao meio ambiente (KNIGHT, 2002). Esse tipo de sistema faz parte do cotidiano da maioria dos seres humanos e são representados pelos sistemas de dispositivos médicos, sistemas de controle de voo em aeronaves, sistemas de armamentos, sistemas nucleares, sistemas de aeronaves não tripuladas, sistemas de fábricas químicas e de pesticidas, sistemas de trens, sistemas de controle de trafego aéreo, sistemas de automóveis e outros (FIRESMITH, 2004). É importante destacar que o escopo dos SCES expande-se constantemente, uma vez que os computadores e sistemas de informação modernos continuam a ser introduzidos em muitas áreas que afetam nossas vidas (KNIGHT, 2002).

A maioria dos SCES também são conhecidos como Sistemas de Software Intensivo (SIS, do Inglês, Software-intensive systems) (WIRSING; HöLZL, 2006; HINCHEY et al., 2008; TIAKO, 2009). Os SIS são definidos como sistemas grandes e complexos, nos quais Software é um componente essencial, em termos de funcionalidade, custo, riscos ou tempo de desenvolvimento, seja interagindo com outros Softwares, sistemas, dispositivos, atuadores, sensores ou pessoas (SOARES, 2010; CRUICKSHANK, 2009). Como esses sistemas estão sendo amplamente utilizados e seu impacto na sociedade está em crescimento, a evolução da engenharia de SIS tem uma grande influência sobre os ganhos de produtividade e prosperidade que a sociedade tem visto nos últimos anos (DEDRICK; GURBAXANI; KRAEMER, 2003). Para esta tese utiliza-se a nomenclatura de Sistemas Embarcados Críticos em detrimento de Sistemas de Software Intensivo.

Diante das definições apresentadas, o Comitê Conjunto de Segurança em Sistema de Software (JSSSC, 1999) define o componente computacional de software de um sistema crítico como: "aquele componente ou unidade cujos erros podem resultar em potenciais danos, perdas de previsibilidade ou de controle de um sistema". Em termos gerais, Software crítico é aquele 
cujo funcionamento pode levar diretamente ou indiretamente a acidentes ou situações de acidente. Observa-se ainda que, embora o Software não cause mortes, ferimento, doenças de trabalho, danos em equipamentos, propriedades ou ao meio ambiente, ele geralmente é diretamente responsável pelas ações do Hardware que controla, e que portanto, podem causar efeitos inseguros (CRUICKSHANK, 2009).

É obvio que, por exemplo: a queda ou colisão de aeronaves comerciais resulta na morte de muitas pessoas; a explosão de usinas nucleares resulta em enormes danos ao maio ambiente. Entretanto, para muitas pessoas, não é trivial observar que a perda de uma ligação telefônica também pode resultar em morte. O serviço telefônico para reportar emergências é um exemplo não trivial de aplicação com infraestrutura crítica. Outros exemplos são os sistemas de banco, sistemas financeiros, geração e distribuição de energia, telecomunicações e os sistemas de gerenciamento de água. Essas aplicações são extensivamente computadorizadas, e uma falha no computador pode resultar na quebra das atividades normais e, em consequência, gerar grandes perdas. Portanto, também considera-se esses sistemas computacionais, nos quais a infraestrutura é crítica, como SCES (KNIGHT, 2002).

$\mathrm{Na}$ história são relatadas diversas falhas de computadores que produziram resultados catastróficos, entre as quais, destacam-se:

- a falha da espaçonave ARIANE 5 (DOWSON, 1997);

- a falha do Therac 25, um sistema de computador terapêutico que matou e mutilou diversos pacientes antes de ser tirado do mercado (DUNN, 2003);

- a falha na contagem regressiva da espaçonave Shuttle no primeiro lançamento (KNIGHT, 2002), entre outros.

Segundo Sifakis (2005), SCES quebram com a tradicional engenharia de sistemas, uma vez que reúnem requisitos técnicos, tais como:

- reatividade: que se refere a responder aos estímulos do ambiente dentro de um atraso conhecido e garantido, como por exemplo, os sistemas controladores de voo;

- autonomia: o sistema deve fornecer serviço contínuo sem a intervenção humana, como por exemplo, sistemas com reinicialização não manual ou sistemas de gerenciamento ótimo de energia;

- robustez: refere-se a garantir um serviço mínimo em qualquer caso, mesmo em casos extremos como ataques ou falhas de hardware;

- escalabilidade: apoiar o crescimento evolucionário ou em tempo de execução do sistema, nesse caso, deve-se apoiar reconfiguração e serviços escaláveis; 
- desafios tecnológicos: capacidade de construir os sistemas e garantir sua funcionalidade e qualidade com custos acessíveis e tempo de desenvolvimento aceitável.

Em resumo, um SCES deve processar dados em tempo real, enquanto consome o mínimo de energia para estender a vida útil da bateria e/ou evitar a necessidade de um ventilador de resfriamento, recuperando-se de possíveis falhas e ainda com um custo acessível e tempo de desenvolvimento aceitável (RA; STRØM, 2004). Esses requisitos devem ser levados em consideração ao se elaborar a arquitetura do sistema.

Para esta tese, a Arquitetura de um sistema é: "a organização fundamental do sistema incorporando seus componentes, os relacionamentos desses componentes entre si e com o ambiente e os princípios orientadores de seu projeto e evolução" (IEEE, 2000). Observa-se que a arquitetura de um sistema embarcado crítico inclui tanto a arquitetura de software quanto a arquitetura do hardware correspondente. Nesse contexto, a arquitetura de software de um sistema deve capturar a especificação comportamental dos seus componentes e sua interação; a arquitetura de hardware deve capturar a estrutura (componentes de hardware e sua conectividade) e comportamento (conjunto de instruções) das arquiteturas programáveis que consistem dos processadores, coprocessadores e memória do subsistema (OQUENDO, 2006).

Em geral, SCES recebem, repetidamente, amostras de sensores, calculam respostas de controle apropriadas e enviam essas respostas aos atuadores. Conforme já foi discutido acima, são requisitados alta confiabilidade e tolerância a falhas conforme discute-se a seguir. Para satisfazer esses requisitos, necessita-se, entre outras coisas, uma arquitetura flexível e distribuída, pois deve-se implementar mecanismos para sincronização, voto, gerenciamento de redundância e adaptabilidade (RUSHBY, 2001).

De acordo com Dunn (2003), a arquitetura de um SCES possui tipicamente cinco componentes primários:

- planta - é a entidade física que o sistema monitora e controla, também é conhecida como aplicação ou processo; plantas típicas incluem, por exemplo: uma aeronave, um braço robótico, um paciente humano ou um freio para automóveis;

- sensor - converte a medida de uma propriedade física da planta em um sinal elétrico corresponde, para entrada em um computador; sensores típicos incluem: os acelerômetros, os transdutores de pressão e os medidores de tensão;

- atuador - converte um sinal eletrônico da saída do computador em uma ação física correspondente, que controla uma função na planta; atuadores típicos incluem: os motores, válvulas, mecanismos de frenagem e bombas;

- operador - corresponde ao humano ou humanos que monitoram e ativam o sistema de computador em tempo real. Operadores típicos são: o piloto de uma aeronave, operador de 
estação ou médico;

- computador - consiste de um hardware e software que usa sensores e atuadores para monitorar e controlar plantas em tempo real. Ele aparece de diversas formas, tais como: controlador de placa única, controlador de lógica programável, computador de voo ou sistema em um chip.

\subsubsection{Nomenclatura}

Um dos termos mais importantes no contexto de Sistemas Críticos é o termo risco ( do Inglês, Hazard), que se refere a uma situação física ou estado de um sistema que pode levar a um acidente (MIL-STD-882B, 1984). Observa-se que nenhuma aeronave poderia voar ou nenhum automóvel poderia se mover, caso fosse necessário eliminar todos os riscos, antes disso.

Embora segurança e confiabilidade (do inglês, reliability), sejam usadas eventualmente como sinônimos, é importante diferenciá-las. Confiabilidade é definida como "a probabilidade que uma peça de equipamento ou componente executará sua função de forma satisfatória para o tempo prescrito e em condições ambientais estipuladas“ (LEVESON, 1995 apud HABLI, 2009). Portanto, enquanto confiabilidade lida com todo tipo potencial de falha, segurança lida somente com falhas que podem causar acidentes.

Pode-se dizer que uma das propriedades básicas de um SCES é a dependability, que segundo (LAPRIE, 1992), refere-se "aquela propriedade de um sistema de computação que permite que a confiança seja colocada justificadamente no serviço que oferece." Portanto, referese à disponibilidade, confiabilidade e manutenibilidade de um sistema.

De acordo com (IEEE, 1990), define-se falha como "a incapacidade do sistema ou de um dos seus componentes de executar uma função requerida de acordo com sua especificação". Uma falha pode ser produzida quando a execução de um software passa por um defeito. Nesse contexto, um defeito é "a manifestação de um erro". Falhas e defeitos são normalmente encontrados por meio de técnicas de Validação e Verificação (V\&V). Validação é o "processo de determinar que os requisitos estão corretos e completos" enquanto verificação é a "avaliação dos resultados de um processo para assegurar corretude e consistência com respeito às entradas e normas oferecidas para esse processo" (RTCA., 1992).

As atividades de gerenciamento de risco são uma das partes centrais da Engenharia de Sistemas Criticos. Um safety risk é definido como a "combinação da probabilidade de dano e da gravidade desse dano". O Dano não é limitado a "morte, danos físicos ou danos para a saúde das pessoas, mas também envolve danos em propriedades ou ao meio ambiente". Um Acidente é um "evento ou sequência de eventos não intencionais que causam danos". Por outro lado, um incidente é "a ocorrência de um risco que poderia ter causado um acidente, mas não o fez" (RTCA., 1992 apud HABLI, 2009). 
Segundo (LUTZ, 2000), existe uma sobreposição substancial entre as técnicas de projeto utilizadas para sistemas críticos e as técnicas de projeto para outros sistemas de grandes consequências, tais como: os Sistemas Confiáveis (Dependable Systems), Sistemas de Segurança (Secure Systems) e Sistemas de Tempo Real (Real-time Systems).

Rushby (2001) define esses sistemas da seguinte forma:

- Sistemas Confiáveis são aqueles para os quais confiança e disponibilidade são aspectos fundamentais da qualidade do serviço que ele oferece. Preocupa-se principalmente com a tolerância a falhas, ou seja, proporcionar um nível aceitável de serviço mesmo em caso de falhas;

- Os Sistemas de Tempo Real envolvem comportamento dependente do tempo, que se comprometido, pode levar a riscos;

- Sistemas de Segurança se concentram em evitar a divulgação não autorizada de informações, em garantir a integridade da informação e garantir a não-interferência. Observa-se que não se deve confundir os Sistemas Seguros com os Sistemas de Segurança.

\subsubsection{Engenharia de Sistemas Críticos}

\subsubsection{Principais desafios}

Conforme discutido anteriormente, os SCES dependem de software para alcançar seus propósitos. O número e o campo de aplicação de tais sistemas aumenta a medida que as evoluções do hardware permitem que recursos adicionais sejam, cada vez mais, realizados em Software. O software pode contribuir para a segurança de um sistema ou pode comprometê-la, colocando o sistema em um estado perigoso, portanto a Engenharia de software de um sistema crítico requer um entendimento claro do papel do software e suas interações com o sistema (LUTZ, 2000). Espera-se que as futuras gerações dos SCES se tornem ainda mais complexas, altamente distribuídas, e exibindo um comportamento adaptativo (WIRSING; HöLZL, 2006).

Conforme apresentado no Capítulo, um dos grandes desafios da sociedade moderna é o desenvolvimento bem sucedido de SCES respeitando suas restrições, tais como: confiabilidade, criticidade, reatividade, autonomia, robustez e escalabilidade, além de estar apto a manter e evoluir esses sistemas (BROY, 2006) com custos e prazos aceitáveis. Esse desafio é associado a outro de grande importância: desenvolver princípios, métodos, algoritmos e ferramentas que sejam usáveis na prática e teoricamente bem fundamentados para a construção de SCES, com uma engenharia confiável, segura, com custo aceitável e eficiente, de forma que cubra todo o ciclo de vida (WIRSING; HöLZL, 2006). Observa-se ainda que em muitos casos, esses sistemas devem proporcionar respostas corretas, respeitando um intervalo de tempo rigoroso (JOHNSON, 2003). 


\subsubsection{Metodologias de desenvolvimento}

Conforme discutido até aqui, os Sistemas Críticos se caracterizam pelo potencial de dano que uma falha em sua execução pode causar. Portanto, um dos focos das metodologias de desenvolvimento é evitar acidentes. Segundo (BOWEN; BOWEN; STAVRIDOU, 1993), "a forma mais eficiente de evitar acidentes durante a operação de um sistema é eliminar ou reduzir riscos ao longo das etapas de projeto e desenvolvimento, e não depois, quando a complexidade se torna esmagadora". O autor também afirma que software e hardware críticos estão intimamente interconectados, e devem ser considerados como um todo, com atenção especial às interfaces.

Em uma típica abordagem de desenvolvimento de SCES do tipo top-down, os engenheiros iniciam com uma descrição mais abstrata do sistema em forma de requisitos do sistema. No passo seguinte é criada uma descrição mais detalhada do que se quer para o sistema, a especificação. A especificação determina apenas como o sistema se comporta, não determina como ele é construído. Os detalhes internos do sistema começam a tomar forma quando se define a arquitetura do sistema, a qual define a estrutura do sistema em termos de seus maiores componentes. Uma vez que se conhece esses componentes, pode-se projetá-los incluindo módulos de software e algum hardware especializado. Baseado nesses componentes, pode-se finalmente construir o sistema completo (WOLF, 2008).

Os requisitos podem ser funcionais ou não funcionais (GLINZ, 2007). Embora seja necessário capturar as funções básicas do sistema, no domínio de SCES, essa descrição funcional não é suficiente. Nesse domínio, a funcionalidade não é útil ou usável sem as necessárias características não funcionais implantadas e testadas nos sistemas. Portanto, a Engenharia de Sistemas Críticos enfoca, entre outros, a garantia e verificação do requisito de criticidade dos sistemas. Conforme apresenta-se na Subseção 1.2.3.3, garantia da segurança é uma parte fundamental da engenharia de SCES. Além disso, técnicas de V\&V também são fundamentais desde os estágios iniciais do desenvolvimento.

Outro ponto chave da Engenharia de Sistemas é o projeto de componentes de software e hardware. A descrição arquitetural informa quais componentes são necessários. Os componentes incluem, em geral, tanto hardware (FPGAs, placas e outros) quanto módulos de software. Segundo Borriello, Chou e Ortega (1996), "a separação tradicional entre as responsabilidades de software e hardware não são mais utilizáveis". Uma das maiores dificuldades, e motivo de problema no desenvolvimento, era o fato de que: apenas após a construção dos componentes, era possível colocá-los junto e ver o sistema trabalhando. Dessa forma, os erros eram descobertos apenas em etapas tardias do desenvolvimento, e consequentemente mais caros de serem consertados. Para reduzir esse problema, surgiu uma técnica para o desenvolvimento de sistemas, chamada de abordagem hardware/software co-design (DE; SAMI, 1996).

Na década de 80 e início da década de 90, a estratégia tradicional de projeto fixava as decisões de particionamento entre software e Hardware nos estágios iniciais do ciclo de 
desenvolvimento. Dessa forma, o projeto de software e hardware eram desenvolvidos separadamente. Contudo, com os avanços tecnológicos, surgiu a possibilidade de obter componentes de hardware de propósito especial com custo e em tempo razoáveis. Ainda, alguns projetos também exigem alguma programação no produto final, o que necessita de uma flexibilização na estratégia de projeto (KALAVADE; LEE, 1992). Nesse sentido, Kalavade e Lee (1992) afirmam que a estratégia de hardware/software co-design: :

"é a estratégia na qual software e hardware são projetados em paralelo, com retroalimentação e interação entre os dois, durante o processo de projeto. A divisão final entre hardware/Software pode ser feita depois da avaliação de estruturas alternativas com respeito a performance, programabilidade, confiabilidade, manutenção, evolução do projeto, custo de desenvolvimento e manufatura".

Segundo Michell e Gupta (1997), hardware/software co-design significa cumprir os objetivos a nível de sistema, explorando a sinergia entre hardware e software por meio de seu projeto simultâneo. Outro fator que colaborou para o interesse nessa técnica foi a introdução de ferramentas CAD (Computer-Aided Design) para projeto, como por exemplo, simuladores comerciais.

Portanto, essa técnica de projeto integra técnicas de projeto de hardware e software que são tipicamente feitas com uso de várias linguagens, formalismos e ferramentas em uma metodologia única. $\mathrm{O}$ uso de um único framework para essa tarefa acelera o processo de projeto, permitindo que a compensação entre hardware e software seja feita dinamicamente enquanto o projeto progride e facilite significativamente a verificação (HOFFMAN; KOGEL; MEYR, 2001). Em estágios avançados do desenvolvimento, surge o problema de particionamento hardware/software, cujo objetivo é encontrar quais partes do modelo são melhor implementadas em hardware e quais são melhor implementadas em software. Esse particionamento pode ser decidido pelo projetista, com um refinamento sucessivo e anotações no modelo inicial, ou pode ser determinado por uma ferramenta CAD (MICHELL; GUPTA, 1997).

O particionamento hardware/software é de grande importância, pois tem um impacto de primeira ordem nas características de custo e performance do projeto final. Portanto, qualquer decisão de particionamento, executada pelo projetista ou por alguma ferramenta, deve levar em conta as propriedades dos blocos resultantes de hardware e software. A formulação do problema de particionamento difere de acordo com o problema a ser confrontado. No caso de sistemas embarcados, esse particionamento representa o particionamento físico das funcionalidades do sistema em hardwares de aplicações específicas e a execução do software em um (ou mais) processador(es) (MICHELL; GUPTA, 1997).

Observa-se que, para aumentar a produtividade e reduzir o tempo de desenvolvimento, é importante estar apto a verificar o projeto de sistemas heterogêneos desde os estágios iniciais do processo de desenvolvimento para evitar re-projetos, que em geral, são caros. Nesse sentido, 
a heterogeneidade não se refere somente a modelos de hardware e software, mas também aos modelos especificados, em cada lado, em diferentes níveis de abstração que precisam ser acoplados. Por exemplo, partes do hardware podem ser reaproveitadas de projetos anteriores e podem estar especificadas em abstrações de baixo nível, como código VHDL/Verilog, enquanto as novas funcionalidades adicionadas ao sistema são especificadas em um nível mais alto de abstração, como a linguagem de programação C. No lado do software, a precisão do modelo pode variar a medida que se converte os modelos definidos, em funcionalidades no código $\mathrm{C}$, por exemplo, para especificar o comportamento da aplicação em uma arquitetura alvo. Por isso, é fundamental ter um ambiente de simulação que compreenda a semântica de todos os modelos utilizados e estabeleça as interfaces para permitir comunicação entre eles. O acoplamento e verificação das diferentes partes do sistema alvo em qualquer momento do processo de concepção é chamado de construção de um protótipo virtual (VP - do inglês, Virtual Prototype) do sistema em software (HOFFMAN; KOGEL; MEYR, 2001).

A ideia de criar um produto virtual com todos os subsistemas associados e então testar e verificar o produto antes da manufatura é atrativa, tanto em termos de custo quanto em tempo de mercado (HENKEL; HU; BHATTACHARYYA, 2003). O objetivo final da abordagem hardware/software co-design é oferecer um rigoroso, porém flexível ambiente, no qual usuários possam desenvolver seus sistemas. Entretanto, os inumeráveis modelos computacionais, ferramentas e fluxos de projeto disponíveis fazem com que a criação de tal ambiente unificado seja um grande desafio. Segundo (HENKEL; HU; BHATTACHARYYA, 2003), "Hardware/Software co-design and co-simulation é um processo indispensável no desenvolvimento de qualquer sistema".

Surgiram várias abordagens que utilizaram e evoluíram o hardware/software co-design. Uma delas é apresentada por Kienhuis et al. (2002), segundo a qual o projeto de sistemas deve assumir que a arquitetura não representa uma instância única, em vez disso, é uma descrição parametrizada de uma arquitetura ou um gabarito de arquitetura. $\mathrm{O}$ gabarito estabelece como os vários elementos devem se comunicar e como a estrutura geral deve parecer. O número de elementos processadores a ser usado, o tipo de funcionalidade que esses elementos fornece e etc, fica em aberto. Apenas por meio da seleção de valores para todos os parâmetros, cria-se uma instância de uma arquitetura em particular. Os autores acreditam que o uso de um gabarito de arquitetura e a exploração desse gabarito com base em dados quantitativos é uma boa abordagem para projetar arquiteturas de sistemas embarcados.

Essa metodologia de projeto se baseia na abordagem $y$-chart e foca em explorar o espaço de projeto de um gabarito de arquitetura de forma sistemática. Essa abordagem fornece aos desenvolvedores uma quantidade de dados obtida por meio da análise de performance das arquiteturas para um conjunto de aplicações. Nela, os projetistas descrevem uma instância particular de arquitetura e utilizam análise de performance para construir um modelo de performance dessa arquitetura. Esse modelo de performance é avaliado para um conjunto mapeado de aplicações. Isso gera números de performance que os projetistas interpretam para que possam propor me- 
lhorias, isto é, outros valores aos parâmetros, resultando em outras instâncias de arquiteturas. Esse procedimento pode ser repetido de forma iterativa até que uma arquitetura satisfatória seja encontrada para um conjunto completo de aplicações. $\mathrm{O}$ fato de que números de performance são encontrados para um conjunto de aplicações em vez de uma só, é fundamental para obter instâncias de arquiteturas que estão aptas a executar um conjunto de aplicações e obedecer a um amplo conjunto de objetivos. Na Figura 1, ilustra-se o processo definido pela abordagem $y$-chart (KIENHUIS et al., 2002).

Figura 1 - Processo de projeto segundo a metodologia y-chart.

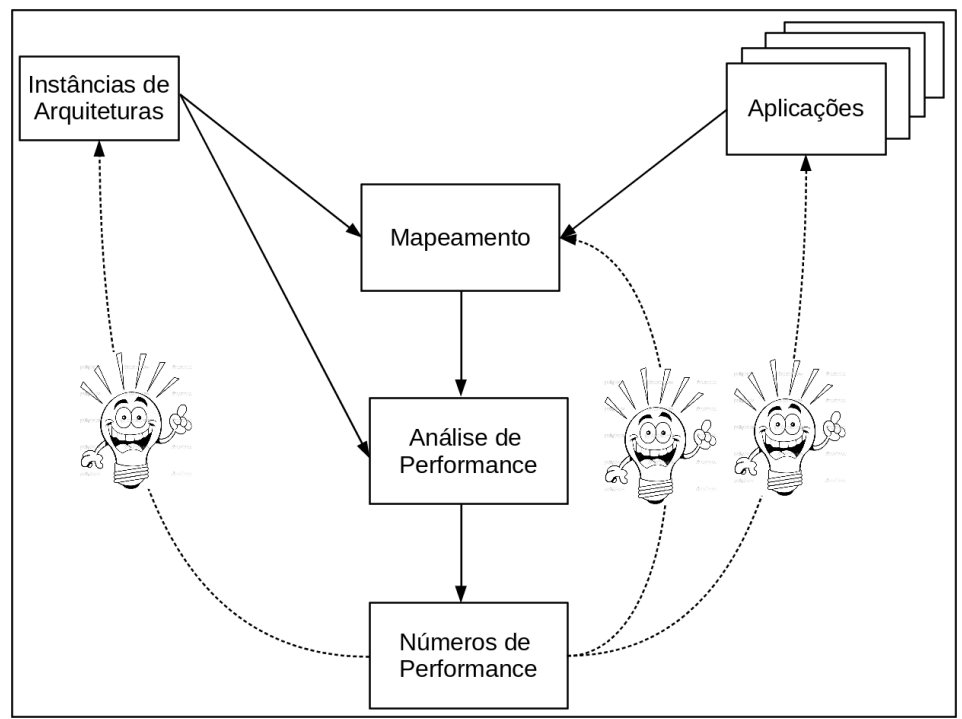

fonte: Kienhuis et al. (2002)

\subsubsection{A avaliação da segurança}

O processo de avaliação da segurança (SAP, do inglês, safety assessment process) é uma parte fundamental de qualquer processo de desenvolvimento de sistemas críticos. Esse processo inclui a identificação dos requisitos de segurança e verificação apoiando as atividades de desenvolvimento de sistemas críticos. Heimdahl (2007) apresenta uma metodologia, em "V", para avaliação de segurança utilizada na indústria de aviação, segundo a qual é conduzida uma análise funcional de riscos (FHA, do Inglês, Functional Hazard Analysis) em nível de aeronave no início do ciclo de desenvolvimento. Além disso, um projeto de sistema atenuante de perigos é iterativamente derivado. Existem dois níveis de FHA para sistemas aviônicos: em nível de aeronave e em nível de sistema. O FHA estabelece os requisitos de segurança derivados para cada sistema de aeronave. Técnicas usadas nesse estágio, incluem, por exemplo, análise de perigo preliminar (PHA, do Inglês, Preliminary Hazard Analysis), modos de falha, efeitos e análise de criticidade (FMECA, do Inglês Failure Modes, Effects, and Criticality Analysis ), árvore de análise de falhas (FTA, do Inglês, Fault Tree Analysis) e análise de riscos e operabilidade 
(HAZOP, do Inglês, Hazards and Operability Analysis)(RAHEJA; ALLOCCO, 2006; STOREY, 1996).

Segundo essa metodologia, a FHA é seguida por uma avaliação preliminar de segurança do sistema (PSSA, do Inglês, Preliminary System Safety Assessment), que deriva primeiramente os requisitos de segurança para os subsistemas com o uso de FTA. O processo PSSA é repetido a medida que o projeto evolui, quando ocorrem mudanças no projeto que exigem mudanças nos requisitos do sistema e quando potenciais problemas de segurança são identificados por meio da retroalimentação do PSSA no processo de projeto. Alguns dos documentos de saída importantes do PSSA são métodos planejados em conformidade com requisitos FHA, atualizações FHA, requisitos de segurança de baixo nível, FTAs qualitativas e requisitos operacionais. Na Figura 2, apresenta-se uma ilustração desse processo no domínio de aviação industrial.

Figura 2 - Processo de avaliação de segurança, em "V" no domínio de aviação industrial.

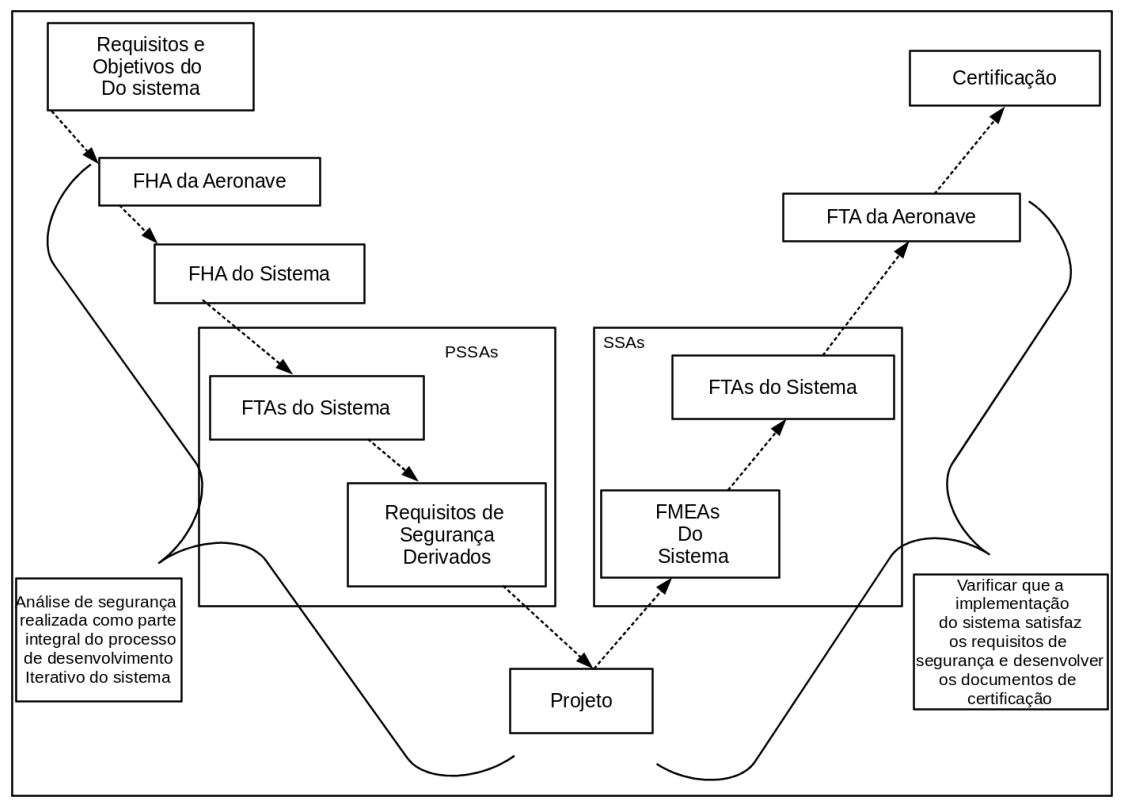

fonte: Heimdahl (2007)

Uma vez que o projeto e implementação são completados (lado esquerdo do V), o processo de avaliação de segurança do sistema (SSA, do Inglês, System Safety Assessment) verifica se os requisitos de segurança são atendidos no projeto implementado (lado direito do V). Uma SSA é uma avaliação sistemática e abrangente do sistema implementado, juntamente com sua arquitetura e instalação para mostrar que os requisitos de segurança relevantes foram atendidos. A diferença entre o PSSA e o SSA é que o PSSA é um método para avaliar arquiteturas propostas e derivar requisitos de segurança do sistema; enquanto o SSA é uma verificação de que o projeto implementado atende qualitativamente e quantitativamente os requisitos de segurança definidos na FHA e no PSSA. Técnicas típicas usadas nesse processo são Fault trees e Failure Modes and Effects Analysis (FMEA) (HEIMDAHL, 2007; LUTZ, 2000). Observa-se que altos níveis de segurança são normalmente melhor alcançados durante o projeto do sistema por meio 
da concepção de segurança desde o início do desenvolvimento, em detrimento da tentativa de adicionar sistemas de proteção ou complexidades adicionais depois da construção do sistema (LEVESON, 1995).

Tentativas de alcançar segurança durante as atividades no lado direito do V na Figura 2 são inúteis a menos que se tenha realizado engenharia de segurança no sistema durante as atividades do lado esquerdo do V. Consegue-se garantia que o software atende a seus requisitos de segurança por meio da demonstração de que o desenvolvimento de software está em conformidade com algumas normas que governam o domínio de software crítico, como por exemplo a norma DO-178B (recentemente atualizada para DO-178C), no caso de aeronaves (DO-178B, 1982).

Existe uma extensa coleção de normas que abrangem o domínio de sistemas críticos e, em geral, lidam com segurança e certificação, por obrigatoriedade ou recomendação de várias técnicas ou processos de desenvolvimento. Nessas normas, não há nenhuma exigência para produzir evidência direta de que os vários requisitos de segurança foram efetivamente atendidos, o que se exige é mostrar que os documentos determinados foram produzidos e as atividades requeridas pela norma foram executadas (HEIMDAHL, 2007). Ao se cumprir esses procedimentos, os órgãos reguladores responsáveis pelas normas, aceitam o software como correto. Observa-se que o foco desta tese não é o processo de certificação, portanto não se pesquisa essa coleção de normas a fundo, embora se comente um pouco a respeito delas a seguir. Uma visão mais detalhada e abrangente das principais normas que regulam a certificação de sistemas críticos, pode ser encontrada no trabalho de Herrmann (2000).

Conforme já discutido nesta seção, a falha de um software é resultado de um defeito de projeto introduzido em algum lugar durante o processo de desenvolvimento. Portanto, a maioria das normas focam no processo de desenvolvimento e recomendam ou exigem várias técnicas de desenvolvimento e avaliação (HEIMDAHL, 2007). O objetivo das normas é reduzir o número de defeitos de software introduzidos durante o desenvolvimento (exigindo, por exemplo, a especificação rigorosa dos requisitos do software) e aumentando o número de defeitos eliminados no processo (exigindo, por exemplo, técnicas de testes rigorosos). Existem dúvidas, contudo, se existe realmente um correlação entre a qualidade do software produzido e as práticas requeridas em cada nível de segurança. Segundo Shooman (1996), "embora as observações sejam em grande parte anedóticas, há alguns indícios de que o desenvolvimento de software para um nível "superior segurança" (por exemplo a norma DO-178B), não necessariamente leva a taxas de falha menores". Essa descoberta levanta dúvidas sobre a eficácia das diferentes técnicas prescritas para os níveis "superiores de segurança” e põe em dúvida a abordagem orientada a processos da maioria das normas (HEIMDAHL, 2007).

Também observa-se que, uma vez que os processos descritos nas normas prescrevem várias técnicas, a adição de técnicas novas e potencialmente muito mais eficazes, aos processos, acontece de forma lenta. Segundo McDermid (2001), para reduzir esses problemas, as normas de certificação devem deixar de ser orientadas a processos e passar a ser orientadas a evidências. $\mathrm{O}$ 
autor descreve as seguintes atividades para a utilização de evidências de segurança no software: identificar os possíveis modos de falha do software, que pode dar origem a, ou contribuir para, riscos no contexto do sistema; e, apresentar provas de que esses modos de falha não podem ocorrer, ou são aceitavelmente improváveis de ocorrer, ou são detectados e mitigados de forma que seus efeitos são aceitáveis.

Os requisitos de segurança do software atuam como restrições sobre o projeto do sistema. Observa-se que pode ser necessário que o software evite que o sistema entre em estado perigoso, detecte um estado perigoso, ou mova de um estado perigoso para um estado seguro (LUTZ, 2000).

Conforme explicado nesta seção, a validação procura garantir que está sendo construindo o sistema correto. Procura-se alcançar esse objetivo por meio de inspeções nos requisitos e revisões nos modelos. Por outro lado, a verificação procura garantir que o sistema satisfaz a sua especificação. Ela é realizada por meio de inspeções nos artefatos de projeto e extensos testes nas implementações. Segundo Heimdahl (2007), “em sistemas de software críticos, a fase de validação e verificação (V\& V) é particularmente cara e pode consumir de $50 \%$ a $70 \%$ dos recursos de desenvolvimento". A Engenharia Orientada a Modelos, discutida na próxima seção, é uma das técnicas que vem sendo utilizada para contornar esse problema com custo de V\&V.

Conforme é apresentado na Seção 1.3, no desenvolvimento orientado a modelos, o esforço de desenvolvimento é centrado em torno de um modelo formal ou semi-formal do sistema de software proposto. Por meio de inspeções manuais, verificação formal, simulação e testes, se convence de que o modelo possui as propriedades desejadas. A implementação é então automaticamente ou semi-automaticamente gerada a partir desses modelos e pouco ou nenhum teste adicional da implementação é necessário (HEIMDAHL, 2007) . Desse modo, com o desenvolvimento orientado a modelos, as técnicas de $V \& V$ que tem se concentrado em analisar e testar código, passam a se concentrar em analisar e testar modelos em mais altos níveis de abstração.

A área de métodos formais também costuma colaborar para redução dos esforços em $\mathrm{V} \& \mathrm{~V}$, pois uma vez que os requisitos são especificados formalmente, pode-se fazer uma análise formal para investigar se certas propriedades de segurança são preservadas. Ferramentas de verificação automática podem ser usadas para mostrar que os requisitos são internamente consistentes e completos, além de permitir aos usuários exercitar os requisitos de segurança.

Conforme tem sido amplamente discutido nesta subseção, o projeto de sistemas críticos deve ser elaborado de modo a garantir segurança por meio da redução dos riscos. Em sistemas de Hardware, redundância e diversidade são as formas mais comuns para reduzir os riscos. Em Software, o projeto pode envolver prevenção de riscos, ou detecção e controle de risco, quando ocorrem. O projeto para prevenção de riscos inclui mecanismos, tais como bloqueios de hardware para proteção contra erros de software, lockins, intertravamentos, temporizadores, isolamento de módulos de segurança crítica, e checagens de que o software está se comportando 
como esperado (LUTZ, 2000).

As decisões de projeto em sistemas críticos costumam envolver compensações entre segurança e outros atributos desejáveis para o produto, tais como: autonomia, velocidade, acoplamento, custo, entre outros. Por exemplo, se por um lado, a utilização de métodos de projeto para tolerância a falhas pode contribuir para o desenvolvimento de sistemas mais seguros, por outro lado, podem criar interações adicionais entre os componentes e os níveis do sistema, o que é indesejável em sistemas críticos (LUTZ; WONG, 1992). Além disso, segundo Leveson (1991), "muitas vezes, a resolução de conflitos entre as restrições de segurança e as funcionalidades desejadas envolve decisões morais, éticas, legais, financeiras e sociais, portanto não é geralmente uma decisão puramente técnica de otimização". Como a demanda por SCES cresce a cada dia, questões comerciais e de marketing, tais como o tempo de mercado e a produção em larga escala também podem se tornar fatores importantes para decisões de projeto (LEVESON, 1991). citetLutzW92 afirmam que os principais problemas de projeto surgem pela falta de utilização de técnicas conhecidas para o projeto de sistemas críticos.

Muitos sistemas embarcados críticos também possuem requisitos de tempo real, que são aqueles cuja corretude não depende somente do valor de sua saída, mas também do tempo em que esse valor é produzido. Geralmente, um sistema de tempo real executa uma coleção de tarefas subjetivas com restrições de prazo e jitter. Uma vez iniciada, uma tarefa deve produzir sua saída antes de um prazo, e com baixa variabilidade (jitter) de uma ativação para outra. Tempo real restrito, se refere a circunstâncias nas quais a perda do prazo é potencialmente catastrófica, ou seja, são os sistemas críticos de tempo real. Portanto, para serem considerados corretos e úteis, sistemas de tempo real devem entregar resultados dentro de intervalos de tempo especificados, sem exceção ou com alta probabilidade de sucesso.

Existem dois grandes problemas no desenvolvimento de sistemas de tempo real: a derivação de restrições de tempo, e a construção de uma estrutura do sistema que garanta a satisfação dessas restrições.

Diante de todos esses desafios, apresenta-se em detalhes, na próxima seção, a Engenharia Orientada a Modelos com seus conceitos, técnicas, ferramentas e formas de aplicação na Engenharia de Sistemas Embarcados Críticos.

\subsection{Engenharia orientada a modelos}

Segundo France e Rumpe (2007), os avanços no desenvolvimento de Software e nas tecnologias de processamento de informação resultaram em tentativas de desenvolver sistemas mais complexos. Entretanto, esses sistemas evidenciaram a inadequação das abstrações fornecidas pelas modernas linguagens de programação de alto nível. Isso levou a uma demanda por linguagens, métodos e tecnologias que aumentem o nível de abstração no qual os sistemas de 
Software são concebidos, construídos e evoluídos, especialmente no domínio de SCES.

O interesse em aumentar o nível de abstração, necessário para programar os sistemas computacionais, é antigo na Ciência da Computação, e provou-se eficaz desde que se passou a utilizar a linguagem de montagem (Assembly) em vez de linguagem de máquina. Posteriormente, as linguagens de montagem ou de baixo nível, foram substituídas por linguagens estruturadas e mais abstratas, até a concepção de linguagens com alto nível de abstração, tais como as linguagens orientadas a objetos (HAILPERN; TARR, 2006). Assim como os pesquisadores comprovaram que é mais rápido e intuitivo para um ser humano escrever código em Java do que código em Assembly, por exemplo, os defensores da Engenharia Orientada a Modelos (MDE, do Inglês Model-Driven Engineering) argumentam que também é mais rápido e intuitivo construir um modelo gráfico em UML, por exemplo, do que escrever código Java (MELLOR; CLARK; FUTAGAMI, 2003).

Nesse sentido, a MDE surgiu como um conjunto de técnicas ou abordagem de desenvolvimento, cujo principal objetivo é o aumento do nível de abstração. Seus princípios básicos são: considerar os modelos como entidades de primeira classe; e, qualquer artefato de software é um modelo ou um elemento de modelo (BÉZIVIN, 2006).

Embora alguns considerem MDE como sinônimo de desenvolvimento orientado a modelos (MDD, do Inglês Model-Driven Development) (HAILPERN; TARR, 2006; BEYDEDA; BOOK; GRUHN, 2005), esta tese segue autores como (WHITTLE; HUTCHINSON; ROUNCEFIELD, 2014) e (AMELLER, 2010), para os quais MDD é um subconjunto do MDE. Enquanto o MDD foca na geração de implementação a partir de modelos, o MDE inclui outros usos de modelos para apoiar o processo de desenvolvimento, tal como engenharia reversa orientada a modelos ou evolução orientada a modelos.

Os principais desafios de desenvolvimento que o uso de MDE procura resolver são:

- aumento do nível de abstração. Segundo Hailpern e Tarr (2006), o principal objetivo do MDE é aumentar o nível de abstração no qual os desenvolvedores operam, e dessa forma, reduzir tanto o esforço quanto a complexidade dos artefatos de software que os desenvolvedores utilizam;

- evitar que os modelos gerados fiquem desatualizados em relação ao código fonte gerado;

- possibilitar que validação e verificação possam ser realizadas em estágios iniciais do desenvolvimento;

- enfrentar a complexidade das plataformas e a incapacidade das linguagens de terceira geração em atenuar essa complexidade (SCHMIDT, 2006);

- expressar os conceitos do domínio de forma eficaz. 
No desenvolvimento "tradicional" (não orientado a modelos) de software, em resumo, um analista elabora documentos, esboços ou modelos e, com base nesses artefatos, o projetista elabora um projeto de arquitetura para o sistema. O programador utiliza esse projeto como base para o código que implementa esse sistema. Entretanto, observa-se que é comum ao programador encontrar problemas ou inconsistências entre os requisitos e projeto ao longo da implementação e essa situação pode resultar, principalmente, em uma das duas alternativas descritas a seguir:

1. o processo de desenvolvimento utilizado é baseado no modelo em cascata. Nesse caso, o desenvolvedor realiza as alterações necessárias em código e os modelos ficam desatualizados;

2. o processo de desenvolvimento utilizado é baseado no modelo iterativo e, nesse caso o desenvolvedor entra em contato com o analista e o projetista para a realização das devidas correções. Essa retroalimentação é dispendiosa ao processo, pois enquanto são realizadas essas alterações, o desenvolvimento pode ficar paralisado até a conclusão das correções. Na prática, por mais que o processo seja iterativo, dificilmente os modelos permanecem atualizados ao final do processo de desenvolvimento.

Diferentemente do desenvolvimento tradicional descrito acima, a utilização do MDE pode evitar que o desenvolvedor tenha que executar tarefas repetitivas necessárias para converter as informações contidas nos modelos em código final executável. Com a utilização de MDE, os modelos deixam de ser uma ferramenta de apoio ao desenvolvimento e passam a ser tão importantes para o Software quanto o código fonte, pois o foco é construir modelos de um sistema que podem ser transformados no próprio sistema (MELLOR; CLARK; FUTAGAMI, 2003). Além disso, pode-se evitar a dispendiosa tarefa de atualização dos modelos por meio da automação dessas atividades, conforme apresenta-se na Figura 3 (LUCRÉDIO, 2009). Observase que o tempo gasto nessas tarefas é significativamente reduzido, mesmo para atividades como correção de erros, executadas nos modelos, sem produzir inconsistência.

Segundo Bézivin (2006), abordagens de MDE são fundamentadas em três ideias centrais:

- representação direta: significa que, ao invés de se realizar diretamente determinadas tarefas em linguagens de propósito geral, como Java, cientistas da computação podem se concentrar na definição de linguagens especializadas (DSLs) e seu manuseio, para que os usuários finais sejam capazes de expressar precisamente as suas contribuições nessas linguagens sem ambiguidades;

- automação: refere-se ao uso de ferramentas computadorizadas que se destinam a processar as contribuições dos usuários representadas nessas DSLs para preencher a lacuna semântica entre os conceitos de domínio e as tecnologias de implementação; 
Figura 3 - Desenvolvimento de software orientado a modelos.

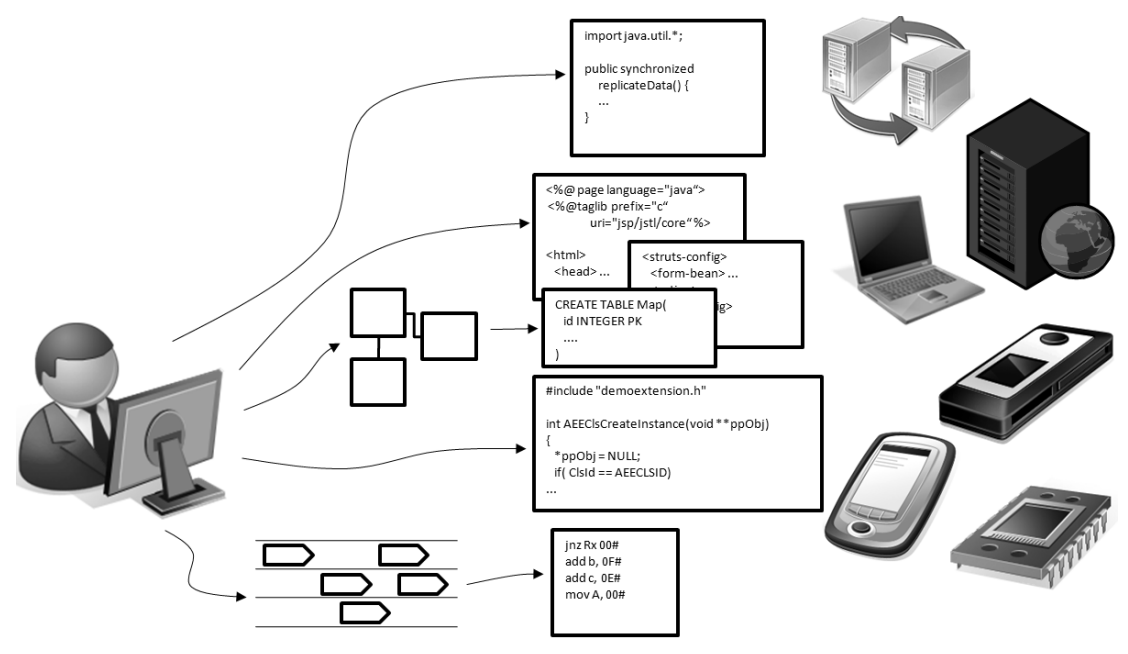

fonte: Lucrédio (2009)

- normas: são necessárias para permitir a interoperabilidade entre as diversas soluções técnicas, pois os modelos devem ser permutáveis.

Os conceitos fundamentais do MDE estão relacionados com diversas outras abordagens, tais como: linguagens específicas de domínio (DSL, do Inglês, Domain Specific Language), fábricas de software, computação integrada a modelo, gerenciamento de modelos, programação orientada a linguagem e diversas outras (BÉZIVIN, 2006). Grandes organizações como OMG (Object Management Group), IBM e Microsoft estão apostando nas ideias do MDE (MENS; GORP, 2006).

Para compreender melhor esses conceitos, é necessário definir o elemento central dessa abordagem, o modelo. Um modelo pode ser definido, de forma abrangente, como: "uma estrutura complexa que representa um artefato de projeto tal como: um esquema relacional, uma definição de interface (API, do Inglês Application Programming Interface), um esquema XML, uma rede semântica, um modelo UML ou um documento hipermídia" (BERNSTEIN; LEVY; POTTINGER, 2000).

Mellor, Clark e Futagami (2003) restringem essa definição e apresentam um modelo como: um conjunto coerente de elementos formais que descrevem algo (por exemplo, um sistema, banco, telefone ou trem), construído com alguma finalidade e que é passível de uma forma particular de análise, como: comunicação de ideias entre pessoas e máquinas; verificação de completude; análise; geração de casos de teste; viabilidade em termos de indicadores como custo e estimativa; padrões; ou, transformação em uma implementação.

No contexto do MDE e para esta tese, um modelo "é uma estrutura que representa algum aspecto de um dado sistema em conformidade com a definição de uma outra estrutura chamada metamodelo" (BÉZIVIN, 2006). Modelos são, comumente usados para fornecer representações 
de situações do mundo real. Um modelo é dito como a representação de um sistema.

Apesar dessa definição mais restrita, segundo Bézivin (2004), a tendência na engenharia de modelos é considerar que os modelos são cidadãos de primeira classe. Como corolário desse princípio declara-se: " tudo é um modelo ". Portanto, pode-se inferir, por exemplo, que uma transformação de modelo, também é considerado um modelo.

A proposta do MDE é fazer com que o engenheiro de software não precise interagir manualmente com todo o código-fonte, podendo se concentrar em modelos de mais alto nível, ficando protegido das complexidades requeridas para implementação nas diferentes plataformas. Um mecanismo automático é responsável por gerar automaticamente o código a partir dos modelos. Qualquer alteração nos modelos é refletida no código por meio das transformações de modelos, portanto os modelos ficam em conformidade com o código do início ao fim do desenvolvimento (STAHL; VOELTER; CZARNECKI, 2006).

Conforme apresentado anteriormente, cada modelo é definido em conformidade com um metamodelo. Metamodelos definem linguagens que permitem expressar modelos, ou seja descrevem os vários tipos existentes de elementos do modelo, a forma como eles são organizados, relacionados, e restringidos (BÉZIVIN, 2006). Um modelo é dito estar em conformidade com o seu metamodelo, conforme ilustra-se na Figura 4, por meio de um exemplo no qual foi definido um modelo relacional de uma tabela de carros em conformidade com o seu metamodelo correspondente.

Figura 4 - Exemplo de relacionamento entre metamodelo e modelo.

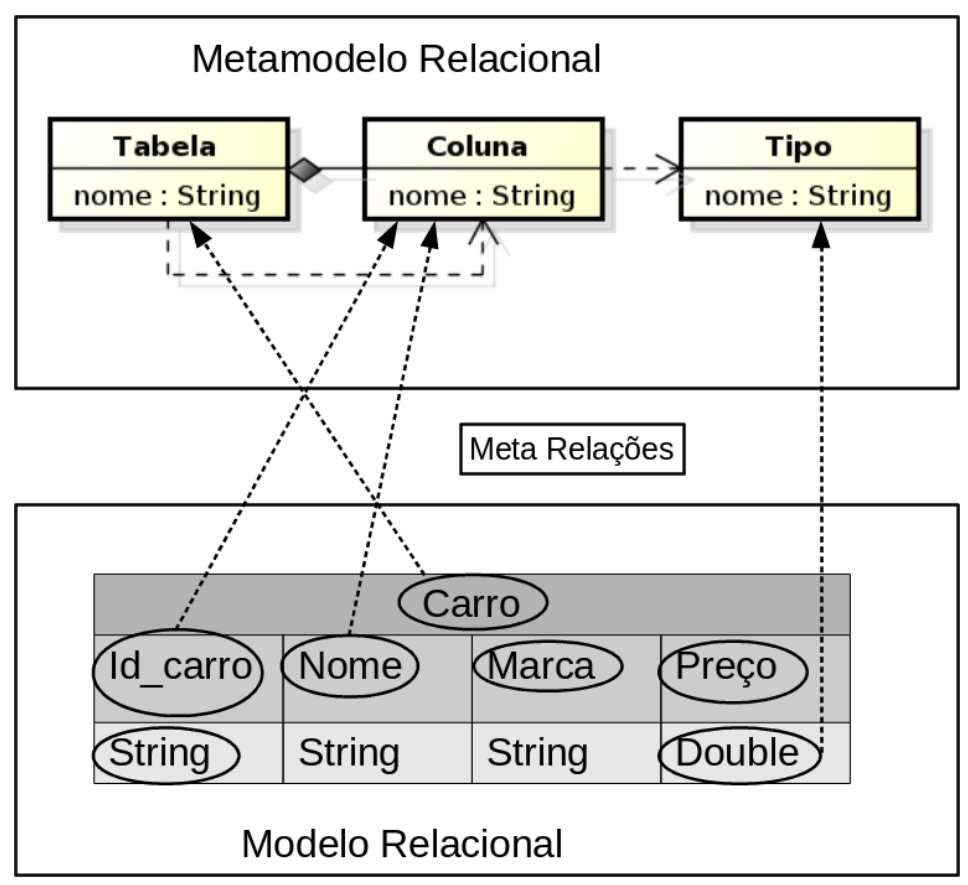

Assim como qualquer outra abordagem de desenvolvimento, a utilização de técnicas de MDE ao longo do desenvolvimento apresenta pontos positivos e negativos conforme apresentamse a seguir: 


\section{Vantagens:}

- aumento de produtividade, pois é possível reduzir o tempo de desenvolvimento, a longo prazo, uma vez que a codificação passa a ser feita de forma automatizada a partir da construção de modelos em alto nível;

- portabilidade, pois o desenvolvedor elabora modelos em alto nível que podem ser utilizados para gerar código em diferentes ambientes/plataformas (MILLER; MUKERJI, 2003);

- interoperabilidade, visto que se pode elaborar diversos modelos que podem ser transformados em código para plataformas diferentes, resultando em um software que executa em um ambiente heterogêneo, porém mantendo a funcionalidade global (MILLER; MUKERJI, 2003);

- facilidade de manutenção e documentação, visto que a manutenção passa a ser feita em modelos de alto nível e eles passam a ser parte, tanto do software quanto da especificação (LUCRÉDIO, 2009);

- reutilização, pois a reutilização em níveis mais altos de abstração, tais como projeto e arquitetura, proporcionam maiores benefícios em relação a reutilização de artefatos de códigos Krueger (1992), Gomaa e Saleh (2005);

- facilidade de verificações e otimizações, pois modelos oferecem maior facilidade para verificadores e ainda podem ser realizadas otimizações automáticas específicas de domínio (LUCRÉDIO, 2009).

- redução de erros, pois além do fato de geradores não introduzirem erros acidentais, como erros de digitação, eles permitem que a identificação de erros conceituais aconteça em estágios iniciais do desenvolvimento.

\section{Desvantagens:}

- aumento da rigidez, pois grande parte do código é gerado e fica fora do alcance do desenvolvedor;

- maior complexidade inicial, pois os artefatos necessários para utilização do MDE, tais como ferramentas de modelagem e geradores de código, introduzem complexidade adicional ao processo, visto que são difíceis de construir e manter;

- perda de desempenho, pois mesmo que algumas otimizações possam ser realizadas pelos geradores, eles acabam incluindo algum código extra, que por conseguinte pode apresentar desempenho abaixo daquele alcançado pelo código escrito por bons programadores; 
- maior curva de aprendizado, pois o desenvolvimento dos artefatos específicos de MDE exigem habilidade na construção de linguagens, ferramentas de modelagem, transformação e geradores de código;

- alto investimento inicial, pois é necessário montar uma infraestrutura de reutilização orientada a modelos que requer mais tempo e esforço. No entanto, os ganhos posteriores podem ser significativos e podem compensar esse alto investimento inicial.

- um dos princípios centrais do MDE é a existencia de múltiplas representações de artefatos inerentes a um processo de desenvolvimento de software, representando pontos de vista ou de níveis de abstração diferentes sobre os mesmos conceitos. Na medida em que são criados manualmente, geram trabalho duplicado e a necessidade de gestão de consistência (HAILPERN; TARR, 2006).

A partir dessas definições iniciais e estendendo a definição de Hailpern e Tarr (2006), esta tese define o MDE como: uma abordagem de engenharia que consiste na utilização de modelos e tecnologias de modelo para elevar o nível de abstração em que os desenvolvedores criam e evoluem sistemas, com o objetivo de simplificar e formalizar as diversas atividades e tarefas que compreendem o ciclo de vida do desenvolvimento de sistemas. O MDE impõe estrutura e vocabulários comuns para que os artefatos sejam úteis para seu propósito principal em seu estágio específico no ciclo de vida (como descrever uma arquitetura), para a necessidade subjacente de ligação com artefatos relacionados (mais cedo ou mais tarde no ciclo de vida), e para servir como um meio de comunicação entre os participantes do projeto. Portanto, uma abordagem MDE deve especificar a linguagem de modelagem, modelos, traduções entre modelos e linguagens, e o processo usado para coordenar a construção e evolução dos modelos (KENT, 2002).

Portanto, para possibilitar a adoção de MDE, segundo Lucrédio (2009), Bragança e Machado (2008) e Hailpern e Tarr (2006) necessita-se:

- que os modelos criados sejam semanticamente completos e corretos, uma vez que devem ser compreendidos por um computador, que diferentemente de seres humanos, não são capazes de corrigir pequenos enganos ou preencher lacunas por si só. Para isso implementase essas características em uma modelagem específica de domínio;

- idealmente, que a ferramenta para definição de transformações possibilite a construção de regras de mapeamento da forma mais natural possível, pois a construção de transformadores é uma tarefa complexa;

- de motores de transformação que efetivamente executem as transformações definidas pelo engenheiro; 
- que a ferramenta de transformação deve ainda manter informações de rastreabilidade, possibilitando saber a origem de cada elemento gerado, tanto no modelo como no códigofonte.

\subsubsection{Metamodelagem}

Assim como os modelos, os metamodelos são composto por elementos. Os elementos de um metamodelo fornecem um esquema de tipagem para os elementos do modelo. Essa tipagem é expressa por meio da meta relação entre o elemento do modelo e o metaelemento (elemento do metamodelo). Também é dito que um elemento do modelo é tipado por seu metaelemento. Um modelo está em conformidade com um metamodelo, se e somente se, cada elemento do modelo tem o seu metaelemento definido no metamodelo (BÉZIVIN, 2006).

A partir de um número crescente de metamodelos surgiu a necessidade de uma estrutura de integração para os metamodelos, o metametamodelo. Essa estrutura é dedicada à definição de metamodelos. Assim como os modelos são definidos em conformidade com o seu metamodelo, metamodelos são definidos por meio da linguagem de metametamodelo. Assim como modelos e metamodelos, o metametamodelo é composto por elementos. Um metamodelo é dito em conformidade com um metametamodelo, se e somente se, cada um dos seus elementos tem seu metaelemento definido no metametamodelo (BÉZIVIN, 2006). Um exemplo de metametamodelo é o Meta-object Facility, que é a proposta do Object Management Group (OMG) para definir metamodelos e é apresentando adiante. O metamodelo relacional definido na Figura 4 está em conformidade com o metametamodelo MOF, conforme apresenta-se na Figura 5.

O conceito de metamodelagem é definido em quatro níveis (OMG, 2004), conforme apresenta-se na Figura 6, por meio de um exemplo prático. O primeiro e mais básico nível, também conhecido como M0, corresponde ao nível dos dados, nele são definidos aspectos de um sistema de computador. O segundo nível, também conhecido como M1, representa um modelo ou metadado (por exemplo, um modelo UML). Observa-se que o termo metadado é utilizado para se referir ao dado que tem como propósito descrever outro dado. O terceiro nível, também conhecido como M2, metamodelo ou metametadado, representa uma linguagem de modelagem que define o metadado (por exemplo, o metamodelo da UML). O termo metamodelo é usado para se referir a um modelo de um tipo de metadado. O quarto e último nível, também conhecido como M3, metametamodelo, metametametadado ou metaobjeto (por exemplo, o padrão MOF), corresponde à linguagem de modelagem que define metamodelos. Não existe um quinto nível visto que os metametamodelos são, por definição, instâncias de si mesmo. O termo metaobjeto é usado para se referir a um objeto abstrato ou tecnologia específica que representam metadados.

Observa-se que a definição de uma linguagem é iniciada pela identificação da terminologia e conceitos para essa linguagem de modelagem. Esses conceitos são documentados formalmente em um metamodelo, que pode ser executado em uma ferramenta de modelagem 
Figura 5 - Exemplo de relacionamento entre metametamodelo e metamodelo.

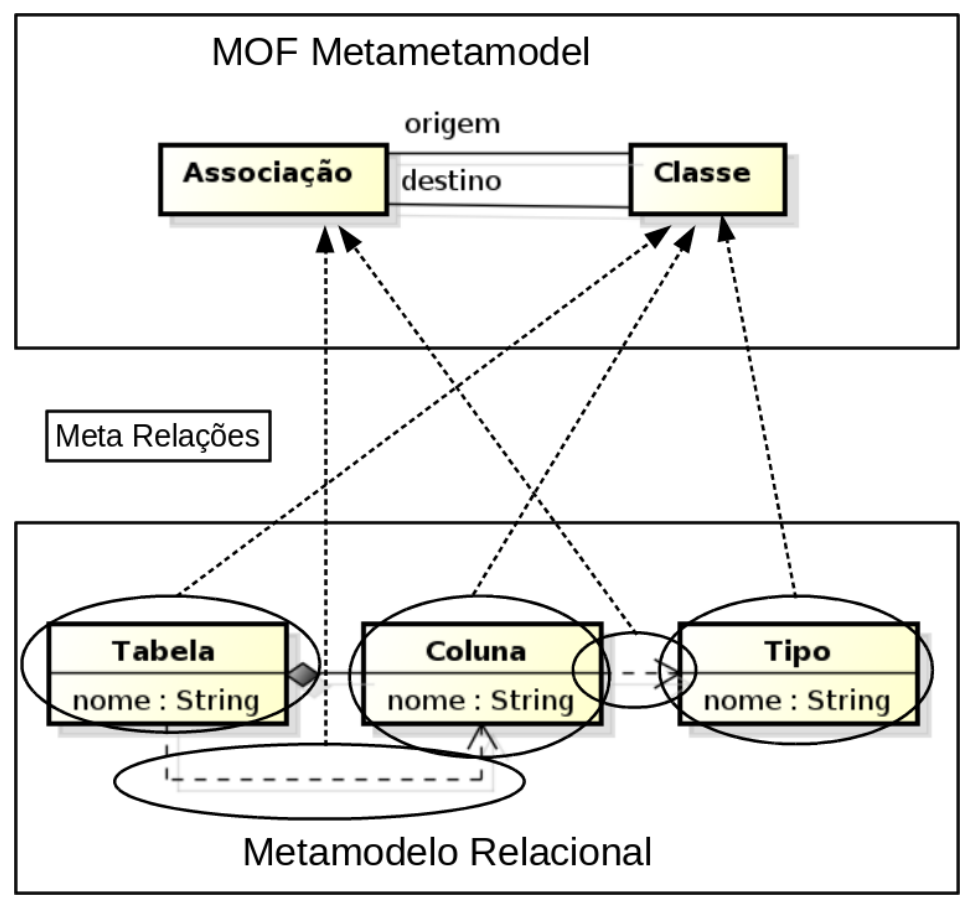

fonte: Lucrédio (2009)

baseada em metamodelos. Além da terminologia, uma linguagem de modelagem específica de domínio segue um modelo computacional, de tal forma que pode-se utilizar motores de transformação para produzir código a partir desses modelos. Um tipo de modelo computacional muito utilizado em sistemas embarcados, por exemplo, são as máquinas de estados (TOLVANEN, 2004).

Segundo (BÉZIVIN, 2006), um metamodelo traz facilidades de engenharia diferente das gramáticas, esquemas XML, ontologias e outras, e mesmo que a sua estrutura e aplicação ainda estejam em evolução, pode-se dizer que um metamodelo ajuda a definir uma DSL. Um metamodelo funciona como um filtro para extrair os elementos pertinentes de um sistema, com o objetivo de construir um modelo correspondente. Qualquer característica (conceito ou relacionamento) que não está presente no metamodelo será ignorada durante a construção do modelo que representa o sistema.

\subsubsection{Linguagens específicas de domínio}

Conforme apresentado anteriormente, o MDE baseia-se, entre outros, nos conceitos de Metamodelagem e em modelagem específica de domínio (DSM, do Inglês, Domain-Specific Modeling), cujo propósito é, primeiramente, criar modelos para computação e, adicionalmente, servir para documentação. Em geral, modelos devem ser processados por ferramentas para gerar código fonte a partir deles. O objetivo de DSM é preencher a lacuna existente entre o domínio 
Figura 6 - Metamodelagem em quatro níveis.

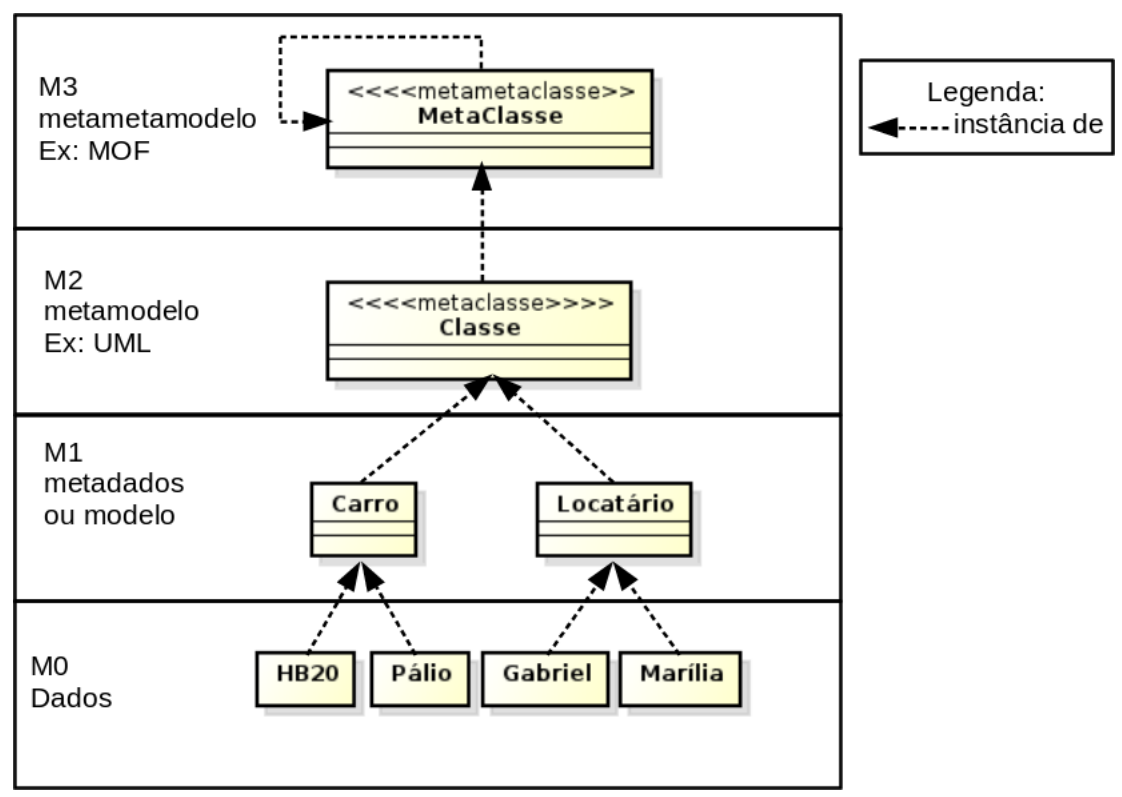

fonte: Lucrédio (2009)

do problema e o domínio da solução por meio de abstração. A DSM é feita com a utilização de DSLs que aumentam o nível de abstração incorporando conceitos de domínio. Quanto mais adaptada for uma DSL para um certo domínio ou propósito, mais eficiente ela e a geração de código serão. Observe que uma DSL é mapeada para uma linguagem de programação, da mesma forma que uma linguagem de programação como Java é mapeada em bytecodes. Analogamente, o compilador corresponde ao gerador de código (DEMIR, 2006).

DSLs tem o objetivo de formalizar a estrutura, o comportamento e os requisitos de uma aplicação em um domínio particular, como por exemplo, software de compras coletivas, serviços financeiros na Web ou até sistemas embarcados críticos. DSLs são descritas utilizandose metamodelos (OMG, 2004). Desenvolvedores utilizam uma DSL para construir aplicações usando os elementos do tipo de sistema definido pelos metamodelos para expressar a intenção do projeto de forma declarativa em vez de imperativa (SCHMIDT, 2006).

\subsubsection{SysML}

O SysML é uma linguagem de modelagem de sistemas que apoia a especificação, análise, projeto, verificação e validação de uma ampla gama de sistemas complexos (Object Management Group, 2012). A linguagem é uma customização da UML para apoiar Engenharia de sistemas e ser aplicada a sistemas que podem incluir hardware, software, informações, processos, pessoas e instalações. SysML é apoiada pelo grupo de interesse especial no domínio de engenharia de sistemas da OMG e pelo INCOSE (Conselho Internacional de Engenharia de Sistemas). Espera-se que SysML se torne o padrão "de fato" para Engenharia de sistemas, da mesma 
forma que a UML é, para a Engenharia de Software. O SysML é eficaz na especificação de requisitos, estrutura, comportamento, alocações de elementos em modelos, e restrições sobre as propriedades do sistema (Object Management Group, 2012), conforme apresenta-se na Figura 7, por meio de sua taxonomia. Nesta tese, utiliza-se o diagrama de requisitos SysML, o qual é detalhado a seguir.

Figura 7 - Taxonomia dos diagramas SysML.

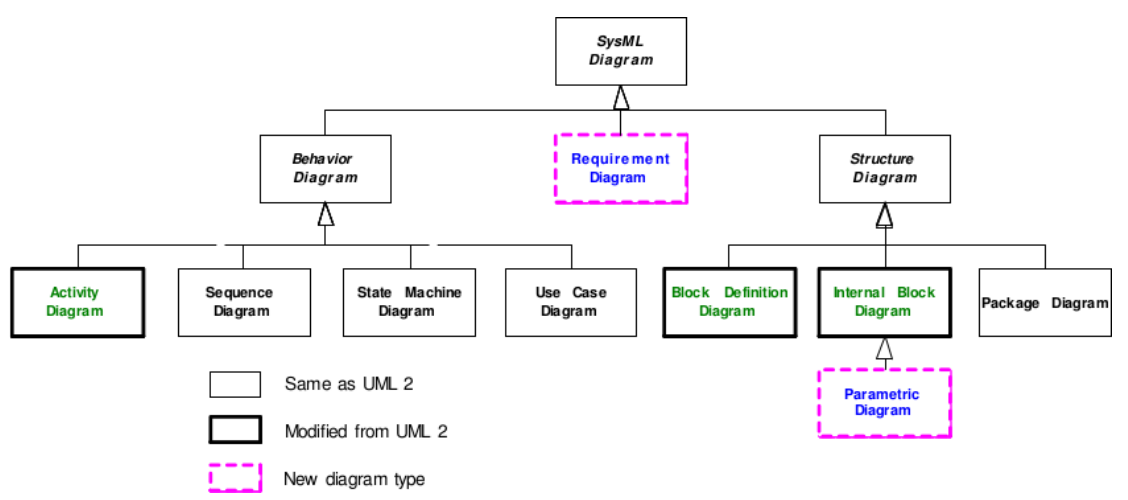

Fonte: Object Management Group (2012)

O perfil SysML fornece um diagrama específico para especificação de requisitos, o que é uma vantagem sobre a UML. Como consequência direta, SysML permite a representação de requisitos como elementos de modelo, o que significa que os requisitos são parte da arquitetura do sistema. As construções de requisitos SysML tem o objetivo de preencher a lacuna entre as ferramentas tradicionais de gestão de requisitos e os outros modelos SysML. Quando combinado com UML, o diagrama de requisitos pode preencher a lacuna entre a especificação de requisitos de usuário, normalmente escritos em linguagem natural, e os diagramas de casos de uso, usados como uma especificação inicial de requisitos do sistema (SOARES; VRANCKEN, 2007).

O diagrama de requisitos SysML também tem a vantagem de oferecer uma padronização aos documentos de requisitos. Existe um padrão específico a ser usado, e dessa forma, reduz-se a quantidade de estilos diferentes de documentos para a especificações de requisitos. Outra vantagem é a existência de uma semântica definida para associar o diagrama de requisitos SysML com outros modelos criados durante o projeto do sistema. Além disso, o diagrama de requisitos SysML pode facilitar a transformação dos requisitos de usuário em requisitos de sistema e melhorar a rastreabilidade dos requisitos ao longo do ciclo de vida do projeto (Object Management Group, 2012).

O diagrama de requisitos SysML possui um nó básico, conforme apresenta-se na Figura 8. Todo requisito possui, pelo menos, o estereótipo $<<$ Requirements $>>$, o nome do requisito, um texto com uma breve descrição e um identificador único.

Requisitos estão frequentemente relacionados uns com os outros, e essas interações afetam o desenvolvimento de software de várias maneiras (SOARES; VRANCKEN, 2007). Por 
Figura 8 - Estrutura de um nó básico no diagrama de requisitos SysML.

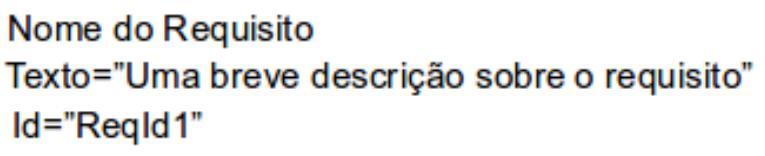

isso, o diagrama de requisitos SysML permite várias formas de representar as relações entre requisitos. Estão incluídos relacionamentos para definir hierarquia de requisitos, derivação de requisitos, satisfação de requisitos, verificação de requisitos e refinamento de requisitos (Object Management Group, 2012).

Com o relacionamento de hierarquia, SysML permite que os requisitos complexos sejam divididos em outros mais simples, como uma hierarquia de requisitos relacionados uns aos outros. A vantagem é que a complexidade dos sistemas é tratada desde o início do desenvolvimento, pela decomposição de requisitos complexos em vários mais simples. O conceito de hierarquia também permite a reutilização de requisitos. Neste caso, um requisito comum pode ser partilhado por outros requisitos (SOARES; VRANCKEN, 2007).

A relação de derivação relaciona um requisito derivado a seu requisito fonte. Durante o processo de engenharia de requisitos, novos requisitos são criados a partir dos anteriores. A relação permite, por exemplo, uma conexão entre o alto nível (orientado ao usuário) e os requisitos de baixo nível (orientados ao sistema). Isso facilita relacionar a dependência dos requisitos do usuário mapeados em requisitos do sistemas. Em um diagrama de requisitos, a relação de derivação é representada pela palavra-chave deriveReqt (Object Management Group, 2012).

A relação de satisfação descreve como um modelo satisfaz um ou mais requisitos. Ela representa uma relação de dependência entre um requisito e outros diagramas ou elementos de diagramas SysML, que representam esse requisito. A palavra-chave satisfy representa essa relação. Um exemplo comum é associar um requisito a um diagrama de bloco SysML (SOARES; VRANCKEN, 2007).

A relação de verificação define como um caso de teste pode verificar um requisito. Isso inclui métodos de verificação padrão para inspeção, análise, demonstração ou teste. Por exemplo, dado um requisito, os passos necessários para a sua verificação podem ser resumidos por uma máquina de estado. A palavra-chave que representa esta relação é verify (Object Management Group, 2012).

A relação de refinamento descreve como um elemento de modelo (ou conjunto de elementos) pode ser utilizado para refinar um requisito em um momento posterior. Por exemplo, como um diagrama de casos de uso pode representar um requisito de texto. A relação está representada no diagrama pela palavra-chave refine (Object Management Group, 2012). 
A relação de rastreamento fornece uma relação de propósito geral entre um requisito e qualquer outro elemento do modelo. Sua semântica não tem limitações reais e não está bem definida como a dos outros relacionamentos. Por exemplo, uma dependência de rastreio genérico pode ser usada para enfatizar que um par de requisitos estão relacionados de duas maneiras diferentes (BALMELLI, 2007).

Os elementos desse modelo são sumarizados por meio do seu metamodelo, conforme apresenta-se na Figura 9.

Figura 9 - Metamodelo do diagrama de requisitos SysML.

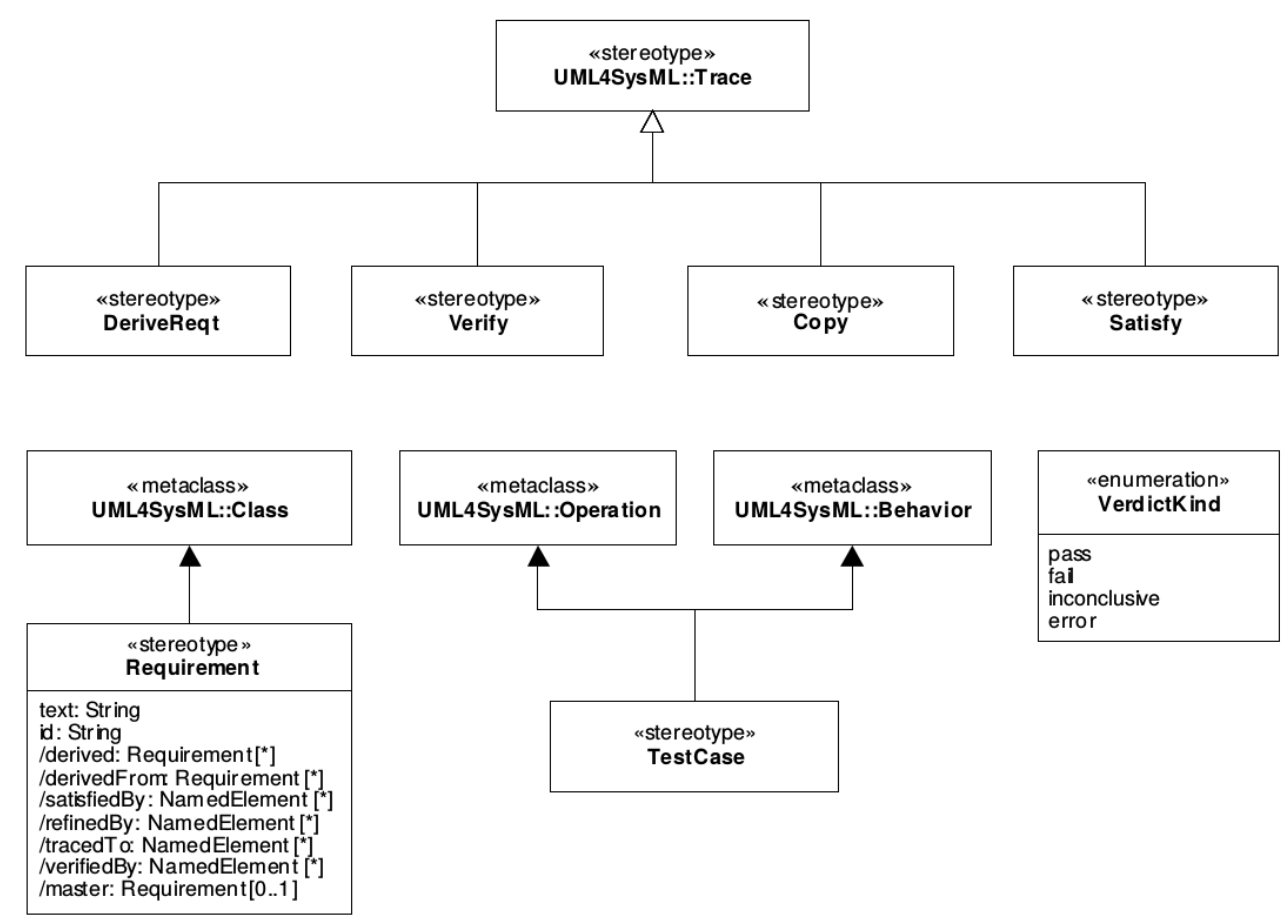

Fonte: Object Management Group (2012)

\subsubsection{MARTE}

Como UML é uma linguagem de modelagem de propósito geral, ela não possui construções e abstrações para representar conceitos específicos de sistemas embarcados de tempo real. A primeira tentativa para tratar esta deficiência foi o UML Profile for Schedulability, Performance and Time Specification (SPT) (OMG, 2009). O SPT fornecia conceitos para permitir a análise de escalabilidade, assim como análise de performance, além de possuir meios para modelar o tempo e mecanismos relacionados ao tempo. Entretanto, SPT possui várias lacunas que impediram sua adoção. O MARTE foi o perfil criado para preencher essas lacunas.

O perfil MARTE (UML Profile for Modeling and Analysis of Real-Time Embedded Systems) (OMG, 2009) é um perfil UML definido pelo OMG, que trata do projeto de aspectos de 
software e hardware em sistemas embarcados, tais como: alocação de elementos; capacidade ampliada para análise de escalonabilidade e performance; especificação de características de sistemas embarcados, como capacidade de memória e consumo de energia; suporte a arquiteturas baseadas em componentes; e, outros paradigmas computacionais, como assíncrono e síncrono (WEHRMEISTER, 2009).

A especificação MARTE se concentra principalmente em quatro características importantes, das quais duas são voltadas para aspectos de modelagem da qualidade de serviço (QoS), um para arquitetura e outra para a plataforma. Os diagramas de modelagem fornecem os recursos necessários a partir de especificações para a implementação final, enquanto os recursos de análise de modelos permitem facilitar a avaliação de desempenho e a programação das atividades (OMG, 2009).

Os pacotes do perfil incluem os recursos necessários para as especificações a segui, conforma apresenta-se na Figura 10.

- NFP: propriedades não funcionais;

- Time: modelagem de tempo causal/temporal, clock/síncrono, e física/tempo-real;

- GRM: modelagem de estereótipos e notações que ajudam na modelagem;

- Alloc: alocação de elementos das plataformas de execução;

- HLAM: suporte a conceitos de modelagem em alto nível para alcançar características de tempo-real;

- GCM: conceitos adicionais (paradigmas de componentes não-usuais) que têm sido identificados como necessários para a esquematização;

- SRM: voltado para a descrição de programação de interfaces de aplicações de suporte a softwares de execução multitarefa;

- HRM: descreve suportes de execução de hardware através de diferentes visões e níveis de detalhes;

- GQAM: domínios especializados com análise baseada no comportamento do software, bem como performance, agendamento, energia, memória, custo, consumo, e segurança;

- SAM: cálculo e análise sensitiva do agendamento;

- PAM: descreve a análise de propriedades temporais de sistemas.

De acordo com o domínio a ser desenvolvido, alguns detalhes de projeto podem ser necessários, tais como modelagem tempo com o pacote Time, descrição detalhada de recursos de hardware com o pacote HRM, descrição de plataformas de software com o pacote SRM, 
Figura 10 - Arquitetura do perfil MARTE.

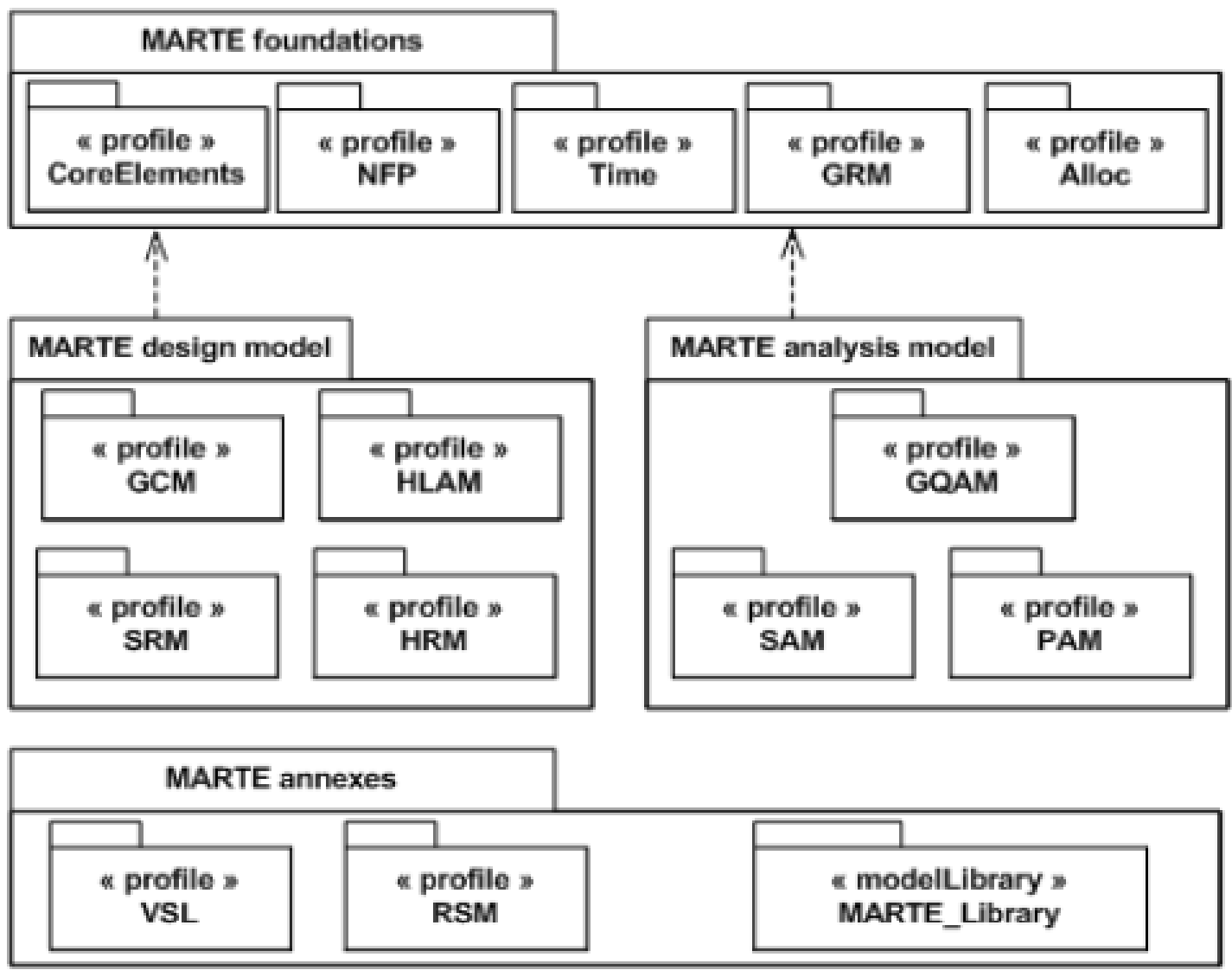

Fonte: OMG (2009)

e definição de alocação entre os elementos de hardware e software com o pacote Alloc. Eles recursos permitem a realização do chamado co-desing.

\subsubsection{Geradores de Aplicações}

Para que se consiga converter uma DSL em código fonte de forma automática, o que é um dos pilares do MDE, necessita-se do apoio de ferramentas especializadas, como geradores de aplicações e ferramentas de transformação. Segundo Tolvanen (2004), a geração de código completa é difícil, senão impossível de ser obtida quando o gerador é projetado para atender a todas as situações. Contudo, a geração de código completa é possível, quando tanto gerador quanto linguagem são projetados para atender as necessidades de um domínio específico. Portanto, um gerador de código deve trabalhar bem com uma DSL da qual recebe entrada e com a plataforma alvo na qual o código gerado irá executar.

Geradores de aplicações são ferramentas capazes de gerar artefatos a partir de uma especificação. A especificação descreve o problema ou tarefa a ser feita pelo artefato. Essa especificação pode ter a forma de um diálogo interativo, no qual o usuário seleciona as opções desejadas a partir de uma série de menus, pode aparecer de uma forma gráfica, no qual o 
usuário edita um diagrama ou pode ser escrita em alguma linguagem. Os artefatos gerados pelo gerador de aplicações podem ser segmentos de código, sub-rotinas, sistemas de software, entre outros. Geradores de aplicações tem como objetivo maximizar a automação do desenvolvimento de aplicações por meio do uso de software customizado reusável (CLEAVELAND, 1988; CZARNECKI; ØSTERBYE; VöLTER, 2002).

Pode-se dizer que um gerador de aplicações funciona de forma semelhante a um compilador, traduzindo as informações em alto nível para implementação de baixo nível. Alguns tipos são compiladores para DSLs. Embora os compiladores possam ser vistos como geradores, a pesquisa e prática em geradores de aplicações foca em diferentes problemas daqueles tratados por compiladores, tais como transformação de programas (SMARAGDAKIS; BATORY, 2000). Sempre que for necessário modificar o produto, basta alterar as especificações de entrada e executá-las novamente no gerador de aplicação.

Na Figura 11 apresenta-se o processo de desenvolvimento de uma aplicação ou código utilizando um gerador de aplicações típico. Os quadrados representam arquivos e as elipses representam programas executáveis. O processo inicia-se com uma especificação que é submetida ao gerador de aplicação. O gerador transforma essa especificação em um programa ou código, por exemplo. Esse programa passa por um compilador de sua linguagem específica, que gera o executável. A aplicação gerada recebe entradas, processa e gera uma saída correspondente.

Figura 11 - Utilização de um gerador de aplicações.

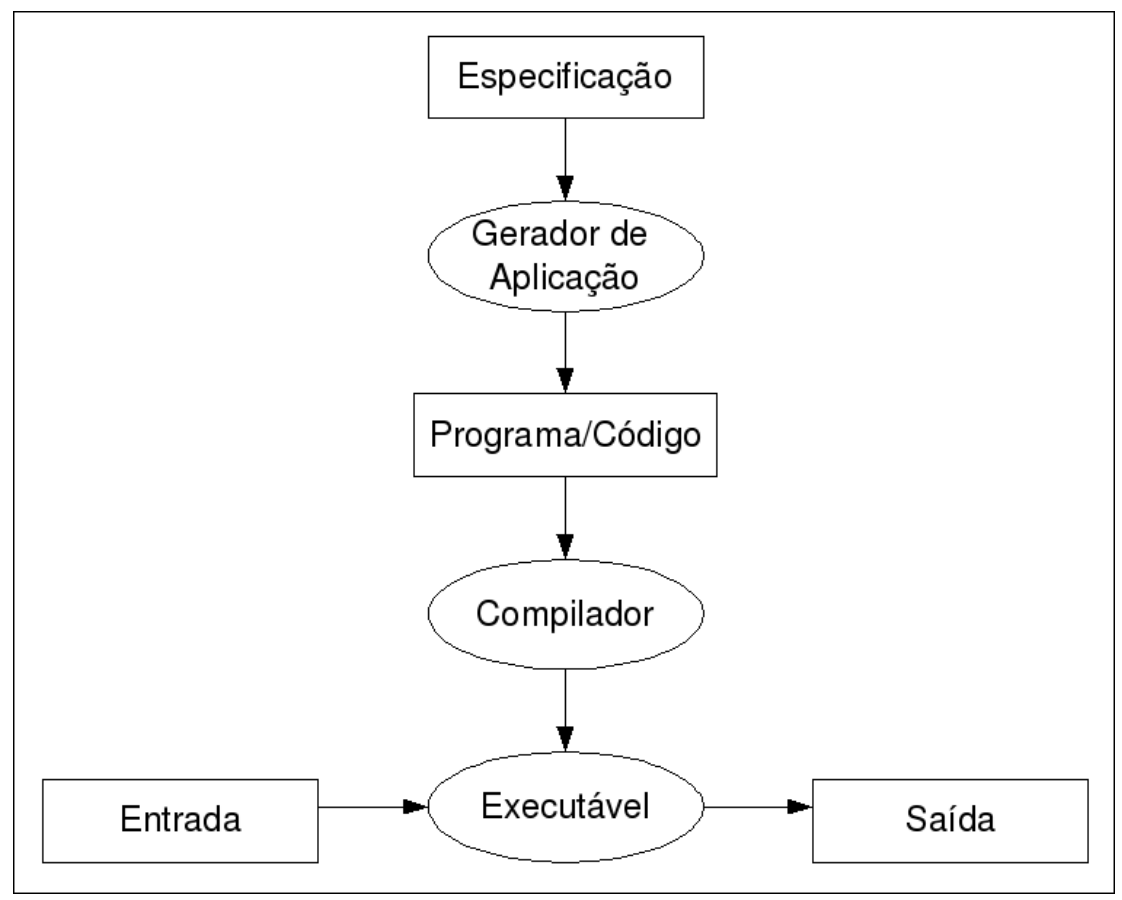

Fonte: Queiroz (2009)

Um dos principais problemas dos geradores é que podem ser usados efetivamente somente em alguns tipos de aplicação (CLEAVELAND, 1988). Para minimizar esse problema, 
foram criados os geradores de aplicação configuráveis (GAC). Os GACs são geradores que podem ser adaptados para trabalharem com diferentes domínios. Um GAC configurado para um certo domínio deve apresentar as mesmas características de um gerador de aplicação específico, ou seja, receber uma especificação, armazená-la em meio persistente, permitir a edição e reedição dessa especificação, validá-la e transformá-la em artefatos de software. A configuração de um GAC pode ser uma atividade menos custosa do que a construção de um gerador de aplicações específico (Shimabukuro Junior, 2006).

Para que os geradores sejam implementados ou configurados, deve-se utilizar uma técnica ou motor de transformação, que conforme advocam Sendall e Kozaczynski (2003), é indiscutivelmente um dos aspectos principais do MDD. Apresenta-se a seguir duas taxonomias propostas para classificar as técnicas de transformação, bem como algumas dessas principais técnicas.

\subsubsection{Classificação das Técnicas de Transformação}

Trabalhos como os de Czarnecki e Helsen (2003), Sendall e Kozaczynski (2003) e Mens e Gorp (2006) definem taxonomias para as principais técnicas de transformações. Essa taxonomia depende dos artefatos de entrada e saída: quando ambos são modelos, a técnica é chamada de transformação de modelo para modelo; quando ambos são programas, ou seja, código fonte, bytecodes ou código de máquina por exemplo, dá-se o nome de transformação de programas (MENS; GORP, 2006); quando o artefato de entrada é/são modelo(s) e o artefato de saída é código fonte, chama-se transformação modelo para código.

Conforme discutido anteriormente, uma vez que representações mais concretas de um programa também podem ser vistas como modelos, a transformação de modelos engloba a transformação de programas e ambos são necessários em ferramentas comuns como geradores de código e parsers. Nesse contexto, segundo Mens e Gorp (2006), “uma transformação é a geração automática de um modelo alvo a partir de um modelo fonte".

A definição de transformação é um conjunto de regras de transformações, que juntas, descrevem como um modelo em uma linguagem fonte pode ser transformado em um modelo na linguagem alvo. Uma regra de transformação é a descrição de como uma ou mais construções na linguagem fonte podem ser transformadas em uma ou mais construções na linguagem alvo. Para (MENS; GORP, 2006), deve-se fazer a generalização de que uma transformação também pode ser aplicada a múltiplos modelos fonte para gerar múltiplos modelos alvo.

Fontes de pesquisa abrangentes a respeito das técnicas de transformação e sua classificação são os trabalhos de Czarnecki e Helsen (2003), Sendall e Kozaczynski (2003) e Mens e Gorp (2006). Entre as técnicas de transformação, pode-se citar os seguintes tipos:

- transformações modelo para código: 
- abordagens baseadas em visitante, como por exemplo framework Jamba (JAMDA, 2003);

- abordagens baseadas em template, como por exemplo JET (M2T, 2007) ou Captor (Shimabukuro Junior, 2006).

- transformações modelo para modelo:

- abordagens de manipulação direta, como por exemplo JMI (DIRCKZE, 2002);

- abordagens relacionais, como por exemplo QVT (OMG, 2011a);

- abordagens baseadas em transformações de grafo, como por exemplo VIATRA (CSERTáN et al., 2002);

- abordagens baseadas em estruturas, como por exemplo OptimalJ (OPTIMALJ, 2002);

- abordagens híbridas, como por exemplo AST+ (OMG, 2011a);

- por fim, destaca-se ainda o framework de transformação definido no CWM (GROUP, 2003) da OMG.

\subsubsection{Model-driven Architecture}

Model-Driven Architecture (MDA) (MILLER; MUKERJI, 2003) é uma abordagem de desenvolvimento orientada a modelos, criada e mantida pelo Object Management Group (OMG) cujos principais objetivos são: portabilidade, por meio da separação entre o conhecimento da aplicação e seu mapeamento para uma tecnologia de implementação; aumento de produtividade, por meio da automação do mapeamento; aumento da qualidade, em decorrência do reúso de padrões comprovados e boas práticas no mapeamento; e aumento da manutenibilidade, pela melhor separação de interesses, melhor consistência e melhor rastreabilidade dos modelos para código (CZARNECKI; HELSEN, 2003). Esses objetivos são alcançados pela especificação do sistema sob três pontos de vista distintos (interesses arquiteturais): um ponto de vista independente de computação, representado por um modelo independente de computação (CIM, do Inglês, Computational Independent Model); um ponto de vista independente de plataforma, representado por um modelo independente de plataforma (PIM, do Inglês, Platform Independent Model); e um ponto de vista específico de plataforma, representado por um modelo específico de plataforma (PSM, do Inglês, Platform Specif Model). Observe que o MDA tem escopo menor que o MDD, pois enquanto o enfoque do MDA é a arquitetura de software, o MDD combina processo e análise com arquitetura (KENT, 2002).

Nesse contexto, uma plataforma é um conjunto de subsistemas e tecnologias que fornecem um conjunto coerente de funcionalidades por meio de interfaces e uso de padrões específicos. Qualquer aplicação que execute em uma plataforma, pode usar esta sem preocupar-se com detalhes de como as funcionalidades oferecidas pela plataforma são implementadas. 
Segundo Miller e Mukerji (2003), o MDA oferece as seguintes vantagens:

- implementação - novas infraestruturas de implementações podem ser integradas em projetos existentes;

- integração - uma vez que não apenas a implementação, mas também o projeto existe em tempo de integração, pode-se automatizar a produção de pontes de integração de dados e conexões para novas infraestruturas;

- manutenção - a disponibilidade de um projeto em uma forma legível por máquina fornece aos desenvolvedores acesso direto à especificação do sistema, tornando a manutenção bem mais simples;

- teste e simulação - já que os modelos desenvolvidos podem gerar código, eles podem ser validados com requisitos, testados em várias infraestruturas e podem ser usados diretamente para simular o comportamento dos sistemas a serem projetados.

A ideia fundamental do MDA é separação da especificação de um sistema, dos detalhes de como o sistema usa as funcionalidades de sua plataforma. Ou seja, é feita uma distinção entre o/os PIM/s e o/os PSM/s. Para se desenvolver um aplicativo usando o MDA, é necessário primeiro criar um PIM do aplicativo, em seguida, transformá-lo, usando um mapeamento padronizado, em um PSM, e, finalmente, mapear o PSM em código do aplicativo (COOK, 2004). Portanto, o MDA apresenta uma abordagem e ferramentas para:

- especificar um sistema, independentemente da plataforma em que será executado;

- especificar plataformas;

- escolher uma plataforma particular para o sistema;

- transformar a especificação independente de plataforma de um sistema em uma especificação particular para uma das plataformas especificadas.

Segundo Chitforoush, Yazdandoost e Ramsin (2007), a abordagem MDA propõe o desenvolvimento do sistema como uma sequência de transformações e aperfeiçoamentos de modelo. Por meio dessas etapas sequenciais, modelos abstratos são gradualmente transformados em modelos concretas, adicionando detalhes técnicos até que um sistema executável seja finalmente produzido.

A abordagem MDA baseia-se nos seguintes padrões e tecnologias da OMG:

- Meta Object Facility (MOF) (omg, 2006): é um padrão para metadados e gerenciamento de modelos; 
- XML Metadata Interchange (XMI) (OMG, 2007): é um padrão para troca de informações de metadados via XML;

- Unified Modeling Language (UML) (OMG, 2011b): é uma linguagem de modelagem padrão. É uma instância do modelo MOF;

- Object Constraint Language (OCL) (OMG, 2012): é uma linguagem formal para descrever expressões na UML ou na MOF para validar os modelos;

- Query/Views/Transformations QVT (OMG, 2011a): linguagem utilizada para consultas, visualizações e transformações nos modelos da MOF.

Um CIM não mostra detalhes da estrutura do sistema. Ele também é conhecido, geralmente, como modelo de domínio e utiliza-se na sua especificação, de um vocabulário familiar aos especialistas do domínio em questão. O CIM tem o importante papel de fazer uma ponte entre os especialistas do domínio e seus requisitos e os especialistas em projeto e construção de artefatos que satisfaçam os requisitos do domínio. O CIM ajuda a representar exatamente o que o sistema deve fazer e deve ser rastreável para o PIM e PSM que os implementa e vice-versa.

Um PIM exibe um grau específico de independência de plataforma de tal maneira que seja adaptável para o uso em diferentes plataformas de tipos similares. Uma técnica comum para alcançar a independência de plataforma é apontar um modelo de sistema para uma maquina virtual, pois ela pode ser vista como uma plataforma neutra. Uma máquina virtual equivale a uma plataforma virtual, pois pode ser implementada em diversas plataformas reais. Observa-se que mesmo que o PIM seja específico dessa plataforma, ele é independente de plataforma no que diz respeito a classe de diferentes plataformas nas quais a máquina virtual pode ser implementada. Tais modelos não são afetados pela plataforma que executa a máquina virtual e assim, são independentes de plataforma. Um PIM será adaptado para um estilo arquitetural em particular ou vários.

Um PSM combina as especificações do PIM com detalhes que especificam como um sistema usa um tipo particular de plataforma. Esses detalhes são descritos em um modelo de plataforma, que oferece um conjunto de conceitos técnicos, que representam diferentes tipos de partes que fazem uma plataforma e os serviços oferecidos por ela. Também fornece, para o uso em um PSM, conceitos que representam os diferentes tipos de elementos a serem usados na especificação e uso de uma aplicação naquela plataforma. Um modelo de plataforma genérico pode chegar a uma especificação de um estilo arquitetural particular.

Conforme apresentado anteriormente, o enfoque do MDA é desenvolver esses modelos e realizar transformações entre eles até que possa-se transformar um ou vários modelos em código fonte. Para isso, a transformação de modelos é fundamental e representa o processo de conversão de um modelo em outro modelo do mesmo sistema. Para fazer essa transformação necessita-se de um mapeamento especial. Um mapeamento MDA fornece especificações para transformação 
de um PIM em um PSM para uma plataforma em particular, conforme apresenta-se na Figura 12. Observa-se que são adicionadas novas informações ao PIM para que seja possível gerar o PSM. O modelo de plataforma determina a natureza do mapeamento. Por fim, transforma-se o PSM ou até mesmo o PIM diretamente para código fonte ou objeto.

Figura 12 - Transformação de PIM para PSM.

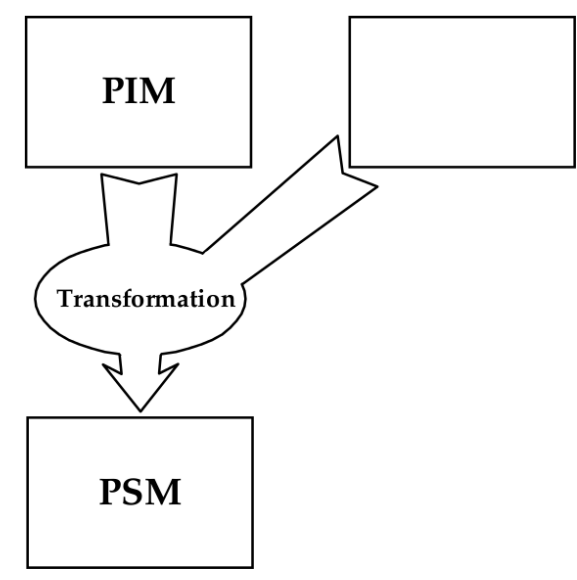

Fonte: Miller e Mukerji (2003)

Cada transformação de modelo tem restrições de tipo implícitas que o arquiteto responsável pelo modelo deve obedecer para que a transformação faça sentido. Essa transformação pode ser implementada utilizando-se diversas técnicas: marcação dos modelos, perfis UML, templates, utilizando uma linguagem de mapeamento (QVT), entre outros. A seguir são apresentados alguns detalhes sobre as principais tecnologias e padrões utilizados pelo MDA.

\section{Meta-Object Facility}

O MOF ${ }^{1}$ é o padrão OMG para metadados e gestão de modelos e está diretamente ligado ao MDA. O MOF especifica: como definir metamodelos (usando um subconjunto da UML); como gerar esquemas XML para intercâmbio de modelos entre ferramentas (XMI); como gerar APIs para manipulação de modelos (por exemplo, projetos UML). Ele também está sendo estendido para especificar serviços para gestão de modelos e seus elementos, tais como identidade, ciclo de vida, controle de versões, visões e transformações (MELLOR; CLARK; FUTAGAMI, 2003).

Pode-se expressar todos os metamodelos usando-se o MOF, com isso permite-se definições padrão para mapear funções entre modelos. Esse mapeamento é feito utilizando-se o padrão QVT sobre as instâncias geradas com o MOF (MELLOR; CLARK; FUTAGAMI, 2003).

O meta-metamodelo MOF é a linguagem usada para definir o metamdodelo UML. O meta-modelo UML, por sua vez, é a linguagem usada para definir modelos UML que é a linguagem utilizada para definir aspectos de um sistema de computador (OMG, 2004a). Na maioria dos casos, o mapeamento entre o meta-metamodelo UML e o meta-metamodelo MOF 
é direto, contudo pode-se apresentar as seguintes diferenças: enquanto o MOF só apresenta associações binárias a UML apresenta associações $\mathrm{N}$-arias; o MOF não representa classes associativas ou associações qualificadas como a UML; o MOF não tem equivalente para templates de UML; entre outros.

O objetivo do MOF é oferecer um framework que apoie qualquer tipo de metadado e que permita que novos tipos sejam adicionados quando necessário. Observa-se que a representação de Classes modela metaobjetos MOF, as associações modelam os relacionamentos binários entre esses metaobjetos, tipos de dados modelam dados e pacotes modularizam os modelos.

Ainda é possível adicionar um elemento chamado de constraint para adicionar regras de consistência para outros componentes do metamodelo. Uma constraint possui um nome, uma linguagem usada para expressar as regras de consistência, uma expressão na linguagem para especificar a regra, uma política de avaliação que determina quando a regra deve ser executada e um conjunto de elementos de restrição. A linguagem utilizada para definir tais Constraints é a OCL, descrita adiante.

\section{XMI}

$\mathrm{O} \mathrm{XMI}^{2}$ utiliza a tecnologia XML para dar apoio à troca de metadados e metamodelos baseados em MOF e outros repositórios de metadados. A especificação do XMI tem duas partes principais: as regras de produção DTD do XML, que definem o mapeamento unidirecional do metamodelo MOF para um DTD (do inglês, Document Type Definition)) XML para intercâmbio de metadados entre documentos; as regras de produção de documento XML, que definem um mapeamento bidirecional entre um documento XML e os metadados baseados em MOF que estão de acordo com o mapeamento abstrato.

Documentos XMI devem ser válidos e bem formados conforme é definido nas recomendações XML. Recomenda-se fazer essa validação com base em um XML schema, que é um documento que oferece meios pelos quais um processador XML pode validar a sintaxe e alguns aspectos semânticos de um documento XML. Como um schema XML não é obrigatório, pode-se observar ganhos em termos de velocidade de processamento com a sua ausência em troca de perda de confiabilidade e qualidade do documento.

Todo schema XMI tem as seguintes declarações: uma instrução de processamento de versão XML, por exemplo <XML version=“1.0" >; uma declaração opcional de codificação que especifica o conjunto de caracteres, por exemplo $<$ XML version="1.0" ENCODING="UCS-2" >; seguido de qualquer instrução de processamento XML válida; um schema XML; a importação de um elemento XML para o namespace XMI; declarações para um modelo específico.

OCL

A OCL $^{3}$ (do inglês, Object Constraint Language) é uma linguagem formal usada para 
descrever expressões em modelos UML. Essas expressões geralmente especificam condições invariáveis que devem valer para o sistema a ser modelado ou consultas sobre os objetos descritos em um modelo. Expressões OCL podem ser usadas para especificar operações/ações que, quando executadas, não alterem o estado do sistema. Pode-se utilizar OCL para especificar restrições nos modelos ou para especificar consultas em um modelo UML. São completamente independentes de linguagem de programação. A OCL corresponde, acima de tudo, a uma linguagem de especificação.

Como o MOF e o metamodelo UML possuem muitos aspectos em comum, o núcleo da OCL foi elaborado para trabalhar com ambos. Observe que um diagrama UML, como por exemplo o diagrama de classes, não é refinado o bastante para carregar todos os aspectos relevantes em uma especificação, ou seja, entre outras coisas, precisa-se descrever restrições adicionais sobre objetos do modelo. Essas restrições poderiam ser escritas em linguagem natural, o que historicamente sabe-se que pode levar a ambiguidades indesejáveis. Para eliminar as ambiguidades foram desenvolvidas linguagens formais. Contudo, linguagens formais tradicionais eram usadas somente por pessoas com uma forte base matemática, causando dificuldade para modeladores de sistemas. OCL surgiu com a necessidade de cobrir essa lacuna e ser uma linguagem formal que seja fácil de ler e escrever.

Uma expressão OCL não causa efeitos colaterais, pois quando é avaliada retorna simplesmente um valor e não altera nada no modelo. OCL não é uma linguagem de programação. Cada classificador definido em um modelo UML representa um tipo distinto em OCL, além de incluir um conjunto predefinido de tipos suplementares.

A OCL pode ser utilizada para atender a diversos objetivos, tais como: linguagem de consulta, especificação de invariantes em classes e tipos em modelos de classe, especificação de tipos invariantes para estereótipos, descrição de pré e pós condições em métodos e operadores, descrição de guardas, especificação de alvos para mensagens e ações, especificação de restrições em operações e derivação de regras para atributos em qualquer expressão sobre modelos UML.

\section{QVT}

QVT $^{4}$ (do inglês, Query/Views/Transformations) é uma linguagem capaz de expressar consultas, visões e transformações sobre modelos MOF. A sintaxe abstrata de QVT é definida como um metamodelo MOF. Esse metamodelo define três sub linguagens para transformação de modelos com construtores imperativos e declarativos: relations, core e operational mappings. Adicionalmente, propõe-se o uso de OCL para consulta em modelos (JOUAULT; KURTEV, 2006). Portanto, a especificação do QVT depende diretamente das especificações MOF e OCL.

O uso conjunto de metamodelo e linguagem relacional apoiam correspondências de padrões de objetos complexas e criação de templates de objetos. O metamodelo e a linguagem definidas no pacote core do QVT usam extensões mínimas para MOF e OCL.

4 http://www.omg.org/spec/QVT 


\subsubsection{Projeto Eclipse}

Fundamentado no projeto de modelagem do eclipse (EMP, do Inglês, Eclipse Modeling Project), tem enfoque na evolução e promoção das tecnologias de MDE na plataforma eclipse por meio da adoção de um conjunto unificado de framework de modelagem, ferramentas, padrões e de implementações (GRONBACK, 2009).

O projeto de modelagem do eclipse é baseado no EMF (do Inglês, eclipse modeling framwork) que permite a manipulação de modelos de acordo com seu metamodelo correspondente. O EMF utiliza XMI para armazenar as definições de modelos. Com o EMF pode-se criar metamodelos de diferentes formas, por exemplo XMI, Java annotations, UML ou XML Schema.

Após a especificação do metamodelo EMF pode-se gerar o código correspondente em JAVA. EMF baseia-se em dois metamodelos: o Ecore e o Genmodel. O meta-metamodelo Ecore possui informações sobre as classes definidas e é equivalente ao MOF da abordagem MDA, já o Genmodel contém informações adicionais para a geração de código.

O projeto EMF corresponde a um framework de modelagem e um gerador de código para desenvolvimento de ferramentas e outras aplicações baseadas em modelos de dados estruturados. A partir de uma especificação de um modelo descrito em XMI, o EMF oferece ferramentas e apoio em tempo de execução para produzir um conjunto de classes java para o modelo, além de um conjunto de classes adaptadoras que permitem a visualização e edição baseada em comando do modelo e um editor básico (GRONBACK, 2009).

Construções EMF incluem Definição de esquema XML (XSD), como um componente do projeto de ferramentas de desenvolvimento de modelos (MDT). Existem ainda outros subprojetos do eclipse, como Model Query, Model Transaction, e Validation Framework.

Além de gerar código a partir dos modelos, o EMF gera interfaces e fábricas para a criação de objetos. Pode-se, ainda, gerar código Java a partir do modelo a qualquer momento. EMF utiliza o JET (do Inglês, Java Emitter Templates) e o JMerge (Java Merge) como ferramentas para geração de código. O JET gera código com base em templates. Possui o conceito de metaprogramação, ou seja, criação de programas para fazer programas, uma vez que utiliza-se código Java dentro dos templates.

Outro projeto importante no âmbito do eclipse é o GMT (Generative Modeling Technologies), cujo objetivo é produzir um conjunto de protótipos na área de MDE. O GMT é a incubadora oficial de projetos de pesquisa do EMP.

Existe ainda, sob o framework EMP do eclipse, o projeto ATL (ATL Transformation Language) que corresponde a uma linguagem e um conjunto de ferramentas de transformação. Oferece formas de produzir um conjunto de modelos alvo a partir de um conjunto de modelos fonte. Trata-se de uma linguagem equivalente ao QTV da OMG, contudo ela foi desenvolvida para trabalhar com o Ecore (JOUAULT; KURTEV, 2006). 


\subsection{Engenharia de Linha de Produtos}

Uma Linha de Produtos, também conhecida como família de produtos, corresponde a um conjunto de sistemas de software que compartilham características comuns e gerenciadas e que satisfazem a uma necessidade específica de um segmento particular de mercado, sendo desenvolvidas a partir de um conjunto comum de ativos centrais, de forma sistemática (CLEMENTS; NORTHROP, 2002). Uma linha de produtos é representada por produtos que, embora possuam requisitos em comum, ao mesmo tempo exibem variabilidade significativa nesses requisitos (GRISS, 2000).

Os ativos centrais incluem, mas não estão limitados a, arquitetura e sua documentação, especificações, componentes de software, ferramentas como com ponentes ou geradores de aplicações, modelos de desempenho, cronogramas, orçamentos, planos de teste, casos de teste, planos de trabalho e descrições de processos (CLEMENTS; NORTHROP, 2002).

Essa técnica de desenvolvimento de software tem como objetivo o desenvolvimento em larga escala. No desenvolvimento de uma linha de produtos, são reconhecidas as semelhanças e variabilidades de um conjunto de software em um certo domínio e é então executada uma engenharia de domínio em que são produzidos um conjunto de artefatos que podem ser reutilizados e combinados de várias formas para produzir sistemas alvo ou membros da linha, por meio de um processo chamado de engenharia de aplicações. Essa técnica permite que grande parte dos requisitos e da arquitetura seja reusada, uma vez que pode-se tirar vantagem de suas características comuns e variabilidades previstas e evitar o esforço redundante no desenvolvimento de cada software independente. Como exemplos de partes variáveis (variabilidades) em LPS pode-se citar: o sistema operacional ao qual elas se destinam; funcionalidades presentes ou não nos produtos da linha; e, funcionalidades presentes em produtos da linha mas com diferença na sua implementação ou no seu uso.

No desenvolvimento de uma LP é projetada uma arquitetura do sistema de modo à atender as necessidades de todo o conjunto de produtos e fornecer um contexto no qual outros recursos, tais como código e testes, possam ser desenvolvidos com flexibilidade o suficiente para satisfazer os diversos produtos derivados da linha e, ainda assim, permitir que novos produtos possam ser adicionados à linha.

As técnicas de linha de produtos são usadas amplamente na indústria automotiva, aeronáutica e eletrônica. Tem-se por exemplo a linha de produtos que representa a família de aviões da Airbus, representada pelos modelos A-318, A-319, A-320 e A-321. São aeronaves com 100 a 220 lugares, movidas por linhas de produtos de motores com linhas de produtos de equipamentos de controle e navegação (CLEMENTS; NORTHROP, 2002).

No âmbito de linha de produtos de software, Clements e Northrop (2002) citam diversas empresas que adotam essa abordagem com grande sucesso. Em decorrência do aumento do 
interesse em LP, muitos trabalhos recentes, principalmente com software para dispositivos móveis e para sistemas embarcados, estão explorando as possibilidades da utilização dessa abordagem. Alguns fabricantes de celulares mantém, entre outras, uma LP para o menu de seus celulares. Existe um núcleo que está presente no modelo mais simples e que vai ganhando variabilidades em outros modelos mais complexos.

Ao contrário dos métodos convencionais de desenvolvimento de software que desenvolvem seus produtos de forma manual como uma arte, a engenharia de software de linha de produtos preocupa-se com a industrialização do processo de desenvolvimento. Essa industrialização inclui: o aprendizado da configuração e montagem de componentes para a produção de produtos similares; integração e automação do processo de produção; desenvolvimento de ferramentas que configuram e automatizam tarefas repetitivas; melhoramento das relações entre clientes e fornecedores para a redução de riscos; automação da produção de variantes dos produtos; distribuição da produção entre os diferentes fornecedores; e padronização de processos (GREENFIELD; SHORT, 2003; WEISS; LAI, 2004).

Vários artefatos são implementados para satisfazer as possíveis funcionalidades de um produto da linha. Um determinado produto é composto utilizando-se artefatos dos diversos tipos de funcionalidades. As diferentes escolhas de artefatos podem fazer com que dois produtos tenham funcionalidades diferentes ou as mesmas funcionalidades com características diferentes. Custo e tempo de desenvolvimento são reduzidos, já que o esforço de desenvolvimento para qualquer produto sozinho é largamente distribuído para vários recursos reutilizáveis, cujo custo é distribuído a todos os membros da linha de produtos. Com essas técnicas, uma organização pode alcançar níveis mais elevados de produtividade e construir sistemas sob demanda de forma mais eficaz (Shimabukuro Junior, 2006).

O benefício chave do uso de LPS resulta do compartilhamento da implementação de artefatos em múltiplos produtos, levando a um menor custo de desenvolvimento e manutenção. Contudo, alcançar esses benefícios na prática não é trivial. Uma grande dificuldade é a escolha da abordagem correta para o desenvolvimento da LPS. Uma escolha errada pode levar a vários problemas (BOSCH, 2004). Os principais problemas e um framework de decisão para resolver esses problemas podem ser encontrados em Bosch (2004). Nas subseções seguintes são apresentadas algumas das técnicas mais conhecidas e bem sucedidas.

Existem várias abordagens para o desenvolvimento de linha de produtos, cada qual com enfoque em uma parte específica do desenvolvimento, por exemplo:

- A abordagem Family-oriented Abstraction, Specification and Translation (FAST) (ARDIS; WEISS, 1997)) foi desenvolvida pela Lucent Technologies na década de 90 e ainda continua em uso (WEISS; LAI, 2004). Essa estratégia enfoca o investimento na produção de facilidades para a família de produtos.

- A Product Line Software Engineering (PuLSE) (BAYER et al., 1999) é uma metodologia 
cujas fases são fortemente centradas no produto. Ela é articulada em torno de três elementos principais: as fases de desenvolvimento, os componentes técnicos e os componentes de suporte (BAYER et al., 1999). Os componentes são customizáveis para atender melhor a diferentes situações e contextos (BAYER; FLEGE; GACEK, 2000).

- A abordagem Product Line Practice (PLP) é uma estratégia para desenvolvimento de linha de produtos desenvolvida pelo SEI ( Software Engineering Institute). Ela é exposta em um documento Web para o apoio à comunidade de software. Cada versão representa uma tentativa incremental de compilar as últimas informações sobre práticas bem sucedidas em LPS (NORTHROP et al., 2009).

- A abordagem Product Line UML-Based Software Engineering (PLUS) (GOMAA, 2004) estende os métodos de modelagem de sistemas únicos baseados em UML (OMG, 2011b) para tratar linha de produto de software (GOMAA, 2004). Ela é baseada no processo de desenvolvimento de sistemas conhecido como Unified Software Development Process (USDP) (JACOBSON; BOOCH; RUMBAUGH, 1999).

- Abordagem Synthesis: foi a predecessora da abordagem FAST (ARDIS; WEISS, 1997). Foi elaborada pelo Software Productivity Consortium e descreve uma metodologia para construção de sistemas de software representando instâncias de uma família de sistemas que possuem descrições similares (GIMENES; TRAVASSOS, 2002).

- Abordagem kobrA: é uma abordagem de desenvolvimento de LPS que usa UML e componentes na implementação da linha (ATKINSON et al., 2002).

Embora cada abordagem tenha um enfoque diferenciado, o que há de comum entre elas é o problema de gerenciamento de variabilidades, conforme apresenta-se a seguir.

\subsubsection{Variabilidades em Linhas de Produtos}

Variabilidade é a habilidade de mudar ou customizar um sistema. Gerenciar a variabilidade em um sistema implica em facilitar a realização de certos tipos de mudança. Em LPS, a arquitetura de um sistema real é fixada cedo, contudo os detalhes de implementação de um produto são atrasadas até a implementação. Refere-se a essas decisões atrasadas como pontos de variação (GURP; BOSCH; SVAHNBERG, 2001).

Segundo Gurp, Bosch e Svahnberg (2001), as variabilidades podem ser pensadas como uma mudança no conjunto de características correspondentes. O conceito de features (característica) surgiu na engenharia de domínio. Uma feature é uma característica de um produto que usuários e clientes vêem como importante na descrição e distinção entre membros de uma linha de produtos (GRISS, 2000). 
Segundo Gomaa (2004), as variabilidades podem ser modeladas com o uso de parametrização, herança ou information hiding. A técnica a ser utilizada depende do nível de flexibilidade desejado para a linha de produtos. Em geral, na implementação de uma LPS, mais de uma dessas técnicas é utilizada.

\subsubsection{Modelo de features para LPS}

Para apoiar o desenvolvimento de LPS, deve-se elaborar o modelo de características (do inglês feature model) (KANG et al., 1990), que é uma representação hierárquica para capturar os relacionamentos estruturais entre as características de um domínio de aplicação. Existem três tipos de relacionamentos distintos entre as características: composição, generalização e implementado-por. Além disso, em uma composição, as características podem ser opcionais, obrigatórias ou alternativas (KANG et al., 1998). Autores como Kang, Lee e Donohoe (Aug. 2002), Gomaa (2004) e (THÜM et al., 2014), apresentam algumas extensões da definição inicial proposta por Kang et al. (1990), algumas das quais são apresentadas a seguir.

Em resumo, o modelo de features é uma hierarquia gráfica de características do tipo $A N D / O R$ que captura os relacionamentos estruturais ou conceituais entre as características (CZARNECKI; EISENECKER, 2000). Existem ainda, features abstratas, que são aquelas sem mapeamento para artefatos de implementação e as concretas em caso contrário (THÜM et al., 2011).

As características relacionadas podem ser agrupadas e classificadas de acordo com Gomaa (2004) como:

- At least one offeature group: no mínimo uma característica do grupo deve ser selecionada..

- Exactly one of feature group: uma e somente uma característica pode ser selecionada de um grupo.

- Zero or more of feature group: nenhuma ou mais características podem ser selecionadas de um grupo.

- zero or one of feature group: nenhuma ou uma característica pode ser selecionada de um grupo.

Na Figura 13, apresenta-se um exemplo de diagrama de características para uma LPS de hotel. Destaca-se que essa LPS possui as seguintes características e grupos de características: Uma característica comum, núcleo do hotel; Um grupo de características do tipo Zero or more of feature group, Opções hotel, que depende do núcleo do hotel; Um grupo de características do tipo Exactly one of feature group, alternativas do hotel, que consiste de dois grupos de características alternativas; dois grupos alternativos do tipo Zero or more of feature group, hotel Convencional e hotel Residencial, que são disponíveis para seleção. 
Figura 13 - Exemplo de modelo de características.

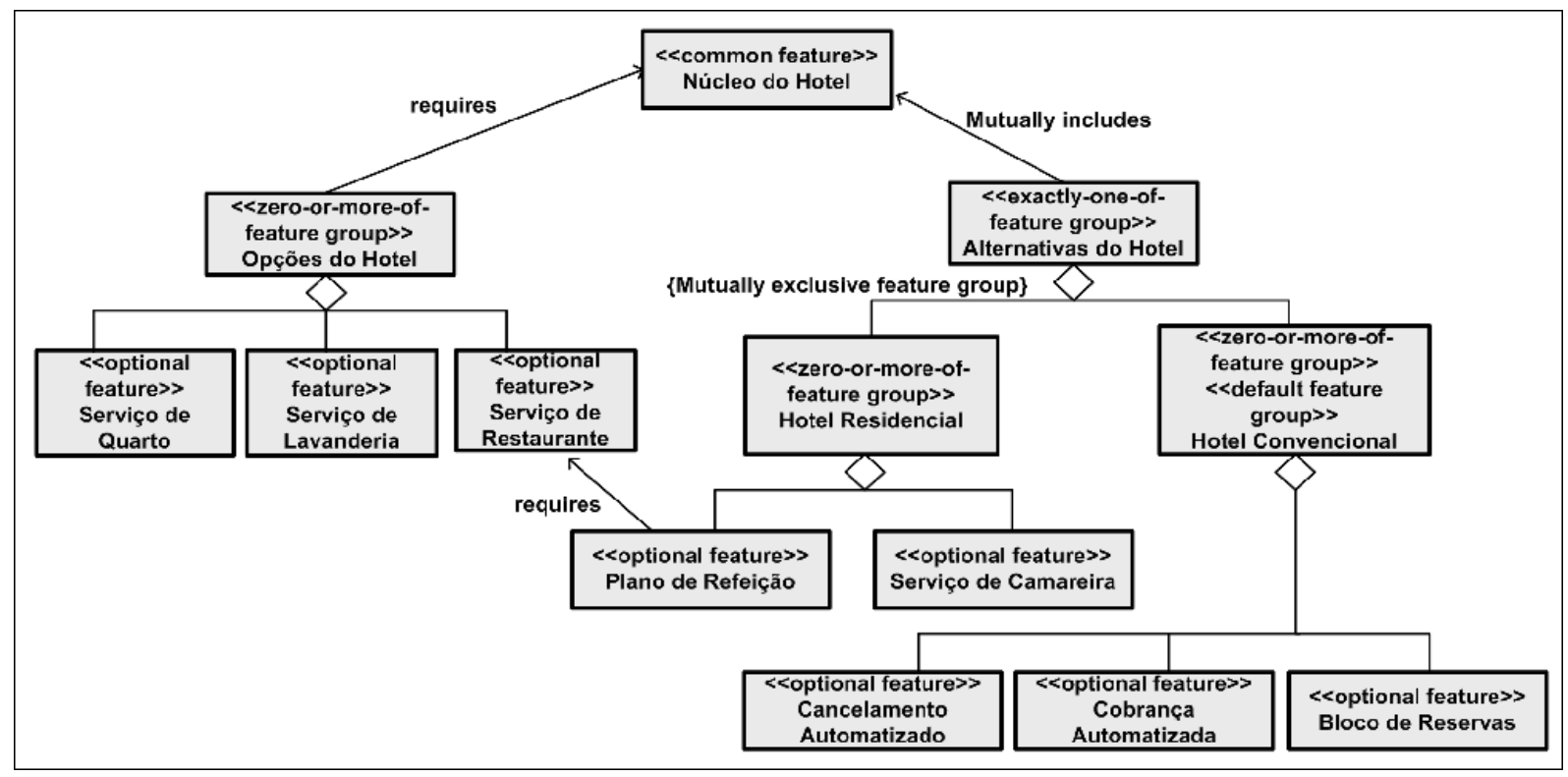

Fonte: Gomaa (2004)

\subsubsection{CVL}

A CVL (do inglês Common Variability Language) é uma linguagem genérica para definir variabilidades. A semântica da CVL é definida como uma transformação de um modelo original (por exemplo, um modelo de linha de produtos) em um configurado, modelo de produto. A CVL combina diagramas de features centrados no usuário, com uma abordagem de automação centrada para a produção de modelos de produtos. Em CVL, o enfoque é a especificação de variabilidade em um modelo separado dos modelos base da linha de produtos. A CVL é executável, ou seja, depois de especificar a configuração de variabilidades, uma ferramenta CVL pode derivar automaticamente o modelo de um produto específico.

Em Haugen, Wasowski e Czarnecki (2012) são apresentados todos os conceitos da CVL, entre quais destacam-se os seguintes:

- Modelo de Base: é um modelo em que a variabilidade é definida utilizando-se a CVL. O modelo base não faz parte da CVL e pode ser uma instância de qualquer metamodelo definido via MOF. Nesta a atividade, o modelo base é o diagrama de requisitos SysML.

- Especificação de variabilidade (Vspec): VSpecs são especificações de variabilidade abstratas e são parte de modelos de variabilidade. Eles podem ser organizados em estruturas de árvores que representam restrições lógicas em suas resoluções. VSpecs podem ter pontos de variação vinculados a eles. Para materializar um modelo base com um modelo de variabilidade sobre ele, devem ser fornecidas resoluções para as VSpecs. Em resumo, é muito semelhante em forma e função ao modelo de features. 
- ponto variação: Os pontos de variação são a especificação de variabilidades concretas no modelo base e fazem parte de modelos de variabilidade. Eles definem modificações específicas a serem aplicadas ao modelo base durante a materialização. Os pontos de variação se referem a elementos do modelo base pode meio de manipuladores do modelo base e são ligados a VSpecs. A vinculação de um ponto de variação a um Vspec significa que a aplicação do ponto de variação para o modelo base durante a materialização depende da resolução para o Vspec. A natureza da dependência é especificada de acordo com o tipo de ponto de variação.

- Substituição (ponto de variação): é um tipo de ponto de variação cuja aplicação envolve a substituição de um elemento por outro no modelo base. Pontos de variação do tipo substituição, incluem substituição de objetos, ligações, suas versões paramétricas, e substituição de fragmento.

- Existência (ponto de variação): é um tipo de ponto de variação cuja aplicação (negativa) envolve a exclusão de elementos do modelo base. Eles são utilizados para expressar os elementos opcionais no modelo de base. Pontos de variação do tipo existência, incluem existência objeto, de ligações, e de valores.

- Atribuição de valor (ponto de variação): é um tipo de ponto de variação cuja aplicação envolve a inserção de um valor em um slot do modelo base. Pontos de variação do tipo atribuição de valor, incluem atribuição de valores em slot e atribuição paramétrica de valor em slot.

- Ponto variação Opaco: é aquele cujo impacto sobre o modelo base é definido pelo usuário e não pré-definido na CVL. O impacto é especificado usando uma linguagem de transformação do modelo como o QVT.

- escolha (ponto de variação): é um tipo de ponto de variação que pode ser ligado a uma escolha. Durante a materialização da decisão de resolução a escolha determina se o ponto de variação vai ser aplicado.

- Ponto variação paramétrico: é um ponto de variação que depende de um parâmetro e não deve ser ligado a uma variável. Durante a materialização, o valor fornecido pela resolução para a variável é utilizado para o parâmetro.

- Ponto variação Repetitivo: é um ponto de variação que pode ser aplicado várias vezes durante a materialização. Ele pode ser ligado a um VClassifier e ser aplicado uma vez para cada instância do mesmo. Substituição de fragmento é um ponto de variação repetitivo.

- escolha: é uma Vspec cuja resolução exige uma decisão do tipo sim/não (verdadeiro/Falso). Quando um ponto de variação está ligada a uma escolha, a decisão que resolve essa escolha determina se o ponto de variação será aplicado durante a materialização. 
- variável: é um Vspec cuja resolução requer o fornecimento de um valor de seu tipo especificado. Quando um ponto de variação do tipo paramétrico está ligado a uma variável, o valor fornecido para a variável como resolução é utilizado como o parâmetro ao se aplicar o ponto de variação durante a materialização.

- Restrições: é uma fórmula lógica ou expressão sobre VSpecs usados para restringir as resoluções permitidas. As restrições podem ser definidas globalmente ou no contexto de um VSPEC.

- Especificação de Resolução de variabilidade (resolução Vspec): A resolução Vspec resolve uma Vspec como parte de um modelo de resolução. Cada tipo de Vspec tem o seu próprio tipo de resolução. Escolhas são resolvidos por meio de decisões negativas ou positivas. As variáveis são resolvidos, proporcionando um valor. Classificadores são resolvidos por instanciação. Quando os VSpecs de um modelo de variabilidade são organizados em estruturas de árvore as resoluções Vspec para eles também são organizados em estruturas de árvore espelhando os VSpecs.

- Modelo de variabilidade: é uma coleção de pontos de variação, VSpecs, e restrições usadas para especificar variabilidade ao longo de um modelo de base.

- modelo de resolução: Um modelo de resolução é um conjunto de resoluções Vspec para resolver o VSpecs de um modelo de variabilidade.

- Manipulador de modelo base: é o mecanismo CVL usado para se referir ao modelo base a partir de pontos de variação. há dois tipos de manipuladores modelo: manipuladores de objetos que referenciam objetos no modelo de base e manipuladores de ligação que referenciam ligações.

- materialização: é o processo de transformação de um modelo de linha de produtos em um modelo de produto por meio da aplicação de pontos de variação. A materialização é guiada por um modelo de resolução que prevê resoluções para as Vspecs definidos no modelo base.

Embora possa haver vários modelos de variabilidades aplicados no mesmo modelo base da linha de produtos, esse modelo base não tem conhecimento dos modelos de variabilidades (há apenas ligações a partir do modelo CVL para o modelo base). Além disso, o conceito básico da CVL é a substituição. Os modelos consistem em elementos do modelo em termos de objetos que estão relacionados por meio de referências. A estrura básica para utilização da CVL é apresentada na Figura 14. Observa-se que o modelo de variabilidades e os modelos de resolução são definidos em CVL, enquanto o modelo base e os modelos resolvidos podem ser definidos em qualquer linguagem baseada no MOF. Visto que a CVL substitui valores ou conjuntos de elementos do modelo, a sua execução pode remover ou substituir uma funcionalidade. 
Figura 14 - Estrutura para utilização da CVL(HAUGEN; WaSOWSKI; CZARNECKI, 2012).

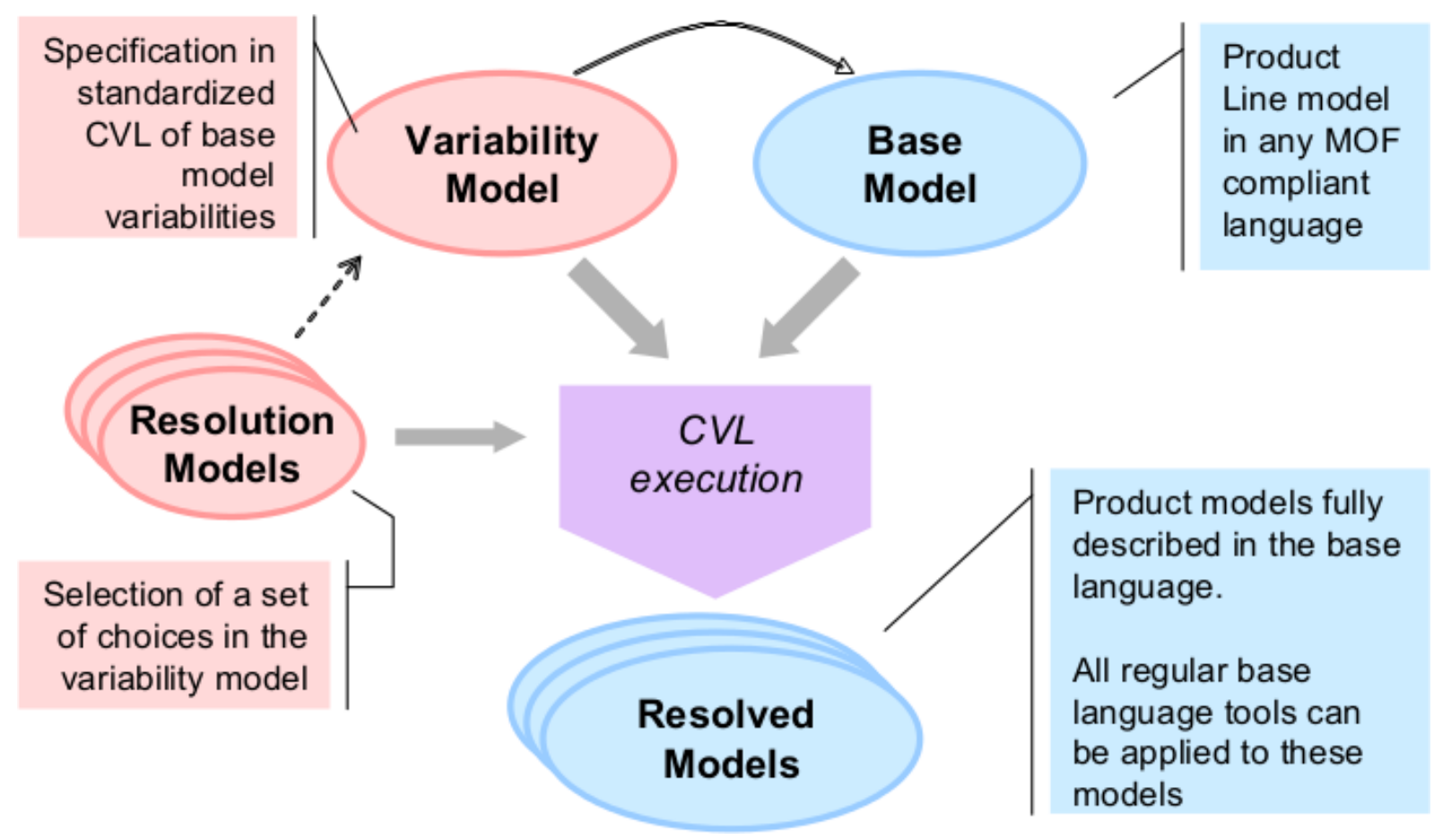

Fonte: Haugen, Wasowski e Czarnecki (2012)

\subsection{Considerações Finais}

Neste capítulo, foram apresentados os fundamentos teóricos das técnicas utilizadas nesta tese: engenharia de sistemas embarcados críticos, engenharia orientada a modelos e engenharia de linha de produtos. Além disso, foram apresentados os principais desafios no desenvolvimento de SCES, bem como as principais abordagens utilizadas nesse domínio. Também foram apresentados as principais técnicas utilizados no MDE e as abordagens clássicas de desenvolvimento de linha de produtos.

Entre esses diversos conceitos apresentados neste capítulo, pode-se destacar as abordagens de co-design e co-simulação, o perfil MARTE, as linguagens SysML e CVL, além do ciclo de vida de linhas de produtos e gerenciamento de variabilidades. Todos esses conceitos fazem parte da abordagem proposta nesta tese, conforme apresenta-se nos capítulos seguintes. 

Parte II

Resultados 



\section{Linha de Produtos Orientada a Mode- los no Domínio de Sistemas Embarca- dos Críticos}

\subsection{Considerações Iniciais}

Neste capítulo, são apresentadas as técnicas e abordagens que combinam os conceitos apresentados no capítulo anterior. Dessa forma, são apresentados os trabalhos que aplicam linha de produtos e desenvolvimento orientado a modelos no domínio de SCES. Além disso, apresentase uma análise das técnicas e conceitos necessários para combinar de forma efetiva e eficaz os conceitos de PLE e MDE. Por fim, são apresentadas as abordagens encontradas na literatura, por meio de uma revisão sistemática, que combinam essas técnicas para o desenvolvimento de SCES.

Os resultados apresentados neste capítulo foram reportados em dois trabalhos apresentados em conferências, como resultado parcial desta tese, na linha de pesquisa de desenvolvimento de SCES:

- Artigo aceito para publicação no SBCARS 2014 (QUEIROZ; BRAGA, 2014c)- Simpósio Brasileiro de Componentes, Arquiteturas e Reutilização de Software : Development of Critical Embedded Systems Using Model-driven and Product Lines Techniques: A Systematic Review.

- Artigo aceito para publicação no Internal Workshop INCT-SEC 2011 (QUEIROZ; BRAGA, 2011) - Desenvolvimento de Sistemas Embarcados Críticos: Técnicas e Perspectivas.

Este Capítulo está organizado conforme apresenta-se a seguir. Na Seção 2.2, são apresentadas formas de combinar a engenharia de linha de produtos com a engenharia orientada a modelos. Na Seção 2.3, apresenta-se uma revisão sistemática cujo objetivo principal foi encontrar abordagens que combinam a engenharia de linha de produtos com a engenharia orientada a modelos para o desenvolvimento de famílias de sistemas críticos. Na Seção 2.4, são apresentados os resultados de um survey com desenvolvedores de sistemas críticos. Por fim, na Seção 2.5, apresenta-se uma sumarização dos tópicos apresentados neste capítulo. 


\subsection{PL e MDE}

Conforme apresentado no capítulo anterior, denomina-se de linguagen específica de domínio, aquelas linguagens de modelagem que são especialmente projetadas para facilitar a modelagem de um domínio em particular. Entretanto, segundo Cook (2004) projetar e usar uma DSL é apenas uma pequena parte de como os modelos podem apoiar o desenvolvimento de um sistema. Esse processo envolve o desenvolvimento, análise e validação de modelos nos diferentes domínios, assim como ferramentas e processos para transformar um tipo de modelo em outro, finalizando com a implantação do sistema.

Dessa forma, o primeiro ponto em comum entre linha de produtos e desenvolvimento orientado a modelos, envolve o projeto de DSLs. Em linha de produtos, durante a etapa de engenharia de domínio, mesmo que informalmente em algumas abordagens, são definidas DSLs que são usadas para modelar a LP. Entretanto, assim como o MDE não se limita a isso, suas contribuições para o domínio de LP também não.

Segundo Bragança (2008), a aplicação de uma abordagem MDE requer, pelo menos, dois níveis de engenharia: o primeiro nível é relativo à metamodelagem e o segundo é relativo à modelagem. O nível de metamodelagem implica na engenharia de domínio, porque o resultado é uma plataforma específica de domínio que será usada para a modelagem de aplicações específicas. Quando o autor se refere à plataforma específica de domínio, ele inclui frameworks orientados a objetos, linguagens de templates e ambientes de modelagem, que são baseados no processo de engenharia de domínio e usados para apoiar a modelagem de aplicações. Entretanto, observa-se que para esta tese, a abordagem de Bragança (2008), assim como as abordagens de Tolvanen e Kelly (2005), Botterweck, O’Brien e Thiel (2007), Voelter e Groher (2007), Weiss et al. (2008) e diversas outras apresentadas na Seção 2.3, combinam PLE e MDE, mas o fazem de forma parcial, pois dão pouco ou nenhum enfoque ao desenvolvimento de domínio com o uso de técnicas MDE, em vez disso, tem foco na engenharia de aplicações, ou seja, na derivação automática de produtos.

Para uma combinação completa entre as técnicas de PLE e MDE, necessita-se ter também uma engenharia de domínios orientada a modelos. Segundo Lucrédio (2009), os trabalhos de Frakes, Díaz e Fox (1998), Bayer, Muthig e Widen (1999), Kim, Yang e Park (2003), Moon, Yeom e Chae (2005) possuem diversas técnicas para análise de domínio. Entretanto, observa-se que a principal diferença em relação à abordagem proposta nesta tese é que nenhum desses trabalhos se preocupa com o uso de transformações de modelo durante a engenharia de domínio. O único trabalho que tem essa preocupação é o de Lucrédio (2009), que difere do trabalho apresentado nesta tese em dois pontos: não tem enfoque em sistemas críticos, portanto não apresenta atividades específicas para garantia de segurança; e não apresenta atividades voltadas para a modelagem de sistemas (software e hardware).

A sinergia entre PLE e MDE tem sido explorada desde o início dos anos 2000, como por 
exemplo nos trabalhos de:

- Deelstra et al. (2003): os autores apresentam como utilizar o MDE para representar variabilidade e derivação automática de produtos. Para isso, os autores fazem uso de modelos de domínio;

- Czarnecki et al. (2005): os autores utilizam modelo de features e templates para representar variabilidades e derivar produtos. Entretanto, não apresentam detalhes sobre como chegar nos templates a partir dos modelos de features.

- Knodel et al. (2005): os autores definem a abordagem Pulse-MDD, segundo a qual o desenvolvimento de transformações e ferramentas de modelagem é altamente ligado à arquitetura da linha de produto, e não em conceitos gerais das tecnologias de implementação;

- (VOELTER; GROHER, 2007): os autores descrevem técnicas baseadas em features e DSL para combinar PLE e MDE. Além disso, fazem uso de orientação a aspectos para modelar e implementar as variabilidades ortogonais.

- (ALFÉREZ et al., 2008): os autores apresentam uma ideia com base no uso de features complementadas por modelos, tais como os de casos de uso e atividades, para representar as variabilidades.

- Lucrédio (2009): apresenta uma abordagem orientada a modelos para reutilização de software, com foco na engenharia de domínio.

Uma vez que o MDE é baseado em metamodelagem e em transformação de modelos, e a metamodelagem tem paralelo com a engenharia de domínio, para se definir uma abordagem completamente orientada a modelos para linha de produtos, necessita-se definir as transformações de modelo nas duas fases de desenvolvimento da linha, ou seja, tanto na engenharia de domínio quanto na engenharia de aplicações. Nesta tese, são propostas transformações de modelos nos dois níveis: durante a engenharia de domínio, para facilitar a criação da infraestrutura de reúso e gerência de variabilidades; durante a engenharia de aplicações para geração de membros da linha de produtos.

\subsection{Revisão sistemática}

Conforme discutido na Seção anterior, existem várias abordagens de desenvolvimento que combinam as técnicas de PLE e MDE, contudo, dada a complexidade de requisitos e restrições dos SCES discutidas nos Capítulos anteriores, o desenvolvimento nesse tipo de domínio requer abordagens específicas. 
Para conhecer o estado da arte da aplicação de linha de produtos e desenvolvimento orientado a modelos no domínio de sistemas embarcados críticos, elaborou-se e executou-se uma revisão sistemática (RS) (KITCHENHAM, 2004). Nessa revisão, o objetivo foi a identificação da aplicação das técnicas de linha de produtos em conjunto com MDE no desenvolvimento de sistemas embarcados críticos e de tempo real. Como resultado, obteve-se um panorama da área e observou-se as tendências para esse tipo de desenvolvimento, assim como foram identificadas lacunas de pesquisa (QUEIROZ; BRAGA, 2014c).

O tema de interesse inicial da RS foi o uso de LP e MDE no desenvolvimento de sistemas embarcados críticos e de tempo real. Contudo, com essa limitação no escopo, muitos trabalhos relevantes na área de sistemas embarcados que podem ser adaptados aos Sistemas Críticos de Tempo Real não seriam encontrados. Dessa forma, os objetivos da revisão sistemática foram definidos como:

- Objetivo 1: Identificar métodos, processos e abordagens de desenvolvimento de linhas de produtos para sistemas embarcados ou sistemas embarcados críticos, ou sistemas de tempo real, com técnicas de desenvolvimento orientado a modelos.

- Objetivo 2: Identificar estudos experimentais que têm sido realizados como forma de validar esses métodos, processos ou abordagens.

Com o intuito de atender aos objetivos propostos, a questão de pesquisa da RS foi definida como: "Qual é o estado da arte da combinação de PLE e MDE para construir sistemas embarcados? Essa questão pode ser dividida em outras sete questões mais específicas:

- Questão Primária (QP): Quais processos, métodos e abordagens têm sido propostos para o desenvolvimento de LP de sistemas embarcados, ou sistemas embarcados críticos, ou sistemas de tempo real com a utilização de MDD?

- Questão Secundária (QS1): Dentre os processos, métodos e abordagens propostas, quais são específicos para: sistemas embarcados, sistemas embarcados críticos, sistemas embarcados de tempo real ou sistemas embarcados críticos de tempo real?

- Questão Secundária (QS2): Quais tipos de estudos experimentais são realizados nos trabalhos encontrados, para validar esses processos, métodos ou abordagens?

- Questão Secundária (QS3): Quais fases ou etapas do ciclo de desenvolvimento de linha de produtos são cobertas pela solução?

- Questão Secundária (QS4): Quais modelos foram utilizados ao longo do desenvolvimento?

- Questão Secundária (QS5): Quais modelos foram utilizados para gerenciar as variabilidades? 
- Questão Secundária (QS6): As abordagens fazem distinção entre as variabilidades de software e hardware?

- Questão Secundária (QS7): Quais ferramentas tem sido usadas neste tipo de desenvolvimento?

A definição completa do protocolo da revisão sistemática, o processo utilizado e a lista de todos os artigos encontrados são apresentados de forma completa no endereço WEB: https://code.google.com/p/systematic-review/.

O processo de busca definido na RS resultou na descoberta de trezentos e nove (309) artigos encontrados em cinco bases de dados. As bases de dados escolhidas para busca foram: IEEE Xplore, ACM Digital Library, Science Direct, Scopus e Web of Science. Para filtrar esses artigos e definir os estudos primários, a RS foi dividida em quatro etapas:

- Primeira etapa: é conhecida como seleção preliminar (KITCHENHAM, 2004) e nela define-se o grupo de estudos que serve de base para a segunda etapa. Na primeira etapa são excluídos os estudos que são versões resumidas de trabalhos completos, trabalhos incompletos, trabalhos indisponíveis, trabalhos duplicados, tutoriais, pôsteres, painéis, resumos e outros similares;

- Segunda etapa: definir a relevância dos trabalhos restantes por meio da leitura do título, resumo e palavras-chave. Para isso, são aplicados os critérios de inclusão e exclusão definidos no protocolo da RS;

- Terceira etapa: cada estudo definido como relevante na segunda etapa é lido da íntegra, e com base nos critérios de inclusão e exclusão, define-se os estudos primários da RS;

- Quarta etapa: um especialista avalia e valida os estudos selecionados. Nessa etapa, estudos excluídos anteriormente podem ser adicionados ou estudos aceitos podem ser descartados.

Após a primeira etapa, restaram cento e quarenta e seis artigos para leitura de título, resumo e palavas-chave. Para a terceira etapa restaram cinquenta e dois artigos identificados como relevantes. Entre esses, dezenove artigos foram definidos como estudos primários na terceira etapa e referendados pelo especialista durante a última etapa de seleção de trabalhos. Destaca-se que os trabalhos encontrados são recentes e foram publicados entre os anos de 2006 e 2013. A seguir apresenta-se uma análise dos estudos primários definidos na RS.

No trabalho apresentado por Ali et al. (2012), os autores definem uma modelagem de LP e uma metodologia de configuração adequada para facilitar a aplicação do teste baseado em modelos (TBM). Os autores focam na modelagem de variabilidades comportamentais, descritas por meio de máquinas de estado da UML, pois eles trabalham com sistemas de vídeo-conferência 
que possuem um forte comportamento baseado em estados, além disso são fundamentais para o TBM. Os autores afirmam que sua abordagem pode ser adaptada para uso com outros diagramas. Os autores definem um mecanismo para especificar e configurar vários tipos de variabilidades usando estereótipos e modelagem orientada a aspectos.

A abordagem definida nesse trabalho inicia-se com a classificação de vários tipos de variabilidades existentes em diagramas de classes e máquinas de estado UML, para modelar comonalidades e variabilidades de uma LP com o objetivo de apoiar o TBM. Os autores citam algumas estratégias para especificar diferentes tipos de variabilidades, porém não definem nada novo nesse quesito.

Os autores também propõem um processo de configuração em seis passos para guiar os testadores na configuração dos modelos da LP para apoiar TBM, usando diferentes técnicas. Além disso, observa-se que nesse trabalho, os autores fazem distinção explícita entre variabilidades de hardware e software, pois organizam seus modelos em dois pacotes distintos: software e hardware. O pacote de software é classificado em comportamentoDoNúcleo, comportamentoFuncional, comportamentoNaoFuncional e configuraçãoDeSoftware.

Entre as limitações dessa abordagem destacam-se: falta de uma etapa específica para elicitação e análise de requisitos; modela variabilidades por meio de estereótipos, porém não define um perfil para isso; apresenta um estudo de caso, mas não compara com outras abordagens; as configurações de hardware são descritas somente por meio de um diagrama de classes.

Asirelli et al. (2011) propõem a aplicação de técnicas de model-checking no projeto e validação de variabilidades em linhas de produto, com foco no desenvolvimento de sistemas críticos. Os autores citaram outros trabalhos recentes definidos por eles, nos quais propõem uma lógica temporal para modelar variabilidades em LP e ainda estenderam essa lógica para capturar também o comportamento da família de produtos, por meio do uso de sistemas modais de transição como semântica do modelo. Os autores também definem algoritmos para derivar produtos válidos, assim como formas de verificar propriedades entre produtos e famílias, baseado em model checkers existentes.

A abordagem proposta pelos autores inicia com a definição de um diagrama de features da LP. Com a ajuda de um conjunto de diretrizes ou possivelmente formalismos em alto nível, define-se o Modal Transition System (MTS) como modelo semântico, juntamente com um conjunto de fórmulas vaCTL. UM MTS é um sistema de transições rotulados que distingue transições obrigatórias e opcionais e que dessa forma, pode modelar características opcionais e obrigatórias de uma LP. vaCTL é uma variabilidade e uma ação baseada em ramificação de tempo definida em lógica temporal interpretado sobre o MTS.

Entre as limitações da abordagem proposta, pode-se destacar: a criação de um novo modelo pode resultar em dificuldade de aprendizado da abordagem; a técnica de modelagem proposta não trata casos de características alternativas OR e XOR; para validar essa técnica de 
modelagem, seria importante fazer uma comparação com outras técnicas existentes, como por exemplo, a utilização de UML statecharts ou CVL.

No trabalho proposto por Baumgartl et al. (2013) os autores definem uma abordagem para desenvolvimento de uma LP de robôs que se inicia com a definição de uma DSL usando o EMF. As variabilidades de componentes de hardware e software são capturadas por meio do modelo de características. Os autores pretendem usar o software FAMILE para mapear os elementos do modelo de features nos fragmentos correspondentes de implementação. Como limitações desse trabalho, pode-se destacar que os autores não especificaram como descrever os requisitos e arquitetura da LP; o estudo de casos não foi concluído; e a abordagem tem foco em gerência de variabilidades de código, o que limita o reúso e evolução da LP.

Bessling e Huhn (2012) apresentam um estudo de caso, no qual apresentam o desenvolvimento de uma LP de marcapasso usando o SCADE. A especificação da LP é feita por meio da CVL. Os autores acrescentam uma safety analysis derivando requisitos de segurança que podem ser verificados por model checkers. A abordagem proposta nesse trabalho é uma extensão da abordagem SCADE, por meio da gerência de variabilidades com a CVL. O objetivo do SCADE é apoiar um desenvolvimento sistemático, correto, baseado em modelos e métodos formais e cobrir todo o processo de desenvolvimento. O SCADE compreende uma linguagem e ferramenta. Como limitações dessa abordagem, pode-se destacar a falta de distinção entre variabilidades de sofware e hardware; a generalidade da linguagem SCADE, cujo foco são sistemas críticos; e, o estudo de caso de marcapasso não é suficiente para mostrar ou avaliar a escalabilidade da abordagem, pois é pequeno.

Em outro trabalho desenvolvido por Huhn e Bessling (2013), as autoras focam na variabilidade de requisitos de segurança. Portanto, as autoras propõem uma integração uniforme dos requisitos de segurança (safety) em uma metodologia de projeto orientada a modelos e características para a LP. Mais uma vez, as autoras estendem o framework SCADE e validam a abordagem por meio do estudo de casos de marcapasso.

No trabalho apresentado por Botterweck, Polzer e Kowalewski (2009) e estendido em Botterweck, Kowalewski e Polzer (2010) os autores focam na configuração e derivação de produtos de uma LP de sistemas embarcados. Os autores mostram como DSLs podem ser traduzidas em modelos configuráveis com semântica formal. Os autores usam o Simulink como DSL para a engenharia baseada em modelos de sistemas embarcados. Além disso, a abordagem definida é estruturada em duas dimensões: verticalmente, são definidas a engenharia de domínio e engenharia de aplicações; horizontalmente, os autores definem uma engenharia de linguagens. Entre as limitações desses trabalhos, pode-se destacar que a abordagem não faz distinção entre variabilidades de hardware ou software e baseia-se em ferramenta proprietária. A engenharia de requisitos, para os autores, faz parte da engenharia de linguagens e não é detalhada nesses trabalhos.

No trabalho descrito por Braga et al. (2012), os autores focam em problemas práticos 
envolvidos na engenharia de linha de produtos para estabelecer uma infraestrutura de LP para certificação de produtos. Nesse trabalho, os autores propõem um metamodelo para capturar as entidades envolvidas na certificação de LP e a relação entre elas. Como validação, os autores modificaram uma abordagem existente e aplicaram no contexto do desenvolvimento de VANTS. Observa-se que o foco dessa abordagem é a certificação de produtos derivados da LPS.

O domínio de SEC também tem se beneficiado da aplicação de LPS, mesmo que ainda de maneira preliminar. Entre esses tipos de abordagem, destacam-se a abordagem ProLiCES (BRAGA et al., 2011b). A abordagem ProLiCES (do inglês, an approach to develop Product Lines for safety-Critical Embedded Systems) (BRAGA et al., 2011b) é uma evolução da abordagem SAFE-CRITES (do inglês, an approach for the development of SAFEty-CRITical Embedded Systems) (BRAGA et al., 2011a).

Em ambas a preocupação é com reúso e qualidade do software resultante. A ideia principal da ProLiCES é permitir o desenvolvimento de LPS para sistemas embarcados, ao contrário da SAFE-CRITES, em que focava-se em um produto único. A ProLiCES possui duas atividades principais: engenharia de domínio e engenharia de aplicações, como na abordagem Plus (GOMAA, 2004). O diferencial está no enfoque dado às atividades de validação que são necessárias para futura certificação do produto, além de algumas etapas específicas de SE, como por exemplo o particionamento entre hardware e software e simulação do sistema.

De acordo com Fragal et al. (2013), o uso de MDE e LP pode oferecer vantagens ao desenvolvimento de sistemas embarcados complexos por meio do uso da especificação de diferentes linguagens, de acordo com o nível de abstração e o controle de variabilidade ao longo do desenvolvimento. Para isso, os autores definiram a abordagem SyMPLES, que permite a criação de LP com uso de SysML. A abordagem inclui duas extensões da linguagem SysML, por meio de perfil UML, para expressar variabilidades e para associar SysML blocks às principais classes dos blocos funcionais. Segundo a abordagem, os modelos SysML criados na engenharia de aplicação da LP são usados para gerar blocos funcionais e máquinas de estado no Simulink. Como limitações da abordagem, pode-se destacar a dependência de ferramentas proprietárias (Simulink) e a falta de uma atividade de fault analyses, o foco na engenharia de aplicações e falta de distinção entre variabilidades de software e hardware.

No trabalho apresentado por Cuenot et al. (2010), descreve-se a EAST-ADL, que é uma linguagem para descrição de arquitetura para software embarcado automotivo. EAST-ADL2 apoia o desenvolvimento baseado em modelos de sistemas embarcados e oferece construções dedicadas para facilitar gerenciamento de variabilidades e de linha de produtos. Além disso, a linguagem oferece apoio à Engenharia de Requisitos, representação de requisitos funcionais e soluções de software e hardware, além de temporização e safety analysis.

No trabalho de Hoyos, Casallas e Jimenez (2012) os autores apresentam o framework HileS2 para a engenharia baseada em modelos de linha de produtos. Esse framework oferece um ambiente para a engenharia de domínio e de aplicações, construção automática de Virtual 
Prototypes (VP) e criação de uma IDE específica para cada LP. Os autores propõem o uso de SysML para a construção do modelo de plataforma para uma LP específica. Com o uso de transformações de modelos os engenheiros de domínio podem gerar automaticamente a plataforma em VHDL-AMS ou Verilog-AMS a partir dos VP. Observa-se que o foco da abordagem são os sistemas embarcados, e portanto o framework não leva em conta os requisitos de criticidade, não faz distinção entre os requisitos de software ou hardware e ainda, embora os autores citem o diagrama de features para gerenciar as variabilidades, eles não mostram como fazem a integração com seu framework.

Hutchesson e McDermid (2010) definem uma abordagem de desenvolvimento de LP baseado em modelos, especialmente desenvolvida para atender às necessidades de sistemas de software de alta integridade (high-integrity software systems). A abordagem consiste na definição de um modelo de arquitetura de referência e no estilo de desenvolvimento baseado em componentes, com apoio de transformações de modelo para instanciar os componentes específicos de projeto e os artefatos de desenvolvimento associados. Os autores utilizam-se do modelo de classes para descrever a estrutura do software e empregam uma transformação do tipo modelo-para-texto para gerar impletações SPARK. Os autores ainda utilizaram um perfil SPARK para estender a UML. Observa-se que embora os autores definam o modelo a ser utilizado para representar a estrutura da LPS, eles deixam em aberto as opções para modelar o comportamento dos sistemas da LP. Os autores também não fazem distinção entre características de hardware ou software.

O trabalho de Mitsching, Weise e Kowalewski (2010) consiste da extensão de autômatos temporais (timed automata) para apoiar o gerenciamento de variabilidade. Os autores ainda mostram como utilizar uma ferramenta de apoio aos autômatos para gerenciar as variabilidades. Nesse trabalho os autores não fazem distinção entre características de software ou hardware, não apresentam validação da técnica proposta nem comparação com outras técnicas existentes, e, por focar em sistemas embarcados, não apresentam alternativas de validação e análise de segurança.

Nos trabalhos apresentados em Polzer, Kowalewski e Botterweck (2009) e Polzer et al. (2012) os autores se preocupam com as variabilidades de hardware e o seu impacto no comportamento do software embarcado (microcontroller) e propõem a utilização do sistema de Rapid Control Prototyping (RCP) em conjunto com técnicas de desenvolvimento baseado em modelos. Os autores modularizam a parametrização dos componetes em uma configuração separada, que é isolada do modelo que define o comportamento do controlador . Portanto, durante adaptações, o modelo pode geralmente permanecer inalterado. Para validar a abordagem os autores apresentam um estudo de caso de aplicação de um assistente de estacionamento. Observa-se que as possíveis configurações de produto são descritas por meio do modelo de features e, enquanto no primeiro trabalho os autores utilizam-se da ferramenta proprietária Simulink, no segundo eles apresentam uma infraestrutura de desenvolvimento baseado em modelos com o EMF. Vale ressaltar que em nenhum dos trabalhos os autores compararam as 
técnicas apresentadas.

No trabalho apresentado por Tokumoto (2010), o autor apresenta o uso de duas DSLs para o desenvolvimento e geração de código para robôs. A primeira DS1 é de mais alto nível e é usada para definir a estrutura, enquanto a segunda, mais específica, é utilizada para definir o comportamento. Observa-se que o autor não detalha a forma de gerenciar variabilidades e o exemplo proposto apresenta-se incompleto.

No trabalho apresentado por Trujillo et al. (2009) os autores estendem a noção de variabilidades de uma LP baseada em modelos para gerência de variabilidades em metamodelos e transformações de modelos. Para isso, os autores propõem a aplicação da técnica de refinamento orientada a features para modelos, metamodelos e transformações de modelos. O foco dessa abordagem são os sistemas embarcados e ela apoia somente a etapa de engenharia de domínio.

No trabalho apresentado por Voelter (2010), o autor mostra como utilizar-se de languages workbenches para integrar diversas DSLs para descrever a LP e gerenciar a customização de produtos específicos. Embora o autor demonstre o uso de ferramentas, o trabalho não define claramente uma abordagem a ser seguida.

Outro trabalho importante na área é o de Habli (2009), que enfoca os desafios de segurança no reúso em linha de produtos. $\mathrm{O}$ autor define e avalia uma abordagem orientada a modelos para certificar sistemas e processos em uma linha de produtos de sistemas críticos. Para isso, o autor define um metamodelo de segurança que captura as dependências entre os safety case, safety assessment e os artefatos desenvolvidos para a linha. A principal diferença desse trabalho com a abordagem definida nesta tese é a preocupação com certificação.

A partir da análise desses trabalhos, as questões de pesquisa são respondidas e apresentadas a seguir.

\section{Questão Secundária (QS1):}

Conforme apresenta-se na Figura 15, a maioria das abordagens encontradas na RS são voltadas ao desenvolvimento de sistemas embarcados, e portanto, não levam em consideração os diversos requisitos complexos dos SCES.

\section{Questão Secundária (QS2):}

Não foram encontrados trabalhos com estudos experimentais para comprovar que as abordagens propostas são factíveis. Entretanto, a maioria dos trabalhos encontrados apresentam provas de conceito para validar as abordagens propostas. Portanto, faltam estudos experimentais que comparem as abordagens propostas com outras existentes.

\section{Questão Secundária (QS3):}

Com relação às fases de desenvolvimento de uma linha de produtos, a maioria das abordagens encontradas atende tanto a ED quanto a EA. Entretanto, em relação ao MDE na ED, a maioria das abordagens não atende a engenharia de requisitos. 
Figura 15 - Distribuição dos sistemas alvo.

Target System

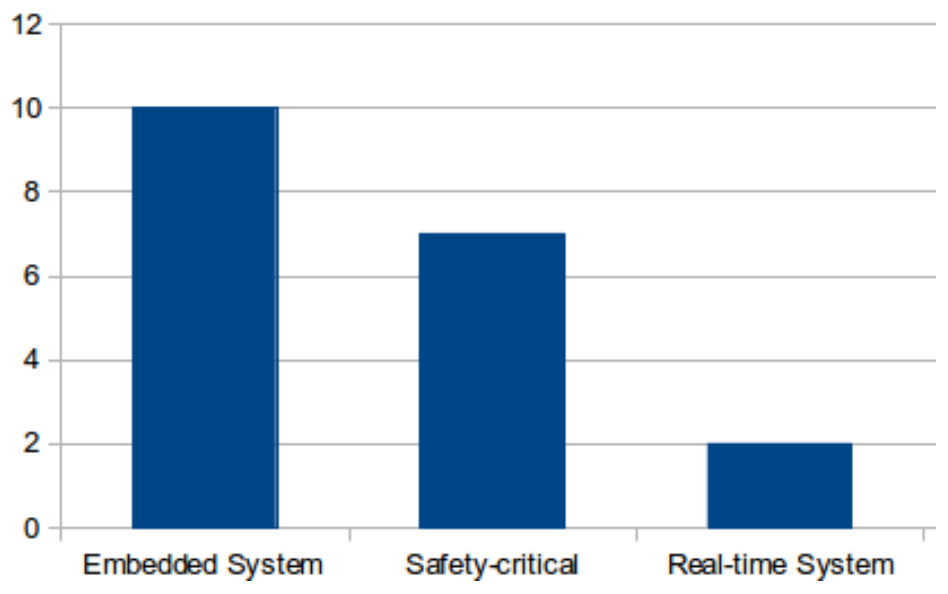

Fonte: Queiroz e Braga (2014c)

Questão Secundária (QS4): Conforme apresenta-se na Figura 16, a maioria das abordagens propõe a utilização de modelos baseados na UML. Esse resultado contradiz alguns estudos que sugerem que o Matlab/simulink é o padrão da indústria de sistemas embarcados (HENZINGER; SIFAKIS, 2007). A adoção de modelos baseados em UML possibilita o uso de diversas ferramentas de apoio com código aberto existentes no mercado.

Figura 16 - Modelos utilizados nos trabalhos encontrados.

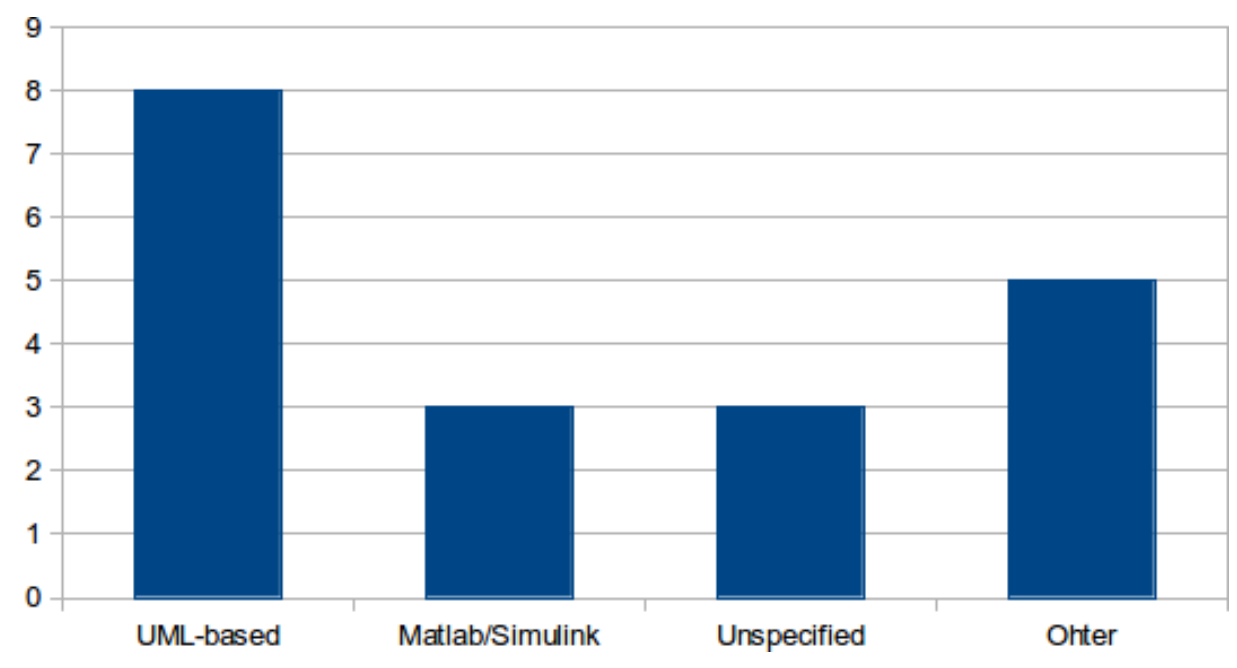

Fonte: Queiroz e Braga (2014c)

\section{Questão Secundária (QS5):}

Conforme apresenta-se na Figura 17, a maiorias das abordagens propõem o uso do modelo de features para o gerenciamento de variabilidades. Entretanto, abordagens mais recentes tem proposto o uso da CVL, o que indica que essa linguagem pode se tornar o padrão de fato. Destaca-se ainda o uso de abordagens baseadas em UML e abordagens baseadas em DSL 
próprias. Para o autor desta tese, as abordagens que utilizam UML, o fazem gerando uma carga extra nos modelos que se estende ao longo do desenvolvimento e as abordagens que utilizam DSL acrescentam uma curva de aprendizado maior, visto que a documentação das DSLs encontradas é menor e menos completa que a documentação da CVL, além da falta de ferramentas.

Figura 17 - Gerência de variabilidades.

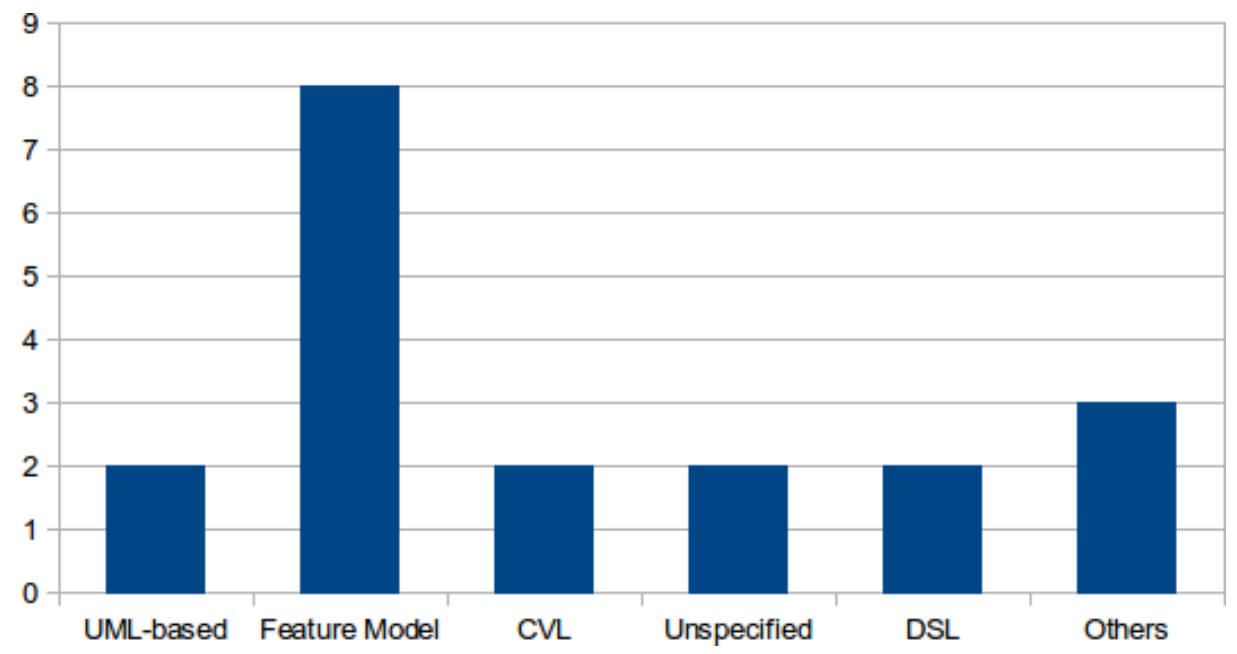

Fonte: Queiroz e Braga (2014c)

\section{Questão Secundária (QS6):}

A maioria das abordagens não faz distinção entre as variabilidades de software e hardware, entretanto essa distinção é fundamental para o desenvolvimento de sistemas embarcados, uma vez que variabilidades de hardware podem gerar variações no software e vice-versa.

\section{Questão Secundária (QS7):}

A maioria das abordagens encontradas utiliza ferramentas livres, entre as quais destaca-se o ambiente eclipse. Entre as ferramentas proprietárias, as mais citadas foram o Pure::variants (Pure Systems, 2012) e o Matlab/simulink (BEUCHER, 2006).

Um quadro comparativo que sumariza as respostas às questões de pesquisa é apresentado na Figura 18.

\subsection{Estado da prática}

Além do estudo de diversos trabalhos científicos sobre a aplicação dessas técnicas no desenvolvimento de SCES, foi elaborado um questionário que foi aplicado a estudantes de pós-graduação e profissionais da indústria. O objetivo do questionário é conhecer os usuários das técnicas de desenvolvimento de SCES e investigar o propósito e uso de metodologias de desenvolvimento, o estado da prática e entender os desafios na construção de sistemas embarcados 
Figura 18 - Sumário dos resultados.

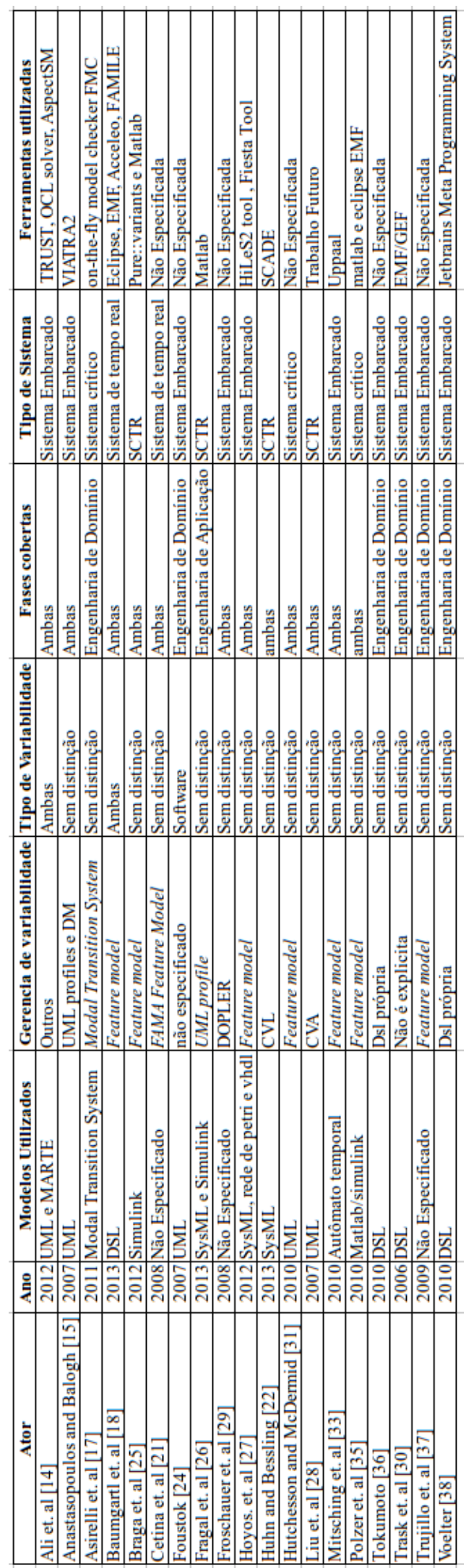

Fonte: Queiroz e Braga (2014c) 
críticos sob a ótica dos desenvolvedores. O questionário completo está disponível no endereço: https://code.google.com/p/questionario-sces/.

O questionário foi respondido por dez profissionais, dos quais sete trabalham com o desenvolvimento de SCES na academia e três trabalham com o desenvolvimento de SCES na indústria. Entre esses profissionais, três trabalham como programadores, três como projetistas e quatro são pesquisadores da área de sistemas críticos.

Após traçar o perfil dos profissionais, as questões tinham o objetivo de saber quais técnicas eram utilizadas na prática para o desenvolvimento de SCES. Apenas dois profissionais apontaram o uso de um processo sistemático para o desenvolvimento de sistemas críticos, o que revela indícios da necessidade de definição de processos ou divulgação dos existentes. Mesmo sem a utilização de processos sistemáticos, oito profissionais afirmaram que técnicas de validação e verificação eram utilizadas ao longo do desenvolvimento, o que vai ao encontro da abordagem proposta neste trabalho.

Em relação aos requisitos, apenas dois afirmaram que eles são elicitados e especificados. Por outro lado, sete afirmaram que a elicitação e especificação dos requisitos é feita parcialmente e um afirmou não haver elicitação e análise de requisitos. Esse dado chega a ser alarmante, visto que é muito mais barato e seguro corrigir erros em etapas inicias do desenvolvimento (PRESSMAN, 2011). Esse dado vai ao encontro do levantamento feito na revisão sistemática, que observou o quando a engenharia de requisitos tem sido negligenciada nas técnicas que combinam PLE e MDE para o desenvolvimento de SCES. Ainda em relação aos requisitos, apenas três afirmaram que as alterações nos requisitos acarretam alterações em outros artefatos previamente construídos e apenas dois afirmaram que a abordagem utilizada faz algum gerenciamento sobre o impacto dos requisitos do hardware nos requisitos do software e vice-versa.

Em relação à importância da engenharia de requisitos, seis profissionais a classificaram como muito importante. Quanto a técnica de definição dos requisitos, a maioria dos profissionais afirma que os requisitos tem sido descritos em textos com linguagem natural, além do que, apenas um deles afirma que os requisitos são coletados com muitos detalhes.

Entre as técnicas de safety analysis, foram citadas as técnicas hazard and operability e safety critical testing. Em relação à validação e verificação, cinco profissionais afirmaram que elas são realizadas durante todo o ciclo de vida do desenvolvimento, dado que vai ao encontro do pensamento do autor desta tese, que considera a aplicação de técnicas de VV\&T durante todo o ciclo de vida de desenvolvimento fundamental para qualquer abordagem de desenvolvimento de SCES.

Embora poucos utilizem, na prática, um processo sistemático, todos os profissionais concordam que o desenvolvimento de SCES precisa de abordagens sistemáticas de desenvolvimento.

Em relação às ferramentas utilizadas, quatro utilizam ferramentas comerciais, três utilizam o Office, que possui equivalente livre e três utilizam somente ferramentas livres para 
o desenvolvimento. A maioria dos profissionais afirma que as ferramentas ajudam muito no desenvolvimento, entretanto destaca-se que dois deles afirmam que a ferramenta é de difícil utilização. Observa-se que entre as de difícil utilização, uma é comercial e a outra é livre.

Entre os modelos utilizados ao longo do desenvolvimento, quatro profissionais afirmaram que utilizam diagramas UML, quatro utilizam diagrama de blocos Matlab/simulink, um utiliza linguagens formais e outro não especificou. Observa-se que nesta tese utiliza-se como base os modelos UML, por ser o padrão da OMG e por possuir apoio de diversas ferramentas livres.

Para os profissionais que responderam o questionário, as maiores dificuldades no desenvolvimento de SCES são:

- lacunas nos processos de desenvolvimento ou em alguma atividade de desenvolvimento;

- falta de ferramentas;

- dificuldade de lidar com as restrições dos sistemas;

- dificuldade em especificar os requisitos;

- falta de técnicas para aumentar a produtividade.

Em relação a questão sobre o que seria mais importante em uma abordagem de desenvolvimento para SCES, os profissionais elencaram na seguinte ordem de precedência: Facilidade de adoção (simplicidade), Preocupação em gerar sistemas livres de erros, Abrangência (Contempla todo o ciclo de vida do desenvolvimento), Aumento da produtividade e Efetividade.

Além disso, apenas quatro profissionais afiram que os modelos elaborados ao longo do desenvolvimento passam por algum processo de validação. Por fim, cinco profissionais afirmaram que o código é gerado automaticamente por ferramentas a partir de modelos de projeto.

\subsection{Conclusões}

Neste capítulo foram apresentadas as principais contribuições da MDE para o domínio de SEC, de PLE para o domínio de SCES, os elementos da sinergia entre as técnicas de LPE e MDE, assim como foram apresentados e analisados os principais trabalhos que procuram unir essas técnicas para o desenvolvimento de SCES. Além disso, apresentou-se o estado da arte e da prática da utilização de técnicas de LPE e MDE para o desenvolvimento de famílias de SCES, definidos por meio de uma revisão sistemática e da aplicação de um questionário.

De acordo com os resultados obtidos, é fundamental a existência de abordagens de sistemas de desenvolvimento que sejam de fácil adoção, facilite a geração de sistemas livres de erros, sejam abrangentes, aumentem a produtividade e sejam efetivas. Além disso, os resultados mostram que necessita-se focar em técnicas de VV\&T ao longo do ciclo de vida, dar 
maior atenção à engenharia de requisitos e gerenciar o impacto dos requisitos do hardware no desenvolvimento de software e vice-versa.

Com base nos resultados obtidos, no próximo capítulo, apresenta-se uma abordagem sistemática de desenvolvimento de linha de produtos de sistemas embarcados críticos com uso de técnicas de desenvolvimento orientado a modelos. 


\section{Visão geral da abordagem ProLCES}

\subsection{Considerações Iniciais}

Neste capítulo é apresentada uma visão geral da abordagem ProLCES, proposta nesta tese. São apresentados o seu objetivo, sua estrutura e uma breve descrição de suas atividades.

Os resultados apresentados neste capítulo foram reportados em dois trabalhos apresentados em conferências, como resultado parcial desta tese, na linha de pesquisa de desenvolvimento de SCES:

- Artigo publicado no SEKE 2014 (QUEIROZ; BRAGA, 2014a) - A Critical Embedded System Product Line Model-based Approach.

- Artigo publicado no ICSEA 2014 (QUEIROZ; BRAGA, 2014b) - Combining MARTEUML, SysML and CVL to Build Unmanned Aerial Vehicles.

Este Capítulo está organizado da seguinte forma. Na Seção 3.2, são apresentados os objetivos da abordagem proposta nesta tese. Na Seção 3.3, são apresentadas as principais características da abordagem. Na Seção 3.4, apresenta-se a estrutura da abordagem. Por fim, na Seção 3.5, apresenta-se uma sumarização dos tópicos apresentados neste capítulo.

\subsection{Objetivos}

Diante do que foi exposto nos capítulos anteriores, definiu-se a abordagem ProLCES, cujo objetivo principal é o desenvolvimento de famílias de sistemas embarcados críticos com técnicas orientadas a modelo, para suprir as lacunas mencionadas. Adicionalmente, são definidos os seguintes objetivos da abordagem:

- Linha de produtos: obter as vantagens da utilização de linha de produtos no domínio de SCES, por meio do reúso sistemático e pré-definido. A engenharia de linha de produtos permite um reúso em níveis mais altos de abstração, o que é reconhecidamente mais eficiente do que reúso de código ou reuso ad hoc (GOMAA, 2004).

- Sistemas embarcados críticos: os diversos requisitos complexos dos sistemas embarcados críticos oferecem grandes desafios para o desenvolvimento em larga escala (HABLI, 2009). Entretanto, o desenvolvimento em larga escala é essencial para redução de custos e popularização deste tipo de sistema. 
- Desenvolvimento orientado a modelos: utilizar técnicas de MDE tais como metamodelagem, aumento do nível de abstração, transformações entre modelos ou de modelo para código e validação de modelos em todo o ciclo de vida de uma linha de produtos. O uso de técnicas de MDE, em conjunto com a PLE pode reduzir o custo e complexidades do desenvolvimento, reduzir o tempo de entrega e aumentar a confiabilidade dos sistemas (PORTER et al., 2009).

- Engenharia de Domínio e Engenharia de Aplicações: uso de técnicas de MDE tanto na fase de engenharia de domínio quanto na engenharia de aplicações. A maioria das abordagens apresentadas no Capítulo anterior, utilizava técnicas de MDE somente em uma das etapas de desenvolvimento de LPS. Entretanto, pode-se obter mais vantagens com a utilização de técnicas de MDE em ambas as etapas (QUEIROZ; BRAGA, 2014a).

- Validação e verificação: o domínio de SCES possui requisitos como confiabilidade e criticidade que exigem, do processo de desenvolvimento, maior atenção com as atividades de validação e verificação em diversas etapas do desenvolvimento para reduzir a quantidade de erros no sistema (KNIGHT, 2002; HEIMDAHL, 2007).

- Gerenciamento de variabilidades: é uma atividade essencial no desenvolvimento de linha de produtos. Todavia, no desenvolvimento de SCES, necessita-se de um gerenciamento de variabilidades diferenciado, que leve em consideração as variabilidades de software e hardware e as dependências entre elas (ALI et al., 2012; QUEIROZ; BRAGA, 2014b)

Portanto, define-se o objetivo da abordagem proposta nesta tese, da seguinte forma.

Fornecer uma abordagem sistemática de desenvolvimento de linha de produtos para a construção de famílias de sistemas embarcados críticos, com a utilização de técnicas de desenvolvimento orientado a modelos aplicadas tanto na fase de engenharia de domínio quanto na engenharia de aplicações, com atividades de validação e verificação em diversas etapas do desenvolvimento e que ofereça recursos para o gerenciamento de variabilidades de software e hardware, assim como as dependências entre elas.

\subsection{Características}

A definição de uma abordagem para alcançar os objetivos destacados acima foi feita de forma iterativa. As características que guiaram a definição da abordagem são apresentada a seguir.

- abrangência: diz respeito as etapas e atividades cobertas pela abordagem.

- simplicidade: está relacionada com a facilidade de adoção da abordagem. É uma característica ligada aos anseios do usuário. 
- efetividade: está relacionada com a capacidade de aumento de produtividade e geração de sistemas seguros.

- flexibilidade: diz respeito a capacidade de adaptação da abordagem de acordo com o domínio a ser desenvolvido.

As características citadas anteriormente foram levadas em consideração durante todo o processo de definição da abordagem proposta, tanto na elaboração das etapas quanto na definição das atividades. Durante a definição da abordagem, procurou-se fornecer métodos, técnicas ou diretrizes para cada etapa fundamental de desenvolvimento, ao mesmo tempo, com cuidado para a abordagem não deixar de ser autocontida. Desta forma, já na construção procura-se atender ao máximo todas essas características, fornecendo diretrizes a partir de informações encontradas em trabalhos da literatura a respeito de cada uma das atividades propostas.

\subsection{Estrutura}

A abordagem é dividida em quatro etapas: análise de mercado, planejamento, Engenharia de domínio e Engenharia de aplicações. A avaliação econômica indica se é ou não vantajoso criar uma linha de produtos para o domínio em questão. Na Engenharia de domínio é definida a estratégia de linha de produtos (proativa ou reativa) (KRUEGER, 2002), análise de domínio, projeto de domínio, implementação de domínio, preenchimento do repositório e definição das diretrizes para derivação de produtos. A Engenharia de aplicações consiste na definição e análise de sistema único e na configuração de produto, por meio da reutilização de artefatos do repositório.

A abordagem é organizada em termos de atividades que são de responsabilidade de um ou vários membro(s) da equipe e pode receber e/ou gerar algum artefato, possivelmente, com base nas diretrizes definidas pela abordagem. Esses elementos são explicados a seguir:

- Atividades: um passo elementar e gerenciado da abordagem (LONCHAMP, 1993). Gerenciado significa que são alocados recursos e programado prazos para a atividade, além da alocação de um ou vários membros da equipe para a execução da atividade.

- Papel: um conjunto de permissões e obrigações associadas a um objetivo funcional (LONCHAMP, 1993). Representa a função de um executor de uma atividade. Pode ser um ser humano ou uma ferramenta computadorizada. Um papel descreve as características da função da entidade, e não a entidade em si, de forma que uma mesma entidade possa desempenhar vários papéis, e um papel possa ser desempenhado por várias entidades (LUCRÉDIO, 2009). 
- Artefato: um produto criado ou modificado durante a aplicação da abordagem, seja como um resultado requerido ou para facilitar a abordagem (LONCHAMP, 1993).

- Diretrizes: utilizadas para ajudar ou guiar na execução de uma atividade para qual não é possível estabelecer passos explícitos (LUCRÉDIO, 2009).

Para facilitar o entendimento e ilustrar as dependências entre as atividades, elas são apresentadas de forma sequencial. Entretanto, isso não implica que o modelo de ciclo de vida utilizado seja o modelo cascata. Na aplicação da abordagem, as atividades devem ser executadas de forma iterativa e incremental, e quando possível, também de forma paralela.

As fases e etapas da abordagem são ilustradas na Figura 19. Observa-se que a abordagem se inicia a partir de uma análise de mercado que visa definir a viabilidade de construção da linha de produtos. Caso a linha de produtos se mostre viável, deve-se elaborar um planejamento inicial que consiste na definição de uma estratégia de construção da LP e na escolha das atividades da abordagem que farão parte do processo. Em seguida, tem início a etapa de engenharia de requisitos que visa definir e gerenciar os requisitos da LP. A etapa de engenharia de requisitos é executada de maneira incremental e iterativa com as etapas de projeto de domínio, cujo objetivo é definir a arquitetura da LP e com as etapas de implementação do domínio e configuração. Ilustrou-se na figura, por meio de círculos vermelhos, as etapas que possuem atividades com as maiores contribuições da abordagem ProLCES. É importante destacar que as atividades de V\&V estão presentes nas diversas etapas conforme é detalhado no capítulo seguinte. Por fim, a abordagem se preocupa com a rastreabilidade dos requisitos entre as diversas fases, etapas e atividades.

Para facilitar a organização e leitura das atividades da abordagem, elas são identificadas por meio de uma sigla com o seguinte padrão: AM.X, PL.X, ER.X, PD.X, EA.X. Observa-se que $X$ representa um número sequencial e AM, PL, ER, PD e EA se referem respectivamente a análise de mercado, planejamento, engenharia de requisitos de domínio, projeto de domínio e Engenharia de aplicações. Analogamente, cada artefato é identificado por uma sigla, no formato AT.ER.X, no qual X também é um número sequencial. O detalhamento das fases da abordagem ProLCES são apresentadas no Capítulo 4.

\subsection{Considerações finais}

Neste capítulo apresentou-se uma visão geral da abordagem, seus objetivos, sua estrutura e sua abrangência. Observa-se que a abordagem tem enfoque nas práticas relacionadas à engenharia. Neste capítulo também foram apresentadas as fases, etapas e atividades da abordagem ProLCES que são detalhadas nos próximos capítulos. 
Figura 19 - Visão geral da estrutura e das fases da abordagem ProLCES.

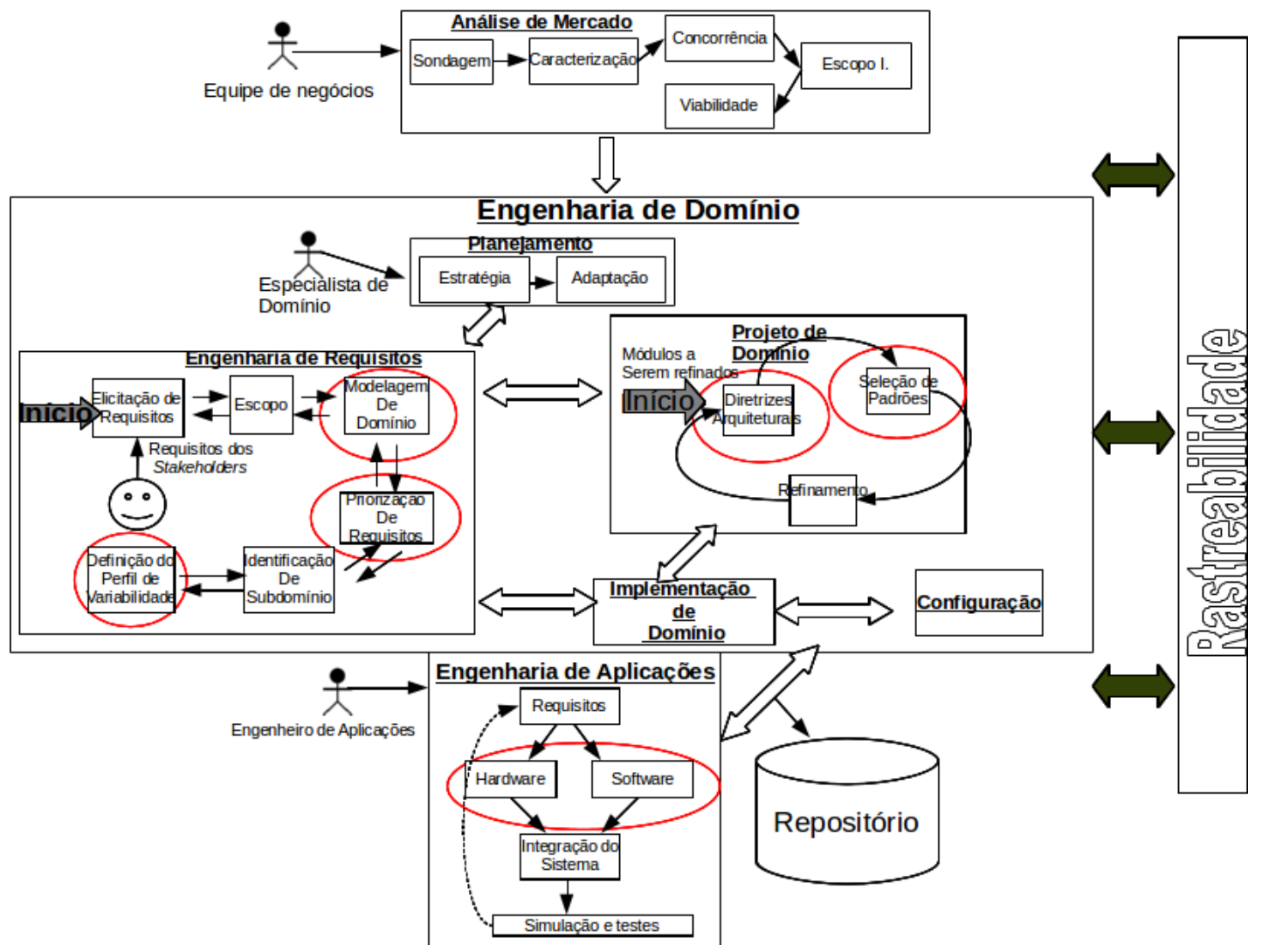





\section{A abordagem ProLCES}

\subsection{Considerações Iniciais}

Neste capítulo são apresentadas as fases de análise de mercado, planejamento, Engenharia de Domínio e Engenharia de Aplicações da abordagem ProLCES. Entre essas fases, a maior contribuição da abordagem está no processo de Engenharia de Requisitos que foi definido como parte da fase de Engenharia de Domínio (ED). A ED corresponde ao processo de Engenharia fundamental na construção de uma linha de produtos. Na Engenharia de domínio são desenvolvidos os ativos centrais da linha para posterior reutilização durante a Engenharia de aplicações.

Conforme apresentado no Capítulo 3, um dos diferenciais da abordagem proposta nesta tese é a utilização de MDE desde as fases iniciais da Engenharia de domínio, além de fornecer subsídios para a derivação automática de produtos na EA. Além disso, o uso de MDE nas duas etapas, segundo proposto por esta abordagem, permite que a ED seja executada de forma mais simples, sem a carga extra espalhada pelos modelos, comum em outras abordagens. Além disso, fornece subsídios para a derivação automática de produtos na EA. Dessa forma, pode-se acelerar consideravelmente o desenvolvimento da linha e, principalmente, realizar validações e verificações desde os estados iniciais de desenvolvimento dos sistemas, isso pode facilitar a adoção da abordagem em projetos acadêmicos ou industriais. Observa-se que todos os conceitos apresentados neste capítulo são exemplificados por meio da apresentação de artefatos gerados no desenvolvimento das linhas de produtos de Veículos Aéreos não Tripulados (VANT) e de marcapasso.

Os resultados apresentados neste capítulo foram reportados em dois trabalhos, como resultados parciais desta tese, na linha de pesquisa de desenvolvimento de SCES:

- Artigo publicado no ICSEA 2014 (QUEIROZ; BRAGA, 2014b) - Combining MARTEUML, SysML and CVL to Build Unmanned Aerial Vehicles.

- Artigo submetido ao journal Software: Practice and Experience - A model-driven requirements engineering methodology to support the development of safety-critical embedded systems product lines and requirements traceability.

Este Capítulo está organizado conforme apresenta-se a seguir. Nas Seções 4.2 e 4.3 apresenta-se uma visão geral das linhas de produtos de veículos aéreos não tripulados e de marcapasso, respectivamente, que são utilizadas para exemplificar a abordagem proposta. $\mathrm{Na}$ Seção 4.4, são apresentadas as ferramentas utilizadas para desenvolver os exemplos presentes no Capítulo. Na Seção 4.5, apresenta-se uma compilação das principais técnicas de análise de 
mercado que podem ser utilizadas para tomar a decisão de construir uma linha de produtos. $\mathrm{Na}$ Seção 4.6, apresentam-se alguns princípios de planejamento da linha de produtos que antecedem a etapa de Engenharia de requisitos do domínio. Na Seção 4.7, apresenta-se a fase de Engenharia de Domínio, e suas etapas de requisitos de domínio, projeto de domínio e implementação de domínio. Na Seção 4.8, apresenta-se a fase de Engenharia de Aplicações. Por fim, na Seção 4.9, são apresentadas as conclusões deste capítulo.

\subsection{Linha de produtos de veículos aéreos não tripulados}

Para ilustrar os conceitos apresentados neste Capítulo, em cada atividade são apresentados exemplos de artefatos gerados a partir do desenvolvimento da linha de produtos de Veículo Aéreo Não Tripulado (VANT), que inclui um sistema embarcado de segurança crítica (piloto automático). O principal objetivo da linha é a implantação de software para uma família de VANTs com diferentes configurações de hardware. Os VANTs voam sem a necessidade de um piloto humano, cumprindo uma missão pré-estabelecida. Os VANTs podem voar sobre áreas onde outros aviões não seriam capazes, por isso, existem diversas aplicações. Uma família pode incluir diferentes configurações de VANTs. A abordagem de LP está sendo usada para cumprir essa meta.

A linha de produtos de VANTS compreende componentes de hardware e software necessários para executar plenamente um SANT (Sistema aéreo não tripulado). Este inclui a aeronave (com seus componentes como sensores, atuadores, antenas, etc.), a carga útil (por exemplo, câmera e outros sensores de missões específicas), o software em execução no VANT (controle de vôo, controle de missão, comunicação, etc), e a estação de solo.

Os produtos da linha de VANTs podem ser utilizados para aplicações civis, especialmente para a agricultura e ambiente de monitoramento; aplicações militares, como defesa; ou outras aplicações como salvamento. As aplicações típicas incluem a detecção de doenças das culturas, levantamentos topográficos, monitoramento de tráfego, planejamento urbano e inspeção de linhas de transmissão.

O VANT pode tirar fotografias aéreas, bem como filmar e transmitir vídeo ao vivo. As imagens capturadas podem ser processadas ou inspecionadas de acordo com as necessidades do usuário. Os usuários finais desses sistemas são pessoas relacionadas a um domínio específico em que o VANT foi configurado, por exemplo, um engenheiro agrônomo em aplicações agrícolas, ou um oficial do exército, no caso de aplicações de defesa. As missões do VANT podem ocorrer somente em espaços aéreos livres de controle (F e G) (EUROCONTROL, 2003), assim, muitas restrições que se aplicam às classes de espaço aéreo controlado (A a E) não precisam ser consideradas. 


\subsection{Linha de produtos de marca-passo}

Outra linha de produtos desenvolvida e utilizada nos exemplos apresentados é a linha de produtos de marcapasso. Os produtos dessa linha atuam no coração humano. Um coração possui quatro câmaras: átrios direito e esquerdo e ventrículos direito e esquerdo. O Sangue desoxigenado do corpo é recolhido no átrio direito e, em seguida, bombeado para dentro dos pulmões pelo ventrículo direito. Nos pulmões, o dióxido de carbono no sangue é substituído por oxigênio. Esse sangue oxigenado, em seguida, passa pelo átrio esquerdo e entra no ventrículo esquerdo, que o bombeia para o resto do corpo.

De um ponto de vista eléctrico, o coração é uma bomba constituída por tecido musculoso, controlado por um sistema eléctrico intrínseco. Um estímulo elétrico é gerado periodicamente (normalmente cerca de 60-100 vezes por minuto) pelo nó sinusal, localizado no átrio direito, percorre as vias de condução e faz as câmaras do coração se contraírem e bombearem o sangue. Os átrios são estimulados e contraídos pouco antes da estimulação e contração dos ventrículos.

Um marca-passo cardíaco é um dispositivo eletrônico implantado no corpo para regular o batimento do coração por meio de estímulos elétricos entregues por cabos-eletrodos que estão em contato com o coração. Esses estímulos são chamados de ritmos. O marca-passo também pode detectar estímulos cardíacos naturais, chamados de sentidos. Os ritmos cardíacos e sentidos são coletivamente conhecidos como eventos.

O marca-passo pode operar em vários modos, que se distinguem pelas câmaras do coração que são sentidas e estimuladas, como os eventos sentidos afetarão o ritmo, e se a frequência de estimulação é adaptada para o estado do paciente. Observa-se que alguns desses modos estão presentes em todos os tipos de marcapasso e outros são opcionais.

\subsection{Ferramentas utilizadas}

Para ilustrar as atividades e artefatos gerados pela aplicação desta abordagem foram elaborados exemplos a partir do desenvolvimento das linhas de produtos de VANTS e de marcapasso. Os exemplos ilustrados neste Capítulo foram implementados com as seguintes ferramentas:

- Eclipse foi usado em conjunto com o Eclipse Modeling Framework e o plugin papyrus (MODELING, 2011) para a modelagem dos diagramas UML, SysML e para a definição do perfil de variabilidades;

- a ferramenta SINTEF-CVLTool (SVENDSEN et al., 2010) foi utilizada para a modelagem de features mais simples; 
- para a definição de diagramas de features mais completos foi utilizada a ferramenta featureIDE (THÜM et al., 2014).

Observa-se que essas ferramentas foram escolhida pois: se mostraram mais eficientes após a utilização de diversas ferramentas similares; possuem uma documentação bem completa e clara; foram utilizadas e explicadas em divertos artigos ciêntíficos.

\subsection{Análise de mercado}

Visto que o desenvolvimento de uma linha de produtos requer um maior investimento inicial, assim como custos contínuos para manter os ativos centrais, a sua adoção é uma decisão de negócio que não deve ser feita de forma aleatória (NORTHROP et al., 2009). De acordo com Northrop et al. (2009), esse maior investimento inicial está presente nas diversas tarefas de construção da linha, conforme apresenta-se a seguir:

- Requisitos: os requisitos são definidos para um grupo de sistemas como um todo. Portanto, a elicitação de requisitos pode exigir técnicas sofisticadas de análise, assim como uma negociação mais intensa para alcançar um acordo tanto em relação aos requisitos comuns quanto em relação aos pontos de variação para todos os sistemas da linha.

- Arquitetura: a arquitetura de uma LP define como cada produto é montado a partir dos ativos centrais. Dessa forma, a arquitetura deve ser flexível o suficiente para apoiar essa variação inerente à linha, o que impõe restrições adicionais a arquitetura e requer grande talento para defini-la.

- Componentes: os componentes que fazem parte dos ativos centrais são a base de construção de cada produto da linha. Alguns são usados sem alteração, outros devem ser adaptados a cada produto de acordo com mecanismos de variação. Portanto, eles devem ser robustos e extensíveis de modo que possam ser aplicados a uma gama de produtos. Eles ainda devem ser projetados para ser genéricos sem perda de performance.

- Modelagem e análise de performance: para produtos que possuem restrições de tempo real, deve-se realizar medições de performance para mostrar que os sistemas derivados da linha são adequados.

- Análise de mercado, estimativas de custo e de tempo: são necessidades existentes no desenvolvimento de qualquer produto, entretanto, no desenvolvimento de uma linha de produtos, deve-se elaborar versões genéricas e extensíveis que atendam a LP inteira e apoiem a variação de produtos. 
- Ferramentas e processos: o desenvolvimento de LP requer infraestrutura em termos de ferramentas e processos diferenciada. Elas devem ser mais robustas, pois uma única linha de produtos possui necessidades diferenciadas em termos de gerenciamento quando comparadas com o gerenciamento de produtos únicos.

- Casos de teste e dados de teste: No desenvolvimento de LP existem artefatos de testes genéricos para um conjunto de produtos com pontos de variação para acomodar a variação de produtos. Portanto, os artefatos de teste devem ser mais robustos para apoiar o teste em mais de um produto, além de serem extensíveis para acomodar variação entre produtos.

- Pessoal: Visto que uma linha de produtos é uma entidade única que envolve múltiplos produtos, o pessoal envolvido em seu desenvolvimento deve ser treinado, além da engenharia de software, em procedimentos para garantir que entendem as práticas de linha de produtos e podem usar os ativos centrais e procedimentos associados a linha.

Observa-se que o custo de investimento inicial é geralmente muito menor do que o valor do benefício, desde que se consiga vender uma certa quantidade de sistemas. Segundo Weiss e Lai (2004), Clements e Northrop (2002), Cohen (2004), a partir da venda do terceiro produto, a LP já começa a se tornar rentável. Por meio do uso da PLE, algumas organizações reduziram o número de defeitos em seus produtos e reduziram os custos e tempo de desenvolvimento em um fator de 10 ou mais (SCHMID; VERLAGE, 2002).

Observa-se, ainda, que a abordagem de linha de produtos não é sempre a melhor escolha para o desenvolvimento de sistemas semelhantes. Existem casos em que os sistemas podem ser proibitivamente diferentes uns dos outros, ou a família de produtos pode conter poucos sistemas, de tal forma que não seja possível recuperar o investimento inicial. Os responsáveis por decisões de negócios devem ser capazes de prever os custos e benefícios do desenvolvimento e evolução de uma linha de produtos, em comparação com a realização de abordagens de desenvolvimento tradicionais (CLEMENTS; MCGREGOR; COHEN, 2006). O objetivo principal das atividades da etapa de avaliação econômica é fornecer as evidências necessárias para uma boa tomada de decisão. Nessa etapa, são realizadas diversas análises, tais como identificação do domínio, dos stakeholders, dos concorrentes e definição inicial do escopo, para a partir dessas análises decidir se é viável construir uma linha de produtos no domínio pretendido.

\section{Atividade AM.1: Sondagem de domínio}

Papéis: especialista de mercado e especialista do domínio

Entradas: Qualquer documento existe sobre o domínio de interesse

Saídas: AT.AM.1 Informações sobre o domínio;

Objetivo: Apresentar o domínio no qual pretende-se construir a linha de produtos 
Descrição: Inicia-se a sondagem por meio da definição do ambiente onde o produto se localiza. Deve-se apresentar as informações a respeito do tamanho, crescimento e estrutura do domínio no qual se pretende construir a linha. Essa informação é geralmente discriminada em termos dos objetivos e pode estar relacionada com a estrutura do domínio em termos estatísticos, práticas de marketing e o composto de marketing (DORNELAS, 2014).

\section{Atividade AM.2: Caracterização dos stakeholders}

Papéis: especialista de mercado e especialista do domínio

Entradas: AT.AM.1 Informações sobre o domínio;

Saídas: AT.AM.2 Caracterização dos stakeholders;

Objetivo: Responder a seguinte pergunta: Quem está Comprando?

Descrição: Inicia-se esta atividade por meio da definição dos possíveis stakeholders. Depois, é importante conhecer seus hábitos e como eles vivem. Se entre os clientes existirem outras empresas, deve-se descobrir como eles operam seu negócio. Para a realização desta atividade recomenda-se a utilização de entrevistas e principalmente questionários, pela sua abrangência.

Diretrizes: A execução de um questionário eficiente, segundo um estudo realizado pelo Massachusetts Institute of Technology MIT (2011), pode ser feita por meio dos passos listados a seguir : criação de pesquisa e definição do perfil da população; definição de incentivos (opcional); teste da pesquisa; deixar o questionário disponível para a população; enviar convites e lembretes; coleta de dados; análise; Arquivamento. Além disso, é importante deixar o questionário o mais simples possível. Maiores detalhes a respeito da construção de questionários, podem ser encontrados em MIT (2011).

Para uma boa caracterização dos stakeholders, recomenda-se investigar diversos aspéctos definidos em Dornelas (2014).

Observa-se que antes de iniciar um questionário, ou outro método para definição dos stakeholders, é importante fazer uma pesquisa para verificar a existência de questionários previamente aplicados sobre o mesmo tema, para evitar o retrabalho.

\section{Atividade AM.3: Análise da Concorrência}

Papéis: especialista de mercado e especialista do domínio

Entradas: AT.AM.1 Informações sobre o domínio;

Saídas: AT.AM.3 Caracterização da concorrência;

Objetivo: Caracterizar a concorrência no domínio.

Descrição: A concorrência deve ser avaliada em relação a produtos/serviços e à organização. De que maneira o produto ou serviço pode ser comparado ao do concorrente? O produto 
responde rapidamente a mudanças? Tem uma equipe gerencial eficiente? A concorrência é líder ou seguidor no mercado? Eles poderão vir a ser os seus concorrentes no futuro?

Diretrizes: em Dornelas (2014) podem ser encontradas uma série de perguntas que podem ser utilizadas para caracterizar eficientemente a concorrência.

\section{Atividade AM.4: Definição inicial do escopo}

Papéis: especialista de mercado e especialista do domínio

Entradas: AT.AM.1 Informações sobre o domínio; AT.AM.2 Caracterização dos stakeholders;

Saídas: AT.AM.4 Lista inicial de características dos produtos da linha;

Objetivo: Definir a gama de aplicações que serão desenvolvidas no âmbito da linha de produtos.

Descrição: A definição do escopo de uma linha de produtos é uma questão chave, se não a atividade-chave no desenvolvimento e evolução da Linha (DALGARNO, 2008). Nela se identifica os pontos em comum entre os membros da linha e as formas em que eles variam. Identificar semelhanças e variabilidades é a essência do conceito de linha de produtos, e também, a essência da atividade de definição do escopo. Essa delimitação é essencial para determinar se um dado sistema pode ser construída dentro da linha de produtos e a partir dos ativos centrais da linha (CLEMENTS; MCGREGOR; COHEN, 2006).

Entretanto, observa-se que neste momento, é feita apenas uma definição inicial do escopo, de tal forma que seja possível definir a viabilidade econômica da Linha de produtos. Essa definição inicial é feita com base nas informações sobre o domínio e stakeholders.

A delimitação do escopo de linhas de produtos é na verdade um processo que pode ocorrer de acordo com os objetivos que se deseja alcançar. Esses objetivos podem ser a identificação do produto, identificação de objetivos de negócio, avaliação ou classificação de produtos e recursos, otimização de portfólio de produtos, planejamento de ativos, otimização de ativos, avaliação do domínio e liberação de planejamento (MORAES, 2010). Observa-se que cada tipo de definição de escopo é aplicável a diferentes estágios do ciclo de desenvolvimento.

Schmid (2000) e Bosch et al. (2001) distinguem entre três formas diferentes de definição de escopo em linha de produtos:

- Escopo de portfólio de Produtos: tem como objetivo identificar os produtos específicos que deveriam ser desenvolvidos, bem como as características que devem fornecer. Geralmente é conduzido a partir aspectos de marketing;

- Escopo de domínio: é a tarefa de delimitar as fronteiras do domínio que são supostamente relevantes para a linha. Envolve a análise de riscos e benefícios de um domínio, assim como análise de potencial de reúso; 
- Escopo de ativos: o foco é identificar os componentes que devem ser desenvolvidos para serem reutilizados.

Nesta atividade de definição inicial do escopo, realiza-se a definição de portfólio de produtos, assim como a análise de riscos e benefícios de um domínio. Observa-se que existem três tipos de aplicações distintas: aplicações existentes (aplicações que foram desenvolvidas antes do início do processo de análise de domínio), aplicações futuras (aplicações para as quais os requisitos estão bem claros, porém o desenvolvimento ainda não foi iniciado) e aplicações potenciais (aplicações para as quais ainda não existem requisitos definidos, mas que são vistas como relevantes) (LUCRÉDIO, 2009).

Diretrizes: Existem diversas práticas para definição de escopo de linha de produtos, tais como a aplicação do padrão what to build (NORTHROP et al., 2009), examinar produtos existentes, conduzir workshops para entender os objetivos da linha e dos produtos, construção de diagramas de contexto, desenvolvimento de uma matriz de atributos/produtos ou desenvolvimento de cenários de linha de produtos (CLEMENTS; NORTHROP, 2002).

É importante estar ciente que no momento atual do desenvolvimento, ainda não foi tomada a decisão sobre a construção ou não de uma linha de produtos, portanto a atividade de definição inicial de escopo deve ser sucinta, simples e suficiente apenas para ajudar na tomada de decisão a respeito da construção da linha. Portanto, abordagem proposta nesta tese recomenda:

D1. Examinar produtos existentes: a realização de um estudo dos produtos existentes ajuda a formar as noções de comunalidade em toda a linha de produtos em potencial e a identificar os tipos de diferenças que possam vir a ocorrer. Em muitos casos, os produtos existentes conterão potenciais ativos da linha de produtos que podem ser extraídos e utilizados na futuro (NORTHROP et al., 2009).

D2. desenvolver uma matriz de atributos/produtos: com base na observação de sistemas existentes, é fácil produzir a matriz, que é uma relação entre os produtos e as características relacionadas a eles. Tipicamente, os atributos que dirigem o mercado estão listados na vertical e do lado esquerdo da matriz, e os diferentes produtos estão listados horizontalmente na parte superior da matriz. A matriz é usada na definição do escopo para definir a variabilidade da linha de produtos (NORTHROP et al., 2009).

D3 . Tentar primeiro encontrar diferenças entre as aplicações de um domínio, para só então tentar identificar as partes em comum: aplicações de um mesmo domínio compartilham um algo grau de funções em comum (COPLIEN; HOFFMAN; WEISS, 1998). Portanto, o espaço em comum deve ser consideravelmente maior do que as diferenças, e por consequência é mais fácil encontrar as diferenças primeiro. A estratégia é, inicialmente, identificar as aplicações existentes, e listar as features que caracterizam cada uma. Encontradas as diferenças, é mais fácil identificar as features comuns (ALMEIDA et al., 2006). 
Os principais riscos na atividade de escopo são: definir um escopo muito pequeno, dessa forma os ativos centrais podem ser desenvolvidos de maneira pouco genérica e por conseguinte pode-se perder oportunidades de negócios no futuro; escopo muito grande, pode gerar um custo bem maior para o desenvolvimento dos ativos centrais e reduzir os ganhos com a adoção de uma abordagem de linha de produtos; inclusão de produtos errados, pode gerar problemas na definição da arquitetura da linha de tal forma que não seja possível acomodar todos os produtos; stackholders essenciais não participaram, pode gerar a definição de escopo inapropriado (CLEMENTS; NORTHROP, 2002).

\section{Atividade AM.5: Definição de viabilidade}

Papéis: especialista de mercado e especialista do domínio

Entradas: AT.AM.1 Informações sobre o domínio; AT.AM.4 Lista de características dos produtos da linha; AT.AM.2 Caracterização dos stakeholders; AT.AM.3 Caracterização da concorrência

Saídas: Reunião de todos os documentos elaborados neste etapa

Objetivo: Responder a seguinte pergunta: Vale a pena construir uma linha de produtos no domínio proposto?

Descrição: Tomar a decisão de construção da linha com base nos artefatos produzidos nas atividades previamente executadas

Diretrizes: A resposta é sim, caso se obtenha a reposta sim para as seguintes perguntas:

- existem pelo menos três sistemas diferentes no escopo da linha de produtos?

- esses sistemas possuem mais características em comum do que características que os distinguem?

- o mercado tem espaço para crescimento, ou não está saturado?

- os clientes tem potencial de investimento na área?

Vale ressaltar que responder a essas perguntas é uma tarefa que pode demandar esforço considerável e para algumas delas, o analista de mercado pode fazer previsões que podem não se concretizar. Isso pode ser conduzida de diferentes formas, mas está fora do escopo desta tese aprofundar-se nesses aspectos.

\subsection{Planejamento}

O planejamento é um aspecto importante a ser considerado em processos desenvolvimento de software, em particular em PLE. Um fator que pode impactar diretamente no sucesso ou 
não da adoção de uma linha de produtos é a estratégia de adoção. Pode-se adotar a estratégia de criação de uma linha completamente nova, por meio do desenvolvimento de uma infra-estrutura de reutilização para toda a gama de produtos desde o início. Pode-se utilizar essa infra-estrutura para desenvolver novos produtos, o que pode reduzir drasticamente os custos em relação ao desenvolvimento tradicional (SCHMID; VERLAGE, 2002). Essa estratégia é chamada de proativa. Os riscos envolvidos nessa estratégia são: mudanças nas regras de negócio ou nas definições do domínio ou produto antes do lançamento de qualquer produto derivado da linha, o que faz com que ativos já criados se tornem inúteis para futuros produtos da linha; além disso, essa abordagem gera um pequeno aumento do tempo de mercado e consequente atraso na captação dos primeiros recursos advindos da linha. Além dessa estratégia, (MCGREGOR, 2008), define as estratégias reativa e incremental.

Na estratégia reativa, os ativos reutilizáveis são recolhidos a partir de produtos criados e implantados. Inicialmente, o produto é construído com o esforço de desenvolvimento de um produto único. Portanto, o conjunto de ativos reutilizáveis deve passar por uma refatoração e evoluir para uma coleção. Essa abordagem reduz o risco dos ativos se tornarem obsoletos. Cada ativo é usado pelo menos uma vez. O maior risco dessa estratégia é a falta de uma arquitetura da linha. Isso pode resultar em lotes de reformulação dos ativos para torná-los adequados para futuros produtos (MCGREGOR, 2008).

A estratégia incremental reforça um compromisso entre as duas outras abordagens. O conjunto de ativos é feito de acordo com incrementos programados. Os incrementos são geralmente definidos para oferecer recursos necessários a um conjunto de produtos que serão produzidos em um futuro próximo. Os riscos das outras abordagens continuam presentes nesta, embora de forma reduzida (MCGREGOR, 2008).

Como o foco da abordagem proposta nesta tese são as práticas de engenharia, a etapa de planejamento consiste na definição da estratégia de adoção de linha de produtos e em uma nova iteração da atividade de escopo. Observa-se que a estrutura da abordagem, com foco na simplificação do processo e em técnicas de MDE, facilita a adoção das estratégias reativa ou incremental, pois a aplicação de uma abordagem MDE pode ser trabalhosa em um domínio completamente novo.

\section{Atividade PL.1: Definição da estratégia de adoção de linha de produtos}

Papéis: especialista do domínio e gerente de projetos

Entradas: AT.AM.1 Informações sobre o domínio; AT.AM.4 Lista de características dos produtos da linha;AT.AM.2 Caracterização dos stakeholders; AT.AM.3 Caracterização da concorrência;

Saídas: Definição da estratégia

Objetivo: Definir a estratégia de adoção de linha de produtos 
Descrição: escolher entre as estratégias: proativa, reativa ou incremental. Além disso, é necessário adaptar a abordagem para a linha de produtos em questão. Embora qualquer estratégia de adoção possa ser utilizada com a abordagem proposta nesta tese, é importante ressaltar que a estratégia incremental é a mais adequada, pois está em harmonia com o modelo de processo proposto para a abordagem, conforme apresentado no Capítulo 3.

\section{Atividade PL.2: Adaptação da abordagem}

Papéis: especialista do domínio e gerente de projetos

Entradas: AT.AM.1 Informações sobre o domínio; AT.AM.4 Lista de características dos produtos da linha;AT.AM.2 Caracterização dos stakeholders; AT.AM.3 Caracterização da concorrência;

Saídas: abordagem adaptada

Objetivo: Definir as atividades da abordagem ProLCES que farão parte do desenvolvimento da linha.

Descrição: de acordo com as necessidades da organização e do tipo de linha de produto ou domínio, pode-se adaptar a abordagem proposta nesta tese ou definir quais modelos ou ferramentas devem fazer parte do desenvolvimento. Embora existam diversas outras técnicas e métodos de suporte ao desenvolvimento de linhas de produtos, eles fogem do escopo da abordagem proposta nesta tese que enfoca as técnicas de Engenharia de linha de produtos.

\subsection{Engenharia de domínio}

A Fase de Engenharia de domínio proposta pela abordagem ProLCES é dividida nas etapas de Engenharia de requisitos de domínio, projeto de domínio e implementação de domínio que são detalhadas a seguir.

\subsubsection{Engenharia de requisitos de domínio}

A Engenharia de requisitos corresponde ao processo pelo qual os requisitos para sistemas ou produtos de software são elicitados, analisados, documentados e gerenciados ao longo do ciclo de vida de desenvolvimento (AURUM; WOHLIN, 2005). É uma fase fundamental no desenvolvimento de qualquer sistema e corresponde a um fator crítico de sucesso (SOARES; VRANCKEN, 2007). Alguns estudos com base em um grande número de projetos, afirmam que a maior causa de falhas nos sistemas são relacionadas a problemas na engenharia de requisitos (STANDISH, 1999). Entre esses problemas estão as especificações de requisitos incompletos, falta de envolvimento do usuário e mudança descontrolada nos requisitos.

$\mathrm{Na}$ Engenharia de requisitos de domínio, o especialista de domínio tem o objetivo de 
definir o espaço do problema, identificar o escopo da linha de produtos, definir os pontos comuns e variáveis do domínio e produzir documentação sobre essas informações. Observa-se que a Engenharia de requisitos (ER) de uma linha de produtos difere da ER de sistemas únicos, pela definição explícita das variabilidades. Define-se variabilidade como a capacidade de um ativo central em se adaptar a usos em contextos de produtos diferentes que estão dentro do âmbito de uma linha de produtos (FELIX; PAUL, 2005).

Para definir os passos e atividades da Engenharia de Requisitos de Domínio, foram feitas as seguintes ponderações referentes ao desenvolvimento de linhas de produtos orientada a modelos para o domínio de sistemas embarcados críticos:

- em relação aos sistemas críticos:

1. a Engenharia de Requisitos é um grande desafio, pois problemas na especificação de requisitos podem implicar em sérias falhas (KNIGHT, 2002);

2. segundo o Standish Group International (STANDISH, 1999), estudos baseados em um grande número de projetos confirmam que a maior causa de falhas em sistemas são relacionadas a problemas na Engenharia de Requisitos;

3. o projeto de sistemas críticos inevitavelmente envolve ponderações, pois os requisitos de segurança podem gerar conflito com outros requisitos, como por exemplo, disponibilidade e performance. Dessa forma, deve-se assumir compromissos e encontrar formas de priorizar os requisitos (FENELON et al., 1994);

4. modelos de maturidade para avaliação de processos de Engenharia, tais como o capability maturity model integration (CMMI) (CHRISSIS; KONRAD; SHRUM, 2007), e especialmente o functional safety standard ISO 26262 (STANDARDIZATION, 2011) esperam que todos os artefatos do processo de desenvolvimento possam ser rastreáveis para os requisitos.

- em relação à Engenharia de Linha de Produtos:

1. a PLE deve especificar e gerenciar uma grande quantidade de produtos variáveis que devem ser desenvolvidos com o menor custo possível e dentro de uma prazo esperado. Para isso, deve-se reutilizar as partes comuns a todos os produtos em conjunto com as variabilidades durante todas as etapas de desenvolvimento, incluindo a ER;

2. para gerenciar as variabilidades de uma LP, todas as variabilidades dentro dos requisitos devem ser muito bem compreendidas (BUHNE; LAUENROTH; POHL, 2005), visto que a complexidade geral do sistema pode ser observada por um grande número de requisitos (potencialmente conflitantes) para diferentes produtos e para um número maior de stakeholders (em relação a sistemas únicos);

3. a ER desempenha um papel central na definição do espaço de problema coberto pela linha de produtos, assim como suas fronteiras (escopo) (DALGARNO, 2008). 
- em relação ao Desenvolvimento Orientado a Modelos:

1. embora os modelos sejam entidades primárias e fundamentais no MDD, com importância semelhante a que possuem em outras disciplinas de Engenharia, além de serem especificados em alto nível de abstração usando linguagens bem definidas (FONDEMENT; SILAGHI, 2004), existem poucas iniciativas que consideram modelos como artefatos centrais na Engenharia de Requisitos (SOARES; VRANCKEN, 2008);

2. técnicas orientadas a modelos, como o MDA, não encorajam os desenvolvedores de software a devotar tempo apropriado na identificação e descrição dos problemas que o software deve resolver. Isso resulta em erros clássicos, porém severos, tal qual desenvolver uma solução perfeita para o problema errado (JøRGENSEN; TJELL; FERNANDES, 2009).

Além disso, a ER de uma linha de produtos desenvolvida com base em técnicas orientadas a modelos deve fornecer modelos de requisitos que possam ser transformados automaticamente ou semi-automaticamente em modelos de projeto da linha de produtos. Em abordagens como as definidas por Gomaa (2004), Lucrédio (2009), Eriksson, Börstler e Borg (2005) e outras, as variabilidades definidas na ER são transportadas para diversos modelos de análise e projeto, o que gera uma complexidade extra nos modelos, tais como uma grande quantidade de relacionamentos, elementos e estereótipos. Quando se trata do desenvolvimento de sistemas grandes e complexos, esse aumento de complexidade nos modelos pode torná-los incompreensíveis e ingerenciáveis, de forma a gerar um grande aumento nos esforços de desenvolvimento da linha, ou mesmo, impossibilitar a sua conclusão.

A partir dessas ponderações, são definidos a seguir os principais desafios da Engenharia de Requisitos orientada a modelos no contexto do desenvolvimento de famílias de sistemas embarcados críticos.

- definir precisamente o espaço do problema coberto pela linha de produto e suas fronteiras;

- definir o subconjunto de requisitos comuns e variáveis que devem ser satisfeitos por produtos específicos da linha;

- fornecer métodos e técnicas para rastrear os requisitos desde o estágio inicial até a etapa de projeto de domínio e codificação;

- reduzir a lacuna entre a etapa de requisitos e de projeto.

A partir da definição dos desafios da ER no contexto estudado por esta tese, são definidos a seguir, os principais objetivos da abordagem de Engenharia de Requisitos definida nesta tese. 
- apresentar a utilização de diagramas de requisitos SysML (Object Management Group, 2012), em conjunto com diagramas de casos de uso e cenários (GROUP, 2007) para preencher a lacuna entre a definição dos requisitos em linguagem natural e o diagrama de casos de uso;

- mostrar como se pode utilizar a Common Variability Language (CVL) (HAUGEN; WaSOWSKI; CZARNECKI, 2012) no modelo de requisitos para reduzir a complexidade dos modelos subjacentes de análise e projeto de domínio, além de fornecer um dos mecanismos de rastreabilidade de requisitos. Esses benefícios podem ser obtidos por meio da resolução de variabilidades em estágios iniciais do desenvolvimento;

- gerenciar explicitamente as dependências entre as características específicas de hardware e software;

- mostrar como se pode criar um perfil UML específico de cada linha de produtos para fornecer mais um mecanismo de rastreabilidade de requisitos da etapa de engenharia de requisitos para a etapa de projeto;

- utilizar modelos semi-formais durante a análise de requisitos e ferramentas verificadoras de modelos para validação dos requisitos;

- identificar e tratar os perigos e modos de falha dos produtos da linha;

- e reduzir a complexidade de desenvolvimento por meio da subdivisão de domínios.

Para alcançar os objetivos definidos acima, a Engenharia de Requisitos de domínio definida nesta tese divide-se em seis etapas, conforme apresenta-se na Figura 20 e explica-se a seguir. Observa-se que algumas etapas são divididas em várias atividades.

- Elicitação de requisitos: consiste na definição dos requisitos para a família de sistemas a ser desenvolvida;

- Definição do escopo: visa definir claramente as fronteiras da LP. Uma técnica muito utilizada para alcançar uma clara especificação das funcionalidades dos produtos de um domínio é a utilização do modelo de features (KANG; LEE; DONOHOE, Aug. 2002);

- Modelagem de domínio: guiada pelas features definidas na etapa anterior, visa detalhar os requisitos de sistema, elaborar os modelos de requisitos da linha e validá-los;

- Priorização de requisitos: criar os documentos de requisitos específicos de produtos, por meio da configuração de variabilidades;

- Identificação de sub-domínios: conforme comentado anteriormente, a maioria dos sistemas embarcados críticos pertencem a domínios com muitas features e alto grau de 
Figura 20 - Visão geral da estrutura e etapas da Engenharia de Requisitos de domínio.

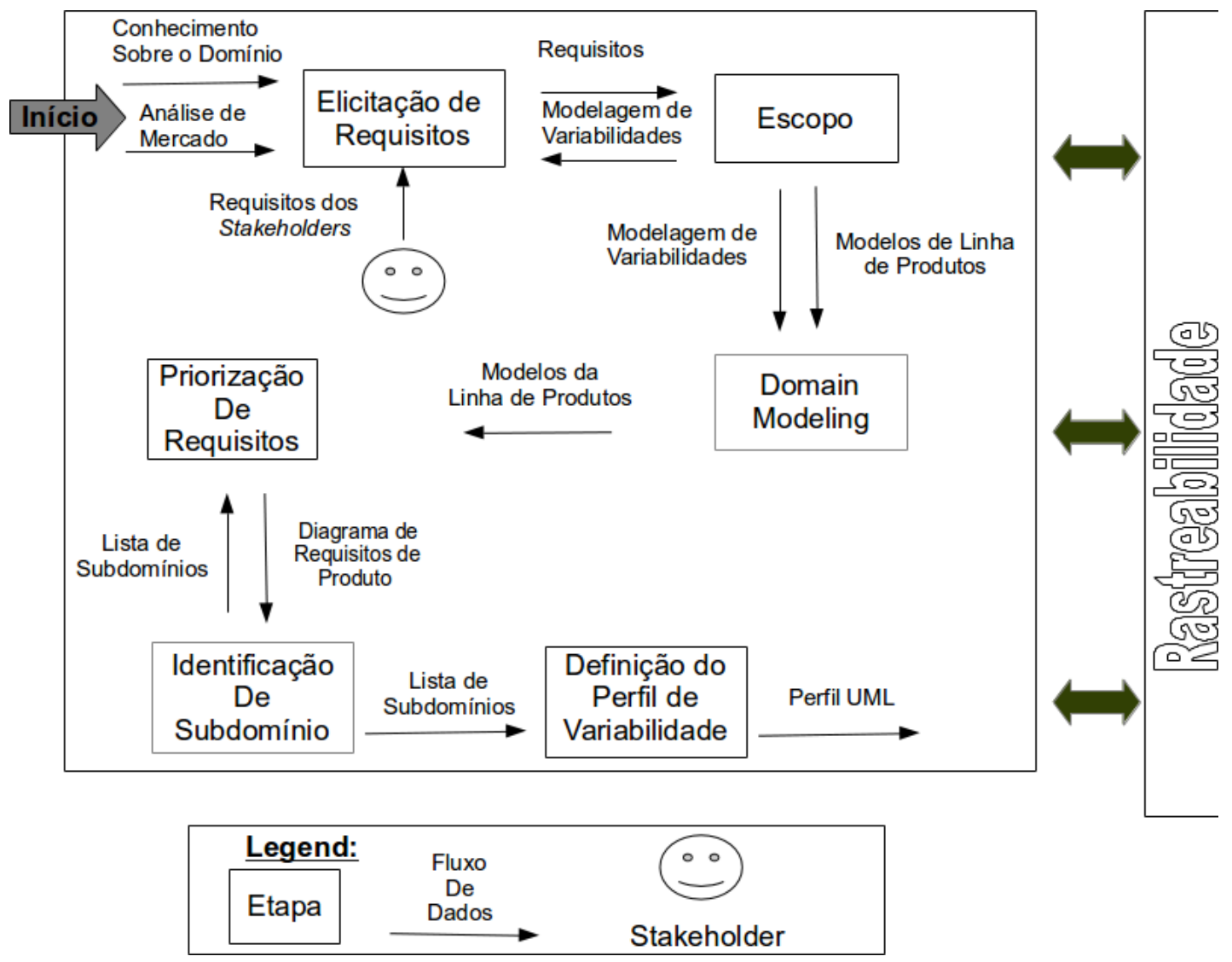

complexidade, o que dificulta a completa especificação de seu comportamento (HADDAD; TESSER, 2002). Além disso, essa complexidade reduz a reusabilidade dos artefatos de domínio, uma vez que o escopo exato de seus elementos e relações se torna difícil de entender e manter. Por essa razão, deve-se decompor o domínio para facilitar o reuso ao longo do processo de desenvolvimento (JARZABEK, 1997);

- Definição de um perfil UML de variabilidade: fornecer uma forma simples de garantir a rastreabilidade dos requisitos e features para arquitetura da linha, por meio de um perfil UML. A realização dessa atividade evita a necessidade da utilização de ferramentas proprietárias como o pure::variants (Pure Systems, 2012).

A partir dessas definiçõos iniciais, são detalhadas, a seguir, as atividades básicas que compõem as etapas definidas para a Engenharia de Requisitos de domínio proposta nesta tese.

\subsubsection{Elicitação de requisitos}

Na Figura 21, apresenta-se as atividades e documentos envolvidos na etapa de elicitação de requisitos. Esta etapa é composta por três atividades: criação do documento de requisitos, validação e criação do diagrama de requisitos. 
A atividade de criação do documento de requisitos recebe, como entrada, o conjunto de documentos sobre o conhecimento de domínio e uma lista de possíveis produtos da linha, obtidos na fase de avaliação econômica apresentada no Capítulo 3 e mais requisitos obtidos dos stakeholders. Como resultado dessa atividade, obtêm-se o documento de requisitos escrito em linguagem natural.

A atividade de validação recebe como entrada o documento de requisitos da LP e tem o objetivo de validá-lo com os stakeholders.

A atividade de criação do diagrama de requisitos recebe como entrada o documento de requisitos revisado e produz um diagrama de requisitos SysML.

Figura 21 - Relação entre as atividades da etapa de elicitação de requisitos e os artefatos requeridos e providos.

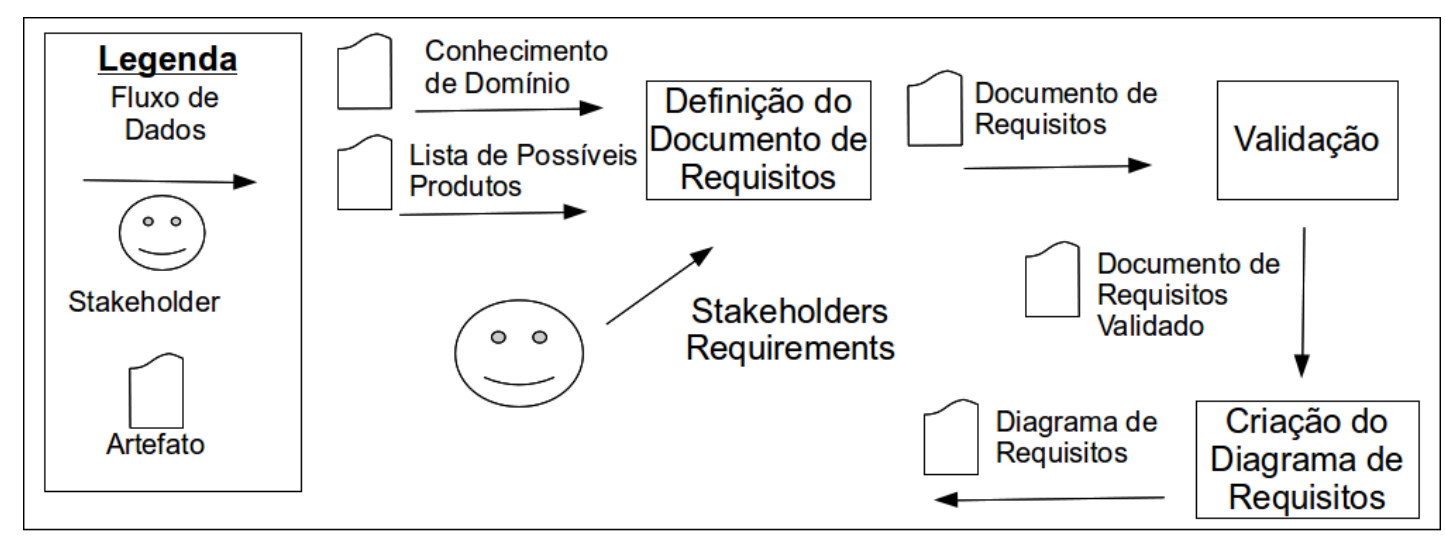

A seguir são apresentados os detalhes dessas atividades.

\section{Atividade ER.1: Elicitação dos requisitos da linha de produtos}

Papéis: Especialista do domínio, analista de domínio

Entradas: AT.AM.4 Lista inicial de características dos produtos da linha

Saídas: AT.ER.1 Documento de requisitos

Objetivo: Definir os requisitos da linha de produtos e fazer a distinção entre os requisitos obrigatórios, opcionais ou alternativos.

Descrição: A Engenharia de requisitos inicia-se por meio da elicitação de requisitos, que é feita a partir de uma pesquisa aprofundada sobre o domínio da LP, incluindo entrevistas com os especialistas nesse domínio, observação das funcionalidades de sistemas existentes, manuais de usuário, dicionários de dados e modelos, quando existirem (LEE; KANG; LEE, 2002).

A elicitação de requisitos vai permitir reunir os requisitos que devem ser cumpridos por possíveis sistemas nesse domínio. Recomenda-se iniciar o processo com a elaboração de documentos de requisitos para três possíveis sistemas-alvo do domínio. Por meio desses três documentos de requisitos, inicia-se a definição do escopo da linha pela separação dos requisitos em obrigatórios, opcionais ou alternativos. 
O artefato de saída gerado por essa atividade é o documento de requisitos da LP, destacando-se os requisitos obrigatórios, opcionais e alternativos. Os requisitos obrigatórios estão presentes em todos os membros da LP, os requisitos opcionais podem ou não estar presentes em algum membro da linha e os requisitos alternativos podem estar presentes com diferentes alternativas nos membros da linha. Esse documento é escrito em linguagem natural e é importante para comunicação e validação junto aos stakeholders, bem como para elaboração do diagrama de requisitos em SysML.

Observa-se que existem três tipos de aplicações distintas em um domínio: aplicações existentes (aplicações que foram desenvolvidas antes do início do processo de engenharia de domínio), aplicações futuras (aplicações para as quais os requisitos estão bem claros, porém o desenvolvimento ainda não foi iniciado) e aplicações potenciais (aplicações para as quais ainda não existem requisitos definidos, mas que são vistas como relevantes) (LUCRÉDIO, 2009). Esse conhecimento é importante, pois o analista de domínio, com base nas informações sobre esses tipos de sistemas e sobre os stakeholders, identifica as aplicações contempladas na linha de produtos.

As diretrizes para definição do documento de requisitos são:

- D1: iniciar a criação do documento de requisitos (DR) da linha, por meio da definição de um DR de um possível sistema único da linha (A), que contém uma visão geral do sistema, os requisitos funcionais (de armazenamento, movimentações e consultas) e os requisitos não funcionais do sistema;

- D2: em seguida, criar os documentos de requisitos de outros dois possíveis sistemas únicos da linha (B e C) seguindo o modelo feito para o sistema A, e de tal forma, que o sistema A seja o mais completo possível, o sistema $\mathrm{C}$ seja um sistema minimalista e o sistema B seja com sistema com uma média de funcionalidades;

- D3: extrair os requisitos comuns e variáveis a partir desses três documentos e montar um único documento. Observa-se que essas comunalidades e variabilidades também existem nos requisitos não funcionais;

- D4: adicionar neste novo documento de requisitos outras variabilidades não previstas nos três documentos iniciais e, possivelmente, encontrados pelo especialista de domínio ou por indicação de stakeholders.

- D5: definir os pontos de variação no documento de requisitos em alto nível por meio da definição dos possíveis variantes para cada ponto de variação.

- D6: por fim, criar um dicionário de domínio que será utilizado na identificação de características em atividades posteriores. 
Deve-se escrever o documento de requisitos da LP seguindo as diretrizes propostas por Faulk (2001):

- D1; primeiro os requisitos comuns (Obrigatórios): requisitos que são comuns a todos os membros da família ou que variam para todos os membros são listados primeiro e devem ser agrupados de acordo com o assunto.

- D2: dependências subordinadas: quando a inclusão de um requisito depender de outro, esse requisito é subordinado na definição do domínio. Organizar os requisitos dessa forma facilita a leitura e a construção do modelo de caracteríticas associado.

- D3: preservar a rastreabilidade: são atribuídos identificadores únicos para os requsitos comuns e variáveis, de forma a refletir seu tipo e local na definição do domínio. Dessa forma, apoia-se a rastreabilidade nos estágios de desenvolvimento subsequentes.

Uma classificação comum para os requisitos encontrada na literatura se baseia no seu nível de abstração, e os classifica como funcionais ou não funcionais (ROBERTSON; ROBERTSON, 2006). Requisitos funcionais descrevem os serviços que o sistema deve fornecer, incluindo o comportamento do sistema em situações particulares. Requisitos não funcionais estão relacionados com as propriedades emergentes do sistema, tais como segurança, confiabilidade e tempo de resposta. Essas propriedades não funcionais não podem ser atribuídas a um componente único do sistema. Em vez disso, elas surgem como resultado da integração de componentes do sistema. Requisitos não funcionais também são considerados como requisitos de qualidade, e são fundamentais para determinar o sucesso de um sistema (SOARES; VRANCKEN, 2008), principalmente no domínio de SCES.

Adicionalmente, Soares e Vrancken (2008) definem os requisitos externos, que correspondem a uma descrição detalhada de todas as entradas e saídas para o sistema de software, tais como interfaces do sistema, hardware, software ou comunicação. É uma classificação importante para decompor o sistema em subsistemas. Esse tipo de requisito não precisa ser adicionado ao documento na primeira iteração desta atividade, pois em geral, eles são elicitados durante o detalhamento dos requisitos em forma de cenários.

Além disso, observa-se que os requisitos não funcionais também podem variar entre os produtos da linha, por isso é fundamental destacar suas possíveis variações no documento de requisitos. Para isso, deve-se definir métricas que possam ser usadas para diferenciar os requisitos não funcionais entre os sistemas da linha de produtos.

De acordo com essas definições e diretrizes, apresenta-se na listagem 5.1 um exemplo de documento de requisitos da LP de sistema de marcapasso. Observa-se que esse documento já representa a fusão de três documentos de requisitos de sistemas no domínio, por isso ele já possui a diferenciação das variabilidades da LP. Observa-se que os códigos dos requisitos são 
formados por números seguido de uma letra no final. A letra $\mathrm{C}$ significa que os requisitos são comuns (obrigatórios) e a letra $\mathrm{V}$, signifique que eles são variantes.

Listagem 4.1 - Parte dos requisitos da linha de produtos de marcapasso.

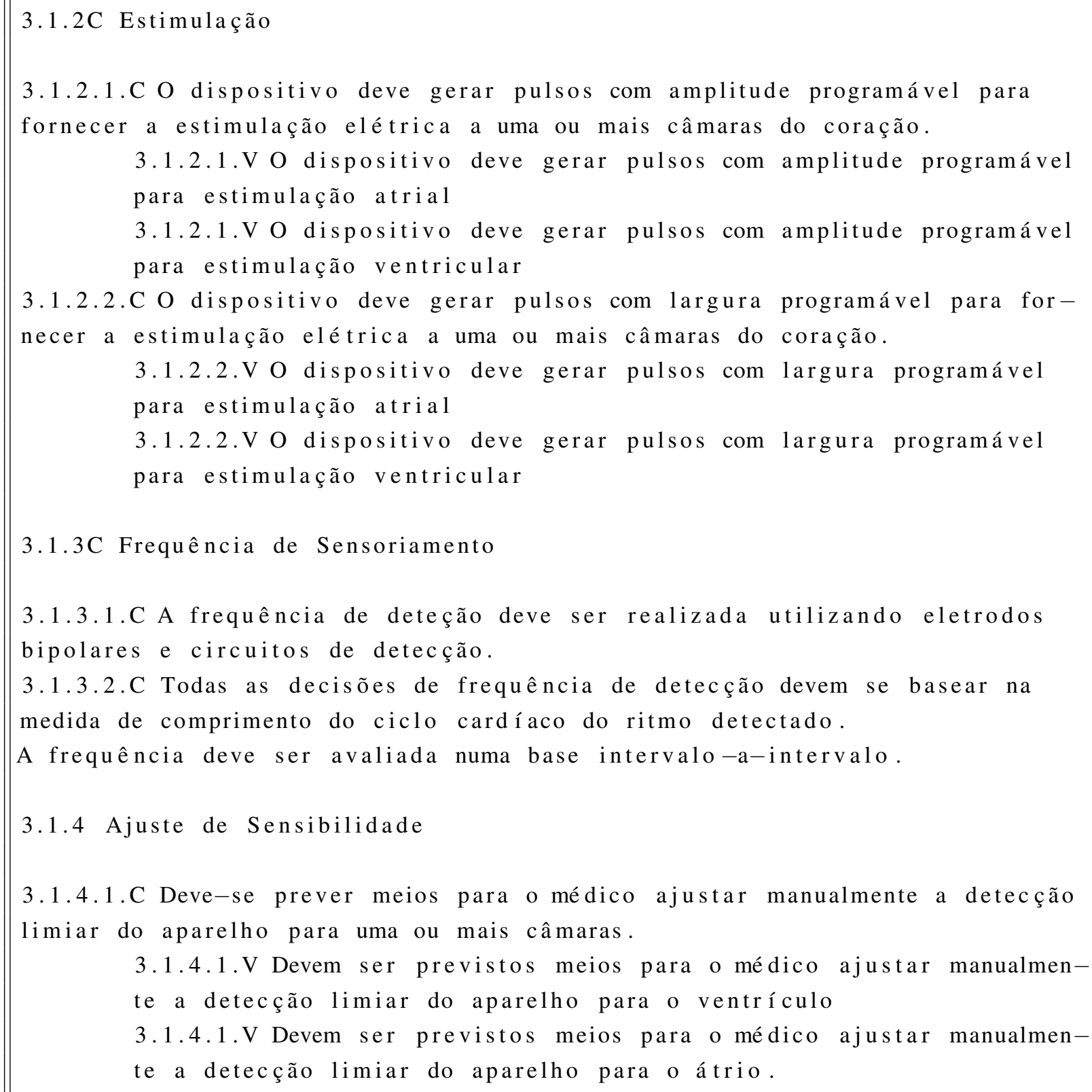

\section{Atividade ER.2: Validação do documento de requisitos}

Papéis: Especialista de qualidade, especialista de domínio, stakeholders

Entradas: AT.ER.1 Inicial.Documento de requisitos

Saídas: AT.ER.1 Validado.Documento de requisitos

Objetivo: Validar o documento de requisitos junto aos stakeholders.

Descrição: $O$ documento de requisitos foi elaborado em linguagem natural para facilitar a comunicação com os stakeholders. Logo após sua produção, recomenda-se a elaboração de um 
workshop com os stakeholders identificados na etapa anterior de desenvolvimento para validar o documento de requisitos. Nesta primeira validação, podem ser adicionados ou retirados tanto requisitos obrigatórios quanto variabilidades, de acordo com as negociações entre os possíveis stakeholders. Observa-se que por se tratar de uma abordagem de desenvolvimento de linhas de produtos no domínio de SCES, as atividades de verificação e validação são de extrema importância e são requeridas em diversas etapas e fases do desenvolvimento.

\section{Atividade ER.3: Elaboração do modelo de requisitos SysML}

Papéis: Especialista do domínio

Entradas: AT.ER.1 Documento de requisitos

Saídas: AT.ER.2 Modelo de requisitos SysML

Objetivo: Criar o modelo de requisitos SysML.

Descrição: Existe uma grande quantidade de abordagens que podem ser aplicadas para descrever as especificações do sistema. Com a UML como padrão para a engenharia de software, o diagrama de caso de uso tem sido amplamente utilizado. Os casos de uso são visuais, o que é bom para os analistas de sistema e usuários compreenderem melhor o sistema. Além disso, um caso de uso pode ser detalhado, e seus vários cenários podem ser descritos em linguagem natural, pseudo-código ou outros diagramas UML.

Entretanto, o documento de requisitos é habitualmente elaborado em linguagem natural para facilitar a comunicação com os stakeholders. Além disso, parece haver uma lacuna entre os textos em linguagem natural e a linguagem gráfica de casos de uso, usado em nível de requisitos do sistema (SOARES; VRANCKEN, 2007). Para facilitar o desenvolvimento por meio de melhoria na organização, a comunicação entre os especialistas de domínio e projetistas, explicitar os vários tipos de relações entre os requisitos e facilitar a verificação de requisitos nos estágios iniciais, esta tese propõe a utilização de diagramas de requisitos da Systems Modeling Language (SysML) (Object Management Group, 2012), descritos na Seção 1.3.3.

O documento de requisitos criado na atividade anterior pode ser transformado no diagrama de requisitos SysML, de acordo com as diretrizes a seguir:

- D1: primeiro os requisitos comuns: criar um bloco de requisito para cada requisito comum, com o mesmo identificador definido no documento, definir um nome significativo para o requisito e adicionar um resumo do requisito no campo text.

- D2: dependências subordinadas: criar um bloco de requisito para cada requisito subordinado com o mesmo identificador, um nome significativo, um resumo no campo text e utilizar a relação de derivação com o requisito subordinador.

- D3: Variantes: criar um bloco de requisito para cada requisito variante e seus subordinados, com o mesmo identificador, um nome significativo e um resumo no campo text. Para as 
etapas subsequentes do desenvolvimento, é importante escolher um conjunto médio de variantes que representa a maioria dos sistemas no domínio e utilizar a relação de herança com o requisito subordinador. As variantes que ficarem sem relação serão especificadas em termos de seus pontos de variação em etapas subsequentes do desenvolvimento.

Um exemplo de modelo de requisitos SysML feito a partir do documento de requisitos apresentado na Listagem 5.1 e seguindo as diretrizes definidas acima, é apresentado na Figura 22. Observa-se a manutenção dos identificadores, desde o documento de requisitos e a utilização de relações no diagrama.

Figura 22 - Modelo de requisitos da linha de produtos de marcapasso em SysML.

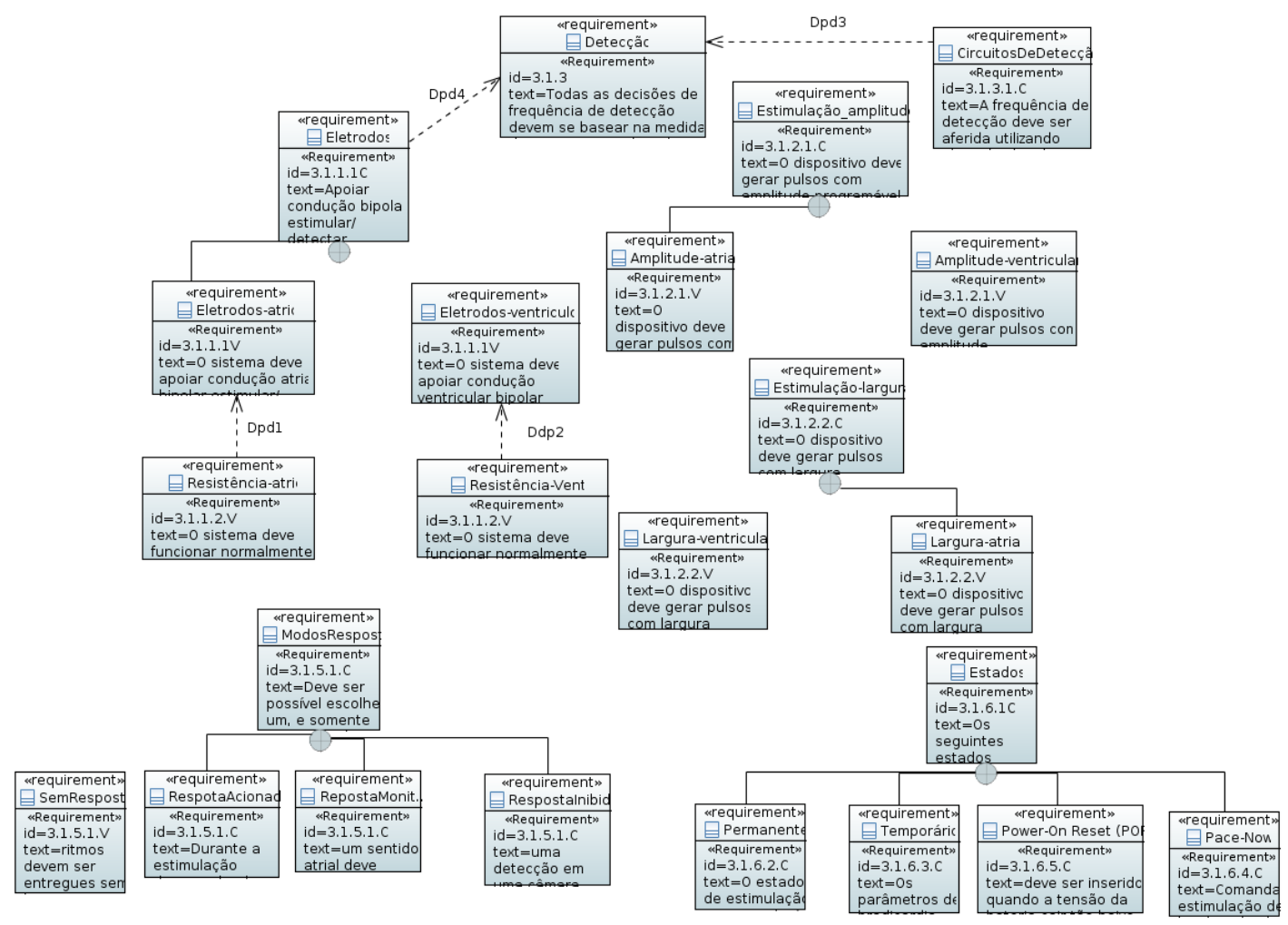

O SysML também permite a representação de requisitos, suas propriedades e relacionamentos em um formato tabular. A tabela proposta nesta tese é feita de forma incremental e se altera em algumas atividades ao longo do desenvolvimento. Inicialmente, propõe-se a utilização do formato proposto por Soares e Vrancken (2008), no qual os campos propostos para a tabela são: o identificador do requisito, o seu nome e tipo. Existe ainda, uma tabela para cada requisito que tem requisitos filhos relacionados pela relação de "hierarquia".

Além das construções básicas do diagrama de requisitos, algumas extensões são necessárias para atender às exigências de modelagem das atividades subsequentes. Os estereótipos são o principal mecanismo utilizado para criar perfis e extensões para o metamodelo UML e também para SysML. Um estereótipo estende uma metaclasse ou outro estereótipo (OMG, 2011b). Exemplos conhecidos de estereótipos para o meta-modelo UML são os estereótipos 
$<<$ controle $>>,<<$ entidade $>>$ e $<<$ fronteira $>>$ aplicados nos elementos de modelo do tipo classe. Quando usado em um diagrama de classes, esses estereótipos, entre outras coisas, melhoraram a semântica para os leitores do diagrama (SOARES; VRANCKEN, 2008).

Depois da criação de um estereótipo, propriedades e restrições específicas podem ser criadas. As propriedades adicionam informações aos elementos do modelo, e estão normalmente associadas aos tagged values. As propriedades são exibidas entre chaves, com a etiqueta e o valor codificados como strings. Os tagged values adicionam semântica extra aos elementos do modelo. Adicionalmente, restrições podem ser utilizadas como restrições semânticas aplicadas aos elementos (OMG, 2011b).

Para aumentar o poder de expressão dos diagramas de requisitos, é utilizada a extensão proposta por Soares e Vrancken (2008), que consiste na definição de três esterótipos: funcional, não-funcional e externo, conforme apresenta-se na Figura 23. Esses estereótipos são utilizados para definir os tipos de requisitos desde os estágios iniciais do desenvolvimento e aumentar a rastreabilidade.

Figura 23 - Estereótipos definidos para estender o diagrama de requisitos.

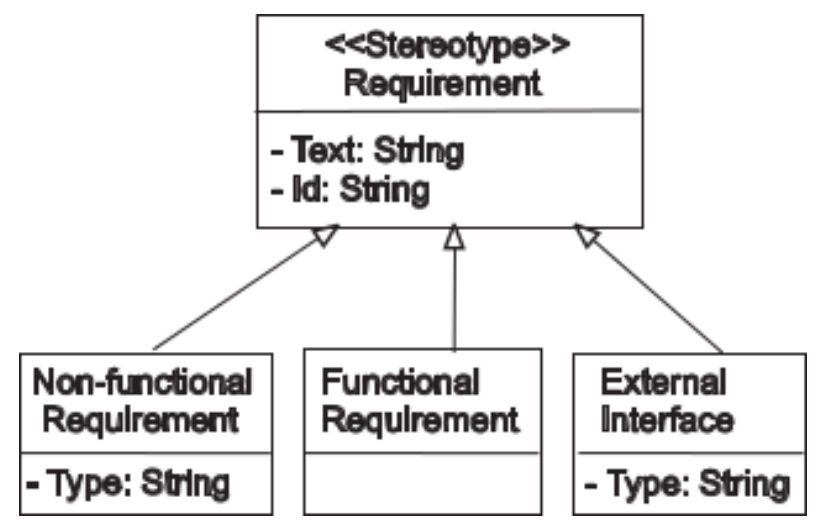

Fonte: Soares e Vrancken (2008)

\subsubsection{Definição do Escopo}

A definição do escopo desempenha um papel fundamental para alcançar a reutilização sistemática, uma vez que define um conjunto de descrições de produtos que identifica claramente os produtos que são apoiados pela plataforma (DERAKHSHANMANESH; FOX; EBERT, 2014). Além disso, identifica os pontos em comum entre os membros linha de produtos e as formas em que eles variam (MORAES, 2010). Identificar semelhanças e variabilidades é a essência do conceito de linha de produtos e a essência da definição de escopo. Esse conhecimento é expresso em termos de modelos de features, conforme apresenta-se a seguir. Na Figura 24, apresenta-se a visão geral dos artefatos de entrada e saída da atividade. 
Figura 24 - Relação de artefatos requeridos e providos pela etapa de definição do escopo.

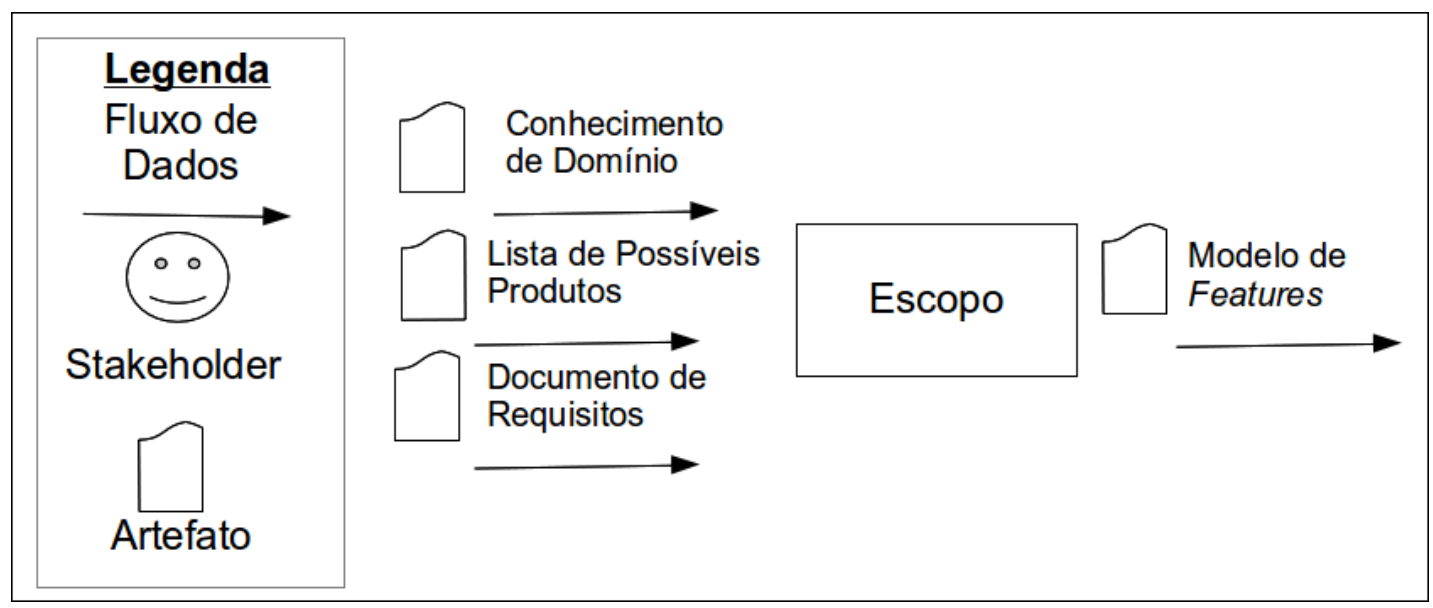

Papéis: Especialista do domínio

Entradas: AT.ER.1 Documento de requisitos, AT.ER.2 Modelo de requisitos

Saídas: AT.ER.2 Modelo de features no nível de sistema; AT.ER.2 Modelo de features no nível hardware; AT.ER.3 Modelo de features no nível de software; AT.ER.4 Modelo de features com as dependências entre os três níveis

Objetivo: Identificar as comunalidades e variabilidades entre os sistemas alvo da linha de produtos.

Descrição: Segundo ThÜm et al. (2014), o principal intuito da análise de domínio é capturar as variabilidade e comunalidades de um domínio de sistema, o que resulta em um modelo de features. O modelo de features mostra uma visão do sistema em termos de funcionalidades visíveis aos usuários finais. Ele agrupa as características do sistema em forma de dependências hierárquicas. As características definidas no modelo de features podem ser agrupadas em três categorias: obrigatórias, opcionais e alternativas. Esse modelo é de grande importância, pois ele é usado como guia no decorrer do desenvolvimento, por intermédio dele é possível saber quais características estão ou não presentes nos membros da linha e é utilizado junto com a CVL para definir transformações entre modelos e para gerar os sistemas alvo.

A fim de desenvolver ativos centrais reutilizáveis, deve-se ter uma capacidade de explorar as comunalidades e gerenciar as variabilidades. Para este fim, esta tese propõe a utilização de CVL, descrita na Seção 1.4.1.2. A CVL utiliza um modelo de características (ver Seção 1.4.1.1) como modelo de decisão para realizar as transformações de modelo. Portanto, antes de iniciar a configuração do domínio com o uso da CVL, é fundamental elaborar o modelo de características do domínio.

Além disso, o modelo de features é o guia para as principais atividades de desenvolvimento de uma linha de produtos, tem várias funções ao longo do desenvolvimento (DERAKHSHANMANESH; FOX; EBERT, 2014) e são utilizadas nas seguintes etapas: na análise 
de requisitos, pois os requisitos são mapeados para as features do domínio e a partir da escolha dessas features para um sistema alvo temos uma configuração; na implementação de domínio, pois os ativos de código também são mapeados para as features; e, na geração do sistema alvo, pois o software é gerado automaticamente a partir de uma dada configuração de features.

Segundo Lee, Kang e Lee (2002), as features de um produto podem ser classificadas em termos de recursos, tecnologias de domínio, técnicas de implementação e ambientes operacionais. Os recursos são features que podem ser identificadas como serviços distintos (por exemplo, transferência de chamada no domínio de telefonia), operações (por exemplo, a discagem no domínio de telefonia) e características não-funcionais (por exemplo, desempenho). Tecnologias de domínio (por exemplo, os métodos de navegação no domínio aviônico) representam a forma de implementação de serviços ou operações. Técnicas de implementação (por exemplo, mecanismos de sincronização) são funções genéricas ou técnicas que são usadas para implementar serviços, operações e funções de domínio. Ambientes operacionais (por exemplo, os sistemas operacionais) representa ambientes nos quais aplicativos são usados.

Além dessa classificação, esta tese também classifica as características em termos de sistemas, hardware e Software. As Features de sistemas (por exemplo, o tipo de aplicação de um VANT) são características de alto nível que podem englobar, quando detalhadas, features de hardware ou Software. As features de hardware (por exemplo, a quantidade de cabos-eletrodos em um sistema de marcapasso) são aquelas características que estão relacionadas exclusivamente aos dispositivos físicos do sistema. As features de Software (por exemplo, navegação autônoma) são aquelas relacionadas a porção de software do sistemas. Observa-se que essa classificação pode ser utilizada de forma complementar a classificação proposta por Lee, Kang e Lee (2002) e fundamental para o desenvolvimento de uma linha de produtos de sistemas.

Segundo Lee, Kang e Lee (2002), a identificação de features envolve abstrair o conhecimento obtido com os especialistas do domínio e outros documentos, tais como livros, manuais de usuário, documentos de projeto e código-fonte. Entretanto, dependendo do domínio, a quantidade de documentos a ser analisado pode ser muito grande. Para esses casos, quatro diretrizes propostas por Lee, Kang e Lee (2002) podem ser úteis:

- Analisar as terminologias usadas no domínio para identificar features: em domínios maduros e estáveis, especialistas de domínio normalmente utilizam a terminologia padrão para comunicar suas ideias, necessidades e problemas. A utilização desses termos padrões na identificação de features pode acelerar a comunicação entre os analistas do domínio e os fornecedores de informação (especialistas de domínio e usuários finais). Lee, Kang e Lee (2002) reportam que, segundo sua experiência, a análise de terminologias é uma forma eficiente e efetiva para identificar features.

- Categorizar as features: tentar categorizar as features. Iniciar a categorização em alto nível, por exemplo, com a utilização das categorias de sistema, hardware e software. Em 
seguida, pode-se refinar essa classificação, em uma classificação mais detalhada, como a proposta por Lee, Kang e Lee (2002): features de recursos, features de tecnologia do domínio, features de técnicas de implementação e features do ambiente operacional.

- Tentar encontrar primeiro as diferenças entre os produtos da linha, para só então tentar identificar as partes em comum: Produtos de uma mesma linha de produtos compartilham um alto grau de comonalidades, portanto o "espaço em comum" deve ser maior do que o "espaço das diferenças" (LEE; KANG; LEE, 2002), portanto, é mais fácil encontrar as diferenças primeiro. A estratégia é, inicialmente, identificar as aplicações existentes, e listar as features que caracterizam cada uma. Encontradas as diferenças, é mais fácil identificar as features comuns. É um exercício semelhante ao que foi executado para elaborar o documento de requisitos.

- Não identificar todos os detalhes de implementação que não se distinguem entre os produtos de um domínio: desenvolvedores talentosos tendem a listar todos os detalhes de implementação e identificá-los como features, mesmo que não haja variações entre eles. Mas é importante notar que um modelo de features não é um modelo de requisitos, que expressa os detalhes de funções internas. Embora o modelo de requisitos também seja usado como base para encontrar as features, deve-se ter o cuidado de não adicionar detalhes desnecessários.

Na Figura 25 ilustra-se uma parte do modelo de features da linha de produtos de VANTs. Observa-se que existem os níveis de abstração de software, hardware e sistema (não mostrado na figura). Também pode-se observar que existem dependências entre algumas features de software e hardware. Por exemplo, a feature de software referente a navegação autônoma depende da presença de um GPS.

Por fim, deve-se organizar o modelo de features de modo a ser o mais simples possível. Algumas diretrizes úteis para simplificar o modelo de features podem ser encontradas em Lee, Kang e Lee (2002). Embora a representação hierárquica seja a mais utilizada, observa-se que as features também podem ser representadas em forma de tabela.

\subsubsection{Modelagem de domínio}

Na modelagem de domínio executada durante a etapa de Engenharia de requisitos, são elaborados modelos de domínio que são mapeados pelos modelos de features identificados na atividade anterior.

Na Figura 26, apresenta-se os artefatos requeridos e providos pela execução da atividade de mapeamento de variabilidades que compõe esta etapa.

Atividade ER.5: Mapeamento de variabilidades em diagramas de requisitos 
Figura 25 - Parte do modelo de features da linha de produtos de VANT a nível de software e hardware.

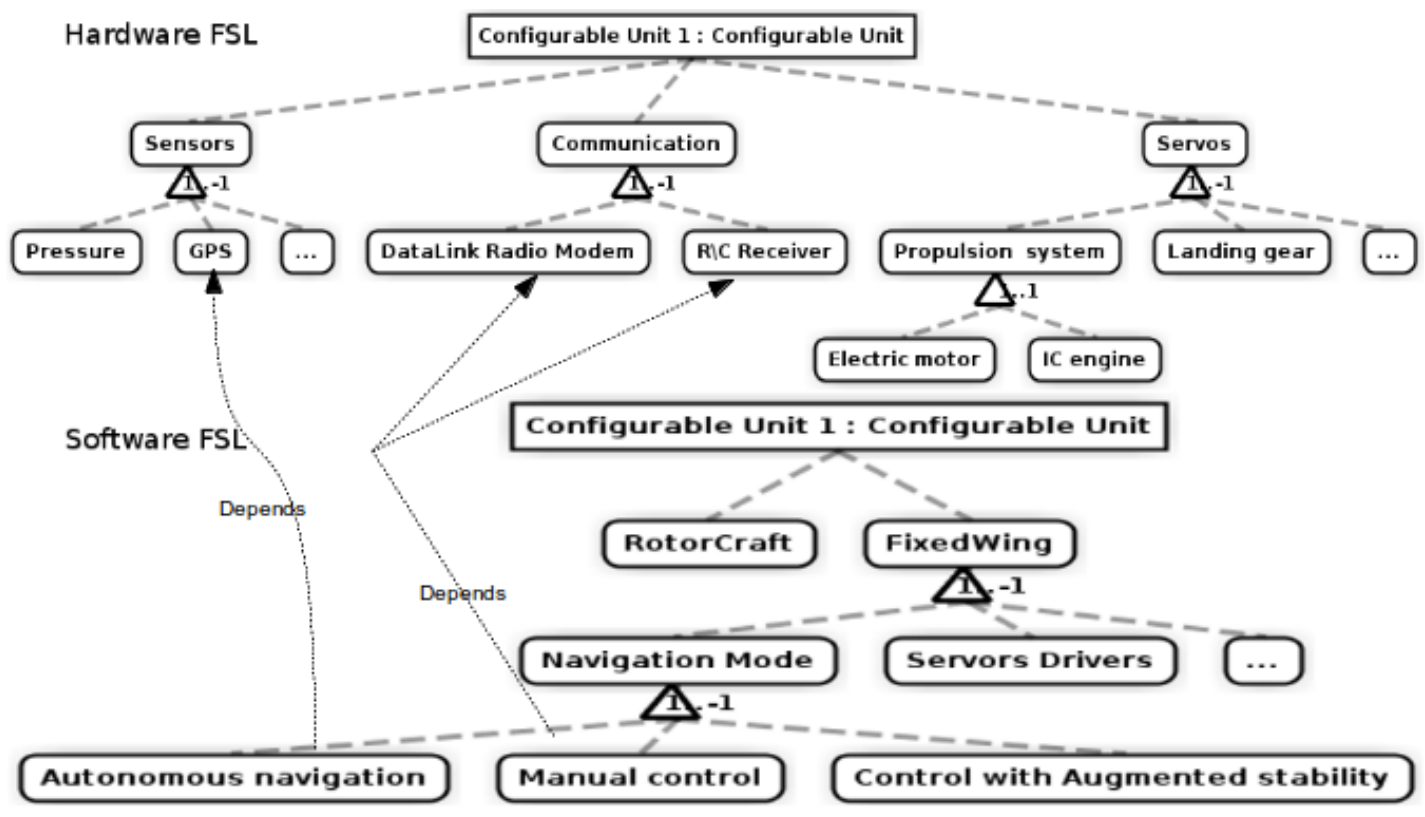

Entradas: AT.ER.2 Diagrama de requisitos, At.ER.4 Modelos de features

Saídas: AT.ER.5 Modelo de variabilidades para o diagrama de requisitos.

Objetivo: Mapear os requisitos para as features do domínio.

Descrição: Um fator importante da qualidade no projeto de sistemas é saber o que acontece com um requisito durante a modelagem do sistema e a especificação. Essa atividade é conhecida como rastreabilidade de requisitos. A rastreabilidade de requisitos é definida por Gotel e Finkelstein (1994) como: "a capacidade de descrever e seguir a vida de um requisito, tanto para frente quanto para trás, ou seja, desde as suas origens, através do seu desenvolvimento e especificação, para sua posterior implantação e uso, e por períodos de refinamento contínuo e iteração em qualquer uma dessas fases ". Basicamente, a rastreabilidade de requisitos ajuda na identificação das fontes, destinos e ligações entre os requisitos e os modelos criados durante o desenvolvimento do sistema.

Identificar e manter traços entre os requisitos é considerada uma das atividades mais importantes durante a engenharia de requisitos (SAHRAOUI, 2005). A rastreabilidade de requisitos é muito útil, por exemplo, para identificar como os requisitos são afetados pelas mudanças, qual é o propósito de um requisito e qual priorizar. A rastreabilidade também oferece a possibilidade de garantir que todos os requisitos sejam atendidos pelos componentes do sistema e sub-sistema (SOARES; VRANCKEN, 2007). Para a abordagem descrita nesta tese, a rastreabilidade dos requisitos também é um fator fundamental, pois é por meio dela que é possível definir uma forma automática de gerar produtos da linha. A maneira proposta por essa abordagem para gerenciar a rastrear os requisitos é por meio do uso CVL (HAUGEN; WaSOWSKI; CZARNECKI, 2012). Ela é aplicada ao diagrama de requisitos SysML, em conjunto com a tabela de requisitos definida 
Figura 26 - Relação de artefatos requeridos e providos pela atividade de mapeamento de variabilidades.

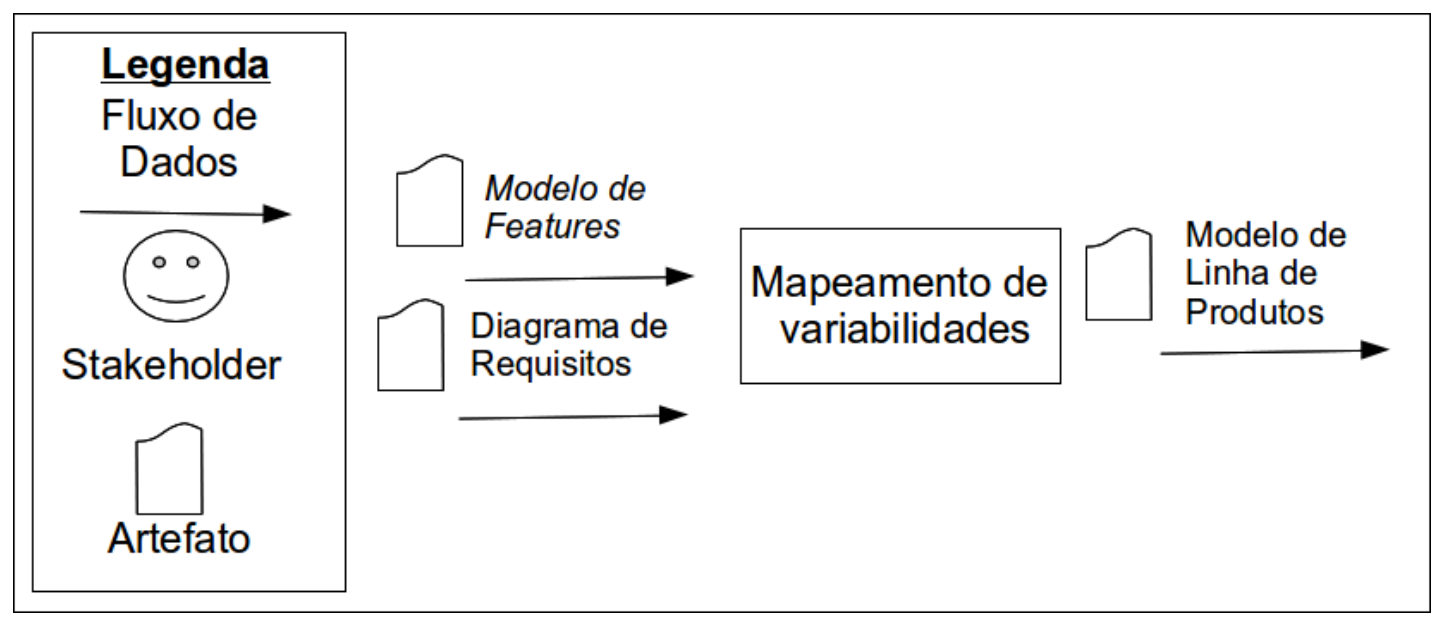

na atividade ER.3.

Conforme mencionado no início do capítulo, uma das desvantagens de métodos que utilizam modelos, tais como os de Lucrédio (2009), Gomaa (2004), Bayer et al. (1999), Eriksson, Börstler e Borg (2005), no desenvolvimento de Linhas de produtos é a carga extra (por exemplo, estereótipos, elementos de modelos adicionais, excesso de relações ou até casos de mudança e outros) que os modelos carregam desde o início do desenvolvimento, na elicitação de requisitos, passando por análise e definição de arquitetura, até a etapa de implementação. Para resolver esse problema, esta tese propõe a utilização de CVL aplicada ao diagrama de requisitos, sem a adição de cargas extras nos modelos subsequentes. Embora a utilização de CVL para modelagem de linhas de produtos já tenha sido explorada em trabalhos como os de Svendsen, A. et al. (Sep. 2010) e Bessling e Huhn (2012), esses autores a utilizam nos modelos que compreendem estágios avançados do desenvolvimento, tais como modelos de arquitetura, o que gera a necessidade da carga extra para gerenciar variabilidades em modelos de etapas anteriores.

A premissa é a de que os ativos centrais são desenvolvidos em separado, mesmo quando os modelos de uma linha de produtos carregam alguma carga extra do início ao fim do desenvolvimento. A utilização da técnica proposta nesta tese reduz a complexidade da Engenharia de Domínio, intercalando-a de forma controlada com atividades semelhantes as da Engenharia de aplicações. Para tanto, nesta atividade os requisitos são mapeados para as features por meio da utilização da CVL.

O processo de utilização da CVL consiste em:

1. definir um modelo base em qualquer linguagem que utilize o metamodelo MOF;

2. definir o modelo de Especificação de variabilidade (Vspec), que é equivalente ao modelo de features, com a diferença que o Vspec só contém as features variantes;

3. criar o modelo de variabilidade (também conhecido como CVL Model), que é o modelo da 
Tabela 1 - Tipos de variabilidades e seu significado

\begin{tabular}{|l|l|}
\hline Tipo de variabilidade & Significado \\
\hline Positiva & Funcionalidade é adicionada \\
\hline Negativa & Funcionalidade é removida \\
\hline Opcional & Código é incluído \\
\hline Alternatival & Código é substituído \\
\hline Função & Mudança nas funcionalidades \\
\hline PLataforma/Ambiente & Mudança na plataforma ou ambiente \\
\hline
\end{tabular}

linha de produtos e consiste do Vspec ligado ao modelo base por meio dos diferentes tipos de pontos de variação e restrições (quando necessárias);

4. criar o modelo de resolução, que consiste de escolhas para cada uma das features contidas no Vspec;

5. executar o motor CVL para realizar a materialização, ou seja, transformar um modelo de linha de produtos em modelo de produto.

Visto que o modelo CVL aponta para elementos do modelo base da LP e define a forma como esses elementos do modelo devem ser manipulados para produzir um novo modelo do produto, existem três tipos possíveis de substituições a serem aplicadas nos modelos base: substituição de valor, substituição de referência e substituição de fragmento. Uma substituição altera os elementos de modelo base chamados de titulares por elementos do modelo base conhecidos como substitutos (HAUGEN; WaSOWSKI; CZARNECKI, 2012).

O Modelo de Variabilidades e os Modelos de resolução são definidos em CVL, enquanto o modelo base e os modelos resolvidos podem ser definidos em qualquer linguagem baseada no MOF. Visto que a CVL substitui valores ou conjuntos de elementos do modelo, a sua execução pode remover ou substituir uma funcionalidade. Portanto, para a utilização da CVL, o especialista de domínio tem três opções para escolher seu modelo base: na primeira alternativa, o modelo base possui o número máximo de características incluídas, ou seja, é um modelo completo a partir do qual a CVL pode remover características ou realizar substituições para produzir um modelo específico; a segunda alternativa consiste de um modelo com o menor conjunto de características incluídas junto com um conjunto de fragmentos que podem ser adicionados de acordo com a escolha de outras características, ou seja, o modelo do produto é gerado por meio da adição de elementos ao modelo base; por fim, na terceira alternativa, é escolhido um modelo base com um número médio de características que pode ser, por exemplo, o modelo base mais próximo da maioria dos possíveis produtos da linha (Svendsen, A. et al., Sep. 2010).

Em resumo, os tipos de variabilidades e seu significado, segundo Gacek e Anastasopoules (2001) são apresentados na Tabela 4.7.1.3. 
Observa-se que, embora o resultado seja o mesmo, independentemente da escolha da estratégia, a abordagem proposta nesta tese recomenda a utilização de um modelo base com uma quantidade média de características, pois o modelo base utilizado é o diagrama de requisitos; é mais simples criar um diagrama de requisitos a partir do documento de requisitos de alguma das aplicações elaborado na primeira atividade desta etapa.

Algumas diretrizes para a utilização da CVL no modelo de requisitos podem ser úteis:

D1. Todos os requisitos obrigatórios fazem parte do modelo base, pois estarão presentes em todos os produtos da linha.

D2. Conforme solicitado na atividade ER.3, alguns requisitos variantes foram adicionados no modelo de requisitos com seus requisitos subordinados e outros ficaram "soltos" no modelo, sem qualquer relação. Além disso, o modelo de features foi elaborado na atividade ER.4. Portanto, recomenda-se iniciar a produção do modelo de variabilidades pela aplicação dos pontos de variação do tipo existência. Ou seja, inicia-se pela definição das ligação das features opcionais com os elementos do modelo de requisitos que estão diretamente relacionados com ela.

D3. A seguir, recomenda-se adicionar ao modelo de variabilidades os pontos de variação do tipo substituição, que representam features alternativas. Algumas já foram adicionadas na atividade de criação do modelo por estarem presentes na maioria dos produtos. Iniciar pelas substituições simples de elementos do modelo e ligações. Após finalizar todas as substituições simples, deve-se adicionar as substituições de fragmentos.

D4. Visto que os pontos de variação de existência e substituição representam a maioria dos pontos de variação em linhas de produtos, após a sua definição no modelo de variabilidades, pode-se adicionar os outros tipos de pontos de variação.

D5. Por fim, deve-se atualizar a tabela de requisitos e adicionar uma coluna de features para relacionar as features ao requisitos.

Na Figura 27 ilustra-se um exemplo de modelo base do tipo completo, a partir do qual somente variabilidades negativas podem ser derivadas.

$\mathrm{Na}$ Figura 28 ilustra-se um exemplo de modelo de linha de produtos aplicado ao modelo base ilustrado na Figura 27. Nele observa-se a modelagem dos pontos de variação do tipo existência.

\subsubsection{Priorização de requisitos}

Na Figura 29, apresenta-se a visão geral dos artefatos de entrada e saída da única atividade que compõe a etapa de priorização de requisitos. Os detalhes da atividade são apresentados a seguir. 
Figura 27 - Exemplo de modelo base completo (LP de VANTs).

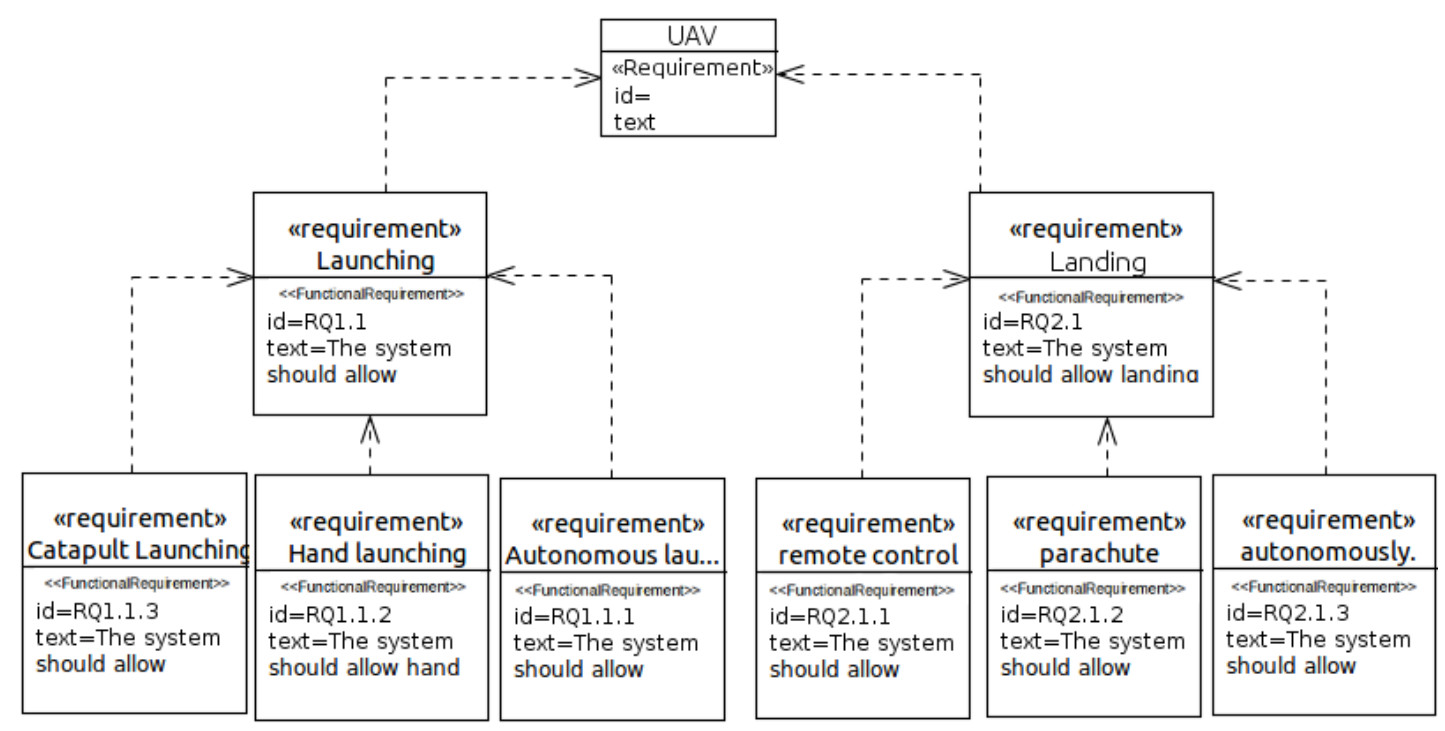

Papéis: Especialista do domínio

Entradas: AT.ER.4 Modelo de features, AT.ER.5 Modelo de variabilidade do diagrama de requisitos.

Saídas: AT.ER.6 Diagrama de requisitos com os requisitos priorizados

Objetivo: criar um modelo de resolução e aplicá-lo ao modelo de variabilidade definido para o diagrama de requisitos

Descrição: Até agora, foi definido um modelo de variabilidade sobre um modelo de requisitos base em SysML, que juntos representam um modelo de linha de produtos. Para derivar um produto de uma linha de produtos deve-se fornecer um modelo de resolução, que resolve as Vspecs em um modelo de variabilidades. Embora a maioria das variabilidades possam ser resolvidas com simples respostas do tipo sim ou não, existem algumas que requerem outros tipos de resolução, tais como valores de parâmetros.

Uma vez que o modelo de resolução é definido, o modelo de linha de produtos é transformado em um modelo de produtos pela aplicação dos pontos de variação da forma que foram descritos no modelo de resolução. Esse processo é chamado de materialização. Observa-se que um ponto de variação é uma modificação aplicada ao modelo base durante o processo de transformação em um modelo de produto.

Um projeto, nem sempre, tem tempo, recursos ou orçamento suficiente para implementar todos os requisitos determinados pelos stakeholder (INOKI; KITAGAWA; HONIDEN, 2014), especialmente quando se trata de uma linha de produtos. O desenvolvimento de uma linha de produtos envolve um alto custo inicial para a preparação dos ativos centrais antes de se poder entregar alguma produto para os clientes. Para reduzir esse custo inicial e tentar entregar produtos da linha o mais rápido possível, os requisitos devem ser priorizados, selecionados e implementados de forma otimizada. 
Figura 28 - Exemplo de modelo CVL da linha de produtos de VANTs.

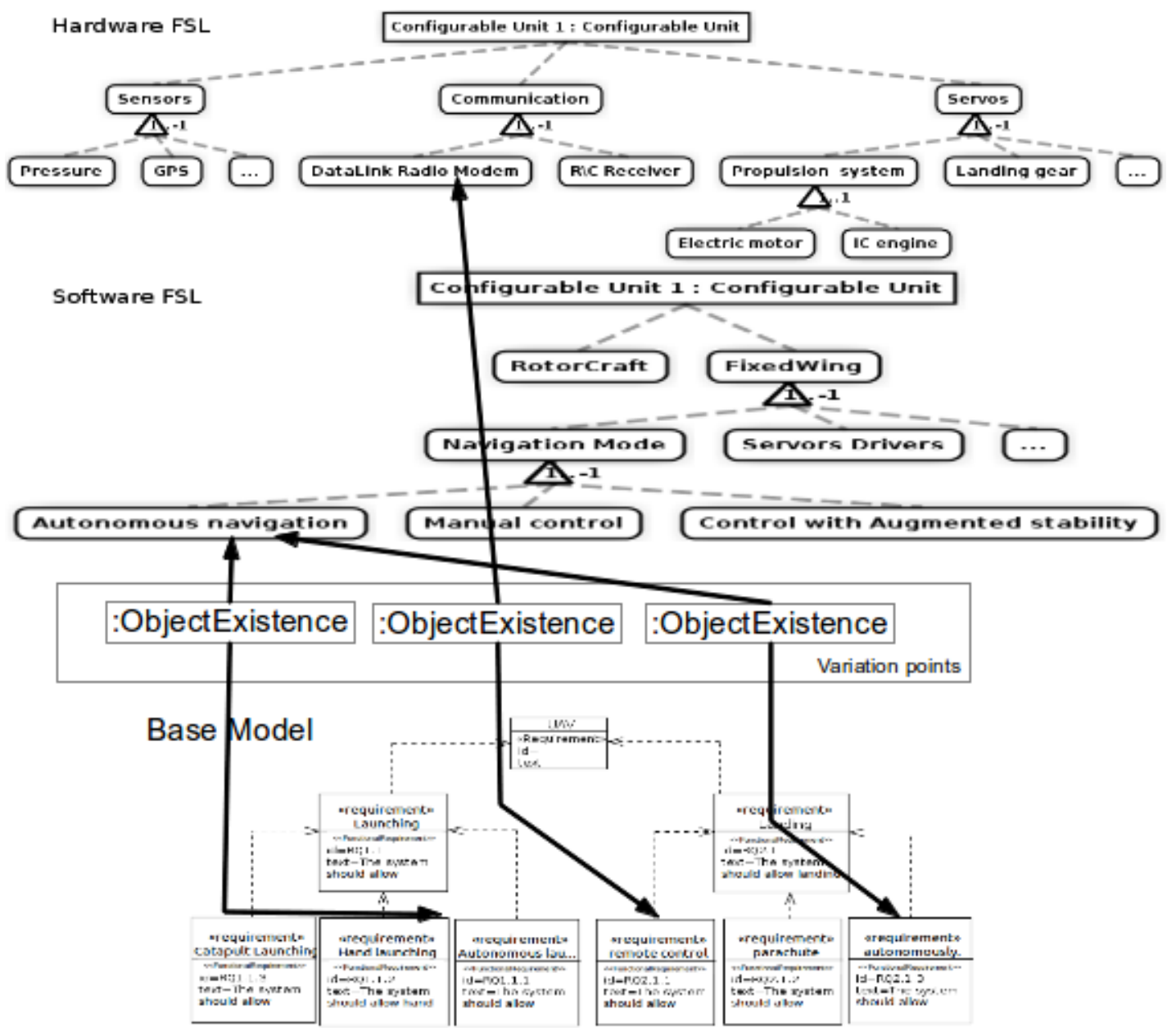

Figura 29 - Artefatos requeridos e providos pela etapa de priorização de requisitos.

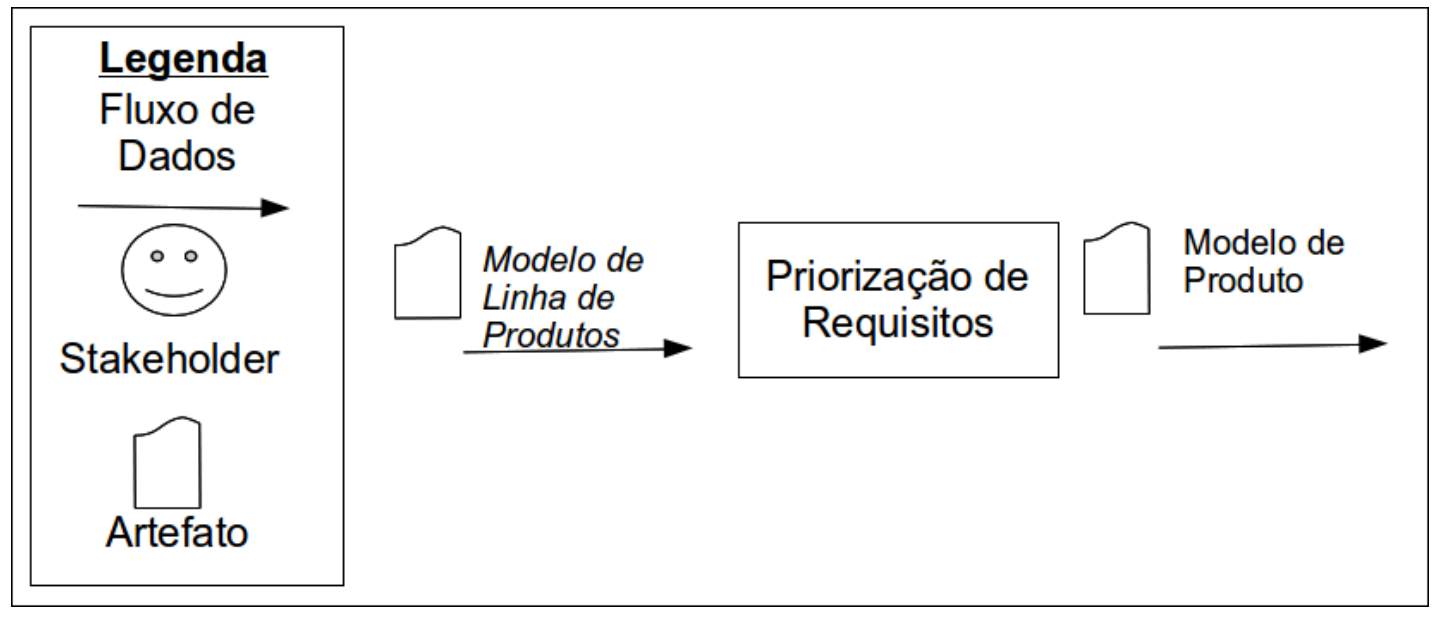

Como a abordagem proposta nesta tese é iterativa e incremental, a cada iteração são escolhidos incrementos de requisitos que são refinados, projetados e implementados nas fases subjacentes. A ideia é que na primeira iteração os requisitos comuns e alguns requisitos variantes sejam escolhidos para as próximas etapas de desenvolvimento. Em cada nova iteração, novos requisitos são selecionados em conjunto com os requisitos comuns. Embora os requisitos comuns 
sejam sempre "escolhidos", não existe um retrabalho nas fases seguintes, mas sim uma adaptação da arquitetura que envolve os requisitos comuns e um conjunto de variantes em cada iteração.

As diretrizes para a escolha dos requisitos em cada iteração são:

D1: selecionar os requisitos obrigatórios. Observa-se que, embora com o uso da CVL eles já sejam "selecionados" por padrão, essa diretriz é importante caso o usuário da abordagem escolha uma outra técnica para a gerência de features.

D2: montar uma tabela com a seguinte estrutura: identificador de um possível sistema alvo da linha na coluna um e os nomes ou identificadores das features da linha de produtos nas colunas seguintes. Escolher, a seguir, as características que fazem parte da maior quantidade de possíveis sistemas alvo. A quantidade de features escolhidas por vez depende do tempo desejado para a construção do incremento. O melhor caso é escolher uma quantidade de features suficiente para gerar algum produto ao final do ciclo de desenvolvimento, entretanto, dependendo do tamanho da linha e da sua quantidade de features, nem sempre isso e possível.

D3: selecionar as features escolhidas no Vspec e executar o motor de transformação da CVL, que retorna um modelo com os requisitos de um produto.

D4: criar um novo campo na tabela de requisitos indicando o número da iteração na qual o requisito foi escolhido.

De agora em diante, os modelos utilizados no desenvolvimento não precisam da carga extra de descrição de variabilidades, a arquitetura da linha vai ser construída de forma incremental, de tal modo que se tenha a arquitetura de, pelo menos, um produto em cada iteração.

Na Figura 30, ilustra-se um exemplo de seleção de features e na Figura 31, apresenta-se o resultado da execução do motor de transformação, ou seja, um modelo de produto.

\subsubsection{Análise}

Durante a análise, os requisitos da linha de produtos são refinados e os cenários do domínio que servem de base para a definição da arquitetura da linha são descritos. Além disso, os requisitos passam por uma validação/verificação e pela análise de segurança, que visa identificar os perigos e modos de falhas dos sistemas da linha. Enquanto a atividade de escopo tinha o enfoque na definição dos produtos da linha, esta etapa se preocupa com a estrutura interna do domínio (LUCRÉDIO, 2009). Na Figura 32, são apresentados os artefatos e relacionamentos entre as atividades que fazem parte desta etapa da Engenharia de Requisitos.

\section{Atividade ER.7: Modelagem de casos de uso}

Papéis: Analista de domínio

Entradas: AT.ER.4 Modelo de features, AT.ER.1 Documentos de requisitos, AT.ER.2 Diagrama de requisitos 
Figura 30 - Exemplo de resolução de variabilidades no modelo da linha de produtos de VANTs.

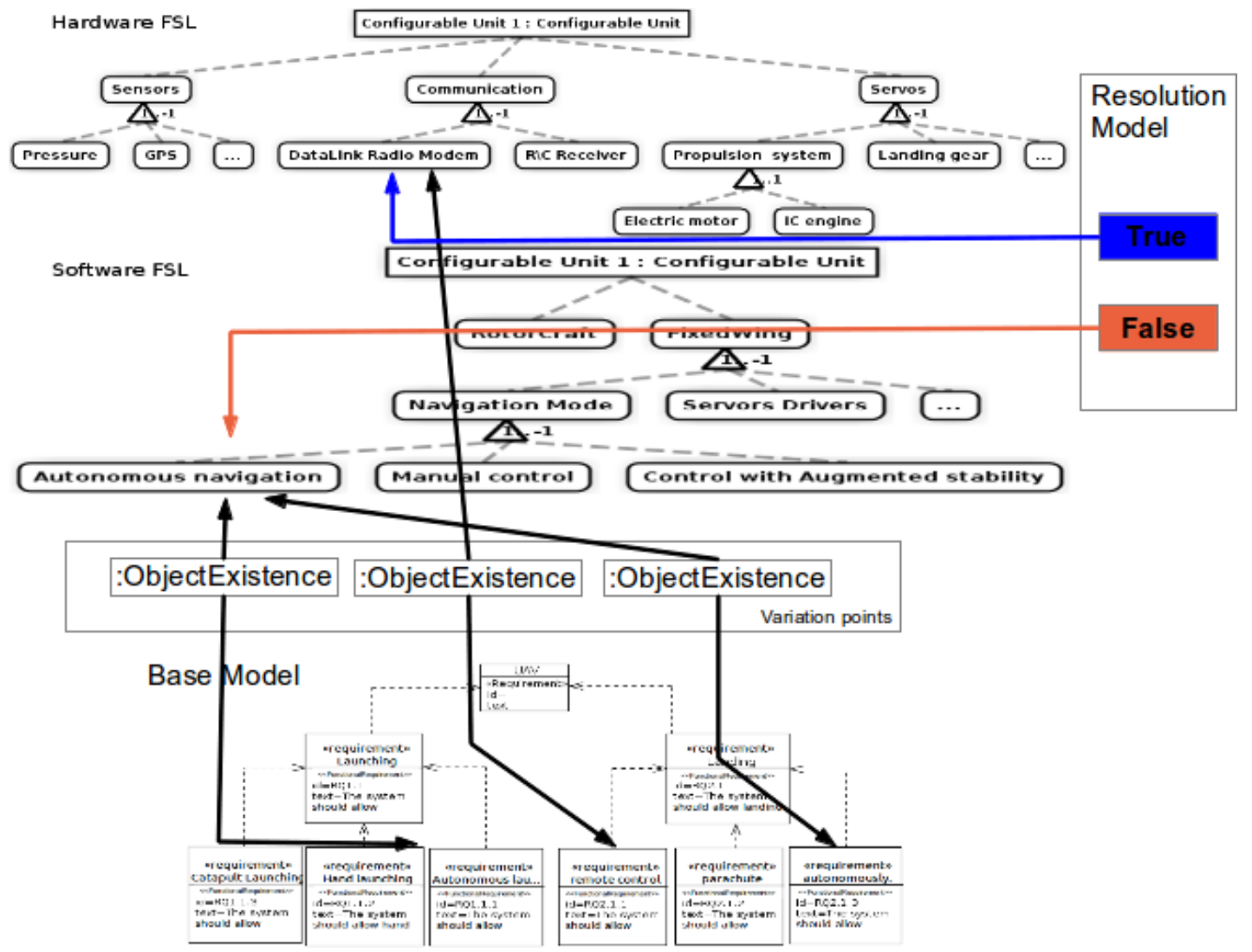

Figura 31 - Modelo de produto de VANT, como resultado da execução da CVL com uma configuração.

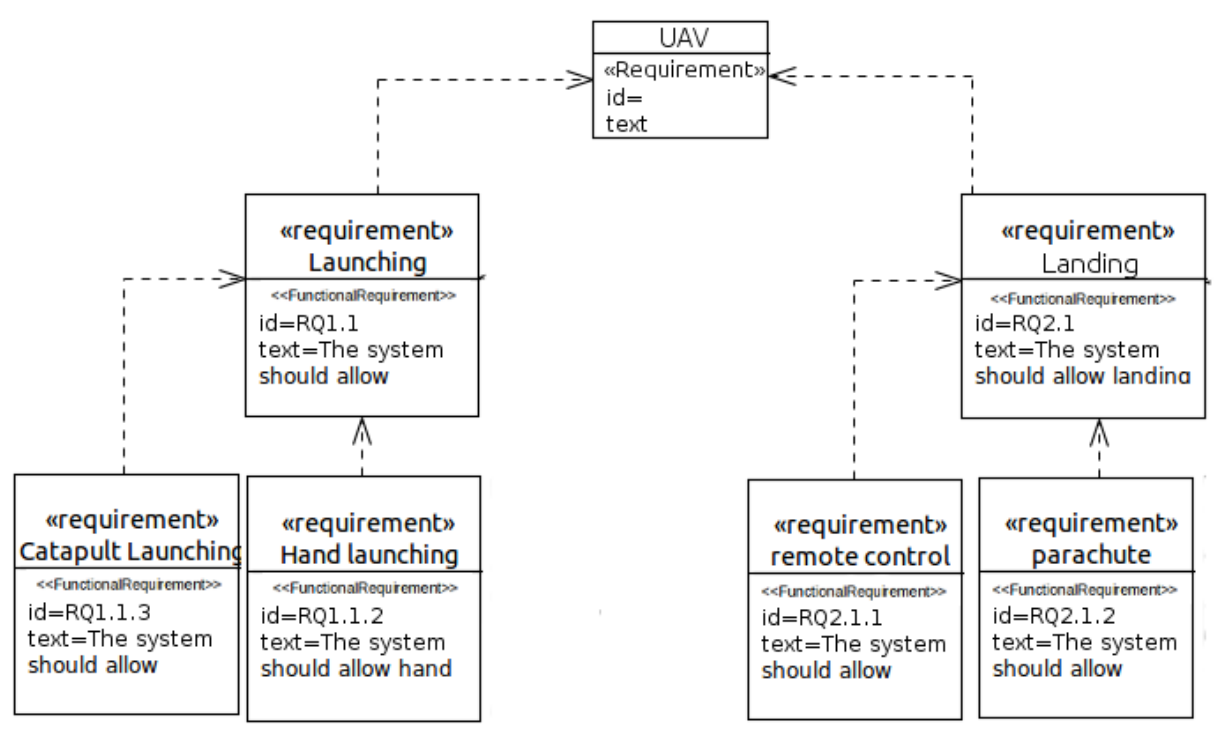

Saídas: AT.ER.7 Modelo de casos de usos, AT.ER.8 Descrição dos cenários

Objetivo: Refinar os requisitos da linha de produtos para que um bom projeto possa ser elaborado. Esse refinamento é feito por meio dos casos de uso,

Descrição: Diagramas de casos de uso (RUMBAUGH; JACOBSON; BOOCH, 2004; FOWLER; SCOTT, 1999) são parte da notação da UML e representam uma técnica poderosa na 
Figura 32 - Relação entre os artefatos e as atividades da etapa de análise.

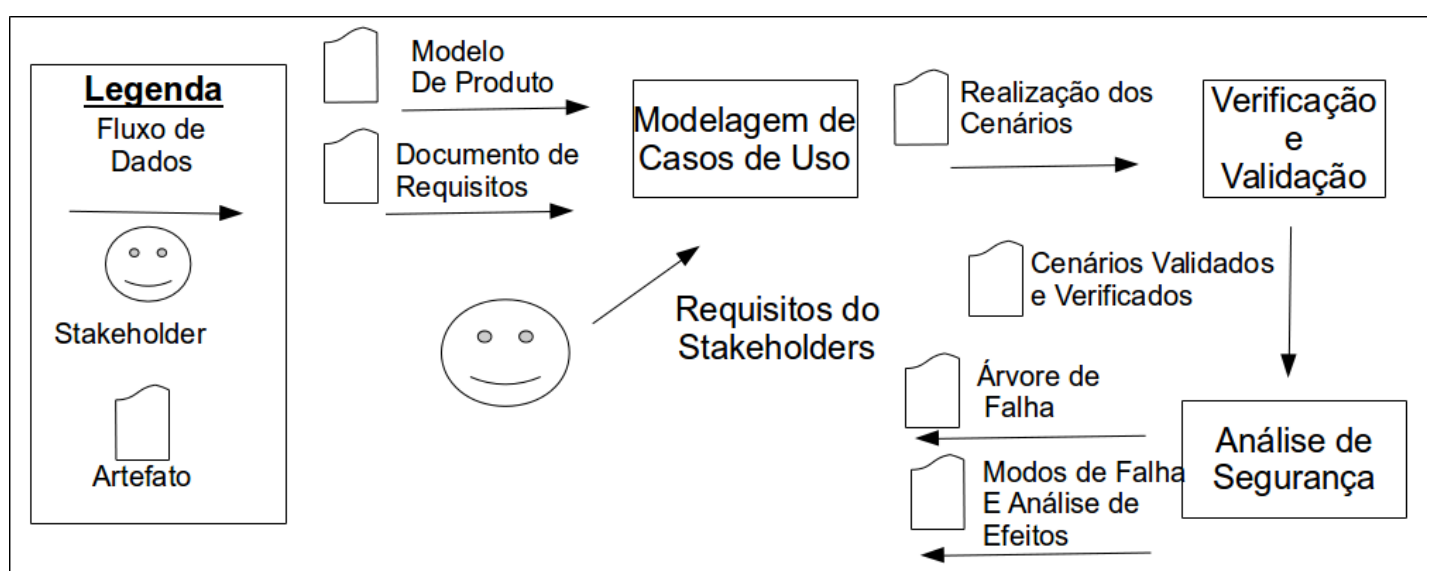

atividade de requisitos de sistemas únicos. Em LP eles também tem uma grande importância, pois representam o início do refinamento dos requisitos da linha. Além disso, embora a modelagem de features identifique os pontos de variabilidade, o impacto destas variabilidades nas funções (comportamento) realizadas pelos produtos do domínio não fica explícito nos diagramas de features (LUCRÉDIO, 2009). Portanto, necessita-se realizar o mapeamento entre a variabilidade no nível de features e os cenários que descrevem a funcionalidade, de forma que seja possível determinar as mudanças no comportamento do domínio. Para facilitar esta tarefa, trabalha-se com o subconjunto de requisitos definidos por meio da escolha de features feita na atividade de priorização de requisitos. Isso significa que o analista de domínio pode trabalhar, a cada iteração, de forma semelhante ao analista de sistemas únicos.

Cenários de uso (MAIDEN; ALEXANDER, 2004) são importantes para refinar os requisitos e entender as características da Linha de produtos (ALFÉREZ et al., 2014). Eles descrevem exemplos de como um ou mais atores (usuários, desenvolvedores, especialistas de domínio, organizações ou outros sistemas) interagem com o sistema por meio da descrição de passos (eventos ou ações) que ocorrem durante a interação (FOWLER; SCOTT, 1999). Cenários podem ser compostos de acordo com combinações específicas de características, e por conseguinte, eles são também úteis para especificar o comportamento dos sistemas alvo de uma PL (ERIKSSON; BöRSTLER; BORG, 2005).

O diagrama de casos de uso do SysML é derivado, sem extensões importantes, do diagrama de casos de uso da UML 2.0. A principal diferença é o enfoque mais amplo, uma vez que possui o objetivo de modelar sistemas complexos que envolvem não somente software, mas também outros sistemas, pessoal e hardware. A idéia é representar o que o sistema irá realizar, não como. Os diagramas são compostos por atores, casos de uso e seus relacionamentos. Existem quatro tipos de relacionamentos: comunicação, generalização, inclusão e extensão (Object Management Group, 2012).

A relação de comunicação é usada para associar os atores e casos de uso quando eles efetivamente participam do comportamento do caso de uso. A relação de generalização ocorre 
de ator para ator ou de caso de uso para caso de uso. A semântica da generalização é o mesma utilizada em outros diagramas, como o Diagrama de Classe da UML: o elemento filho herda todo o comportamento de seu pai, e pode adicionar um comportamento mais específico. A relação de inclusão fornece um mecanismo útil para modelar uma sequência de eventos que é comum a mais de um caso de uso. Essas sequências de eventos podem ser encapsuladas em um caso de uso e ser reutilizadas por outros casos de uso. A execução do caso de uso base implica na execução dos casos de uso incluídos. A relação de extensão fornece uma funcionalidade opcional, que estende o caso de uso base em pontos de extensão definidos em condições específicas. Essa relação é útil quando um caso de uso é muito complexo, com muitas alternativas e sequências opcionais de interações. A solução é separar cada alternativa ou opção para o caso de uso base em um outro caso de uso, e relacioná-los usando a palavra-chave estender. O caso de uso base é independente dos estendidos que só podem ser executados se a condição no caso de uso base que faz com que eles sejam executados seja definida como verdadeira (SOARES; VRANCKEN, 2008).

A sequência detalhada de eventos em um caso de uso pode ser representada de diferentes maneiras. É comum se descrever a sequência de eventos em linguagem estruturada com base em um padrão pré-definido. Um exemplo é dado pelo metamodelo apresentado na Figura 33, em que o documento possui os seguintes campos: nome, os atores envolvidos, descrição, pré-condição, Pós-condição, fluxo básico, fluxo alternativos, passos. Considerando-se uma abordagem orientada a modelos, também é possível especificar o comportamento dos caso de usos por diagramas de atividades (ALMENDROS-JIMÉNEZ; IRIBARNE, 2005), diagramas de sequência (ALMENDROS-JIMÉNEZ; IRIBARNE, 2007), redes de Petri, diagramas de estado, linguagens formais, pseudo-código, entre outros (COCKBURN, 2000). A escolha da técnica depende da natureza do comportamento do caso de uso, bem como da intenção do leitor. Uma combinação de técnicas também podem ser utilizadas, de modo que a melhor maneira possa ser apresentada para cada stakeholder.

A relação SysML refinar pode ser usada para relacionar os requisitos com outros modelos SysML. Por exemplo, os requisitos podem ser associados pela relação refinar aos casos de uso, o que significa que os requisitos podem ser representados pelo caso de uso. Dessa forma, se mantém a rastreabilidade entre os requisitos e os casos de uso, conforme ilustra-se na Figura 34.

Entre os possíveis modelos para especificar o comportamento dos casos de uso, nesta atividade, é proposta a utilização do diagrama de atividades, pelos motivos apresentados em Bornia (2005) e resumidos a seguir:

- segundo Armour e Miller (2001), os diagramas de atividades são uma notação mais clara para a representação de paralelismos, elementos de lógica condicional e sincronização do que os diagramas de sequência e diagramas de estado. Além disso, apoiam a decomposição hierárquica por meio do uso de sub-diagramas; 
Figura 33 - Metamodelo da descrição textual de casos de uso.

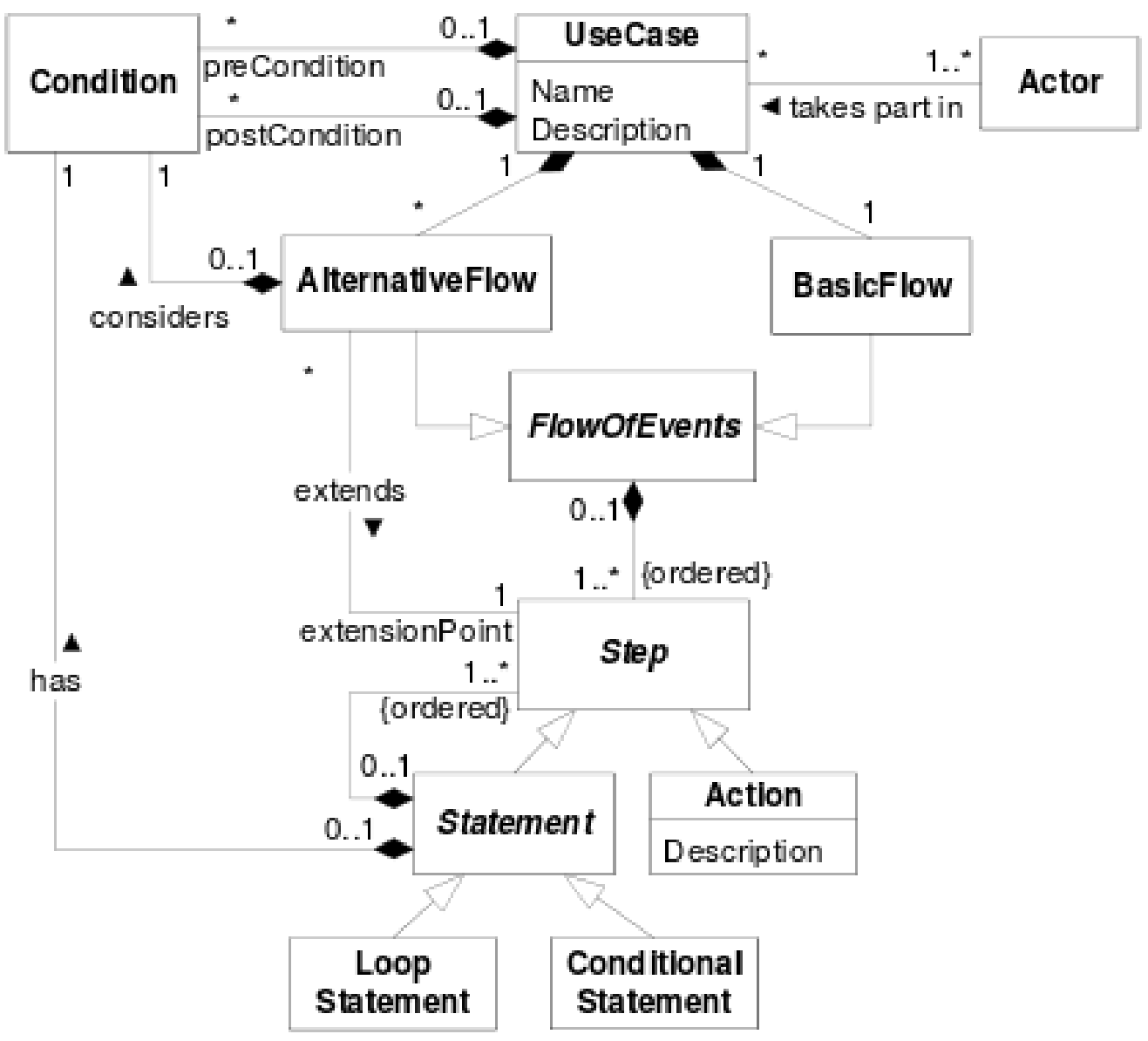

Fonte: Siqueira e Silva (2011)

Figura 34 - Uso da relação refinar para manter a rastreabilidade dos requisitos para os casos de uso.

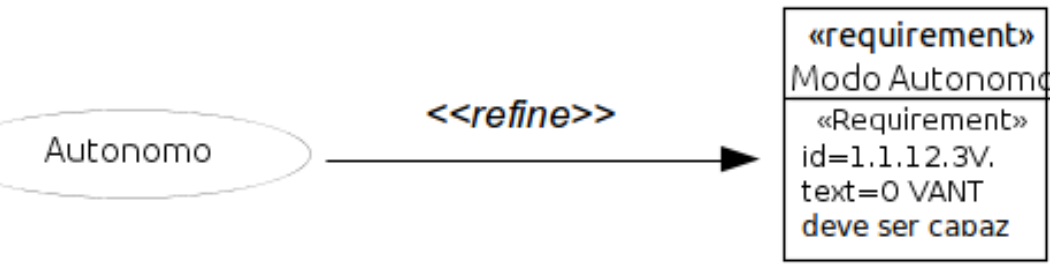

- possuem características que permitem a formalização dos fluxos de descrição de um casos de uso por meio de semânticas formais (ESHUIS; WIERINGA, 2001);

- podem ser verificados por meio de ferramentas de verificação formal (ESHUIS; WIERINGA, 2004);

- favorecem a geração de casos de teste a partir dos fluxos definidos (LINZHANG et al., 2004)

- possuem propriedades que permitem a descrição de Workflows (DUMAS; HOFSTEDE, 
2001).

Figura 35 - Metamodelo do diagrama de atividades da UML.

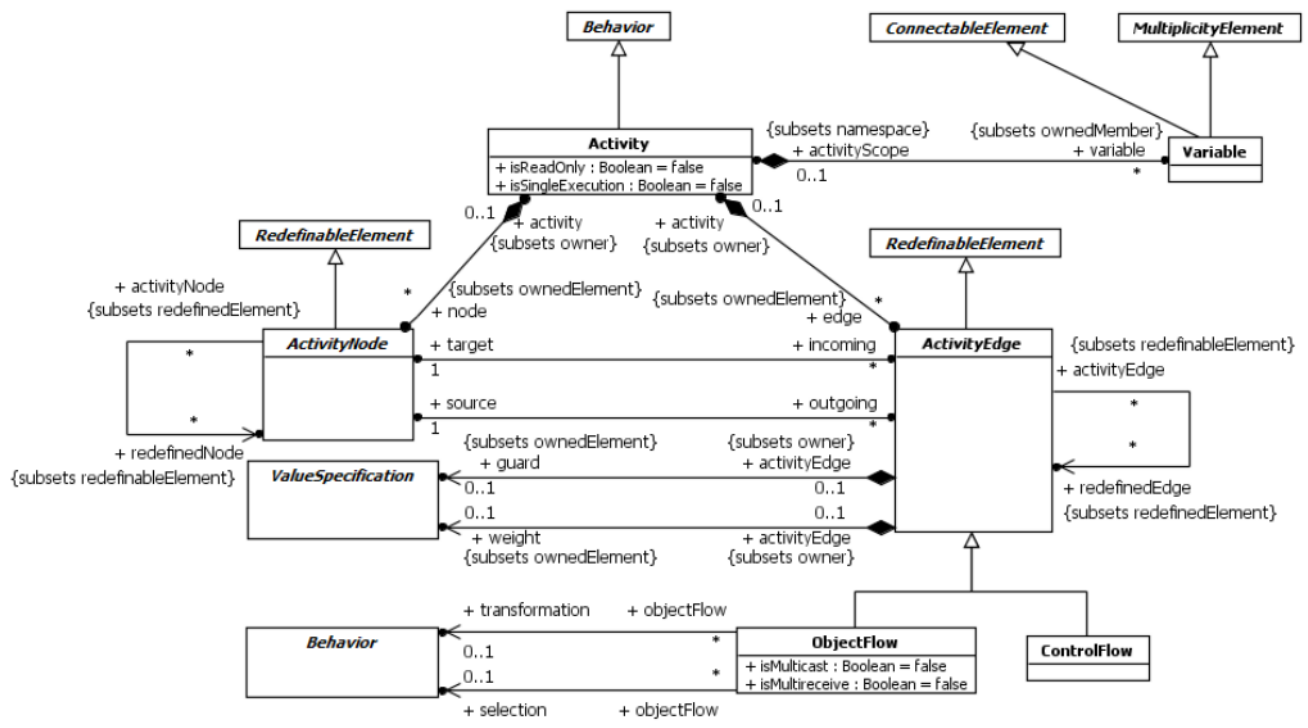

Fonte: OMG (2011c)

Em Bornia (2005), apresenta-se em detalhes o algoritmo de transformação de uma descrição textual de casos de uso em um diagrama de atividades. Além disso, o autor descreve a implementação de uma ferramenta que automatiza esse processo e pode ser utilizada nesta atividade de desenvolvimento da abordagem proposta. Observa-se que são elaborados um diagrama de atividade para cada cenário de uso. Portanto, cenários comuns que possuem pontos de extensão, serão alterados em cada iteração da abordagem.

Em resumo, pode-se seguir o metamodelo do diagrama de atividades apresentado por meio da Figura 35.

\section{Atividade ER.8: Verificação e validação dos requisitos}

Papéis: Especialista do domínio

Entradas: AT.ER.7 Modelo de caso de usos AT.ER.8 Descrição dos cenários

Saídas: AT.ER.7 Validado.modelo de caso de usos, AT.ER.8 Validado.descrição dos cenários

Objetivo: Realizar verificação formal por meio de validadores de modelos nos diagramas de atividades

Descrição: Muito do esforço de construção de sistemas complexos consiste no entendimento, especificação, e validação dos requisitos do sistema. Para SCES, erros de requisitos representam uma importante fonte de problemas de desenvolvimento (FAULK, 2001). As abordagens de desenvolvimento orientadas a modelos aumentam a importância dos modelos ao 
longo do desenvolvimento, por isso, sua verificação e validação se transforma em uma tarefa fundamental no domínio de SCES.

Segundo Braga et al. (2012), a verificação busca ter certeza de que um modelo tem propriedades gerais, tais como: "consistência (BRAGA; HæUSLER, 2010), o que garante que as propriedades de um modelo são satisfeitas e, portanto, ele pode ser instanciado; ou, temporais (CLARKE JR.; GRUMBERG; PELED, 1999), que são aquelas relacionadas com os aspectos comportamentais de um modelo. A validação procura aferir que um conjunto de invariantes (WARMER; KLEPPE, 2003) realize um cenário ou modelo específico, tais como examinar a presença de ciclos em uma hierarquia de classes em um diagrama de classes qualquer que seja uma instância do metamodelo UML."

As técnicas de verificação e validação também podem ser aplicadas em transformações de modelos, visto que em abordagens orientadas a modelos, a especificação de uma transformação também é um modelo, chamado modelo de transformação em (BÉZIVIN et al., 2006). Para realizar a validação e a verificação os diagramas de atividades criados na atividade anterior, propõe-se a utilização de verificadores de modelos, tais como: FDR (XU; MIAO; PHILBERT, 2009), SPIN (HOLZMANN, 2003) UPPAAL (BEHRMANN; DAVID; LARSEN, 2004) e outros.

\section{Atividade ER.9: Análise de Segurança}

Papéis: Analista de segurança

Entradas: AT.ER.4 Modelo de features, AT.ER.1 Documentos de requisitos, AT.ER.2 Diagrama de requisitos

Saídas: AT.ER.9 Análise de causa consequência dedutiva

Objetivo: determinar como modos de falhas a nível de componente causalmente se relacionam com os perigos do sistema.

Descrição: A análise de segurança (safety analysis) é uma atividade fundamental em qualquer processo de desenvolvimento de linha de produtos de sistemas críticos e pode ser realizada por meio de atividades como análise de perigos, de riscos ou causas (OLIVEIRA et al., 2014). Essas atividades fornecem uma avaliação de segurança preliminar para a arquitetura da linha de produtos por meio de técnicas como análise de árvores de falha (FTA, do inglês Fault Tree Analysis) e Modo de falha e análise de efeito (FMEA, do inglês Failure Mode and Effect Analysis) (COMMISSION, 2006). Essas técnicas fornecem a informações causais sobre o impacto de falhas nos elementos de projeto em caso de ocorrência de perigos, e alocação de requisitos de segurança necessários para minimizar os efeitos de perigos (OLIVEIRA et al., 2014)

Entretanto, é importante notar que segurança é uma propriedade de sistemas únicos, não de um conjunto de sistemas. Assim, qualquer análise de segurança feita durante a engenharia de domínio no início da linha de produtos deve ser reavaliada, ajustado, e concluída durante 
engenharia de aplicação (FENG; LUTZ, 2005).

Entre as várias técnicas formalmente fundamentadas para a realização dessa tarefa, Bessling e Huhn (2012) propõem a utilização da análise causa consequência dedutiva (DCCA, do inglês Deductive Cause Consequence Analysis) (ORTMEIER; REIF; SCHELLHORN, 2005; GüDEMANN; ORTMEIER; REIF, 2007), pois formaliza técnicas como Fault Tree Analysis (FTA) e Failure Mode and Effect Analysis (FMEA) (COMMISSION, 2006), que são técnicas estabelecidas e recomendadas pelas principais normas técnicas (BESSLING; HUHN, 2012).

Além disso, os modos de falha e perigos identificados podem ser reutilizados em atividades de garantia de segurança para verificar formalmente que foram tomadas medidas suficientes para evitar os perigos identificados (para mais detalhes e formalizações ver Güdemann, Ortmeier e Reif (2007) e Daskaya, Huhn e Milius (2011). Observa-se que as atividades de análise de segurança podem ser feitas em paralelo com o desenvolvimento da LP.

Para minimizar esse retrabalho, técnicas orientadas a modelos, tais como a proposta por Oliveira et al. (2014), podem se encaixar nesta atividade da abordagem proposta nesta tese. A ideia é combinar ferramentas de análise de segurança orientada a modelos com ferramentas de gerência de variabilidades que estabelecem um mapeamento entre elementos de modelo por meio de expressões de features e suas regras de transformação (OLIVEIRA et al., 2014), de forma semelhante como foi proposto nesta tese com o diagrama de requisitos e a CVL. Dessa forma, pode-se gerar fault trees e FMEA para os diversos produtos da linha. Em (OLIVEIRA et al., 2014) encontram-se todos os detalhes dessa técnica. Observa-se que o aprofundamento em questões de análise de segurança estão fora do escopo desta tese.

\subsubsection{Identificação e análise de sub-domínios}

A etapa de identificação e análise de subdomínios é realizada por meio das atividades de identificação de subdomínios, identificação de linguagens de modelagem e identificação de ferramentas. Os artefatos requeridos e providos pelas atividades desta etapa são apresentados na Figura 36.

\section{Atividade ER.10: Identificação de sub-domínios}

Papéis: Especialista de domínio

Entradas: AT.ER.4 Modelo de features, AT.ER.1 Documentos de requisitos, AT.ER.2 Diagrama de requisitos

Saídas: AT.ER.10 Lista de subdomínios identificados

Objetivo: reduzir os esforços do desenvolvimento, encontrando subdomínios menos complexos

Descrição: 
Figura 36 - Relação entre os artefatos e atividades da etapa de identificação e análise de subdomínios.

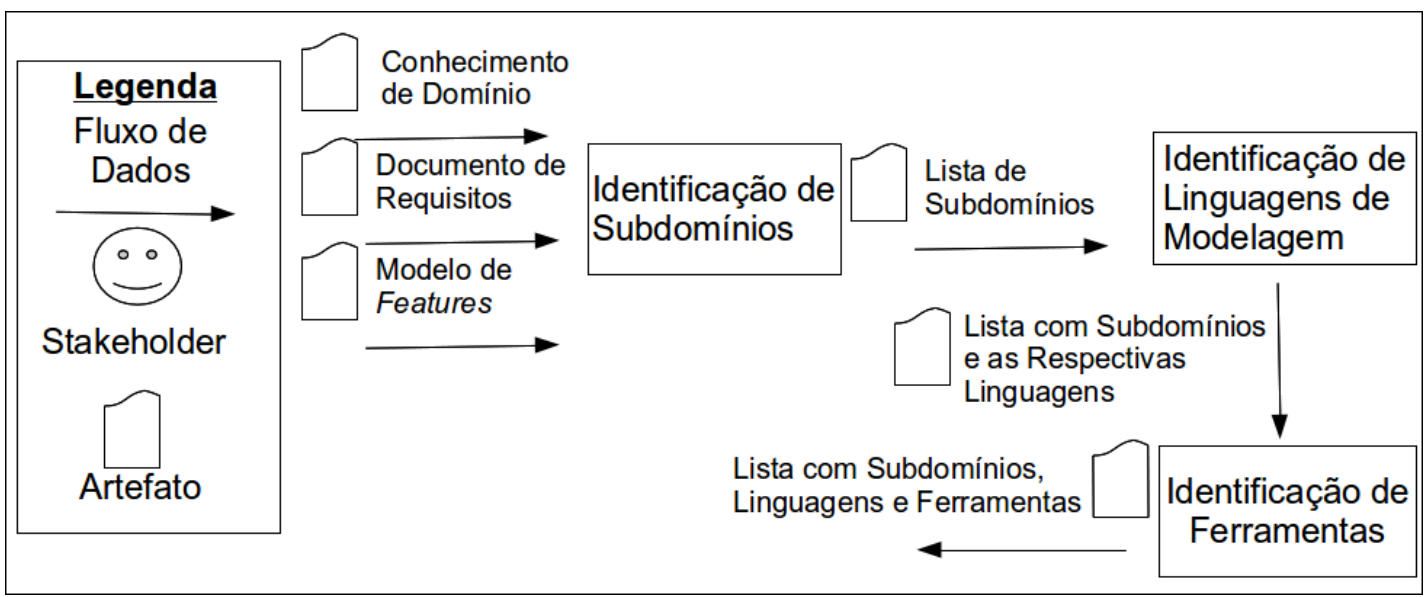

Muitos dos sistemas embarcados críticos pertencem a domínios grandes e com alto grau de complexidade, o que dificulta a tarefa de especificar seu comportamento por completo (HADDAD; TESSER, 2002). Essa complexidade também reduz a reusabilidade dos artefatos do domínio, uma vez que o escopo exato dos seus elementos e seus relacionamentos é difícil de compreender e gerenciar. Por esses motivos, existe a idéia de que um domínio deve ser decomposto para facilitar o processo de desenvolvimento para reutilização (JARZABEK, 1997).

Além disso, segundo (LUCRÉDIO, 2009), grandes sistemas dificilmente podem ser automatizados por um único gerador. Normalmente são necessários diferentes geradores trabalhando em conjunto para possibilitar a automação de um domínio completo. Por estes motivos, na engenharia de domínio com a utilização de técnicas do MDD, a identificação dos sub-domínios é uma tarefa crucial, pois permite ao engenheiro de domínio projetar e implementar ferramentas de modelagem, transformações e geradores específicos para os sub-domínios que possuem maior capacidade de automação, de forma mais controlável (LUCRÉDIO, 2009).

Por se tratar de SCES, a princípio já se pode esperar que sejam encontrados subdomínios de hardware e de software. Um exemplo de domínio complexo que possui vários subdomínios, é o domínio de veículos aéreos não tripulados que vem sendo discutido ao longo deste capítulo. Nesse domínio, pode-se destacar subdomínios de hardware tais como sensores, atuadores, infraestrura de rede, carga útil e outros. Além disso, também existem subdomínios de software tais como o controle de voo, controle de missão, o software da estação de solo e outros. Para cada subdomínio desses pode-se projetar e implementar ferramentas de modelagem, transformações e geradores específicos que possuem maior capacidade de automação.

Como o objetivo da tese não é reinventar técnicas estabelecidas, apresenta-se,a seguir, as diretrizes criadas por Lucrédio (2009) para a definição de subdomínios com algumas adaptações que são explicitadas ao longo da descrição das diretrizes. É importante observar que por meio da utilização da abordagem proposta nesta tese, a identificação de subdomínios também é feita de forma incremental. Em cada iteração, são encontrados os subdomínio das features escolhidas 
na atividade de priorização dos requisitos. Dessa forma, o analista responsável por esta tarefa, também pode ganhar experiência ao longo do processo de desenvolvimento.

- D1: Foco na simplificação da complexidade: Como os SCES apresentam grande complexidade de requisitos e restrições, qualquer possibilidade de subdividir essa complexidade deve ser aproveitada. Para Lucrédio (2009), o principal critério para decompor um domínio, no desenvolvimento orientado a modelos, é a sua possibilidade de ser automatizado, por meio de ferramentas de modelagem e transformações. Entretando, a experiência adquirida com o desenvolvimento das linhas de produtos para validação desta abordagem, mostrou que mesmo em casos que a automatização não é possível, essa simplificação compensa ao longo das próximas etapas de desenvolvimento;

- D2: Importância do especialista do domínio: muitos autores concordam que o conhecimento do especialista do domínio é extremamente valioso nesta atividade (JARZABEK, 1997; HADDAD; TESSER, 2002). Desta forma, a identificação de sub-domínios deve ser guiada por este profissional. Observa-se que a aplicação da abordagem proposta nesta tese, fornece subsídios para que os especialistas de domínio amadureçam ao longo do processo de desenvolvimento;

- D3: Dividir para conquistar: o conceito básico de divisão de um problema grande em partes menores é também útil no processo de desenvolvimento para reutilização. Diferentes técnicas podem ser utilizadas, dependendo do contexto. Segundo Lucrédio (2009), relacionamentos do tipo ÉParteDe e ÉUm podem ser utilizados como técnica de decomposição, na qual cada sub-domínio ou é parte de um sub-domínio maior, ou uma instância. Além disso, a divisão deve seguir a categorização natural do domínio, o que mais uma vez ressalta a importância do especialista nesta tarefa;

- D4: Relacionamentofeatures/sub-features: features são divididas em sub-features para ajudar na tarefa de compreensão do domínio e sua variabilidade. A análise desses relacionamentos (LEE; KANG; LEE, 2002) leva a uma sub-divisão natural do domínio.Features muito próximas são boas candidatas a pertencerem a um mesmo sub-domínio. Também deve-se dar atenção às features que aparentam estar separadas das demais, pois pode levar à identificação de um sub-domínio distinto;

- D5: Domínios atômicos: idealmente, o sub-domínio identificado deve ser atômico, ou seja, não pode ser substancialmente decomposto sem alterar suas propriedades primárias (HADDAD; TESSER, 2002). Isto é importante para manter o sub-domínio simples e gerenciável, e portanto mais fácil de automatizar;

- D6: Repetição: uma indicação a respeito do que pode ser automatizado é o nível de repetição que ocorre em um projeto, estrutura ou trecho de código. Se algum trecho de código aparece repetidas vezes em diferentes partes do produto, mesmo que não exatamente 
igual, é provável que uma máquina consiga fazer o trabalho de cópia parametrizada. Pode valer a pena tentar procurar um sub-domínio associado a este trecho. Outra técnica para encontrar repetições é a busca por padrões recorrentes (KNODEL et al., 2005); e

- D7: aumento incremental: Segundo Tolvanen e Kelly (2005), um aumento incremental do escopo é a melhor forma de se chegar ao tamanho ideal do sub-domínio, começandose com um escopo pequeno, desenvolvendo partes da linguagem e transformações, e incrementando-o sucessivamente.

Na Figura 37, ilustra-se a aplicação dessas diretrizes para encontrar subdomínios em um subdomínio da linha de produtos de VANTs.

Figura 37 - Subdomínios da linha de produtos de VANTs.

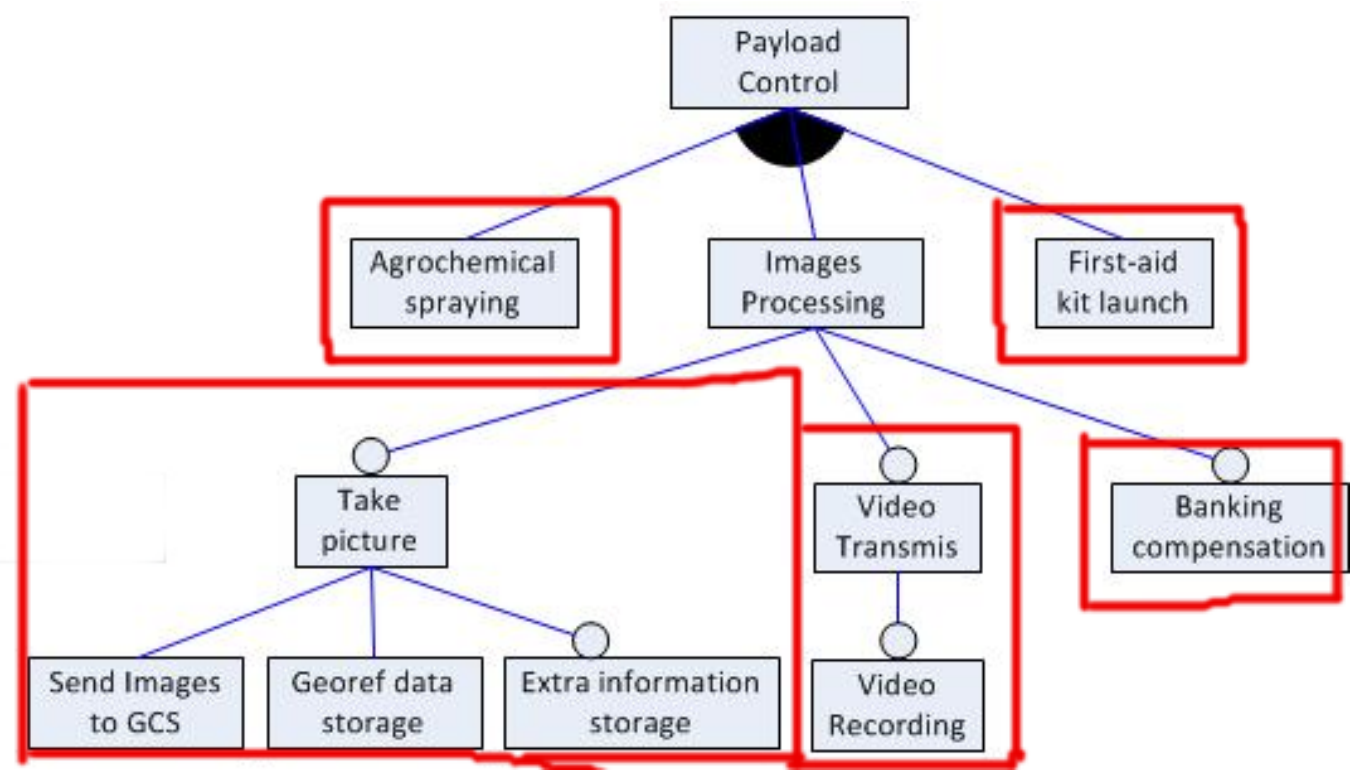

\section{AD.11. Identificação de linguagens de modelagem}

Papéis: Especialista de domínio

Entradas: AT.ER.4 Modelo de features, AT.ER.1 Documentos de requisitos, AT.ER.2 Diagrama de requisitos, AT.ER.10 Lista de subdomínios

Saídas: AT.ER.10 Lista de subdomínios atualizada com suas linguagens associadas

Objetivo: encontrar linguagens de modelagem existentes para os subdomínios identifica$\operatorname{dos}$

\section{Descrição:}

Os objetivos da identificação de sub-domínios são: possibilitar a definição de uma DSL que consiga representar a variabilidade não capturada nas features; simplificar e automatizar a construção dos ativos centrais da linha. Domínios mais maduros e desenvolvidos, podem já possuir linguagens em utilização, ou mesmo que, por algum motivo não possam ser diretamente 
utilizadas, essas linguagens podem oferecer pistas e informações importantes na definição de uma nova DSL (LUCRÉDIO, 2009).

Diretrizes úteis para identificação de linguagens podem ser extraídas de Lucrédio (2009) e são descritas a seguir:

- D1: Caso exista código-fonte disponível, há a possibilidade de existirem exemplos de modelos ou linguagens específicas para o domínio ou algum sub-domínio. Observa-se que modelos nem sempre possuem uma representação gráfica que segue alguma linguagem conhecida, tal como a UML, por exemplo.

- D2: Outras representações, tais como arquivos de configuração e modelos textuais, também devem ser consideradas.

- D3: O modelo de features também pode oferecer dicas sobre o que procurar. Palavras-chave presentes no modelo, tais como nomes de features, podem ocorrer dentro da documentação ou código-fonte.

Ao final desta atividade, cria-se uma lista com as linguagens identificadas, associando-as com os sub-domínios correspondentes. Caso seja encontrada alguma linguagem referente a um sub-domínio ainda não identificado, acrescenta-se esse novo subdomínio ao conjunto de subdomínios.

\section{AD.11. Identificação de ferramentas}

Papéis: Especialista de domínio

Entradas: AT.ER.4 Modelo de features, AT.ER.1 Documentos de requisitos, AT.ER.2 Diagrama de requisitos, AT.ER.10 Lista de subdomínios

Saídas: AT.ER.10 Lista de subdomínios com suas linguagens e ferramentas associadas

Objetivo: encontrar linguagens de modelagem e ferramentas específicas existentes para os subdomínios identificados

\section{Descrição:}

Assim como no caso das linguagens específicas de domínio, a existência de ferramentas de configuração ou modelagem, é um indício de maturidade do sub-domínio. Em domínios maduros, podem até existir geradores de código que podem ser reaproveitados.

Assim como em todas as atividades da engenharia de domínio, o conhecimento do especialista do domínio é essencial. Além disso, os manuais e documentação também devem ser consultados, uma vez que podem referenciar ferramentas usadas para criar modelos ou gerar partes da aplicação. O código-fonte também deve ser inspecionado, pois é comum a existência, no código gerado, de dados sobre a ferramenta que o gerou, data da geração, entre outras informações úteis (LUCRÉDIO, 2009). 
Ao final desta atividade, atualiza-se a lista com as linguagens identificadas, incluindo toda informação possível sobre as ferramentas encontradas, uma descrição de suas funcionalidades, os artefatos que podem ser gerados por ela e referências para fontes externas associando-as com os sub-domínios correspondentes. Caso seja encontrada alguma ferramenta referente a um sub-domínio ainda não identificado, acrescenta-se esse novo subdomínio ao conjunto de subdomínios.

\subsubsection{Definição de perfil UML para variabilidade}

A etapa de definição de perfil UML para variabilidade é realizada pela atividade de mesmo nome, cujo artefato requerido é o modelo de features e o artefato de saída é um perfil UML. Ilustra-se os artefatos requeridos e providos pela atividade na Figura 38.

Figura 38 - Visão geral dos artefatos requeridos e providos pela atividade de definição do perfil.

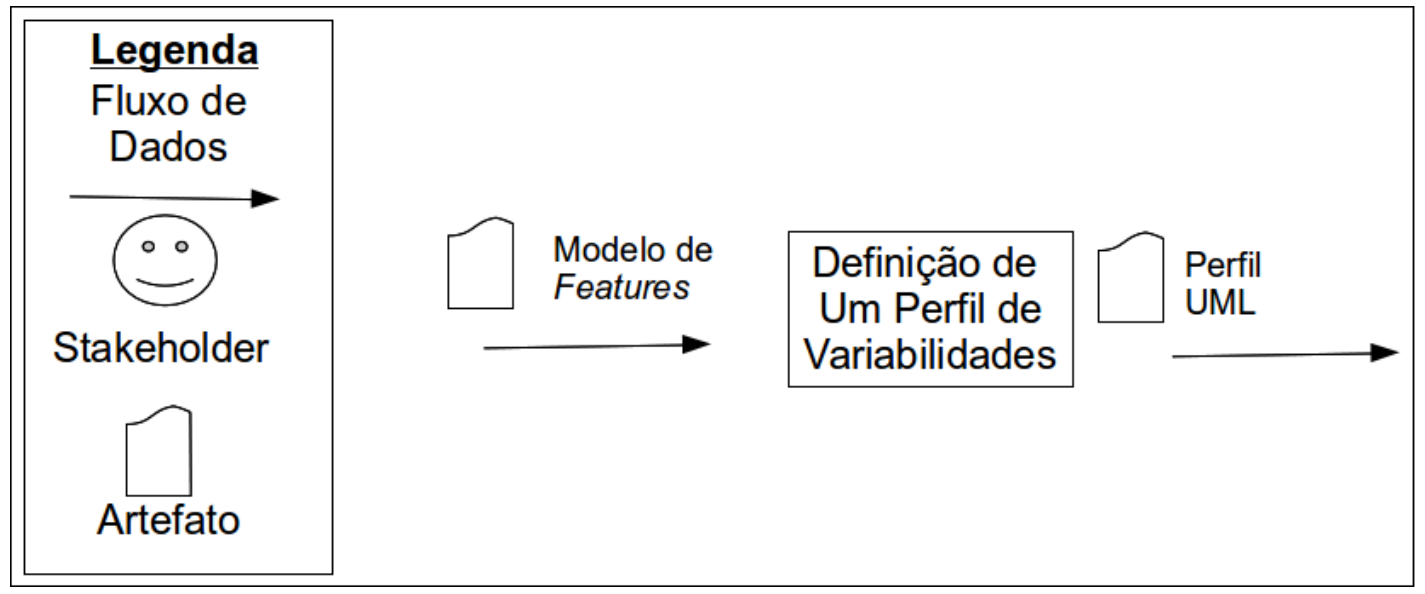

AD.13. Definição de um perfil de variabilidade

Papéis: Especialista de domínio

Entradas: AT.ER.4 Modelo de features, AT.ER.1 Documentos de requisitos, AT.ER.2 Diagrama de requisitos

Saídas: AT.ER.11 Perfil UML em forma de uma conjunto de estereótipo

Objetivo: fornecer um perfil UML para garantir a rastreabilidade das features de forma simples nos artefatos de projeto

\section{Descrição:}

Abordagens de desenvolvimento que utilizam a UML para expressar variabilidade, tais como proposto por (GOMAA, 2004), (LUCRÉDIO, 2009), (QUEIROZ, 2009) ou (JUNIOR; GIMENES; MALDONADO, 2010), utilizam-se de estereótipos genéricos, tais como $<<$ Mandatory $>>,<<$ Optional $>>,<<$ Alternative $>>$ e outros para modelar as variabilidades nos modelos de arquitetura. Entretanto, esses estereótipos não oferecem tantos benefícios, pois após a implementação, os produtos são configurados e montados com base nas suas features. 
Além disso, entre os requisitos, existem diversos opcionais, por exemplo, portanto a utilização do estereótipo $<<$ Optional $>>$, por exemplo, não ajuda em nada em relação à rastreabilidade do requisito, conforme pode-se observar na Figura 39. Em estágios mais avançados do desenvolvimento não se sabe qual feature ou requisitos está ligado com essa classe. Essa informação é muito importante, principal na etapa de implementação e configuração da linha de produtos.

Figura 39 - Exemplo de utilização dos estereótipos definidos por Gomaa (2004).

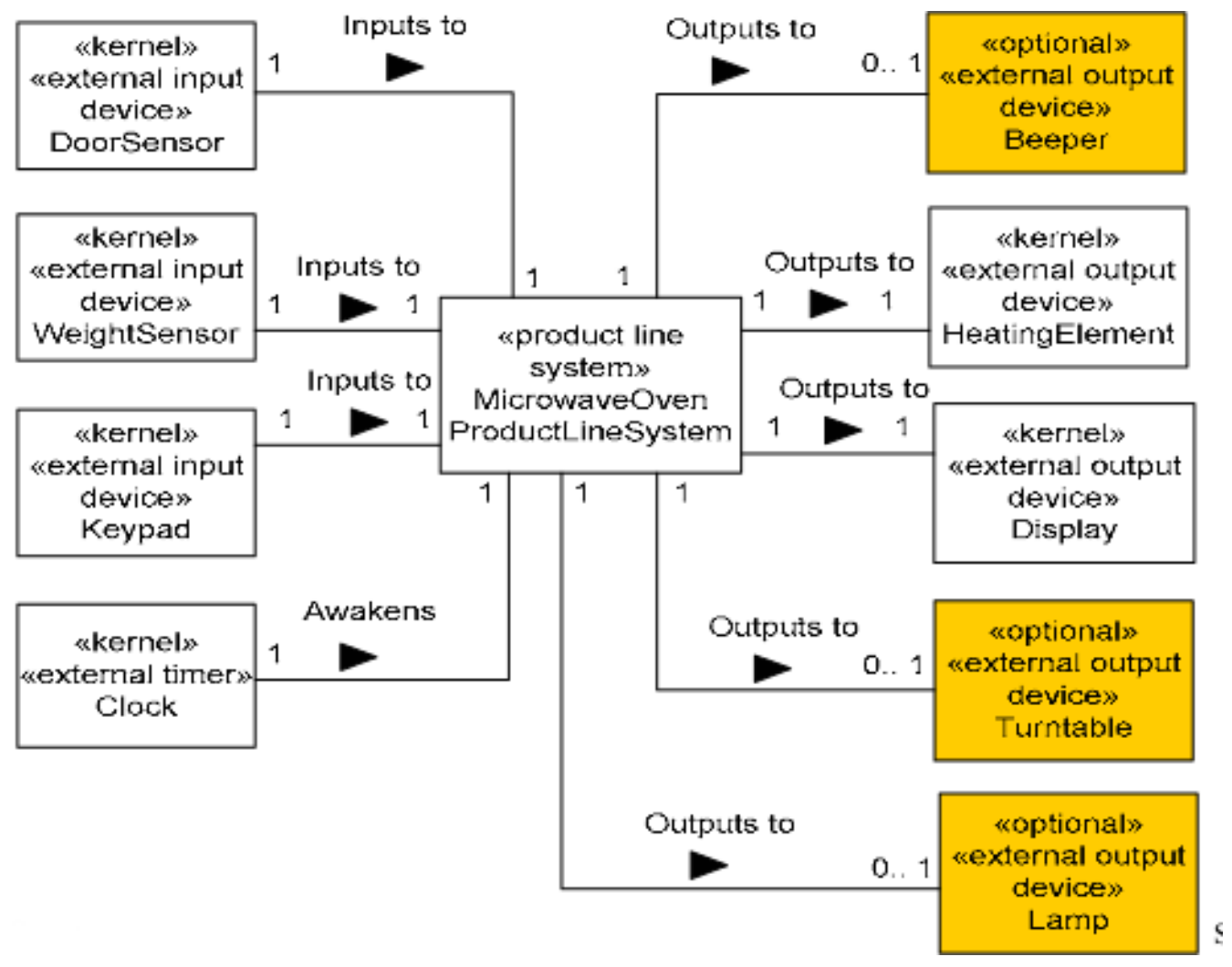

Fonte: Gomaa (2004)

Para garantir a rastreabilidade da fase de Engenharia de Requisitos de domínio para a Fase de projeto de domínio, por exemplo, são utilizadas tabelas (LUCRÉDIO, 2009) ou ferramentas como pure::variantes (Pure Systems, 2012). Entretanto, essas ferramentas são proprietárias e adicionam atividades extras ao desenvolvimento. Para simplificar essas atividades, esta tese propõe a criação de um perfil UML de variabilidades com base no modelo de features.

Para criar esse perfil, deve-se criar um estereótipo para cada feature do domínio, dessa forma, cria-se um perfil de variabilidade específico para cada linha de produtos. Esses estereótipos devem ser utilizados nos modelos de arquitetura e fornecem a ligação necessária entre os requisitos e o projeto, pois as features já são ligadas aos requisitos por meio da CVL. Na Figura 40, ilustra-se a definição de alguns esterótipos para a linha de produtos de VANT. Observa-se que são utilizadas features específicas de hardware, como por exemplo, flap e aileron que são aplicados na meta-classe device definida no perfil MARTE; assim como features específicas de software como navigation mode e telecontrol que podem ser aplicados na meta-classe class. No 
Capítulo 5 são apresentados exemplos de utilização desse perfil. Essa técnica é muito importante durante a etapa de implementação e configuração da linha, para facilitar a tarefa de geração automática de membros da linha.

Figura 40 - Parte dos estereótipos do perfil da linha de produtos de VANTs.

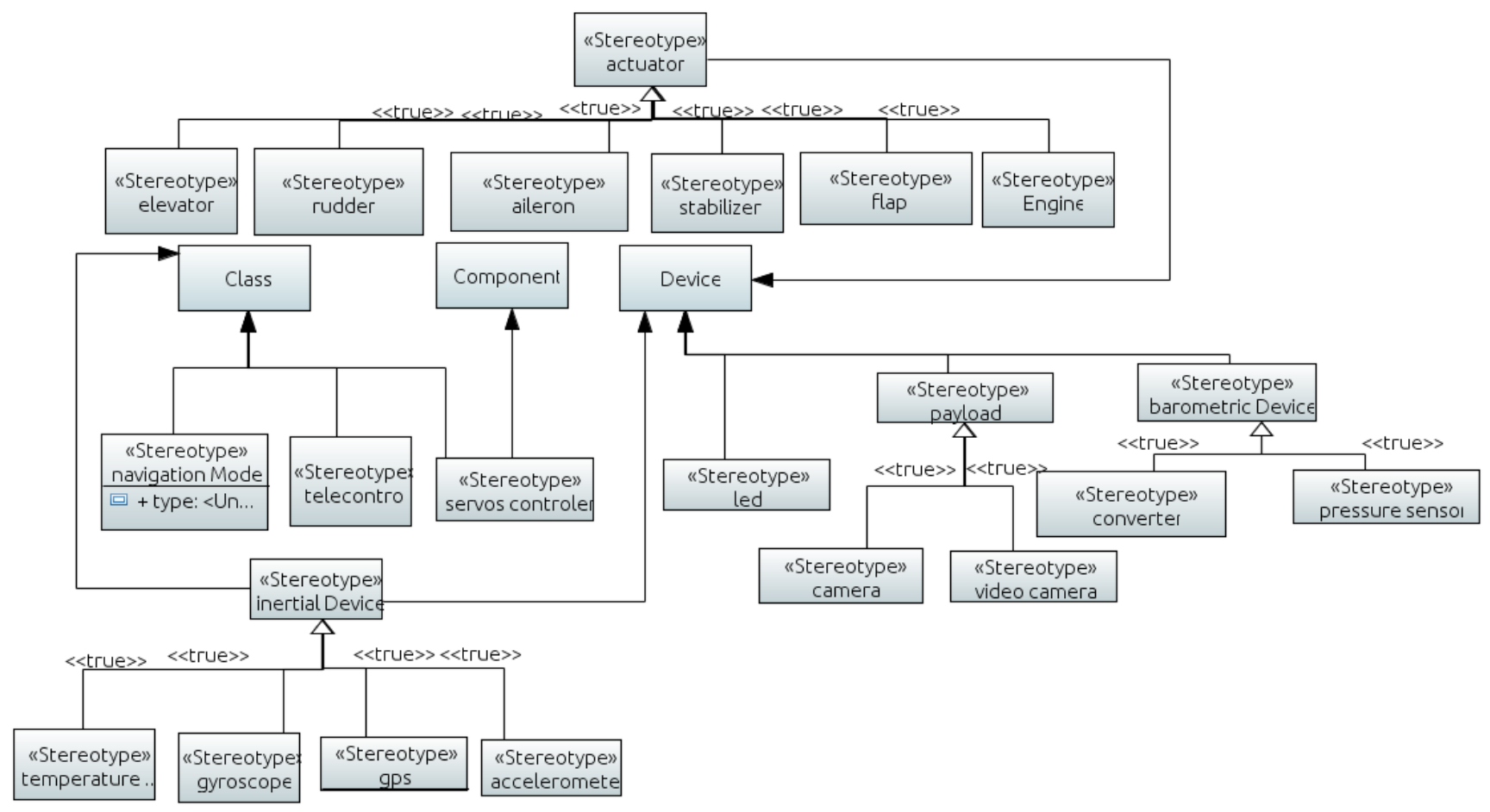

A Engenharia de Domínio de uma linha de produtos é eficiente quando torna possível realizar a Engenharia de Aplicações por meio da seleção de features e geração de produtos customizados. Para isso, deve-se manter, tanto os requisitos, quanto as features rastreáveis até código. A técnica apresentada nesta atividade também facilita a rastreabilidade entre projeto e implementação, para posterior configuração de uma ferramenta de geração de código.

\subsubsection{Projeto de domínio}

Após a realização da Engenharia de Requisitos, na qual se compreende os requisitos da linha, define-se o escopo e trata-se do espaço do problema a ser resolvido pelos sistemas da linha de produtos, inicia-se a fase de projeto de domínio, cujo enfoque é o espaço da solução. Ou seja, enquanto o foco da análise é criar modelos lógicos do sistema que captem as suas funcionalidades para satisfazer os requisitos, o propósito do projeto é especificar como essas funcionalidades serão implementadas (ARLOW; NEUSTADT, 2002).

O projeto de um sistema é o processo de derivação, a partir dos requisitos, de um modelo a partir do qual o sistema pode ser gerado, mais ou menos automaticamente (HENZINGER; SIFAKIS, 2007). No caso do projeto de software, trata-se de um processo para derivar um 
programa compilável. Em relação ao projeto de hardware, refere-se ao processo de derivar uma descrição de hardware a partir da qual pode-se sintetizar um circuito.

Segundo Bass, Clements e Kazman (2003), a arquitetura de software de um programa ou sistema computacional é a estrutura ou estruturas de seus sistemas, que compreendem elementos de software, propriedades externamente visíveis desses elementos e os relacionamentos entre eles. Observa-se que as propriedades "externamente visíveis" se referem as suposições que um elemento pode fazer a respeito de outro elemento, tais como os serviços providos, características de performance, manipulação de falhas, uso de recursos compartilhados e outros.

Arquiteturas de linha de produtos (APL) fornecem abstrações que permitem que variações e similaridades de um domínio sejam simultaneamente gerenciadas. Uma APL pode ser entendida com base na noção de arquiteturas de referência, que é um conjunto de decisões de projeto que são simultaneamente aplicáveis a múltiplos sistemas relacionados, sendo normalmente partes de um domínio, com pontos de variação explicitamente definidos (TAYLOR; MEDVIDOVIC; DASHOFY, 2009).

Para definir os passos e atividades da fase de projeto de domínio, foram consideradas as seguintes ponderações referentes ao projeto de linhas de produtos orientada a modelos para o domínio de sistemas embarcados críticos:

- em relação aos sistemas críticos:

1. engenharia de sistemas críticos é baseada na análise de pior caso (ou seja, aproximações conservadores da dinâmica do sistema) e na reserva de recursos estáticos (HENZINGER; SIFAKIS, 2007).

2. projetistas de sistemas lidam com uma grande variedade de componentes, cada um com características distintas, a partir de uma grande variedade de pontos de vista, cada um destacando diferentes dimensões de um sistema (KOPETZ, 1997).

3. a confiança é alcançada principalmente por meio da utilização de redundância, e por estaticamente implantar todos os equipamentos para a detecção e recuperação de falhas (HENZINGER; SIFAKIS, 2007).

- em relação à Engenharia de Linha de Produtos:

1. um dos pontos principais na definição da arquitetura do domínio é a reutilização dos elementos de software que compõem a arquitetura (LUCRÉDIO, 2009).

2. a capacidade de gerar produtos similares sem grandes mudanças arquiteturais é um fator fundamental (CZARNECKI et al., 2005).

3. deve-se oferecer um bom suporte à comunalidade e variabilidade do domínio (NORTHROP et al., 2009)

- em relação ao Desenvolvimento Orientado a Modelos: 
1. inicia-se a partir da descrição do sistema com fragmentos rastreáveis de uma DSL e, idealmente de forma automática, deriva-se uma implementação que obedece a um conjunto de restrições (HENZINGER; SIFAKIS, 2007)

2. o uso de linguagens gráficas aumenta a inteligibilidade do sistema, uma vez que permite que os projetistas possam fornecer descrições de alto nível do sistema (QUADRI; SADOVYKH; INDRUSIAK, 2012).

Observa-se, ainda, que em uma linha de produtos de sistemas embarcados críticos os diversos sistemas executam em mais de uma plataforma de hardware ou sistema operacional, ou seja, são multiplataforma. Um software multiplataforma é aquele que tem capacidade de funcionar independente de uma arquitetura.

A partir dessas ponderações, são definidos a seguir, os principais desafios do projeto de domínio orientada a modelos no contexto de desenvolvimento de famílias de sistemas embarcados críticos.

- uma vez que os sistemas embarcados envolvem cálculos sujeitos a restrições físicas, não existe a separação do software com a plataforma e ambiente. Portanto, é necessário integrar paradigmas essenciais do projeto de hardware e projeto de software de maneira consistente e controlada (HENZINGER; SIFAKIS, 2007);

- abordagens de hardware dependem de análise estática, enquanto abordagens de software dependem de adaptações dinâmicas. Consequentemente, eles adotam diferentes modelos de computação e utilizam diferentes plataformas de execução, middleware e redes (KOPETZ, 1997);

- a arquitetura projetada deve não somente prever os pontos de variação, mas também efetivamente providenciar o suporte requerido para sua implementação (BASS; CLEMENTS; KAZMAN, 2003);

- o projeto representa todas as decisões técnicas que precisam ser elaboradas pela equipe de projeto, portanto, tornando-se difícil de explorar (QUADRI; SADOVYKH; INDRUSIAK, 2012);

- reduzir o tempo de desenvolvimento e a complexidade do desenvolvimento multiplataforma são as principais fronteiras para os projetistas de sistemas embarcados (SANGIOVANNIVINCENTELLI et al., 2009).

A partir da definição dos desafios do projeto de domínio no contexto estudado por esta tese, são definidos a seguir, os principais objetivos da abordagem de projeto definida nesta tese. 
- definir uma arquitetura de software específica de domínio, e um conjunto de artefatos reutilizáveis que podem ser combinados para desenvolver aplicativos mais rapidamente e com maior qualidade;

- promover um sucessivo refinamento de modelos arquiteturais para atender aos requisitos;

- explorar as várias configurações de arquitetura para promover a simulação e análises em nível arquitetural;

- aproveitar o avanço da capacidade dos circuitos integrados e direcionar o desenvolvimento de sistemas para ambientes com alto nível arquitetural, tornando-os mais distantes dos detalhes de hardware;

- reagir rapidamente à troca de requisitos funcionais e tecnológicos das plataformas;

- permitir especificações independentes e paralelas de hardware e software do sistema, assim como sua eventual alocação e possibilitar a integração de componentes heterogêneos ao sistema;

- representar todo o hardware funcional e não funcional, além dos aspectos de software, por uma linguagem de modelagem única;

- automatizar o processo de projeto.

Para alcançar os objetivos definidos acima, o projeto de domínio definido nesta tese divide-se em três etapas, conforme apresenta-se na Figura 41. Observa-se que algumas etapas são divididas em várias atividades. Além disso, a abordagem de projeto alterna entre os fluxos top-down e bottom-up e segue um padrão preestabelecido, conforme descreve-se a seguir. Essas etapas são realizadas tanto para o projeto de componentes de hardware quanto para o projeto dos elementos de software da linha de produtos, com algumas diferenças que são explicadas a seguir. A abordagem definida nesta Seção é inspirada nas abordagens de projeto de domínio definida por Lucrédio (2009) e no processo de refinamento, integração e análise (SANGIOVANNIVINCENTELLI et al., 2009), com três principais diferenças:

- o refinamento da arquitetura ocorre em dois níveis: o primeiro é executado durante a etapa de Engenharia de Requisitos, por meio da atividade de priorização de requisitos; o segundo é em termos de componentes e corresponde a primeira atividade desta fase.

- as etapas definidas nesta abordagem seguem dois fluxos distintos para o projeto de software e hardware. Embora as atividades sejam parecidas, existem algumas peculiaridades exploradas em cada fluxo.

- os modelos de plataforma são utilizados para simulações e validações, sem a necessidade de gerar obrigatoriamente um PSM. 
Figura 41 - Visão geral das etapas principais do projeto de domínio.

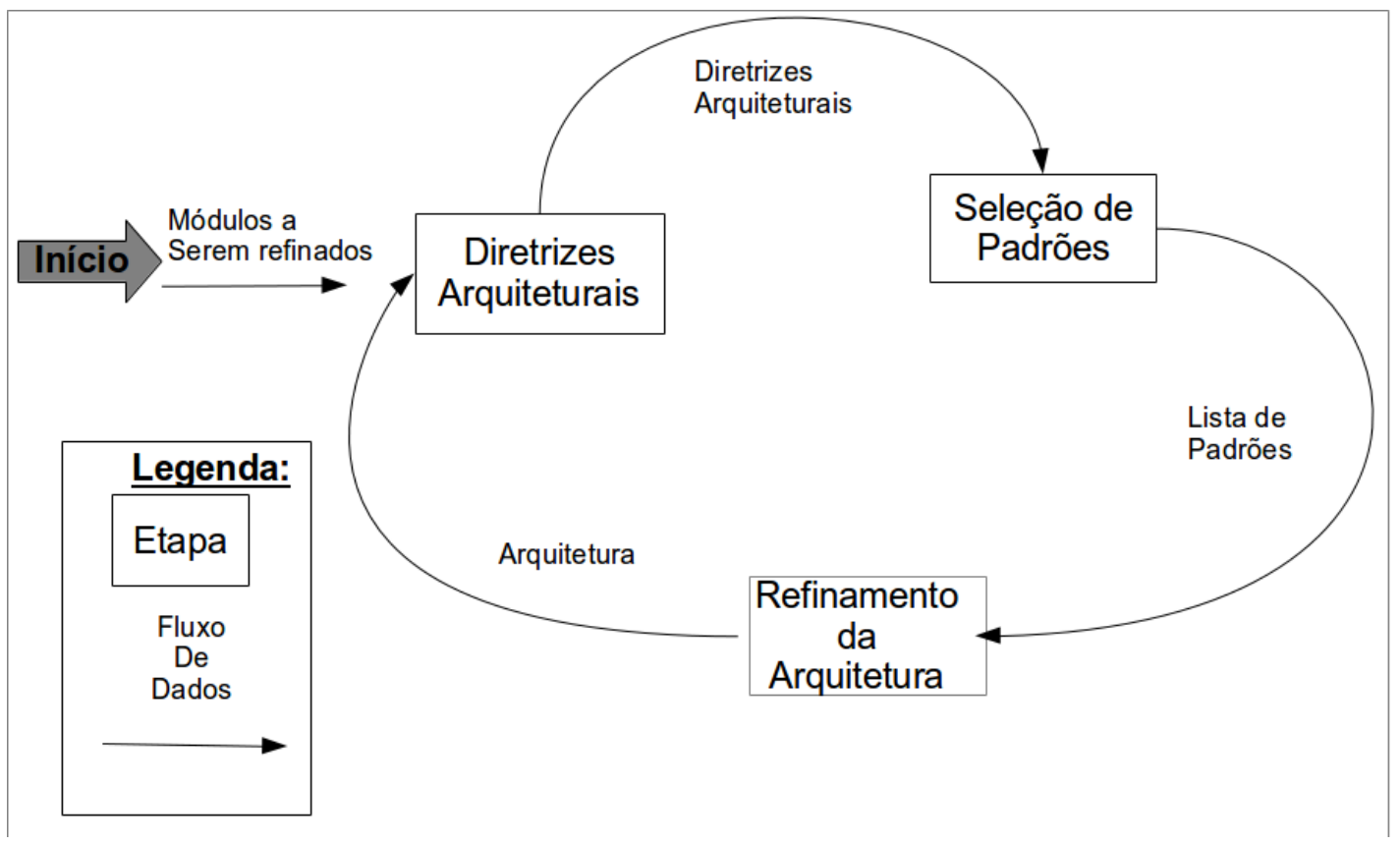

Portanto, o projeto de domínio é um processo orientado a modelos, iterativo e com base em refinamento. Tem início com o domínio completo (parte dele escolhida durante a priorização de requisitos), que passa por sucessivos refinamentos em cada iteração, até a conclusão do projeto. Esse processo de refinamento consiste na decomposição de componentes em componentes menores para gerenciar sua complexidade e facilitar sua implementação e verificação (SOARES; VRANCKEN, 2008). Esse processo envolve o aumento do nível de abstração, escondendo complexidades desnecessárias quando possível, por meio de uma série de modelos que representam diferentes aspectos do comportamento do sistema em diferentes níveis de abstração.

Além do refinamento, a fase de integração corresponde ao arranjo de vários modelos, para explorar especificações de modelagem distintas, tanto entre modelos exclusivamente no fluxo de software, quanto entre modelos exclusivamente do fluxo de hardware ou ainda, uma combinação entre modelos de ambos os fluxos. Por fim, a fase de análise do processo consiste na inspeção de comportamento do sistema de acordo com a especificação do projeto (LUCRÉDIO, 2009).

A primeira atividade visa definir os módulos a serem refinados (Atividade PD.1) e antecede as etapas definidas para esta fase. Além disso, atividade PD.1 deve executada no início de cada iteração. Em seguida, as atividades da etapa de seleção das diretrizes arquiteturais são realizadas para escolher os requisitos mais importantes a serem atendidos pelo projeto da arquitetura. Em geral, cada diretriz é responsável pela escolha de um ou mais padrões arquiteturais. Os padrões são então aplicados durante a etapa de refinamento dos módulos, de forma a definir novos módulos e a arquitetura em si. Ainda na etapa de refinamento, a arquitetura passa por sucessivas avaliações, até a definição da arquitetura que atende ao subconjunto de requisitos da linha, em cada iteração. 


\section{Atividade PD.1: Escolha dos módulos a serem refinados}

Papéis: Projetista de domínio

Entradas: AT.ER.6 Diagrama de requisitos com os requisitos priorizados, AT.ER.7 Modelo de casos de usos e AT.ER.10 Lista de subdomínios

Saídas: AT.PD.1 Módulos a serem refinados

Objetivo: definir, em cada iteração, os módulos que devem ser refinados

\section{Descrição:}

O processo de definição de arquitetura proposto nesta tese inicia-se com a escolha dos módulos a serem refinados. Inicialmente, esses módulos são definidos em alto nível, ou seja, em nível de sistema. A partir de sucessivos refinamentos, o processo passa a ocorrer em dois fluxos contínuos e paralelos para tratar o projeto de software e hardware. Esse processo se iniciou na atividade de priorização de requisitos (Atividade ER.6), a partir dos quais são realizadas divisões até serem obtidos os módulos que irão formar a arquitetura final desse subconjunto de requisitos (fluxo top-down). Esse fluxo se repete até que todos os requisitos da linha de produtos tenham sido projetados e implementados, ou seja, tenham sido escolhidos pelo menos uma vez na atividade de priorização de requisitos.

Portanto, nesta primeira atividade realiza-se a escolha dos módulos a serem refinados. O refinamento ocorre em duas dimensões (LUCRÉDIO, 2009):

- Dos requisitos comuns para os variáveis: neste refinamento, inicia-se o projeto considerandose apenas os pontos comuns. Em seguida, a cada iteração, acrescenta-se um conjunto de pontos de variação no projeto. Isso é feito durante a etapa de priorização de requisitos que faz parte da fase de Engenharia de Requisitos; e,

- De módulos para sub-módulos: esse refinamento é feito após a escolha dos requisitos a serem refinados e inicia-se por meio da definição de uma arquitetura de sistema em alto nível. Em seguida os módulos são subdivididos sucessivamente.

Após uma primeira divisão de módulos, o projetista do domínio avalia a arquitetura existente até o momento, identifica se existem módulos que ainda precisam ser refinados, e os lista. Para cada um destes, executa as atividades seguintes, refinando o módulo novamente. O refinamento segue até o projetista decidir que não é necessário acrescentar mais detalhes (LUCRÉDIO, 2009).

A arquitetura deve armazenar apenas as informações mais importantes do projeto, e portanto não são necessários muitos detalhes. Normalmente, três níveis de divisão são suficientes (BASS; CLEMENTS; KAZMAN, 2003) 
Observa-se que a divisão em subdomínios feita na fase anterior é uma divisão conceitual, com o objetivo de identificar partes do domínio que possuem ferramentas e linguagens desenvolvidas que podem ser reutilizadas. A divisão feita nesta atividade tem o objetivo de implementar as técnicas do MDE para, a partir da especificação inicial do sistema, refiná-la de modo a alcançar um produto com diferentes níveis de modelagem, no qual a medida em que se aumenta o detalhamento, também se aumenta a dependência da plataforma de destino.

\subsubsection{Diretrizes arquiteturais}

As diretrizes arquiteturais são uma combinação de requisitos funcionais e não-funcionais (de qualidade) que guiam a definição do "formato" da arquitetura de um domínio ou módulo em particular (BASS; CLEMENTS; KAZMAN, 2003). As diretrizes são normalmente representadas por meio de cenários que testam a capacidade da arquitetura em satisfazer um ou mais atributos de qualidade (LUCRÉDIO, 2009). Segundo Bragança (2008) os casos de uso são a força que guia a definição da arquitetura da linha de produtos.

As diretrizes arquiteturais são identificadas a partir da definição dos objetivos de negócio mais importantes. Esses objetivos são transformados em cenários ou casos de uso, a partir dos quais, os que possuem maior impacto na arquitetura são escolhidos como diretrizes (BASS; CLEMENTS; KAZMAN, 2003).

Segundo Lucrédio (2009), a identificação dessas diretrizes pode ser feita com a utilização de técnicas como a árvore de utilidade (CLEMENTS; KAZMAN; KLEIN, 2002), ou sessões de brainstorming podem ser utilizadas.

Para a abordagem proposta nesta tese, ao menos quatro tipos de diretrizes devem estar presentes com maior prioridade:

- Requisitos críticos: o projeto arquitetural precisa considerar os requisitos críticos do sistema. Esses pontos devem ser explícitos para que a arquitetura possa dar suporte a segurança e confiabilidade.

- Variabilidade em termos de features: para o projeto arquitetural, a variabilidade é descrita também na forma de cenários, visando facilitar seu entendimento e futura avaliação;

- Variabilidade em forma de DSLs: casos mais complexos de variabilidade exigem um mecanismo mais expressivo para expressá-la apropriadamente (LUCRÉDIO, 2009). Para o projeto arquitetural, são utilizadas DSLs para descrever esse tipo de variabilidade; e,

- Integração entre sub-domínios: o projeto arquitetural precisa considerar os pontos onde diferentes sub-domínios irão interagir. Isto envolve, por exemplo, a integração entre código gerado e não-gerado. Estes pontos de interação devem ser explícitos para que a arquitetura possa dar suporte adequado à geração de código (LUCRÉDIO, 2009). 
As atividades desta etapa do projeto de domínio, bem como os artefatos requeridos e providos são ilustrados por meio da Figura 42. Os detalhes das atividade que fazem parte desta etapa são apresentados a seguir.

Figura 42 - Artefatos requeridos e providos pela etapa de definição das diretrizes arquiteturais.

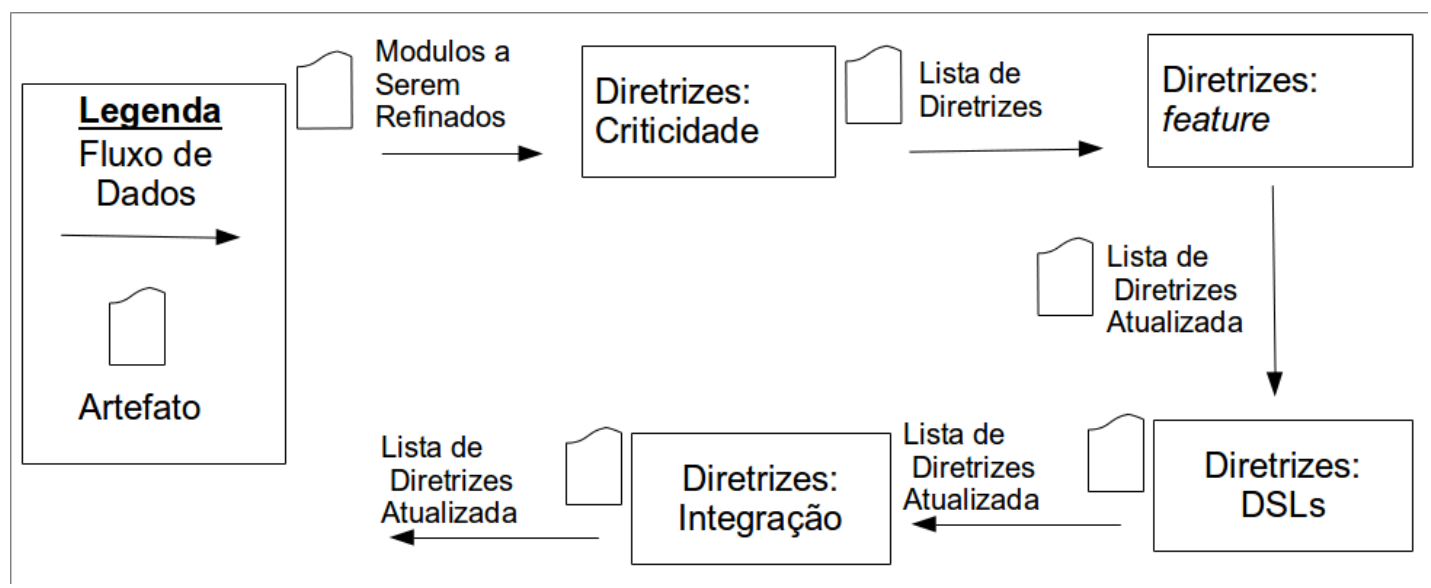

Atividade PD.2: Seleção das diretrizes arquiteturais de requisitos críticos

Papéis: Projetista do domínio, especialista do domínio, demais stakeholders.

Entradas: AT.PD.1 Módulos a serem refinados

Saídas: AT.PD.2 Diretrizes arquiteturais

Objetivo: Definir as diretrizes arquiteturais em relação aos requisitos não funcionais de criticidade

Descrição:

O objetivo desta atividade é descrever cenários que ilustrem os requisitos críticos, tais como segurança, confiabilidade e outros. Ao seguir a abordagem completa definida nesta tese, deve-se chegar a este ponto do desenvolvimento com os cenários já identificados, durante a análise de segurança. Portanto, aqui é necessário somente selecionar, dentre os cenários descritos na análise, aqueles que descrevem o requisito que diz respeito ao módulo sendo refinado na iteração atual.

Neste ponto, deve-se fazer uso dos esterótipos definidos ao final da fase anterior, na atividade de definição de um perfil de variabilidade (Atividade AD.13). O estereótipo correspondente a variabilidade que diz respeito ao módulo sendo refinado, deve ser utilizado no módulo. Adicionalmente, caso seja necessário, pode-se enriquecer esses cenários com mais informações, tais como atributos de qualidade a serem atendidos pela arquitetura.

Atividade PD.3: Seleção das diretrizes arquiteturais de variabilidade baseada em features

Papéis: Projetista do domínio, especialista do domínio, demais stakeholders. 
Entradas: AT.PD.1 Módulos a serem refinados

Saídas: AT.PD.2 Diretrizes arquiteturais atualizadas

Objetivo: Definir as diretrizes arquiteturais em relação aos requisitos que dizem respeito a variabilidades defindas por features

\section{Descrição:}

O objetivo desta atividade é descrever cenários que ilustrem as variabilidades que ocorrem na presença ou ausência de features. Ao Seguir a abordagem completa definida nesta tese, devese chegar a este ponto do desenvolvimento com os cenários já descritos, durante a análise, na atividade de modelagem de casos de uso (atividade ER.7). Portanto, aqui é necessário somente selecionar, dentre os cenários descritos na análise, aqueles que descrevem a variabilidade que diz respeito ao módulo sendo refinado na iteração atual.

\section{Atividade PD.4: Seleção das diretrizes arquiteturais de variabilidade baseada em} DSLs

Papéis: Projetista do domínio, especialista do domínio, demais stakeholders.

Entradas: AT.PD.1 Módulos a serem refinados, AT.PD.2 Diretrizes arquiteturais

Saídas: AT.PD.2 Diretrizes arquiteturais atualizadas

Objetivo: Definir as diretrizes arquiteturais em relação às variabilidades definidas por DSLs

\section{Descrição:}

Conforme apresentado no capítulo anterior, variabilidades mais complexas requerem uma descrição mais rica. Esta abordagem propõe o uso de linguagens específicas de domínio para formalizar o espaço de variação em áreas particulares do domínio (sub-domínios), definindo os conceitos e introduzindo restrições e regras relacionadas à variabilidade neste sub-domínio (LUCRÉDIO, 2009).

DSLs também são utilizadas para guiar o desenvolvimento de transformações de software e geração de código, nas atividades de implementação. Esta atividade cuida apenas da seleção de DSLs que descrevem o sub-domínio relacionado ao módulo sendo refinado. Caso seja necessário desenvolver uma nova DSL, esta deve ser realizada posteriormente (LUCRÉDIO, 2009), em uma atividade dedicada para tal tarefa, descrita mais adiante.

\section{Atividade PD.5: Seleção das diretrizes arquiteturais de integração entre sub-domínios}

Papéis: Projetista do domínio, especialista do domínio, demais stakeholders.

Entradas: AT.PD.1 Módulos a serem refinados, AT.PD.2 Diretrizes arquiteturais

Saídas: AT.PD.2 Diretrizes arquiteturais atualizadas

Objetivo: Definir as diretrizes arquiteturais em relação à integração entre os sub- 
domínios

\section{Descrição:}

Dificilmente são encontrados sub-domínios isolados entre si. Por exemplo, com relação ao domínio de UAV, mostrado na Figura 43, o sub-domínio de comunicação tem interação constante com diversos outros sub-domínios, como por exemplo, o de propulsão. Assim, a arquitetura precisa estar preparada não só para a existência de múltiplos sub-domínios e possivelmente múltiplas DSLs (HESSELLUND; CZARNECKI; WASOWSKI, 2007), mas também para a interação entre eles. Pode ser necessário, por exemplo, desenvolver um único metamodelo para os múltiplos sub-domínios, e então desenvolver diferentes sintaxes concretas, de forma que estes sub-domínios estejam integrados mas ainda assim possuam diferentes visões (LUCRÉDIO, 2009).

Figura 43 - Domínio de VANTs simplificado, descrito por meio de features.

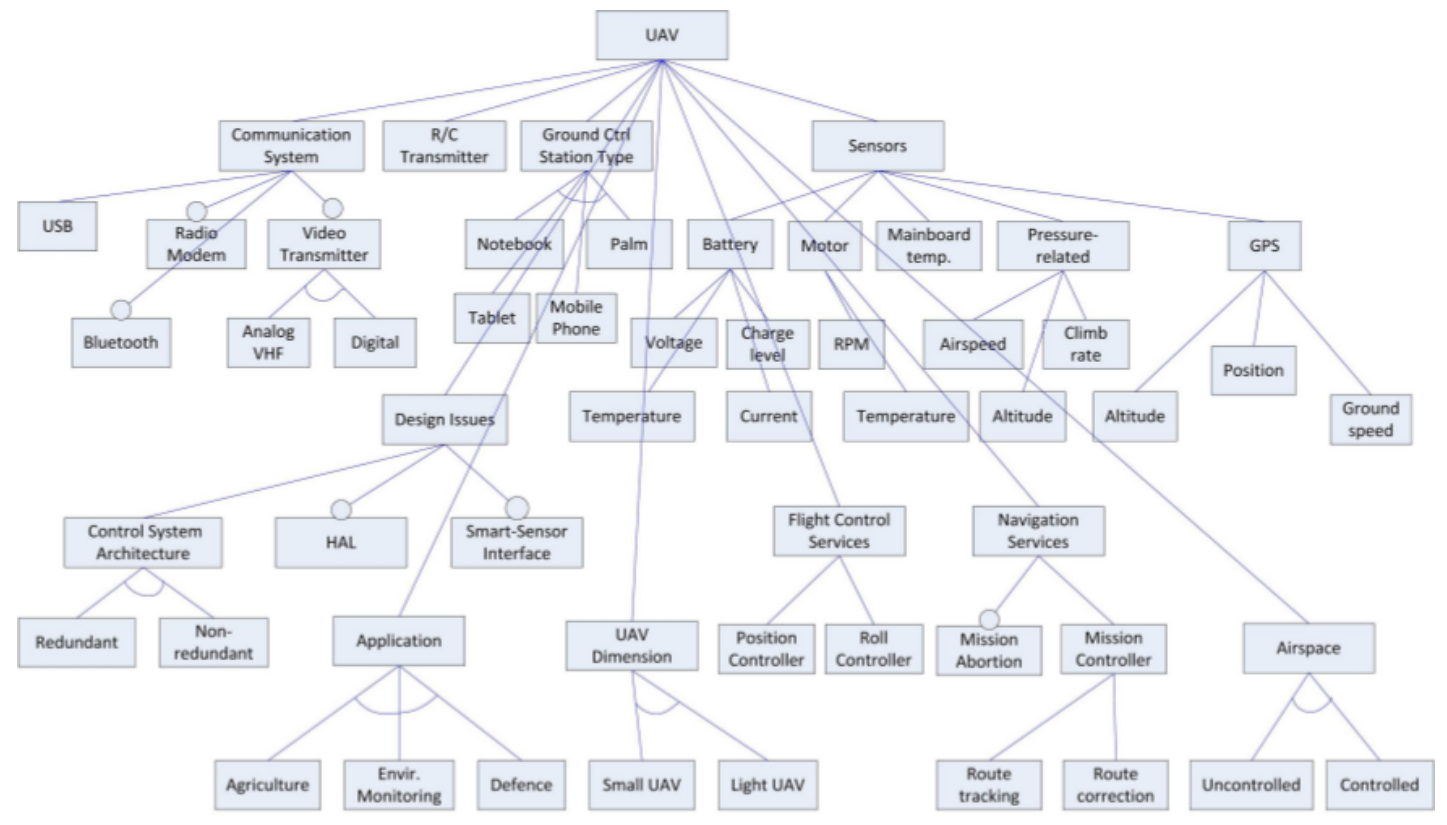

Fonte: Braga et al. (2012)

Nesta atividade, as interdependências entre sub-domínios são explicitadas, pois podem ter impacto nas decisões de projeto, principalmente quando relacionam sub-domínios do fluxo de software com sub-domínios do fluxo de hardware. As restrições de inclusão e exclusão mútua entre as features indicam algumas destas dependências, porém outras podem se tornar aparentes somente após a implementação estar avançada (LUCRÉDIO, 2009). Por este motivo, a cada iteração, os sub-domínios devem evoluir, com o avanço da implementação e identificando novas relações entre os sub-domínios. 


\subsubsection{Padrões e táticas para definições arquiteturais}

Nesta etapa de projeto, deve-se selecionar ou definir táticas e padrões para satisfazer às diretrizes arquiteturais. $\mathrm{O}$ uso de padrões é considerado uma das técnicas mais úteis durante a fase de projeto de software. Por meio do uso de padrões, pode-se reaproveitar soluções recorrentes e comprovadamente bem sucedidas, poupando-se esforço e riscos nesta atividade. Em termos de projeto arquitetural, são conhecidos como padrões (BUSCHMANN et al., 1996), estilos (BASS; CLEMENTS; KAZMAN, 2003) ou abordagens (CLEMENTS; KAZMAN; KLEIN, 2002) arquiteturais.

A diferença entre um padrão arquitetural e um padrão de projeto está na abrangência e impacto da solução. Enquanto padrões de projeto normalmente são utilizados para resolver problemas mais detalhados, padrões arquiteturais descrevem soluções mais abrangentes que envolvem todo o escopo de um domínio ou sistema, ou seja, eles são usados de forma complementar. Normalmente, inicia-se com padrões arquiteturais que definem a macro-estrutura do domínio, até chegar em padrões menores que resolvem problemas mais específicos de partes do domínio (LUCRÉDIO, 2009).

Além disso, um padrão arquitetural implementa uma tática, que por sua vez tem o objetivo de alcançar um ou mais atributos de qualidade (BASS; CLEMENTS; KAZMAN, 2003). Uma tática descreve uma estratégia a ser utilizada para se alcançar um determinado atributo de qualidade. Portanto, para cada diretriz arquitetural, são selecionadas uma ou mais táticas, e em seguida são selecionados os padrões para implementar estas táticas. Uma lista de táticas bem conhecidas e utilizadas em diversos cenários é apresentada em (BASS; CLEMENTS; KAZMAN, 2003), porém esta não inclui táticas para lidar com criticidade, com variabilidade em um domínio, nem com a integração entre sub-domínios, como é o caso da abordagem proposta nesta tese.

O processo de descrição architetural descrito por Douglass (2002) identifica cinco visões arquiteturais, que não são completamente independentes nem devem ter conflito entre si. A melhor forma de compreender isso é entender que existe um único modelo que representa a arquitetura do sistema, neste caso, as visões arquiteturais enfocam em parte deste modelo que são relacionadas entre si de formas específicas. Portanto, não existem aspectos independentes, mas sim, uma visão que filtra apenas certos aspectos por vez (DOUGLASS, 2002). Essas visões são:

- Componente e subcomponente: Componente e subcomponente: identifica, em larga escala, as peças do sistema e como elas se encaixam. Geralmente é apresentada por meio de um diagrama de subsistema, que pode ser um diagrama de classes que mostra principalmente os subsistemas.

- Concorrência e recursos: centra-se no gerenciamento de recursos e os aspectos concorrentes de execução do sistema. 
- Segurança e confiabilidade: examina como a redundância do sistema pode ser definida para elevar a confiabilidade e segurança do sistema. Uma arquitetura segura e confiável se preocupa com o funcionamento correto na presença de falhas e erros. A redundância pode ser usada de muitas formas para obter diferentes graus e tipos de segurança e confiabilidade.

- visão de implantação: se concentra em como a arquitetura de software é mapeada para os dispositivos físicos, tais como processadores, discos, exposições, e assim por diante.

- visão de distribuição: trata como objetos que podem estar em espaços de endereçamento diferentes se encontram e colaboram entre si.

Além dessas cinco visões, observa-se que no projeto de linha de produtos existe um aspecto adicional que é fundamental e entrecorta essas cinco visões: as variabilidades. Portanto, neste trabalho o enfoque é em relação aos padrões e estilos com enfoque nas visões: componente e subcomponente, segurança e confiabilidade (criticidade) e distribuição. Além desses, os padrões para descreverem as variabilidades também fazem parte do escopo deste trabalho. Observa-se que as visões de recurso e implantação são discutidas, porém não são aprofundadas. Padrões para essas visões de recurso e implantação podem ser encontrados em Kircher e Jain (2004).

Existe uma grande quantidade de fontes de padrões e estilos arquiteturais, entre as quais destaca-se a série de cinco volumes conhecida como POSA (Pattern-Oriented Software Architecture) (BUSCHMANN et al., 1996), que apresenta diversos padrões voltados para diferentes tipos de problemas arquiteturais. Além disso, existe o catálogo clássico de padrões de projeto (Design Patterns) (GAMMA et al., 1995) que também pode ser útil nesta atividade, além de outras fontes citadas por Bass, Clements e Kazman (2003).

Em relação ao problema de criar uma arquitetura com suporte à criticidade em sistemas embarcados, existem alguns trabalhos, tais como Armoush (2010) e citetDouglass2002, que propõem o uso de padrões de projeto para tratar esse problema, tanto em relação as características de software quanto as de hardware.

Com relação ao problema da variabilidade, trabalhos como os de Almeida et al. (2007), Keepence e Mannion (1999) e Lee e Kang (2004), enfocam o uso de alguns padrões de projeto com o objetivo de resolver este problema.

Para esta abordagem, foram selecionados alguns padrões que auxiliam na implementação das táticas específicas para garantia de segurança e confiabilidade, assim como para variabilidade e integração entre sub-domínios, apresentados mais adiante nesta seção.

A escolha das táticas e padrões a serem utilizados é guiada por dois fatores: o requisito em si, explicitado pela diretriz arquitetural, e os efeitos colaterais que o emprego de uma tática ou padrão provoca nas demais diretrizes (BASS; CLEMENTS; KAZMAN, 2003). Caso não seja possível encontrar alguma tática e/ou padrão que sirva para um cenário específico, pode-se modificar ou adaptar táticas e padrões existentes, ou mesmo criar novas técnicas especialmente 
para este domínio. Estas técnicas passam a fazer parte do catálogo da organização, e podem ser reaproveitadas em projetos futuros e se tornarem padrões.

As atividades desta etapa relativa à seleção de padrões, bem como os artefatos requeridos e providos são ilustrados por meio da Figura 44. Os detalhes das atividade que fazem parte desta etapa são apresentados a seguir.

Figura 44 - Artefatos requeridos e providos pela etapa de definição das diretrizes arquiteturais.

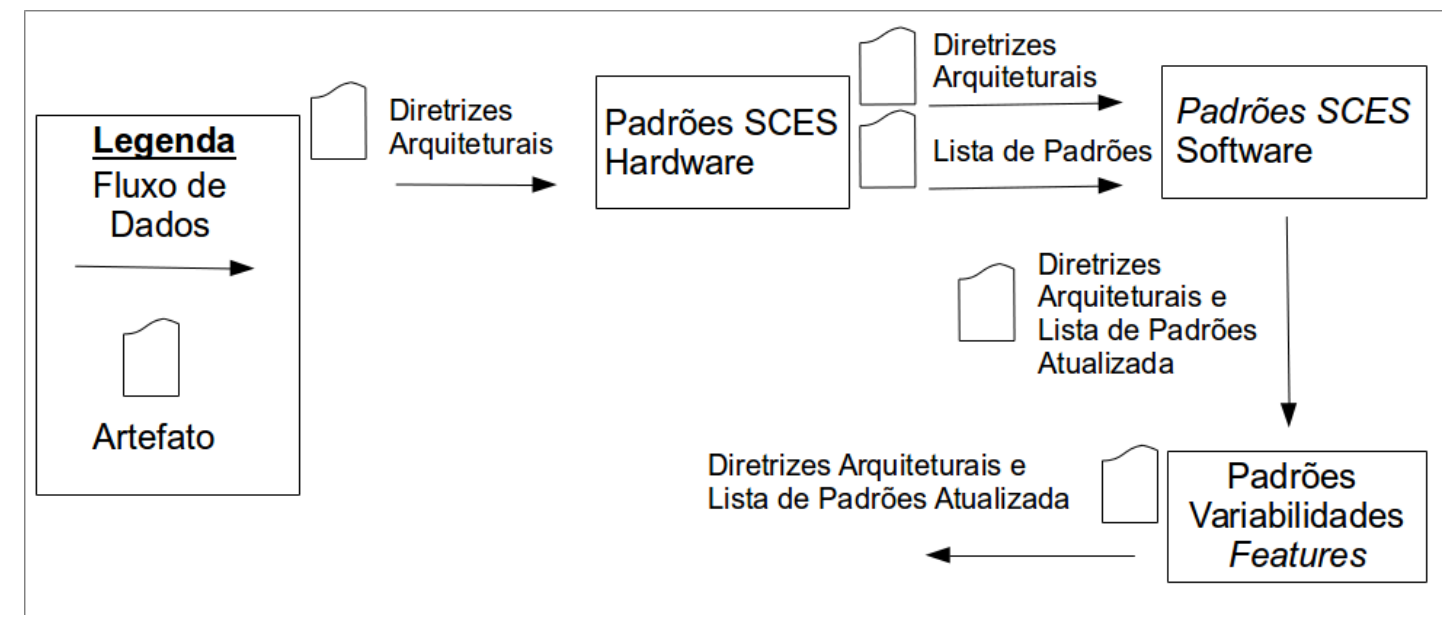

Uma lista completa com padrões e diretrizes para variabilidade baseada em features, variabilidade baseada em DSLs e integração entre sub-domínios pode ser encontrada em (LUCRÉDIO, 2009). De forma semelhante, uma lista completa com padrões para garantia de segurança e confiabilidade é apresentada em Armoush (2010) e citetDouglass2002.

\subsubsection{Padrões arquiteturais para sistemas críticos}

Atividade PD.6. Padrões arquiteturais para sistemas críticos referentes a hardware

Papéis: Projetista de domínio

Entradas: AT.ER.6 Diagrama de requisitos com os requisitos priorizados,AT.ER.7 Casos de uso e AT.ER.10 Lista de subdomínios

Saídas: AT.PD.3 Padrões de hardware escolhidos

Objetivo: Escolher os padrões de hardware que contém redundância explícita para aumentar a confiabilidade e segurança do sistema.

Descrição: Nesta atividade, deve-se escolher os padrões voltados para aumento de confiabilidade e segurança do sistema. Em Armoush (2010), diversos padrões deste tipo são apresentados e discutidos exaustivamente. Para guiar a escolha do projetista, apresenta-se a seguir um breve resumo com o título e a uma breve descrição da estrutura de cada padrão.

A maoria dos padrões com enfoque em hardware, possuem componentes comuns definidos nesta seção. Apresenta-se a seguir um sistema básico definido por Armoush (2010), que 
inclui os componentes gerais, como um padrão de referência. A sua estrutura é apresentada na Figura 45 e seus componentes são apresentados a seguir.

Figura 45 - Componentes gerais de um sistema básico.

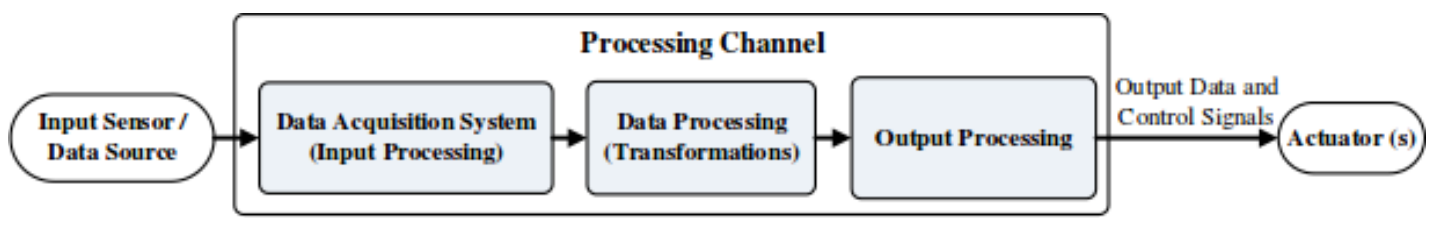

Fonte: Armoush (2010)

- Canal de processamento: representa um subsistema que realiza algumas funções no sistema completo. Recebe um conjunto de dados de entrada de uma fonte externa, como um sensor, e realiza alguma transformação nesses dados. Em seguida ele utiliza os resultados para gerar sinais de comando apropriados para ativar algum atuador externo.

- Sensor de entrada/Fonte de Dados: Representa a fonte de informação que é usado como entrada para o sistema projetado. Tipicamente, esses dados provém do utilizador do sistema, ou de sensores externos que monitoram algumas variáveis ambientais, tais como: a temperatura, pressão, velocidade, luz, etc.

- Aquisição de Dados (Processamento de entrada): O processo de entrada ou a unidade de aquisição de dados recolhe os dados brutos do sensor de entrada e pode converter os dados para outra forma, como por exemplo a conversão analógica para digital, e, em seguida, envia os dados para o unidade de transformação de dados.

- Processamento de Dados (Transformação): Essa parte pode conter múltiplos componentes de transformação de dados. Cada componente desempenha uma única transformação ou processamento sobre os dados recebidos para executar o algoritmo desejado, a fim de gerar os sinais de controle necessários. O subcomponente final envia o resultado final computado para a unidade de processamento de saída.

- Processamento de saída: A unidade de processamento de saída recebe os dados computados a partir da unidade de transformação de dados e gera os dados finais e sinais de controle para ativar os atuadores. Pode ser considerada como um controlador de dispositivo para o atuador.

- Dados de saída e sinais de controle: Os dados de saída podem conter alguns sinais de controle para ativar alguns atuadores ou mensagens para outros componentes fora do sistema.

- Atuador(es): O atuador representa o hardware real que executa a ação definida pelo canal. Exemplos de aturadores são: a motor, interruptor, aquecedor ou qualquer outro dispositivo que executa uma função específica. Pode haver mais de um atuador em um único canal. 
Os padrões que adaptam essa estrutura de modo atender requisitos de criticidade, são:

- Padrão Duplex Homogêneo: pode ser aplicado a diferentes níveis: a partir de um único componente a um subsistema completo (canal). De um modo geral, consiste em dois módulos idênticos; um módulo primário (ativo) e um secundário (standby), e uma unidade de detecção de falhas que monitora o módulo primário e muda para o módulo secundário quando uma falha aparece no primário.

- Padrão Duplex Heterogêneo: é semelhante ao padrão duplex homogêneo visto que ele também consiste de dois módulos (canais) que possuem a mesma funcionalidade. Um módulo primário (ativo) e um secundário (standby), e uma unidade de detecção de falhas que monitora o módulo primário e muda para o módulo secundário quando uma falha aparece no primário. A diferença principal é que os dois módulos possuem projeto ou método de implementação diferentes, o que fornece ao padrão, a possibilidade de lidar com falhas sistemáticas, assim como com as randômicas.

- Padrão de redundância modular tripla: contém três módulos idênticos ou canais para operar em paralelo. Essa estrutura é usada para evitar que a falha de um único componente possa levar a uma falha total do sistema. Em caso de falha num único canal, os outros dois canais irão continuar a trabalhar corretamente e produzir os sinais de controle de atuação corretos. O eleitor tem um papel fundamental neste padrão, aplicando a política de voto para levar a maioria dos resultados que representa o resultado real correto.

- Padrão de Redundância Paralela M-oo-N: contém N módulos ou canais idênticos em que $\mathrm{M}$ desses $\mathrm{N}$ canais devem estar funcionando para que o sistema possa funcionar e produzir os sinais de controle corretos aos atuadores. O elemento de votação desempenha o papel principal nesse padrão, pois é utilizado para encontrar o possível resultado correto efetuando a estratégia de voto M-oo-N. Como em TMR, esse padrão não identifica o tipo ou a razão para a falha, ele apenas determina os módulos que contêm a culpa sem ter de procurar razões.

- Padrão Monitor-Atuador: é constituído por dois canais que executam de forma independente e em paralelo para proporcionar a funcionalidade necessária, e um método de monitoramento para mudar o sistema para o estado fail-safe na presença de falhas.

- Padrão Sanity Check: É composto por dois canais que funcionam de forma independente e em paralelo para fornecer a funcionalidade necessária, e um método de monitoramento de segurança para alternar o sistema para seu estado de fail-safe, na presença de falhas.

- Padrão cão de guarda: o padrão cão de guarda tem um canal de atuação para fazer atuação de ponta a ponta, ele difere do canal de sanidade que é substituído neste padrão com o componente de cão de guarda. O cão de guarda recebe liveness mensagens (strokes) a 
partir do canal de atuação de forma periódica ou em uma base de sequência pré-definida. O cão de guarda deve ser "acariciado" dentro de um determinado período de tempo ou ele vai iniciar umas ações corretivas, como um sinal de desligamento. Em outras palavras, ele verifica a sequência ou os cronogramas dos cursos para detectar possíveis falhas no canal de atuação.

- Padrão executivo de segurança: baseia-se num canal de atuação para executar a funcionalidade necessária e um canal de processamento opcional a prova de falhas, que é dedicado à execução e controle do processamento a prova de falhas. A parte central deste padrão é a existência de um componente executivo de segurança centralizado coordenando todas as medidas de segurança necessárias para desligar o sistema ou para mudar para o canal de processamento a prova de falhas. O componente executivo de segurança também pode ser usado para controlar vários canais de atuação do sistema.

\section{Atividade PD.7: Padrões arquiteturais para sistemas críticos referentes a software}

Papéis: projetista de domínio

Entradas: AT.ER.6 Diagrama de requisitos com os requisitos priorizados, AT.ER.7 Casos de uso e AT.ER.10 Lista de subdomínios

Saídas: AT.PD.4 Padrões de software escolhidos

Objetivo: Escolher os padrões de projeto de software crítico cujos objetivos são aumentar a confiabilidade e segurança do sistema.

Descrição: São apresentados de forma resumida alguns padrões definidos por (ARMOUSH, 2010), por meio do nome, estrutura.

- Padrão de programação em N versões (NVP): padrão de programação em N-versões é uma abordagem tolerante a falhas bem conhecida que é utilizada para aplicações críticas devido ao alto custo de desenvolvimento (STOREY, 1996). A ideia é baseado no conceito de geração independente de $\mathrm{N}$ versões funcionalmente equivalentes a partir da mesma especificação inicial. Os resultados dessas versões são enviados para o eleitor que executa uma estratégia de votação para determinar a saída mais correta. O objetivo deste padrão de programação é minimizar a probabilidade de falhas simultâneas nestas versões.

- Padrão de bloco de recuperação (RB): Semelhante ao NVP, o padrões de Bloco de recuperação é uma abordagem tolerante a falhas bem conhecida que é utilizada para aplicações com alta e moderadamente criticidades, devido ao alto custo de desenvolvimento. A diferença é que no teste padrão do bloco de recuperação, apenas uma única versão é executada a qualquer momento. Ele pode ser usado para o software completo ou para uma parte crítica do software. Baseia-se no conceito de geração independente de versões funcionalmente equivalentes a partir da mesma especificação inicial e a utilização de detecção de falha 
- Padrão de voto de aceitação: O padrão de voto de aceitação representa uma combinação do sistema de detecção de falhas fornecida pelo teste de aceitação e do regime de mascaramento de falhas fornecida pela NVP com direito a voto. Inclui N versões independentes e funcionalmente equivalentes que são tipicamente executadas em paralelo para executar a tarefa desejada.

- Padrão de programação com N auto verificações (NSCP): Este padrão é uma abordagem tolerante a falhas bem conhecida e que é baseada no conceito de diversidade de projeto de software e identificação de erros por programação de auto verificação. Trata-se de uma execução em paralelo de pelo menos dois componentes de auto-controle dispostos em hot standby redundancy, onde cada componente inclui duas versões independentes e funcionalmente equivalentes que são executados em paralelo e são auto-controlados por meio de um algoritmo de comparação.

- Padrão de bloco de recuperação com voto de backup(RBBV): Este padrão representa uma combinação da detecção de falhas fornecida pelo teste de aceitação no padrão RB e a culpa mascarada fornecida pelo eleitor no padrão NVP. Pode ser considerado como uma solução para o problema de casos de testes falsos negativos de fraca aceitação, que inclui uma consideração errada de saídas corretas pelo teste de aceitação como saídas erradas. (PUCCI, 1990).

\subsubsection{Padrões arquiteturais para projeto com variabilidade}

\section{Atividade PD.8: Padrões arquiteturais para variabilidade baseada em features}

Papéis: Projetista de domínio

Entradas: AT.ER.6 Diagrama de requisitos com os requisitos priorizados, AT.ER.7 Casos de uso e AT.ER.10 Lista de subdomínios

Saídas: AT.PD.5 Padrões arquiteturais para variabilidades

Objetivo: escolher os padrões arquiteturais para que a arquitetura de software específica de domínio seja preparada para diferentes tipos de variabilidades baseadas em features

\section{Descrição:}

Entre os diversos padrões que podem ser utilizados para ajudar a tornar uma arquitetura de software específica de domínio preparada para os diferentes tipos de variabilidade baseada em features, destacam-se os padrões do livro padrões de projeto (GAMMA et al., 1995), que podem facilitar a representação da variabilidade no projeto arquitetural, resolvendo alguns dos problemas relacionados à implementação das features (ALMEIDA et al., 2007).

Além disso, quando se trata do desenvolvimento orientado a modelos, é necessário considerar também como os geradores de código se integram com cada padrão, já que partes 
do software são automaticamente geradas, e precisam ser integradas ao restante do software (LUCRÉDIO, 2009). Nesse sentido, o uso de padrões facilita o trabalho dos geradores, pois menos código precisa ser gerado para que as variantes sejam incluídas(LUCRÉDIO, 2009). O princípio é o seguinte: um modelo de features descreve os pontos comuns e variáveis. Um gerador de código usa como entrada uma seleção de features que faz parte da aplicação gerada, e precisa produzir o código correspondente. Para cada tipo de features, um ou mais padrões definidos por (GAMMA et al., 1995) é utilizado.

Observa-se que de acordo com o tipo de variabilidade da feature os padrões indicados para o seu projeto são diferentes. (LUCRÉDIO, 2009) define que:

- Para as Features alternativas mutuamente exclusivas:

- Quando uma feature pode ser mapeada diretamente em uma única classe, o padrão Abstract Factory (GAMMA et al., 1995) é indicado. Neste padrão, um elemento que realiza o papel de fábrica abstrata e um elemento que realiza o papel de produto abstrato representam um ponto de variação, uma feature. Fábricas e produtos concretos representam variantes alternativas. $O$ gerador somente precisa gerar o código de instanciação da fábrica concreta correspondente, e o restante do código permanece independente (LUCRÉDIO, 2009).

- O padrão Prototype (GAMMA et al., 1995) pode ser utilizado com o mesmo propósito, nos casos onde se deseja evitar a criação de subclasses para os objetos construtores. Neste padrão, cada alternativa é implementada como uma classe diferente de um protótipo comum. O gerador de código é responsável por gerar código que instancia somente a alternativa selecionada (LUCRÉDIO, 2009).

- Uma solução mais simples é a utilização do Template method (GAMMA et al., 1995) com o objetivo de criar a instância correta. A seleção da alternativa acontece via parâmetro, e não herança, como no caso do Abstract factory. Para implementar features alternativas, basta criar um método que aceita como parâmetro a alternativa a ser criada, e o método cria uma instância correspondente, através, por exemplo, de um bloco switch ou um conjunto de comandos if que faz a seleção (LUCRÉDIO, 2009).

- Caso uma feature (GAMMA et al., 1995) precise ser implementada por diferentes classes, sugere-se o uso do padrão Facade em conjunto com um dos três acima: Abstract Factory, Prototype ou Template method (LUCRÉDIO, 2009).

- Quando as features alternativas correspondem a comportamentos alternativos, que devem ser mapeados em um único método ao invés de toda uma classe, os padrões Strategy (GAMMA et al., 1995) ou Template method (GAMMA et al., 1995) podem ser utilizados (LUCRÉDIO, 2009).

- Para as Features alternativas do tipo ou: 
- O padrão Chain of Responsibility pode ser utilizado quando as diferentes features introduzem funcionalidades complementares, que são executadas uma após a outra (LUCRÉDIO, 2009).

- Em interações mais complexas, onde a ordem de chamada dos comportamentos específicos não é seqüencial, exigindo um código específico para isso, o padrão Decorator pode ser utilizado (LUCRÉDIO, 2009).

- Para as Features opcionais:

- para features opcionais, pode-se utilizar os mesmos padrões utilizados para as features alternativas do tipo ou, com a diferença de que neste caso não é necessário garantir que ao menos uma feature esteja presente na aplicação (LUCRÉDIO, 2009).

Além desses padrões, dois outros padrões conhecidos para a escrita de geradores de código podem ser utilizados. O primeiro padrão é conhecido como a abordagem visitante (CZARNECKI; HELSEN, 2006). Neste padrão, o modelo de entrada é percorrido e cada elemento é visitado. Para cada elemento, um template correspondente é chamado, de acordo com o tipo do elemento. No cenário de engenharia de domínio, este padrão é particularmente útil para diferentes tipos de features mandatórias e opcionais (LUCRÉDIO, 2009).

O padrão visitante é uma boa opção quando é possível encapsular a funcionalidade de uma feature em uma única classe. Caso não seja possível, a abordagem template (CZARNECKI; HELSEN, 2006) pode ser utilizada. Consiste em um único template que é o ponto de entrada, responsável por consultar os modelos e chamar outros templates (LUCRÉDIO, 2009). A principal diferença em relação ao padrão visitante, e que no padrão template a ordem e lógica por trás das chamadas é explicitamente programada pelo desenvolvedor. Além disso, um template pode introduzir apenas um único método, um pedaço de texto, que pode ser inserido em outros artefatos, ou até hierarquias completas de classes (LUCRÉDIO, 2009).

\subsubsection{Refinamento dos módulos}

Nesta etapa, deve-se realizar o refinamento dos módulos, partindo-se de um arquitetura em alto nível até chegar em um projeto a nível de classes e componentes de hardware. A arquitetura inicial é derivada a partir dos requisitos da linha ou de algum dos sistemas da linha, e expressa a primeira subdivisão visível, do sistema em componentes. Na Figura 46 ilustra-se a arquitetura inicial, em alto nível, da linha de produtos de VANTS. Nessa definição inicial foi levado em consideração os grandes subsistemas de um VANT, derivados a partir dos requisitos. Um VANT é formado por uma sistema de controle, sistema de navegação, unidade inercial e unidade barométrica.

A partir dessa definição inicial, são escolhidos módulos para serem refinados. Esse refinamento é guiado pelos casos de uso que descrevem o módulo escolhido. Para alcançar o 
Figura 46 - Arquitetura inicial, em alto nível do VANT.

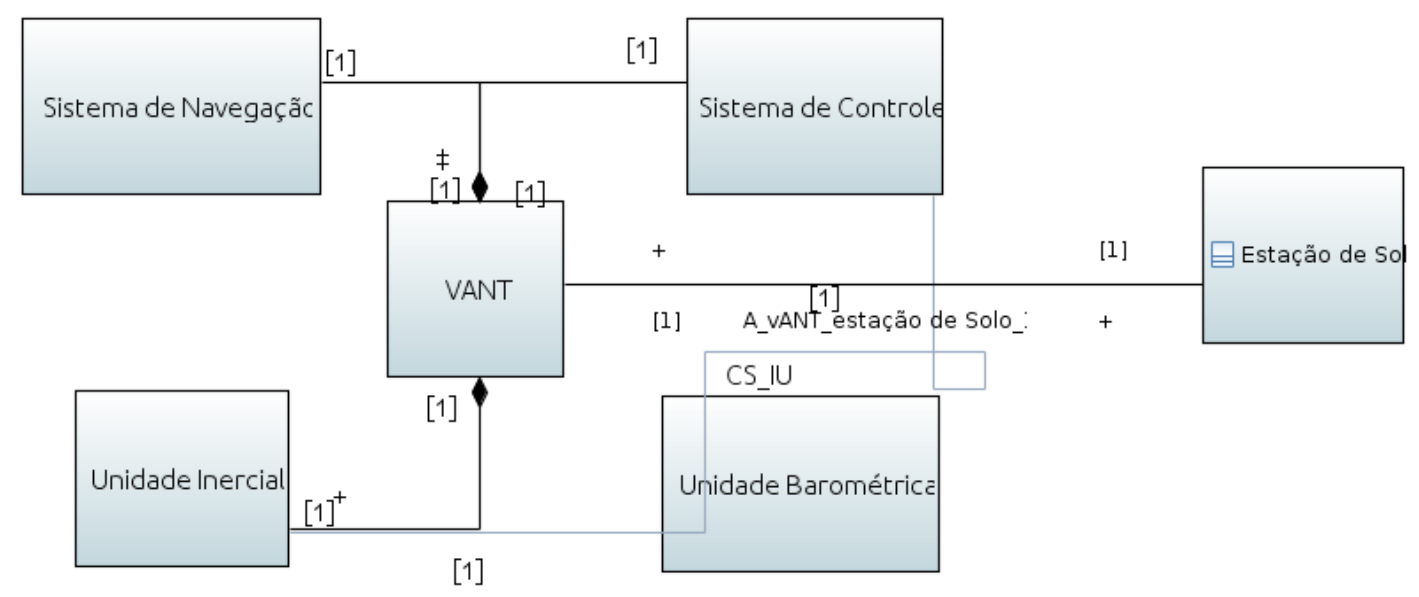

nível de refinamento de hardware e software são aplicados padrões arquiteturais para melhorar a modularização desses subsistemas e padrões de projeto, de acordo com as diretrizes selecionadas, que guiam o refinamento do domínio em módulos e sub-módulos. É importante observar que a arquitetura inicial em alto nível não faz distinção entre os componentes de software ou hardware. Esses componentes passam a ser definidos a medida que a arquitetura passa por sucessivos refinamentos.

\section{Atividade PD.9: Aplicação dos padrões de projeto e refinamento dos módulos}

Papéis: projetista de domínio

Entradas: AT.PD.2 Diretrizes arquiteturais;

Saídas: AT.PD.6 Arquitetura do sistema

Objetivo: Refinar os módulos do sistema iterativamente até obter uma arquitetura para o sistema

\section{Descrição:}

Conforme descrito no início deste capítulo, o refinamento ocorre em duas dimensões: de ponto comum para ponto variável e de módulo para sub-módulo. No caso de um refinamento por meio de inclusão de ponto de variação, deve-se definir quais novos elementos são necessários para implementar este ponto de variação. Uma boa alternativa é iniciar a definição desses elementos por meio da realização dos casos de uso que descrevem o ponto variável escolhido. O resultado é o surgimento de novos módulos que implementam o ponto de variação de acordo com táticas e padrões, que correspondem a soluções já testadas e comprovadas (LUCRÉDIO, 2009).

Em relação a um refinamento na dimensão de divisão em módulos e sub-módulos, definem-se quais novos sub-módulos irão realizar os papéis do padrão. O resultado é uma decomposição plausível, guiada por um padrão que tem por objetivo atender às necessidades arquiteturais específicas daquele módulo (diretrizes) (BASS; CLEMENTS; KAZMAN, 2003). 
Conforme já mencionado, uma descrição arquitetural identifica, pelo menos, cinco visões arquiteturais, que não são completamente independentes nem devem ter conflito entre si. Portanto, para garantir que a divisão escolhida atende aos requisitos, são criados diferentes modelos que representam diferentes visões da arquitetura. Pode-se utilizar, por exemplo a visão de compononente e subcomponente para ilustrar as peças do sistema e como elas se encaixam. A visão de segurança que examina como a redundância do sistema pode ser definida para elevar a confiabilidade e segurança do mesmo. Esses são tipos de visões, que devem ser utilizadas de acordo com o padrão a ser aplicado, de forma que seja capaz de transmitir a informação de forma consistente e completa.

Nesta atividade, também se descrevem as interfaces dos módulos recém criados. Além das informações requeridas/providas para que cada módulo seja capaz de executar sua responsabilidade, são descritos também os requisitos e funções que devem ser atendidos por aquele módulo específico, considerando-se a divisão que foi realizada (LUCRÉDIO, 2009).

Conforme apresentado na Subseção 4.7.2.3, o elementos de implementação de redundância para garantia de segurança são caros de serem implementados, portanto, como se trata de uma linha de produtos, a recomendação é variar quanto a aplicação desses padrões para garantia de segurança nas diferentes features variantes da linha de produtos, de acordo com a diretriz arquitetural de segurança que os produtos que serão compostos por aquele variante devem ter ou mesmo que o próprio variante exige. Por exemplo, o grau de criticidade de um VANT para aplicação militar é maior do que o grau de criticidade de um VANT para aplicação na agricultura, portanto o primeiro deve possuir maior investimento em padrões de garantia de segurança mais robustos. Em relação as features variantes em si, observa-se que uma feature opcional de envio de vídeo ao vivo em aplicações vigília de fronteira também possuem um grau de criticidade menor do que a feature de pouso autônomo, por exemplo. Essas são algumas das diretrizes que devem ser levadas em consideração na escolha dos padrões adotados.

Observa-se, ainda, que os padrões para implementar variabilidades podem ser utilizados em conjunto com os padrões para garantia de segurança voltados para software. Por exemplo, o padrão de programação em $\mathrm{N}$ versões, que pode ser combinado com o padrão Abstract Factory ou Prototype, para gerenciar e instanciar as diversas versões. A diferença é que em vez de escolher somente uma versão, deve-se adaptar o padrão para escolher um conjunto delas.

$\mathrm{Na}$ Figura 47, apresenta-se um exemplo de arquitetura inicial em alto nível do VANT, junto com um exemplo de refinamento de um de seus componentes. Observa-se que a medida que o refinamento ocorre, pode-se começar a distinguir entre os componentes de software e hardware.

Dependendo do domínio em estudo, pode ser interessante integrar os modelos UML com ferramentas usadas na engenharia de controle, tais como o Matlab e o MATRIXx (MATHWORKS, ). Segundo Vanderperren e Dehaene (2006) existem duas abordagens possíveis para essa integração: 
Figura 47 - Arquitetura em alto nível do VANT com o refinamento do módulo X.

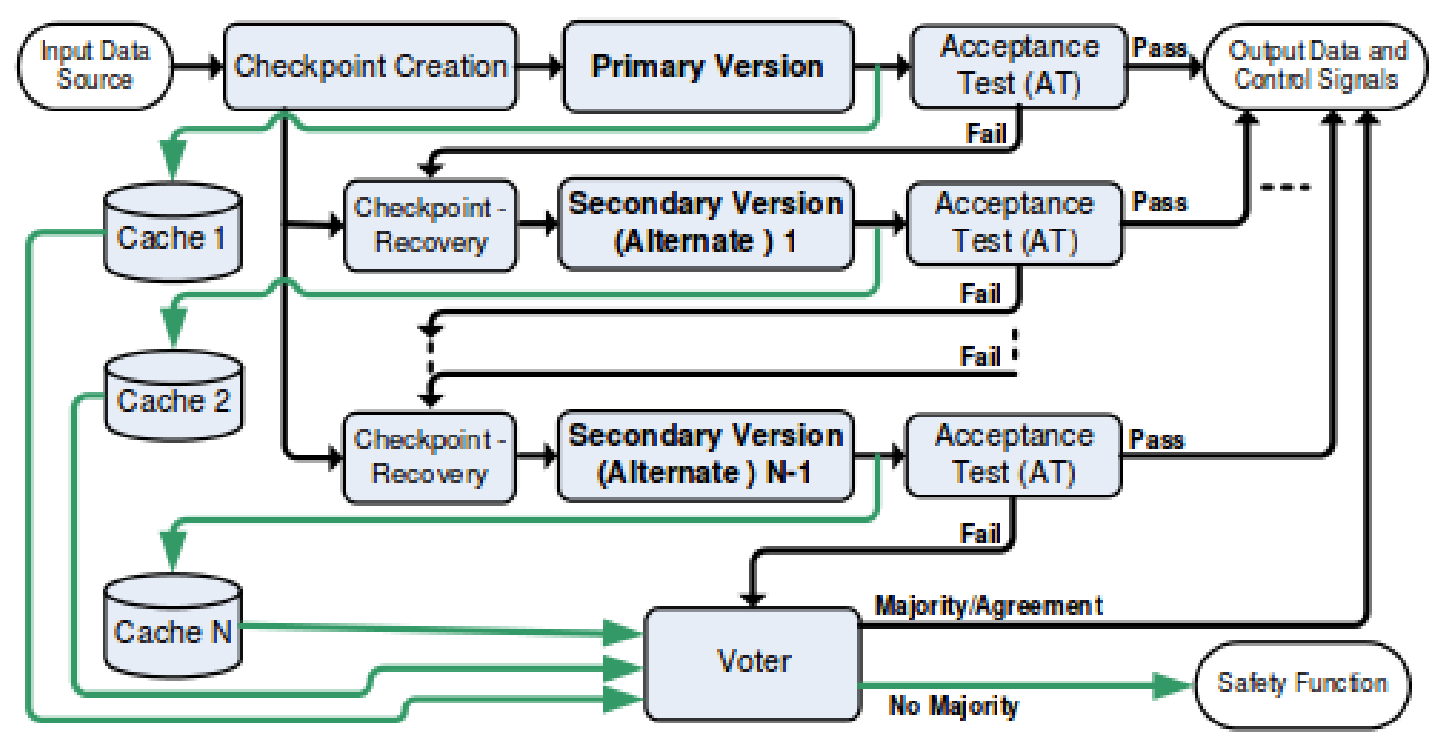

Fonte: Armoush (2010)

- Co-simulação, ou seja, onde as simulações UML e Matlab Simulink se comunicam via uma ferramenta intermediária.

- Integração baseada em uma linguagem comum de execução, ou seja, gerar código para o modelo UML e uní-lo ao código gerado pelo Matlab.

Segundo (MELLOR; BALCER, 2002) um modelo executável tem basicamente três diagramas UML:

- diagramas de classe, para modelar dados, descritos como classes, atributos, associações e restrições;

- diagramas de máquina de estados, para modelar controle, descritos como estados e transições;

- diagramas de atividades, para modelar algoritmos, descritos com ações.

A partir da definição da arquitetura, deve-se simular a integração dos componentes de hardware e software. Essa tarefa é simplificada por meio do processo de abstração da plataforma de execução. Pode-se criar um modelo que represente a plataforma do sistema, conhecido na nomeclatura do MDA como modelo de descrição de plataforma (PDM) para simular os modelos arquiteturais criados. Com esses modelos e a utilização de model checkers como o UPAAL pode-se validar algumas propriedades da arquitetura proposta.

A grande vantagem dessa técnica é que para a mesma plataforma pode-se testar várias configurações de arquiteturas. Um exemplo desse conceito é apresentado para a linha de produtos 
de marcapasso, cuja plataforma na qual o sistema opera é o coração humano, modelado por meio de diagrama de estados anotados com o perfil MARTE. Os diversos marcapassos gerados a partir da linha, também modelados por meio de diagrama de estados, podem ser validados nessa mesma plataforma.

Pode-se utilizar o perfil MARTE para adicionar detalhes de propriedades não funcionais por meio do pacote High-Level Application Modeling (HLAM); definir as plataformas de hardware por meio do HRM; e, definir as plataformas de software por meio do SRM.

\section{Atividade PD.10 Avaliação de arquitetura}

Papéis: projetista de domínio

Entradas: AT.ER.6 Diagrama de requisitos com os requisitos priorizados, AT.ER.7 Casos de uso e AT.ER.10 Lista de subdomínios

Saídas: AT.PD.7 Módulos a serem refinados

Objetivo: Avaliar se a arquitetura obtida atende as diferentes diretrizes definidas.

\section{Descrição:}

De acordo com o método PuLSE-DSSA (DEBAUD; FLEGE; KNAUBER, 1998), o projeto arquitetural pode produzir múltiplas arquiteturas, cada uma oferecendo uma alternativa para atender às diferentes diretrizes. Portanto, é importante definir uma atividade responsável por avaliar as alternativas e selecionar qual delas se confirmará como a arquitetura de referência da linha. Esse processo de avaliação arquitetural é iterativo, e deve ser executado quando o refinamento da arquitetura alcançar os níveis de detalhe de software e hardware.

O objetivo desta atividade é avaliar as alternativas arquiteturais projetadas na etapa anterior e selecionar a que melhor atende aos requisitos do domínio, ou seja, a que melhor acomoda as variabilidades.

Esta atividade pode ser realizada por meio de métodos como: SAAM (do inglês, Software Architecture Analysis Method) (CLEMENTS; KAZMAN; KLEIN, 2002); ATAM (Architectural Trade-off Analysis Method) (CLEMENTS; KAZMAN; KLEIN, 2002); EATAM (do inglês, extended Architecture Tradeoff Analysis Method (KIM et al., 2008), entre outros.

Após a seleção da arquitetura, retorna-se às atividades iniciais desta etapa, para buscar novas táticas/padrões arquiteturais que implementem as mudanças sugeridas nesta avaliação. Este ciclo se repete até que não sejam necessárias mais mudanças. Após esta atividade, tem-se a arquitetura projetada e avaliada com base nas informações disponíveis até o momento. Observase que, como este é um processo iterativo, e a arquitetura vai sofrer alterações posteriores para acomodar os requisitos escolhidos para implementação em cada iteração. 


\subsubsection{Implementação de domínio}

Durante a Engenharia de Requisitos, foi definido o espaço do problema, durante o projeto arquitetural começou a ser definido o espaço da solução, entretanto ainda necessita-se definir questões de baixo nível, tais como: qual tecnologia de comunicação deve ser utilizada em um domínio distribuído? Qual algoritmo de busca deve ser utilizado? Esse tipo de questão é o foco desta etapa, que também engloba o refinamento do projeto de alto nível em um projeto detalhado.

Conforme comentado nos capítulos anteriores, na maioria das abordagens de linhas de produto, ao se alcançar a etapa de implementação, os modelos estão saturados com relacionamentos para expressar variabilidades e cheios de opções de variantes. Na abordagem proposta nesta tese, a resolução de variabilidades é feita na Engenharia de Requisitos, o desenvolvimento passa a ser semelhante ao desenvolvimento de sistemas únicos, mantendo a rastreabilidade das features por meio do perfil criado ao final da etapa de requisitos. Dessa forma, a etapa de implementação deve focar em gerar todo o sistema de software do domínio, as descrições de hardware, enquanto mapeia as features para esses ativos de código.

Na prática, isso significa que em vez de se preocupar com técnicas de implementação de variabilidades complexas, como por exemplo a Programação orientada a aspectos (KICZALES et al., 1997) ou carregamento dinâmico de classes (GACEK; ANASTASOPOULES, 2001), o foco é é utilizar a tecnologia generativa (CZARNECKI; EISENECKER, 2000) para produzir componentes.

Em resumo, o objetivo desta fase é implementar o domínio, ou seja, implementar componentes, DSLs, transformações e geradores de código, seguindo o projeto definido na fase anterior, alguns critérios defindos por Gacek e Anastasopoules (2001) e Atkinson et al. (2002), além dos requisitos dos sistemas críticos:

- Esforço de implementação: deve-se introduzir pouca ou nenhuma sobrecarga no trabalho de implementação, de forma a oferecer poucas barreiras para sua adoção;

- Separação de interesses: separação das variantes do código comum, de forma que mudanças em ambos os lados possam ser feitas de forma efetiva;

- Desempenho: a implementação deve proporcionar desempenho do produto final de acordo com os requisitos;

- Diferentes tipos de código-fonte: os mecanismos normalmente citados na literatura são fortemente atrelados a uma linguagem de programação, e normalmente utilizam conceitos de orientação a objetos. Entretanto, na área de hardware, por exemplo, pode-se gerar código VHDL para ser executado em SoC FPGA (System-o- $a$-Chip FPGA);

- Esforço de reutilização: a implementação deve permitir a reutilização de forma simples e com pouco esforço; 
- Escalabilidade: a implementação deve ser escalável, podendo produzir grandes extensões de código sem um impacto muito grave nas demais propriedades;

A fase de implementação segue a mesma estrutura que vem sendo utilizada desde o início do desenvolvimento. Inicialmente, são implementados os elementos que estão relacionados às features comuns, em seguida as variabilidades são introduzidas uma a uma a medida que passarem pelas etapas de Engenharia de requisitos e Projeto, de modo que ao final tem-se uma implementação que cubra todas as possibilidades. Para realizar essa implementação com base em MDE, a maioria das abordagens utiliza o MDA, entretanto, o processo apresentado nesta tese é baseado em desenvolvimento por meio de exemplos (WIMMER et al., 2007), pois facilita a tarefa do desenvolvedor e, principalmente, a etapa subjacente, de configuração da linha de produtos.

\section{Atividade IP.1: Definição de DSLs e ferramentas}

Papéis: Implementador do domínio, Especialista do domínio

Entradas: AT.ER.X Modelagem do domínio, AT.ER.10 sub-domínios, AT.PD.X Projeto do domínio

Saídas: AT.IP.1 DSLs (linguagens abstratas e concretas)

Objetivo: definir as DSLs para os subdomínios

\section{Descrição:}

Conforme visto na subseção 4.7.1.6, um domínio pode ser dividido em vários subdomínios, alguns dos quais com maturidade a ponto de ter ferramentas e DSLs próprias. Para todo o domínio, uma ferramenta de features é normalmente utilizada, junto com uma ferramenta de configuração automática (LUCRÉDIO, 2009) ou um gerador de aplicações com wizard baseados nas features (QUEIROZ, 2009). Entretanto, antes de configurar essa ferramenta para o domínio inteiro, deve-se utilizar as vantagens da subdivisão do domínio e gerar as implementaçõe que serão posteriormente configuradas no gerador.

Enquanto alguns sub-domínios que não possuem DSL definida podem se utilizar das features como DSL, outros podem exigir uma solução baseada em uma DSL mais completa, incluindo uma ferramenta de modelagem e geradores dedicados. Em Lucrédio (2009) são definidas as seguintes diretrizes para identificar a necessidade de criação de uma DSL própria para um dado subdomínio:

- D1. Procurar por configurações de features que não mudam entre as aplicações: se uma feature representa um ponto de variação, sua configuração deve mudar de alguma forma quando as diferentes aplicações variam com relação a este ponto. Porém, se duas aplicações diferem em algum ponto, mas as configurações das features que descrevem aquele ponto 
são as mesmas, isto pode indicar que há alguma variabilidade que não pode ser representada como features, e talvez seja necessária uma DSL (LUCRÉDIO, 2009).

- D2. Explorar o espaço de variabilidade: se não existirem aplicações para análise por meio da diretriz D1, pode-se tentar esboçar configurações de produto que introduzem variações diferentes, para determinar se o modelo de features pode representar todas as possibilidades. Se todas as combinações puderem ser completamente identificadas em termos de uma sub-árvore de features, ou mesmo um caminho dentro do modelo de features, isto significa que a variabilidade deste sub-domínio é coberta pelo modelo de features (CZARNECKI et al., 2005).

- D3. Procurar por máquinas de estados: muitos sub-domínios podem ser representados por máquinas de estados, principalmente no domínio de sistemas embarcados. Se for este o caso, este sub-domínio irá provavelmente requerer uma DSL (máquina de estados) para sua variabilidade.

- D4. Tentar o caminho mais fácil primeiro: Sempre que houver dúvida com relação à caracterização da variabilidade no sub-domínio, o caminho mais fácil deve ser preferido, isto é, com um wizard ou configuração de features. Se estes se mostrarem insuficientes, então uma DSL mais complexa pode ser desenvolvida.

Nos casos de variabilidade mais simples, baseada em features, a DSL pode ser composta por símbolos que representam features individuais, para indicar sua presença ou ausência. Em casos de variabilidades mais complexas, a DSL deve definir quais conceitos podem ser utilizados, como eles se relacionam entre si, e possíveis restrições que possam existir. A DSL deve também ser capaz de produzir modelos que sirvam de entrada para transformadores e geradores, o que inclui muitos detalhes que são específicos à plataforma e arquitetura escolhidas (LUCRÉDIO, 2009). É muito difícil perceber tais detalhes sem um investigação mais aprofundada na implementação, e portanto uma abordagem bottom-up é utilizada, em seguida, para refinar esta DSL inicial. Esta atividade corresponde à parte top-down do desenvolvimento da DSL.

Uma DSL pode ser textual (programas) (BÉZIVIN et al., 2006) ou visual (diagramas) (GHOSH, 2010), e é normalmente composta de três elementos: a sintaxe abstrata, a sintaxe concreta e a semântica.

A sintaxe abstrata define os conceitos do domínio, e as relações e restrições que se aplicam a estes conceitos, em linguagens de modelagem, corresponde ao metamodelo que define a estrutura dos modelos que podem ser criados (GUIZZARDI; PIRES; SINDEREN, 2002).

A sintaxe concreta fornece um sistema para representar os conceitos do domínio de forma concreta, ou seja, consiste de símbolos, que podem ser caracteres organizados em palavras segundo uma gramática bem definida (linguagem textual), ou ícones gráficos com características visuais que representam diferentes atributos (GUIZZARDI; PIRES; SINDEREN, 2002). 
A semântica define o significado dos elementos da sintaxe abstrata, e pode variar de acordo com o objetivo desejado. A semântica é definida em forma de ações a serem executadas por um interpretador automático (Kleppe, 2007).

Nesta atividade, a meta é o desenvolvimento das sintaxes abstrata e concreta das DSLs, além de ferramentas que permitam a criação de instâncias (programas ou diagramas) da DSL. Mesmo quando o modelo de features não é suficiente para identificar conceitos de uma DSL, ele é um bom ponto de partida (CZARNECKI et al., 2005), pois posteriormente pode ser complementado com informações de outros artefatos, como a arquitetura do domínio e o conhecimento do especialista (TOLVANEN; KELLY, 2005).

Visto que o desenvolvimento de DSLs é considerado uma ciência à parte (CZARNECKI; EISENECKER, 2000), dada sua complexidade, e não é um processo muito previsível, pois exige um algo grau de criatividade (VISSER, 2008) como uma arte (MAUW; WIERSMA; WILLEMSE, 2004), não faz parte do escopo desta abordagem detalhar esse processo, entretanto são fornecidas algumas orientações apresentadas a seguir. Observa-se que (MAUW; WIERSMA; WILLEMSE, 2004) definem um processo para definição de DSL com vários passos semelhantes aos definidos pela Engenharia de domínio apresentada nesta tese.

- identificar as features: identificar as features que irão dar início à formação da sintaxe abstrata da DSL;

- definição da sintaxe abstrata: as features são analisadas de forma mais aprofundada, para determinar como elas se relacionam entre si, e se conceitos adicionais são necessários. Estes conceitos adicionais são descritos em um metamodelo, que corresponde à sintaxe abstrata da DSL.

- Definição da sintaxe concreta: em DSLs textuais externas (FOWLER, 2005), a sintaxe concreta é fortemente acoplada à sintaxe abstrata, aparecendo na forma de palavras reservadas e tokens descritos na gramática da linguagem. Em DSLs visuais, blocos decorados e linhas são a notação padrão.

- Construção da ferramenta de modelagem específica de domínio: Uma vez que as sintaxes abstratas e concretas estejam definidas, uma ferramenta de modelagem específica para a DSL é construída. Frameworks de DSLs, como GMF ou openArchitectureWare, entre outros, são a tecnologia de escolha para a implementação da ferramenta, uma vez que eles exigem pouco conhecimento na construção de linguagens para se alcançar resultados práticos rapidamente (LUCRÉDIO, 2009).

Após a realização desses passos, obtém-se um conjunto de DSLs e ferramentas que permitem que um desenvolvedor represente diferentes tipos de variabilidade em cada subdomínio identificado, desde casos mais simples, baseada em features, até a variabilidade mais 
complexa. Entretanto, as DSLs definidas ainda não estão completas, pois podem existir detalhes adicionais que precisam ser incluídos antes que a DSL sirva de entrada para transformações e geração de código.

\subsubsection{Configuração}

\section{Atividade IP.2: Desenvolvimento das transformações}

Papéis: Implementador do domínio, Especialista do domínio

Entradas: AT.ER.X Modelagem do domínio, AT.ER.10 sub-domínios, AT.PD.X Projeto do domínio

Saídas: AT.IP.1 Linguagens específicas de domínio, AT.IP.2 Suporte ferramental para DSLs, AT.IP.3 Transformações do domínio, AT.IP.4 Implementação de referência

Objetivo: Elaborar as transformações que são utilizadas para gerar o código

\section{Descrição:}

$\mathrm{Na}$ atividade anterior, as DLS foram definidas por meio de sua sintaxe abstrata e concreta. Entretanto, sem a definição de uma semântica, essas DSLs não tem grande utilidade no cenário de MDE, em especial, de geração de código. A semântica é definida em forma de ações a serem executadas por um interpretador automático, que traduz o modelo (programa ou diagrama) em outra linguagem bem conhecida (Kleppe, 2007).

Portanto, agora é necessário produzir as transformações, ou seja, definir a semântica das DSLs. Para isso, utiliza-se uma abordagem bottom-up, semelhante a utilizada por (LUCRÉDIO, 2009), que se inspirou em Varró (2006), Wimmer et al. (2007), Robbes e Lanza (2008).

O princípio é que partir de uma instância concreta de como o código deve ser é mais fácil do que identificar todos os detalhes a partir de uma perspectiva de mais alto nível (ROBBES; LANZA, 2008). Além disso, a ideia deste projeto de doutorado surgiu com enfoque no desenvolvimento de VANTs, para as quais já existia código pronto, e portanto, uma abordagem do tipo bottom-up vai ao encontro dos recursos disponibilizados ao projeto.

Esta atividade é realizada em quatro passos, apresentados a seguir.

- desenvolver ou encontrar uma implementação de referência (WIMMER et al., 2007). Essa implementação de referência tem a finalidade de servir como um framework de domínio. Dessa forma, o gerador precisa gerar somente o código necessário para preencher os pontos flexíveis do framework. Adicionalmente, a implementação de referência deve fornecer exemplos concretos das variabilidades restantes, servindo como um "retrato" do código que as transformações e geradores de código devem produzir.

- Inspeção de código e mapeamento para elementos das DSLs. O segundo passo con- 
siste na inspeção do código da implementação de referência em busca de trechos que correspondam a elementos de alguma DSL do domínio. O objetivo é identificar principalmente a presença de variantes no código, e mapeá-las para as DSLs correspondentes. Observa-se que caso a implementação de referência tenha sido feita seguindo fielmente o projeto, fica mais fácil obter essa informação, pois cada elemento do projeto carrega a informação da feature que ele representa por meio da utilização do perfil de variabilidades definido ao final da engenharia de requisitos (LUCRÉDIO, 2009).

- Refinamento das DSLs. Durante a atividade de inspeção de código, o implementador do domínio pode descobrir que mais detalhes ou informações precisam ser incluídos em alguma DSL antes que se possa utilizá-la como entrada para transformações e geradores de código.

- Desenvolvimento das transformações e geradores de código. Com o refinamento das DSLs, é possível produzir geradores de código baseados em templates. Para isso, o gerador realiza um processo conhecido como migração de código, no qual o código da implementação de referência é anotado com marcações especiais, como tags e scriptlets, que fazem a associação entre o código e a DSL. Cada trecho de código correspondente a alguma variabilidade e recebe algum tipo de anotação.

Geradores baseados em templates representam transformações modelo-para-texto, em um único passo. Porém, transformações modelo-para-modelo também podem ser utilizadas. Nestes casos, deve-se tomar um cuidado especial para que não seja necessário modificar os modelos intermediários, visando evitar problemas de inconsistência. Pode-se evitar este tipo de problema por meio da aplicação de alguns padrões e práticas de sucesso na construção de geradores de aplicações (VöLTER, 2003).

\section{Atividade IP.3: Testar a implementação de referência}

Papéis: Analista de testes, testador

Entradas: AT.IP.4 Implementação de referência

Saídas: AT.IP.4.Atualizada Implementação de referência corrigida

Objetivo: Reduzir a quantidade de defeitos na implementação de referência

\section{Descrição:}

A implementação de referência deve passar por diversos tipos de teste, tais como testes funcionais, estruturais de regressão. A disciplina de teste de linha de produtos é uma área a parte da ciência, portanto foge do escopo do trabalho definir técnicas nesta área.

A maior dificuldade é: como testar um sistema de forma eficiente uma vez que, se acontecer uma falha durante o teste de um VANT, o veículo pode cair e causar danos? Por isso, antes de testar o software embarcado no dispositivo físico que ele opera, realiza-se o teste por 
simulação, conhecido como hardware-in-the-loop (HIL), que é uma técnica para executar teste no nível de sistema, de forma abrangente, econômica e repetível em diversos tipos de sistemas embarcados (LENDIN, 1999).

As simulações HIL são usadas por engenheiros projetistas e de teste para avaliar e validar componentes de sistemas durante o desenvolvimento de novos sistemas embarcados, ou de seus subcomponentes. Em vez de testar estes componentes em um sistema completo, HIL permite o teste de prototipos num ambiente em que softwares simulam o resto do sistema, subsistemas ou o ambiente. A aplicação desta técnica reduz enormemente os custos, a complexidade e o tempo demandado, enquanto aumenta a seguranca, possibilitando realizar diferentes testes em diferentes cenários, em um ambiente proximo do real. Por isso, ela é ideal para o desenvolvimento de linhas de produtos de sistemas críticos, uma vez que, ao mesmo tempo em que se pode testar várias configurações de produtos ou versões de componentes em uma mesma configuração do simulador, para validar as variabilidades de software, pode-se elaborar diferentes configurações do simulador para validar as variabilidades de hardware.

A simulação em HIL requer o desenvolvimento de um simulador em tempo real que modele alguma parte do sistema embarcado sob teste (SUT) e todas as interações significativas dele com o ambiente de operação. O simulador monitora os sinais de saída do SUT e injeta sinais de entrada gerados por ele. Tipicamente, os sinais de saída do SUT incluen comandos para atuadores ou informações para o monitor do operador. As entradas para o SUT devem incluir sinais de sensores e comandos do operador. A saída do sistema em teste é a entrada do simulado, da mesma forma, a saída que o simulador gera é a entrada para o sistema (LENDIN, 1999).

Esta estrutura permite avaliar o comportamento do sistema como um todo, tornando possível a otimização dos algoritmos, alem de permitir experimentar sensores diversos em uma dinâmica próxima da real, pois inclui interação com efeitos do hardware, como amostragem e quantização de sinais, atrasos de tempo, erros e ruídos dos sensores, etc (COELHO, 2007).

Quanto ao HIL, existem outros dois pontos a se considerar:

1. embora possa se tornar caro construir um simulador, ainda é mais barato do que quebrar dispositívos físicos em testes, como por exemplo, um avião;

2. muitos domínios possuem simuladores prontos, para avião por exemplo, existem vários, como por exemplo o AeroSim (UNMANNED DYNAMICS LLC, ).

\subsection{Engenharia de Aplicações}

Nesta seção, são descritas as atividades relativas a engenharia com reúso. O Engenheiro de aplicações trabalha em projetos específicos e tem o objetivo de entregar produtos completos a partir dos ativos centrais (DERAKHSHANMANESH; FOX; EBERT, 2014). O trabalho do 
Engenheiro de aplicações se inicia com a derivação dos requisitos do produto. Um dos objetivos centrais da abordagem definida nesta tese é realizar a Engenharia de domínio de modo a facilitar a fase de Engenharia de aplicações. Enquanto o MDE era utilizado na Engenharia de domínio para gerar ativos centrais, ele é usado na Engenharia de aplicação para derivação automática de produtos. Portanto, a atividade de Engenharia de aplicações consiste basicamente em:

- elicitar os requisitos de um sistema de modo simplificado, por meio da seleção de features a partir de um conjunto previamente definido (Engenharia de Domínio);

- caso exista a demanda por novas features, verifica-se se é viável a reconfiguração da LPS para adição das variabilidades do sistema que se deseja gerar;

- Caso seja viável, realizam-se os passos da abordagem;

- Se o sistema pertence a linha de produtos, ele pode ser derivado automaticamente por meio da escolha das features do sistema alvo.

Observa-se o quanto a Engenharia de aplicações é simplificada e automatizada com a aplicação da abordagem proposta. Dessa forma, a partir de uma Engenharia de domínio robusta, a Engenharia de aplicações pode se tornar uma tarefa trivial, sem a exigência de um especialista para sua realização.

\subsection{Considerações Finais}

Neste capítulo foi apresentada a abordagem ProLCES em detalhes, com suas fases de Análise de mercado, planejamento, Engenharia de Domínio e Engenharia de Aplicações. A Engenharia de domínio tem início com a etapa de Engenharia de requisitos de domínio, com atividades para promover o entendimento do domínio. Para isso, foram propostas atividades para elicitação de requisitos, modelagem de requisitos, gerenciamento de variabilidade desde os estágios iniciais, resolução de variabilidades desde a engenharia de requisitos, modelagem de casos de uso, identificação de subdomínios e definição de um perfil UML de variabilidades.

As principais contribuições da abordagem de Engenharia de requisitos proposta nesta tese são:

- o gerenciamento de variabilidades explícito desde o documento de requisitos;

- a resolução de variabilidades de forma incremental desde a Engenharia de requisitos para simplificar as próximas etapas de desenvolvimento;

- a divisão de domínios grandes em subdomínios, em especial levando em consideração os aspectos de hardware e software, bem como a interdependência entre eles; 
- garantia de rastreabilidade por meio de identificadores nos documentos de requisitos, utilização da CVL, tabela de requisitos e um perfil de variabilidade a ser utilizado para garantir a rastreabilidade na etapa de projeto.

Além disso, foi apresentado uma abordagem para o projeto de linha de produtos com uso de MDE no domínio de SCES. Destaca-se a atividade de refinamento iterativo da arquitetura por meio de padrões. Para ajudar nesta atividade, foram apresentados alguns padrões importantes encontrados na litetura.

Os padrões encontrados tinham diversos objetivos: alguns auxiliavam na subdivisão dos elementos de hardware do sistema para garantir confiabilidade e segurança; outros auxiliavam na subdivisão dos elementos de software do sistema para garantir confiabilidade e segurança; por fim, foram listados alguns padrões de projeto clássicos que podem auxiliar no desenvolvimento para reúso.

Por fim, apresentou-se um processo simplificado para a realização da Engenharia de aplicações segundo a abordagem ProLCES. Observa-se que no capítulo seguinte, apresenta-se a aplicação da abordagem em um estudo de caso de marcapasso. 



\section{Avaliação da Abordagem Proposta}

A utilização de técnicas orientadas a modelos no domínio de sistemas embarcados críticos tem como promessa o aumento do nível de abstração, possibilidade de validação e verificação em estágios iniciais do desenvolvimento e redução da complexidade das plataformas, como definido pelos pesquisadores (DE; SAMI, 1996; KALAVADE; LEE, 1992; HOFFMAN; KOGEL; MEYR, 2001; MICHELL; GUPTA, 1997; HENKEL; HU; BHATTACHARYYA, 2003; SCHMIDT, 2006). Entretanto, o desenvolvimento de sistemas críticos ainda não atende toda a demanda. Para isso, é necessário uma abordagem de reutilização em larga escala, como o uso de linha de produtos sem perder os benefícios alcançados com uso de MDE. Inclusive, pesquisadores como (CZARNECKI et al., 2005) concordam que MDE e LP são esforços complementares.

A presente tese buscou investigar de forma mais aprofundada esta idéia: defende-se que é possível produzir sistemas embarcados críticos em larga escala por meio de um processo sistemático e ainda manter os benefícios obtidos com a utilização de técnicas orientadas a modelo. Para isso, deve-se inserir técnicas de MDE ao longo do ciclo de vida de uma linha de produtos, tanto na engenharia de domínio para gerar ativos centrais quanto na engenharia de aplicações para derivar produtos automaticamente ou semi-automaticamente.

Dessa forma, esta tese possui dois interesses principais:

1. os benefícios trazidos pela linha de produtos no desenvolvimento de SCES. Os benefícios associados à utilização de LP não se limitariam ao desenvolvimento de software, e portanto, seriam insuficientes para aumentar efetivamente a produtividade? Esta tese defende que NÃO: é possível definir uma abordagem de linha de produtos de sistemas que auxilia de forma mais adequada o desenvolvimento de sistemas críticos e oferece meios concretos para aumentar a produtividade e continuar garantindo a segurança nesse domínio;

2. manter os benefícios do MDE mesmo com a utilização de linha de produtos. Não seria o MDE uma técnica que gera um aumento de trabalho sem um ganho equivalente quando aplicado em conjunto com linha de produtos? Esta tese defende que NÃO: as duas técnicas possuem objetivos e atividades semelhantes, de tal forma que é mais vantajoso utilizá-las em conjunto do que separadamente, principalmente em um domínio no qual uma delas já mostrou que oferece muitos benefícios;

Esses são os pontos principais a serem avaliados. Com o objetivo de embasar a discussão em problemas práticos, foi feito um estudo de caso para este trabalho. Uma linha de produtos foi implementada com base na abordagem de linha de produtos orientada a modelos para o domínio de sistemas embarcados críticos. Este estudo de caso ajudou a levantar indícios de que essa combinação é viável e a aplicação de linha de produtos no domínio de sistemas embarcados 
críticos leva a resultados melhores, comparados aos métodos tradicionais de desenvolvimento de SCES.

Para viabilizar a apresentação do estudo de caso de forma clara, nesta tese, foi escolhida a linha de produtos de marca-passo, que é menor e mais gerenciável que a linha de produto de veículos aéreos não tripuláveis apresentada nos exemplos do Capítulo 4. Além disso, para fins acadêmicos, algumas fases, como a de análise de mercado são suprimidas neste Capítulo, que se concentra nas questões de engenharia da linha.

O Capítulo está organizado conforme apresenta-se a seguir. Na Seção 5.1, são apresentadas as principais ferramentas utilizadas no desenvolvimento do estudo de caso. Na Seção 5.2, são apresentados os passos e artefatos realizados no desenvolvimento da linha de produtos de marca-passo. Na Seção 5.3, são apresentadas as discussões relevantes para adoção da abordagem. Por fim, na Seção 5.4, são apresentadas as conclusões deste capítulo.

\subsection{Ferramentas utilizadas}

O estudo de caso ilustrado neste Capítulo foi realizado com apoio das seguintes ferramentas:

- LibreOffice Writer para a escrita dos requisitos e LibreOffice calc para a construção das tabelas de apoio.

- Eclipse foi usado em conjunto com o Eclipse Modeling Framework e o plugin papyrus (MODELING, 2011) para a modelagem dos diagramas UML, SysML e para a definição do perfil de variabilidades;

- a ferramenta SINTEF-CVLTool (SVENDSEN et al., 2010) foi utilizada para a modelagem de features mais simples;

- para a definição de diagramas de features mais completos foi utilizada a ferramenta featureIDE (THÜM et al., 2014).

- UPPAAL model checker utilizado para validar os modelos criados em cima de um modelo de planta, no caso do exemplo, um coração humano.

\subsection{Engenharia da linha de produtos}

Antes de iniciar o desenvolvimento é fundamental definir a estratégia de adoção de linha de produtos, conforme apresentado no Capítulo 4. Para este estudo de caso, adotou-se a estratégia incremental. 
Ressalta-se que é importante conhecer o domínio da linha de produtos em desenvolvimento, conforme apresenta-se a seguir.

\subsubsection{Engenharia de requisitos}

O primeiro passo para definir os requisitos da família de sistemas de marca-passo é compreender o contexto no qual esse tipo de sistema deve atuar, ou seja, deve-se compreender o funcionamento do coração. Esse funcionamento é descrito a seguir conforme apresentado por Jee, Lee e Sokolsky (2010) e já introduzido brevemente no Capítulo 4.

Um coração humano tem quatro câmaras: átrios direito e esquerdo e ventrículos direito e esquerdo. O sangue desoxigenado do corpo é recolhido no átrio direito e, em seguida, bombeado para dentro dos pulmões pelo ventrículo direito. Nos pulmões, o dióxido de carbono no sangue é substituído por oxigênio. Esse sangue oxigenado, em seguida, passa pelo átrio esquerdo e entra no ventrículo esquerdo, que o bombeia para o resto do corpo.

De um ponto de vista eletrônico, o coração é como uma bomba constituída por tecido musculoso, controlado por um sistema elétrico intrínseco. Um estímulo elétrico é gerado periodicamente (normalmente cerca de 60-100 vezes por minuto) pelo nó sinusal, localizado no átrio direito, percorre as vias de condução e faz as câmaras do coração se contraírem e bombearem o sangue. Os átrios são estimulados e contraídos pouco antes da estimulação e contração dos ventrículos.

Sob certas condições, esse sistema cardíaco intrínseco não funciona corretamente e a frequência cardíaca torna-se excessivamente rápida, lenta, ou irregular. Nessas situações, o organismo pode não receber sangue suficiente, o que pode causar vários sintomas, tais como pressão arterial baixa, fraqueza ou fadiga. Para evitar esses problemas, um marca-passo pode ser utilizado para regular o ritmo cardíaco.

Um marca-passo cardíaco é um dispositivo eletrônico implantado no corpo para regular o batimento do coração por meio de estímulos elétricos entregues por cabos-eletrodos que estão em contato com o coração. Esses estímulos são chamados de ritmos. O marca-passo pode também detectar estímulos cardíacos naturais, chamados sentidos. Refere-se aos ritmos cardíacos e sentidos, coletivamente como eventos.

Um marca-passo deve atender a três requisitos médicos fundamentais: a frequência de contração das câmaras cardíacas não deve ser muito elevada; a frequência de contração das câmaras cardíacas não deve ser muito baixa; e, os ventrículos devem se contrair em um determinado intervalo após a contração dos átrios. Esses requisitos gerais são concretizados pela definição de valores ou intervalos específicos para os parâmetros configuráveis do marca-passo.

O marca-passo pode operar em vários modos, que se distinguem pelas câmaras do coração que são sentidas e estimuladas, como os eventos sentidos afetarão o ritmo, e se a 
frequência de estimulação é adaptada para o estado do paciente.

Para especificar os requisitos da linha de produtos de sistema de marca-passo foram observados e estudados três tipos distintos de marca-passo representados pelas seguintes siglas VVI, AAI e DDD. O primeiro tipo(VVI) representa um marca-passo que detecta apenas contrações ventriculares e realiza apenas a estimulação ventricular. Nesse modo, a estimulação é inibida se as contrações ventriculares são sentidas. O segundo tipo (AAI) é uma variante que estimula e detecta apenas eventos que ocorrem no átrio. Diferentemente, um marca-passo DDD detecta e estimula ambas as câmaras.

Esses modos de operação são categorizados por um código internacional, NASPE/ BPEG (BERNSTEIN et al., 2002). Sua definição envolve cinco letras. A primeira refere-se à câmara cardíaca estimulada pelo eletrodo. A segunda, à câmara de onde parte a atividade elétrica sentida pelo MP. A terceira, ao modo de resposta do aparelho depois de captar ou sentir atividade elétrica, se inibido (I), ou ativado (T), ou ambos (D). A letra dessa posição é diretamente atrelada à da segunda, pois, sem captação do estímulo não é possível obter nenhuma resposta do dispositivo gerador. A quarta refere-se aos parâmetros que podem ser programados: $\mathrm{R}$ é relativo à frequência de resposta; $\mathrm{C}$ se o MP é capaz de receber ou transmitir dados; $\mathrm{M}$ indica que pode ser programado em mais de três parâmetros; $\mathrm{P}$ é limitado a menos de três parâmetros e $\mathrm{O}$, que é raramente encontrada e não-programável para nenhum parâmetro.

De acordo com essas definições e com os requisitos definidos pelo Boston Center (SCIENTIFIC, 2007), apresenta-se na listagem a seguir, um subconjunto dos requisitos da LP de sistema de marca-passo que são utilizados para mostrar a abordagem proposta.

Listagem 5.1 - Parte dos requisitos da linha de produtos de marca-passo.

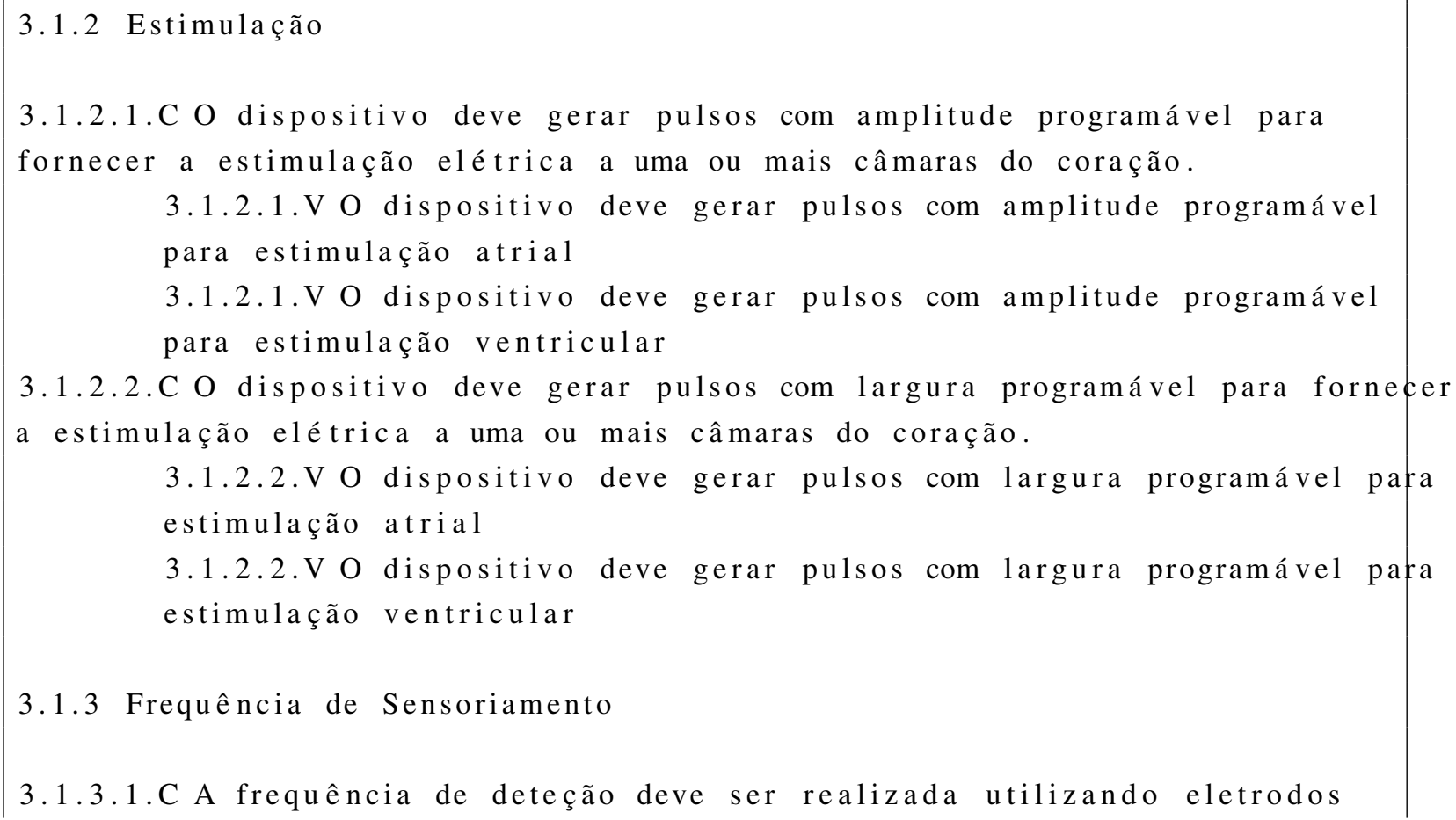




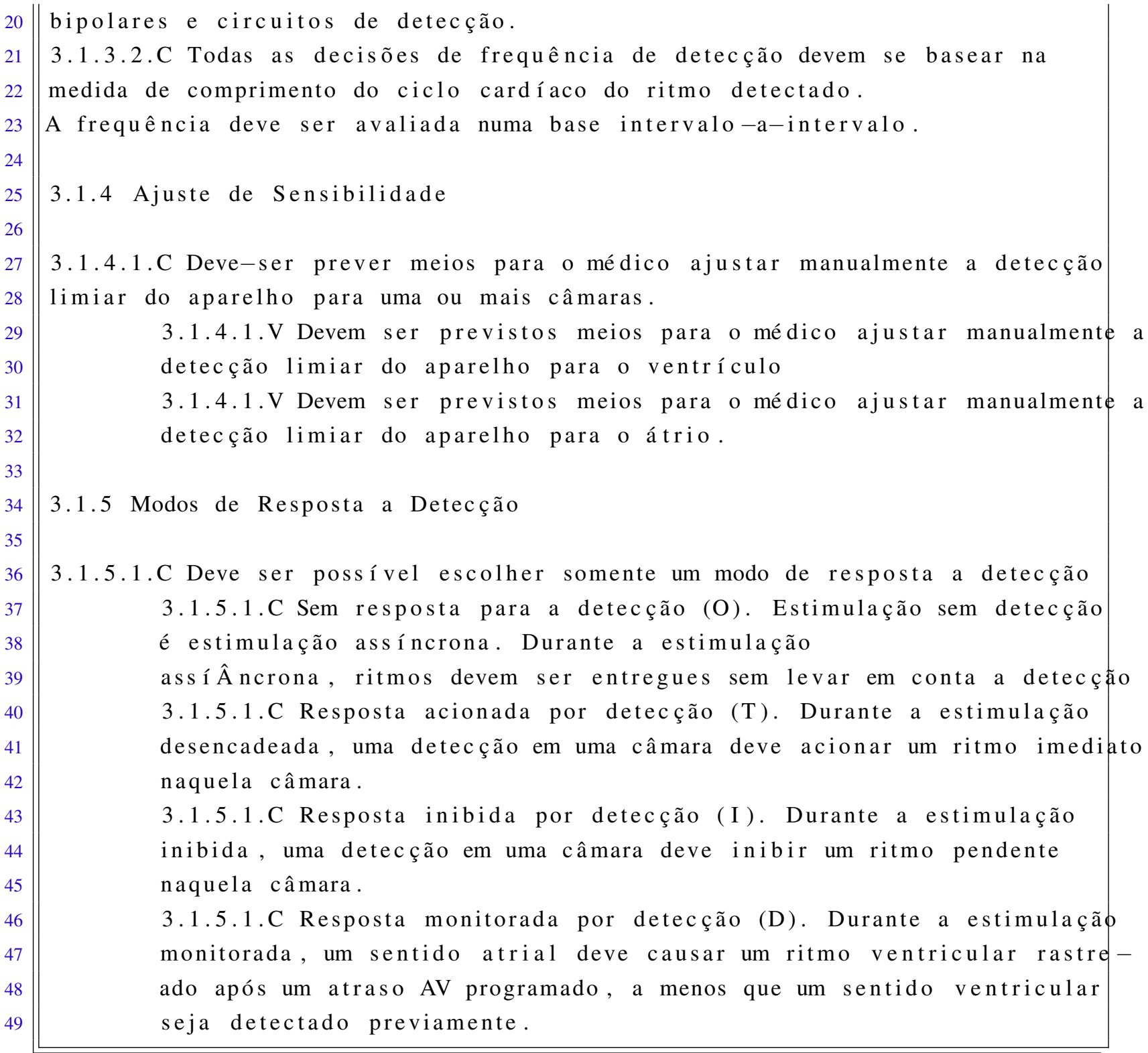

Os requisitos do núcleo, que correspondem aos obrigatórios e são identificados pela letra "C" existente em seu código identificador, são transformados em razão de 1 para 1 em requisitos do diagrama de requisitos SysML, conforme apresenta-se na Figura 48.

Além dos requisitos, conforme apresentado no Capítulo 4, é importante elaborar desde o início do desenvolvimento uma lista com os possíveis sistemas derivados da LP. Para esta linha de produtos, os possíveis sistemas são apresentados na tabela apresentada por meio da Figura 49 com uma lista inicial das características que eles devem atender. Foram selecionados dezoito tipos de marca-passos diferentes e definidas as features que os distinguem.

É importante destacar o quanto as técnicas de Engenharia de linhas de produtos e Engenharia orientada a modelos se combinam. Na escrita do documento de requisitos foi utilizada uma técnica de linha de produtos; a descrição dos requisitos em diagrama de requisitos é uma técnica orientada a modelo; a tabela de possíveis sistemas alvo da linha é uma técnica de origem na Engenharia de linha de produtos. 
Figura 48 - Parte do diagrama de requisitos SysML da linha de produtos de marca-passo.

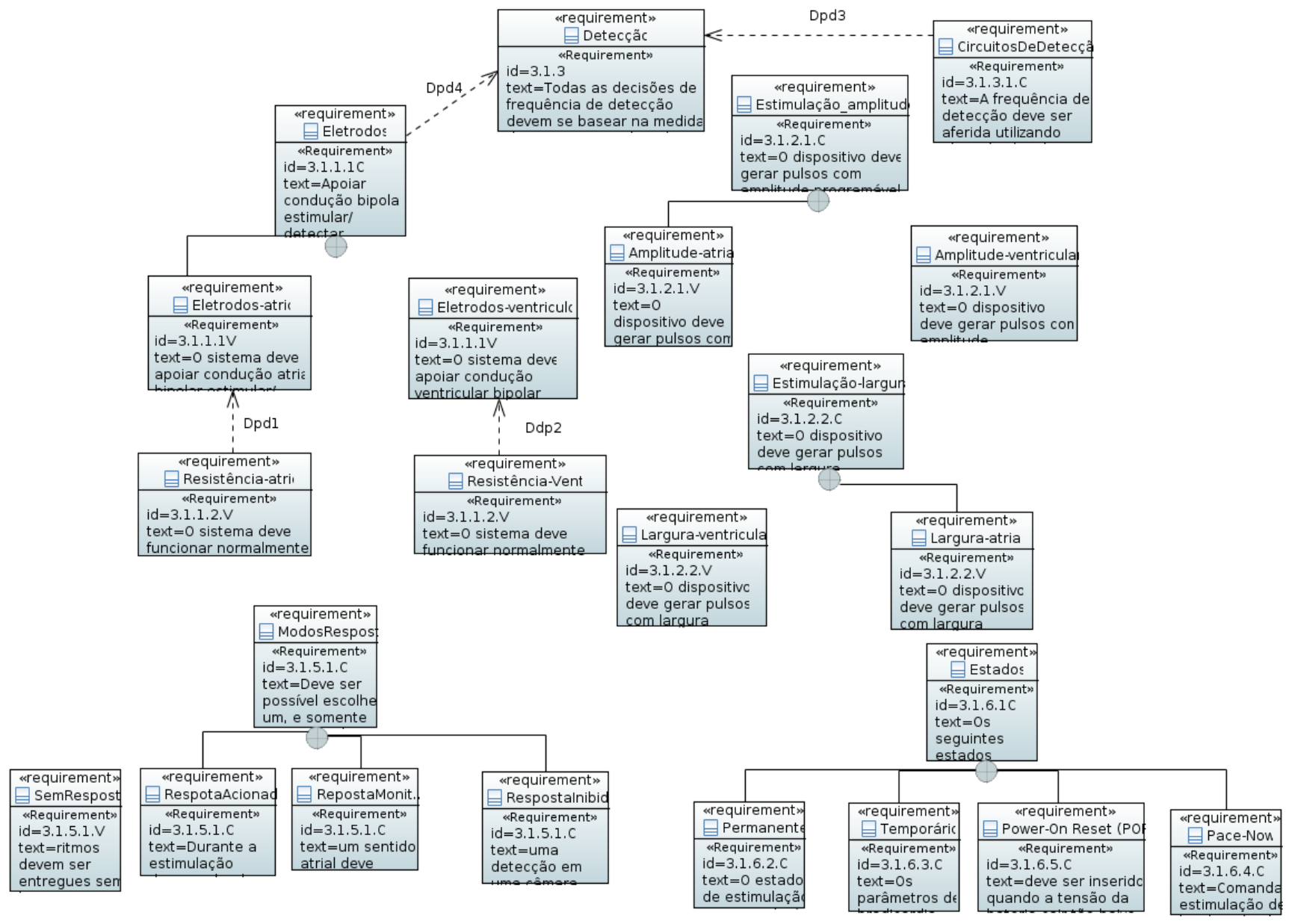

Figura 49 - Tipos de sistemas marca-passo e suas features.

\begin{tabular}{|c|c|c|c|c|c|c|c|c|c|c|c|c|c|c|c|c|c|c|}
\hline FeaturesiSistemas & \begin{tabular}{|l}
$\mathrm{A}$ \\
$\mathrm{A}$ \\
$\mathrm{T}$
\end{tabular} & $\begin{array}{l}\mathrm{V} \\
\mathrm{V} \\
\mathrm{T}\end{array}$ & $\begin{array}{l}\text { A } \\
\text { O } \\
\text { O }\end{array}$ & $\begin{array}{l}\text { A } \\
\text { A } \\
\text { I }\end{array}$ & $\begin{array}{l}\mathrm{V} \\
\mathrm{O} \\
\mathrm{O}\end{array}$ & $\begin{array}{l}\text { V } \\
\text { V } \\
\text { I }\end{array}$ & $\begin{array}{l}\mathrm{V} \\
\mathrm{D} \\
\mathrm{D}\end{array}$ & $\begin{array}{l}D \\
O \\
O\end{array}$ & $\begin{array}{l}D \\
D \\
I\end{array}$ & $\begin{array}{l}D \\
D \\
D\end{array}$ & $\begin{array}{l}A \\
O \\
O \\
R\end{array}$ & $\begin{array}{l}\mathrm{A} \\
\mathrm{A} \\
\mathrm{I} \\
\mathrm{R}\end{array}$ & $\begin{array}{l}\mathrm{V} \\
\mathrm{O} \\
\mathrm{O} \\
\mathrm{R}\end{array}$ & $\begin{array}{l}\mathrm{V} \\
\mathrm{V} \\
\mathrm{I} \\
\mathrm{R}\end{array}$ & $\begin{array}{l}V \\
D \\
D \\
R\end{array}$ & $\begin{array}{l}\mathrm{D} \\
\mathrm{O} \\
\mathrm{O} \\
\mathrm{R}\end{array}$ & \begin{tabular}{|l}
$D$ \\
$D$ \\
$I$ \\
$R$
\end{tabular} & $\begin{array}{l}D \\
D \\
D \\
R \\
\end{array}$ \\
\hline Detecçāo Atrial & $\mathrm{X}$ & & & $\mathrm{X}$ & & & & & & & & $\mathrm{X}$ & & & & & & \\
\hline Detecçāo Ventricular & & $\mathrm{x}$ & & & & $x$ & & & & & & & & $\mathrm{X}$ & & & & \\
\hline Detecçāo Dupla & & & & & & & $\mathrm{X}$ & & $\mathrm{X}$ & $\mathrm{x}$ & & & & & $\mathrm{X}$ & & $\mathrm{X}$ & $x$ \\
\hline Estimulaçāo Atrial & $\mathrm{X}$ & & $\mathrm{x}$ & $\mathrm{x}$ & & & & & & & $\mathrm{x}$ & $x$ & & & & & & \\
\hline Estimulaçāo Ventricular & & $\mathrm{x}$ & & & $\mathrm{X}$ & $\mathrm{X}$ & $\mathrm{X}$ & & & & & & $\mathrm{X}$ & $\mathrm{x}$ & $\mathrm{X}$ & & & \\
\hline Estimulaçāo Dupla & & & & & & & & $\mathrm{X}$ & $\mathrm{x}$ & $\mathrm{x}$ & & & & & & $\mathrm{X}$ & $\mathrm{X}$ & $x$ \\
\hline Resposta a Detecçāo Inibida & & & & $\mathrm{X}$ & & $\mathrm{x}$ & & & $\mathrm{x}$ & & & $\mathrm{X}$ & & $\mathrm{X}$ & & & $\mathrm{X}$ & \\
\hline Resposta a Detecçāo Dupla & & & & & & & $\mathrm{X}$ & & & $\mathrm{X}$ & & & & & $\mathrm{x}$ & & & $\mathrm{X}$ \\
\hline Resposta a Detecçāo Ativada & $\mathrm{x}$ & $x$ & & & & & & & & & & & & & & & & \\
\hline Taxa de modulação adaptativa & & & & & & & & & & & $\mathrm{X}$ & $\mathrm{x}$ & $\mathrm{X}$ & $\mathrm{X}$ & $\mathrm{x}$ & $\mathrm{x}$ & $\mathrm{X}$ & $\mathrm{x}$ \\
\hline
\end{tabular}

A seguir, na Figura 50 ilustra-se uma parte das features da linha de produtos de marcapasso por meio do modelo de features hierárquico. Essas features são capazes de descrever 945 configurações diferentes de produtos.

O próximo passo da abordagem proposta nesta tese é criar o modelo de requisitos de linha de produtos, que é composto pelo modelo de features, pelos pontos de variação e pelo modelo base. Este modelo é ilustrado na Figura 51, de forma simplificada para facilitar o entendimento. 
Figura 50 - Features da linha de produtos de marca-passo .

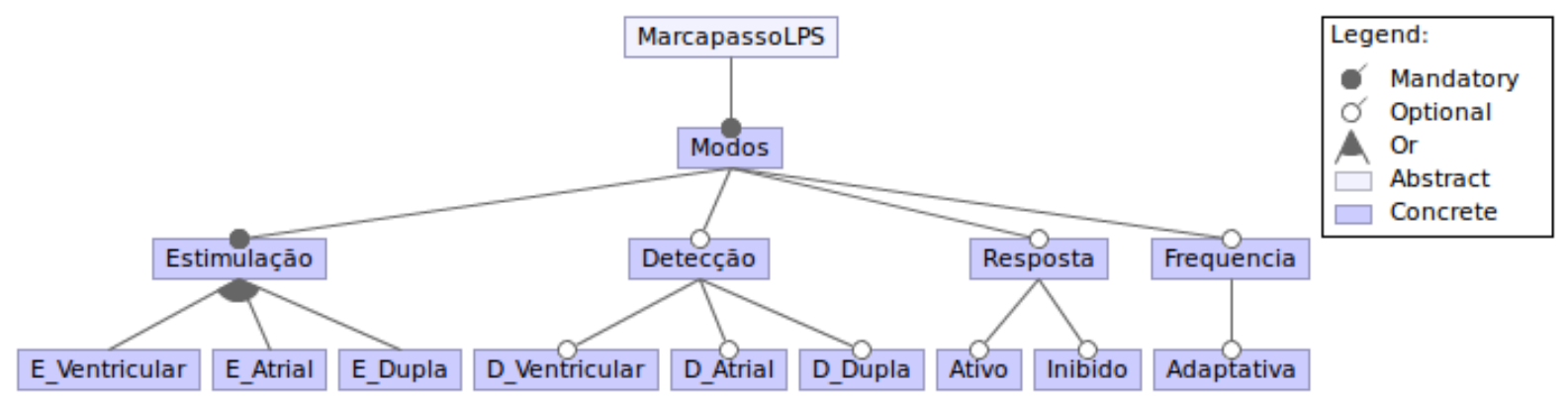

Observa-se que o modelo base escolhido é o modelo de requisitos completo, com todos os requisitos possíveis. Dessa forma, implementa-se o tipo de variabilidade negativa, na qual a funcionalidade é removida de acordo com os requisitos específicos do produto.

Na primeira iteração, são priorizados os requisitos obrigatórios da linha de produtos. Em relação à linha de produtos de marca-passo, com os requisitos obrigatórios obtêm-se mais de um produto funcional, que pode ser um marca-passo do tipo A00 ou V00 ou D00. Portanto, deve-se escolher um deles para iniciar a primeira Iteração. Neste exemplo, foi escolhido, aleatoriamente, o V00, ou seja, um marca-passo que fornece somente estimulação ventricular.

Partes da descrição de casos de uso para o caso de uso estimulação atrial são apresentados na Listagem 5.2.

Listagem 5.2 - Parte dos requisitos da linha de produtos de marca-passo.

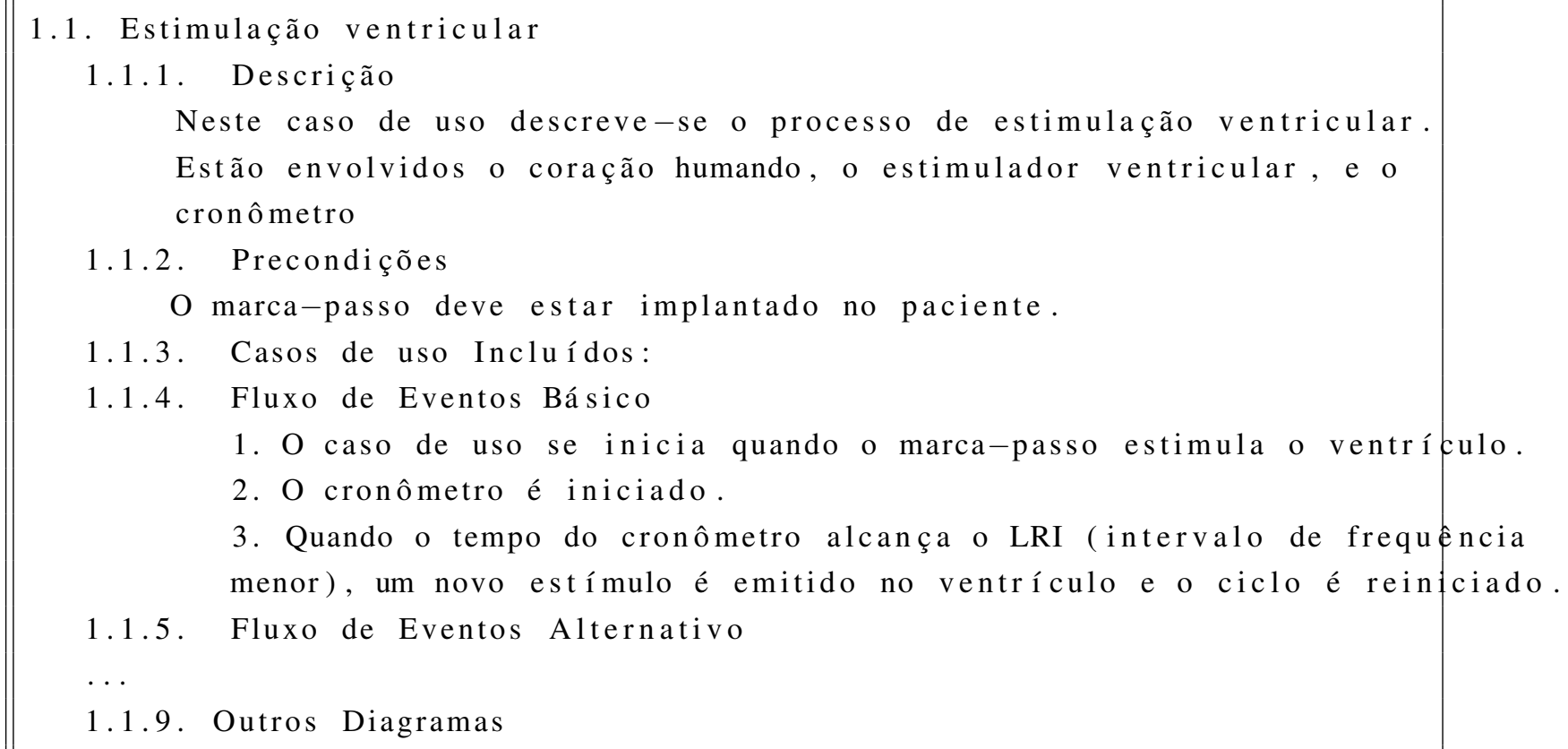

O caso uso é então relacionado ao requisito funcional de estimulação Ventricular, por meio da relação refine. Visto que um marca-passo pode ser descrito em termos de estados com grande comportamento temporal, o caso de uso de Detecção Ventricular também é descrito por 
meio de um autômato temporal, para que possa ser validado por uma ferramenta de model check como o UPPAAL, o que resulta no modelo apresentado na Figura 52.

Observa-se que o statechart possui somente dois estados: o estado inicial e o estado de espera. A partir da primeira estimulação, o marca-passo inicia o cronômetro e entra em estado de espera, até que o tempo do cronômetro fique igual ao tempo definido no RI. Quando essa condição é alcançada, um novo estímulo é realizado e o marca-passo vai para o estado de espera VRP.

Para que um modelo de sistema embarcado seja validado, necessita-se definir o modelo da planta de execução do sistema. No caso de um marca-passo, ele opera no coração humano, portanto necessita-se simular o comportamento do coração, conforme apresenta-se na Figura 53.

Figura 51 - Modelo de requisitos de linha de produtos.

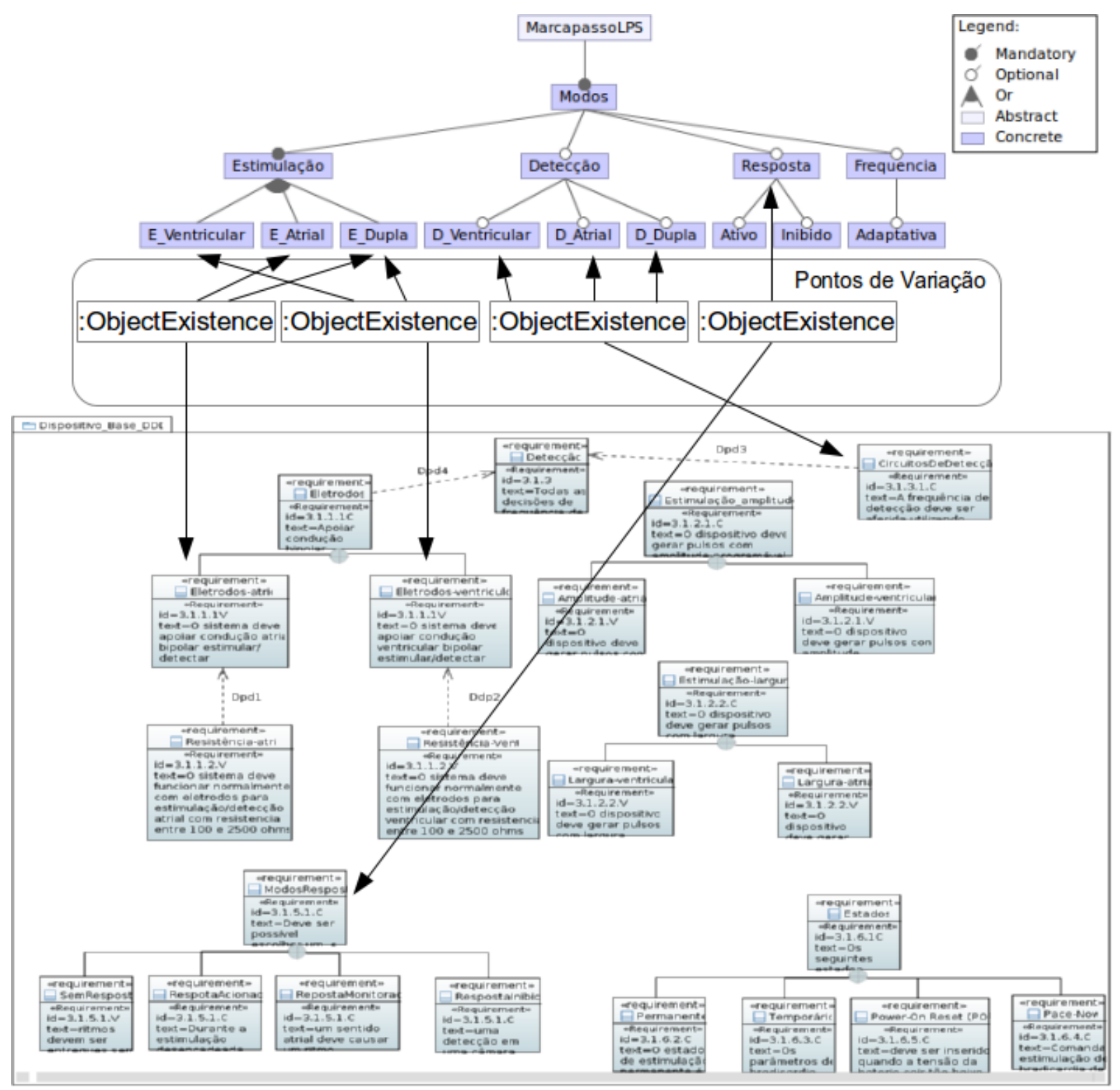


Figura 52 - autômato temporal do marca-passo VVI.

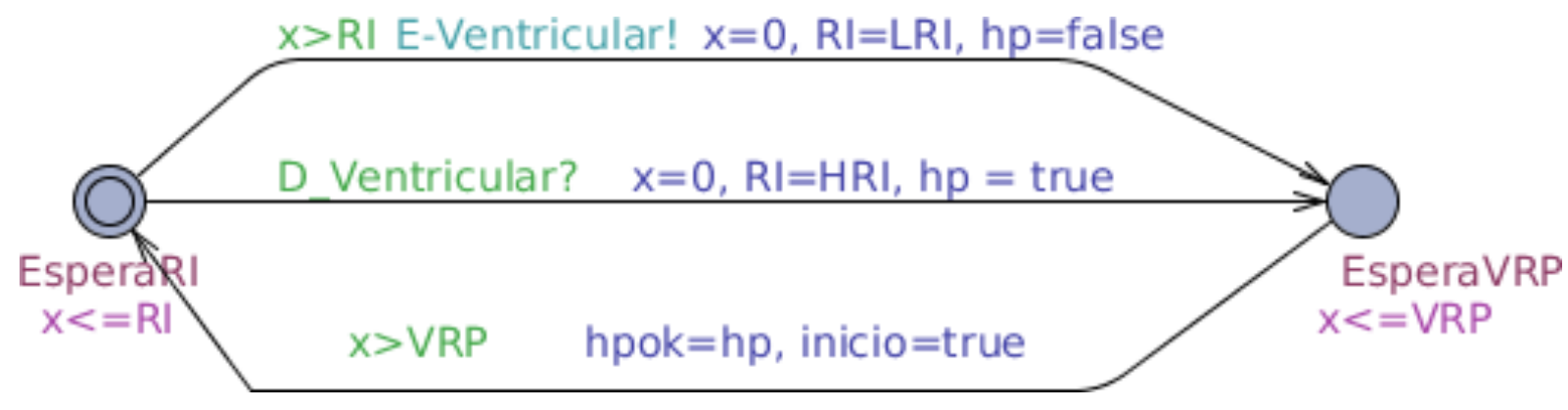

Esse modelo de coração é uma abstração que apresenta apenas os aspectos relevantes para que o modelo de marca-passo possa ser simulado e verificado. Ele possui apenas um estado, "pronto", no qual o coração espera por uma estimulação ventricular do marca-passo por um tempo de espera máximo, chamado de EM. Uma vez que ele recebe um evento de estimulação, ele volta para o estado "pronto" e reinicia o cronômetro.

Figura 53 - Modelo do coração humano.

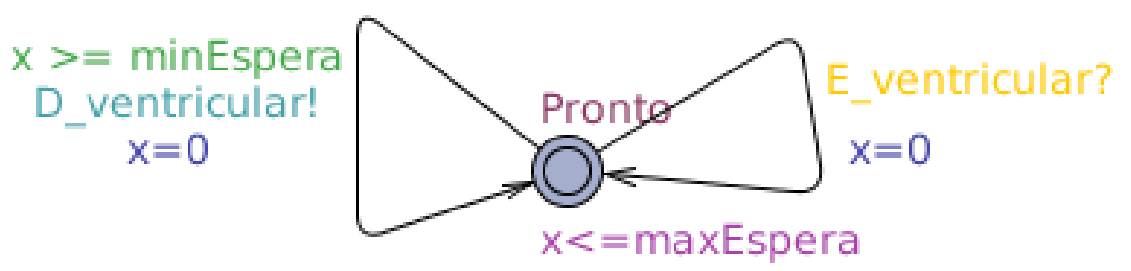

Na Figura 54, apresenta-se o modelo do marca-passo no UPPAAL para validação. Pode-se utilizar o MARTE para modelar as propriedades temporais em máquinas de estado e converter o modelo MARTE na linguagem aceita por algum validador de modelos. Por exemplo em Cheddar (2007) apresenta-se uma ferramenta para converter modelos em MARTE em XML que pode ser lido pelo CHEDDAR (SINGHOFF et al., 2004). Em http://mast.unican.es/umlmast/marte2mast, apresenta-se outra ferramenta capaz de converter modelos em MARTE para serem validados pelo MAST (HARBOUR et al., 2001), entre outros.

Entre os subdomínios do domínio de marca-passo, para fins de simplificação, pode-se dividi-lo nos subdomínios de estimulação, detecção, resposta a detecção e frequência de resposta. Para nenhum desses subdomínios foram encontradas DSLs ou ferramentas específicas.

O perfil de variabilidade para a linha de produtos de marca-passo é apresentada na Figura 55, e foi feita de acordo com as diretrizes definidas no Capítulo 4

\subsubsection{Projeto de domínio}

Quanto ao projeto, ele se inicia com um modelo de arquitetura em alto nível extraído dos requisitos, conforme apresenta-se na Figura 56. Observa-se que o marca-passo é composto por um gerador de pulsos (GP) que contém a parte lógica do sistema, possui um atuador, que 
Figura 54 - Modelo sendo validado pela UPPAAL.

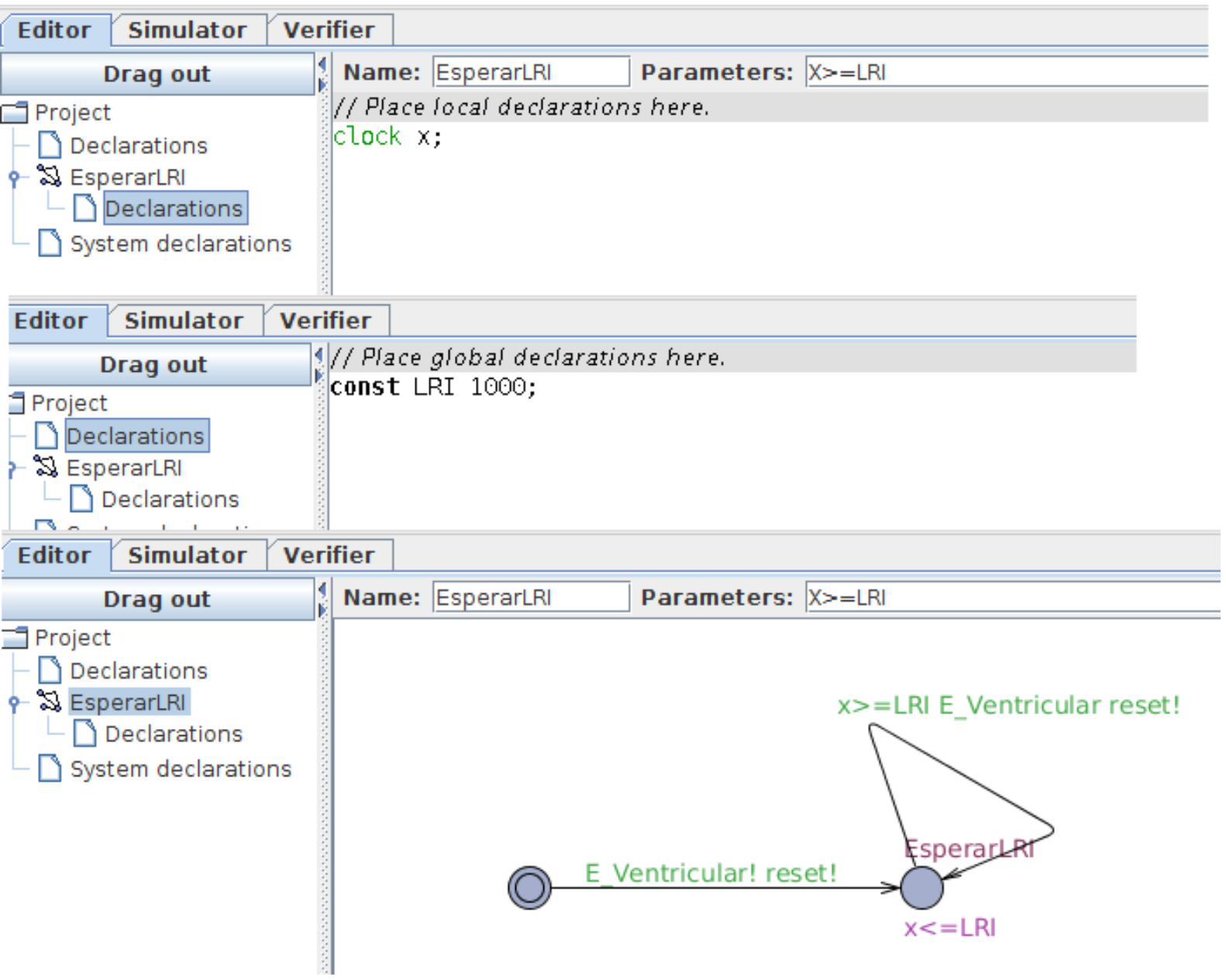

Figura 55 - Estereótipos do perfil de variabilidade.

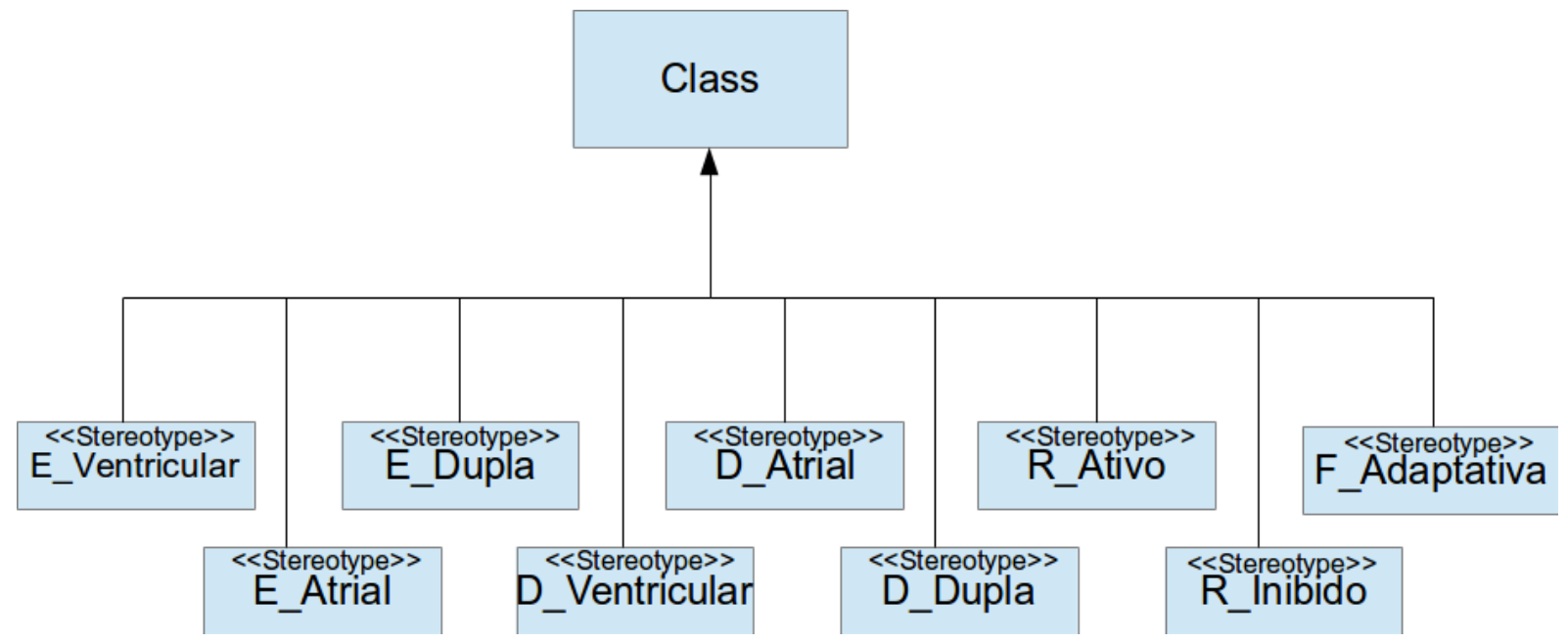

de acordo com as ordens do GP, envia os pulsos ao coração por meio dos eletrodos. Para compor o sistema, também foi modelado o coração. As diretrizes que guiam o desenvolvimento desta arquitetura são definidas pelo caso de uso Estimulação Ventricular. A máquina de estado 
elaborada durante a Engenharia de requisitos já representa uma das visões da arquitetura do marca-passo.

Figura 56 - Arquitetura em alto nível.

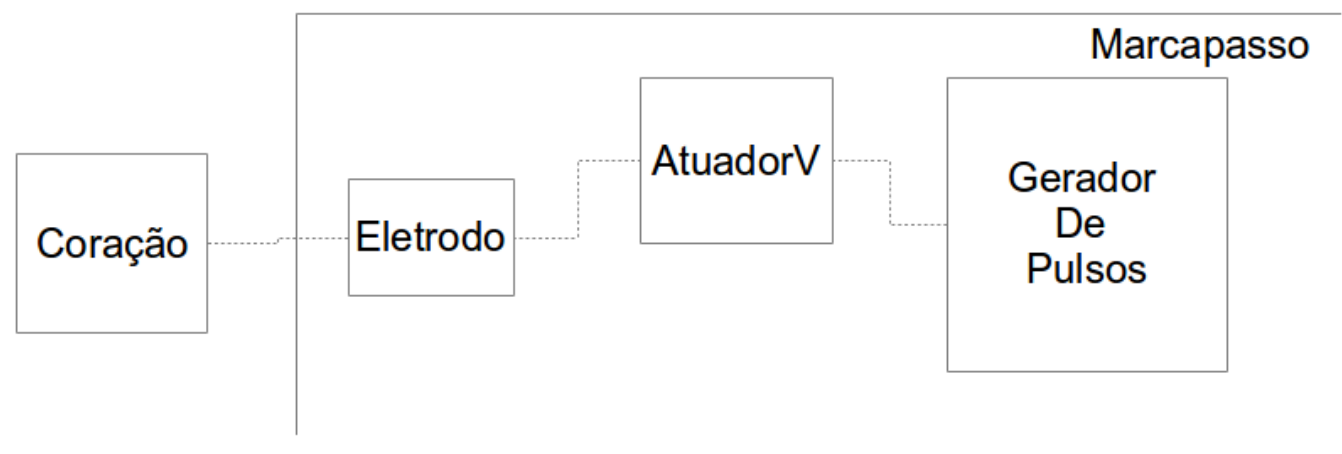

Os próximos passos consistem em refinar essa arquitetura inicial. Uma boa estratégia é começar aplicando algum padrão. O refinamento consiste em detalhar o componente Gerador de pulsos que é o componente principal do padrão. Observa-se que o comportamento do gerador de pulsos é exatamente o comportamento descrito pela máquina de estados.

No próximo refinamento é necessário decidir qual outro padrão pode ser aplicado. Visto que um marca passo precisa ter um alto desempenho, pois precisa gerar pulsos em intervalos curtos de tempo, optou-se por não aplicar nenhum padrão de redundância.

\subsubsection{Implementação de domínio}

Neste ponto entra em cena a abordagem bottom-up, que se inicia por meio da implementação ou descoberta de uma implementação de referência. Neste estudo de caso, utilizou-se a implementação de referência apresentada por Gomes e Oliveira (2011), apresentada na Listagem 5.3. A partir desta implementação pode-se retirar trechos específicos para a estimulção ventricular.

Listagem 5.3 - Parte da implementação de referência.

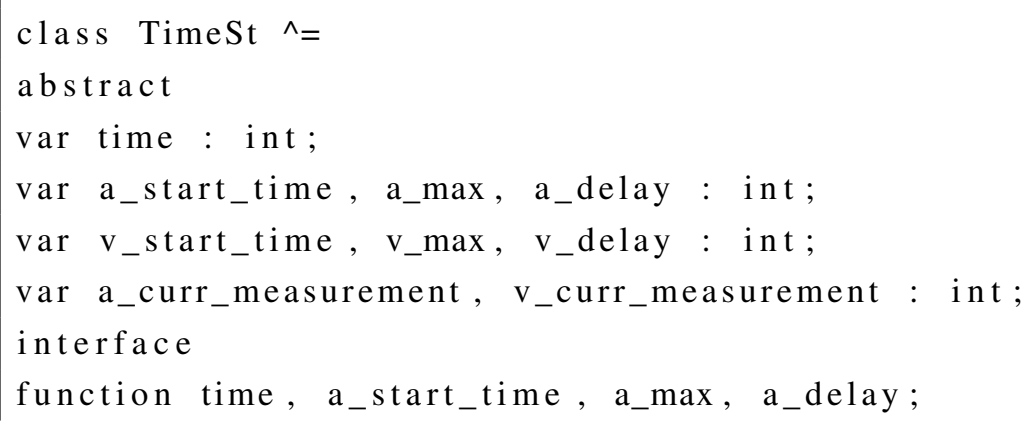




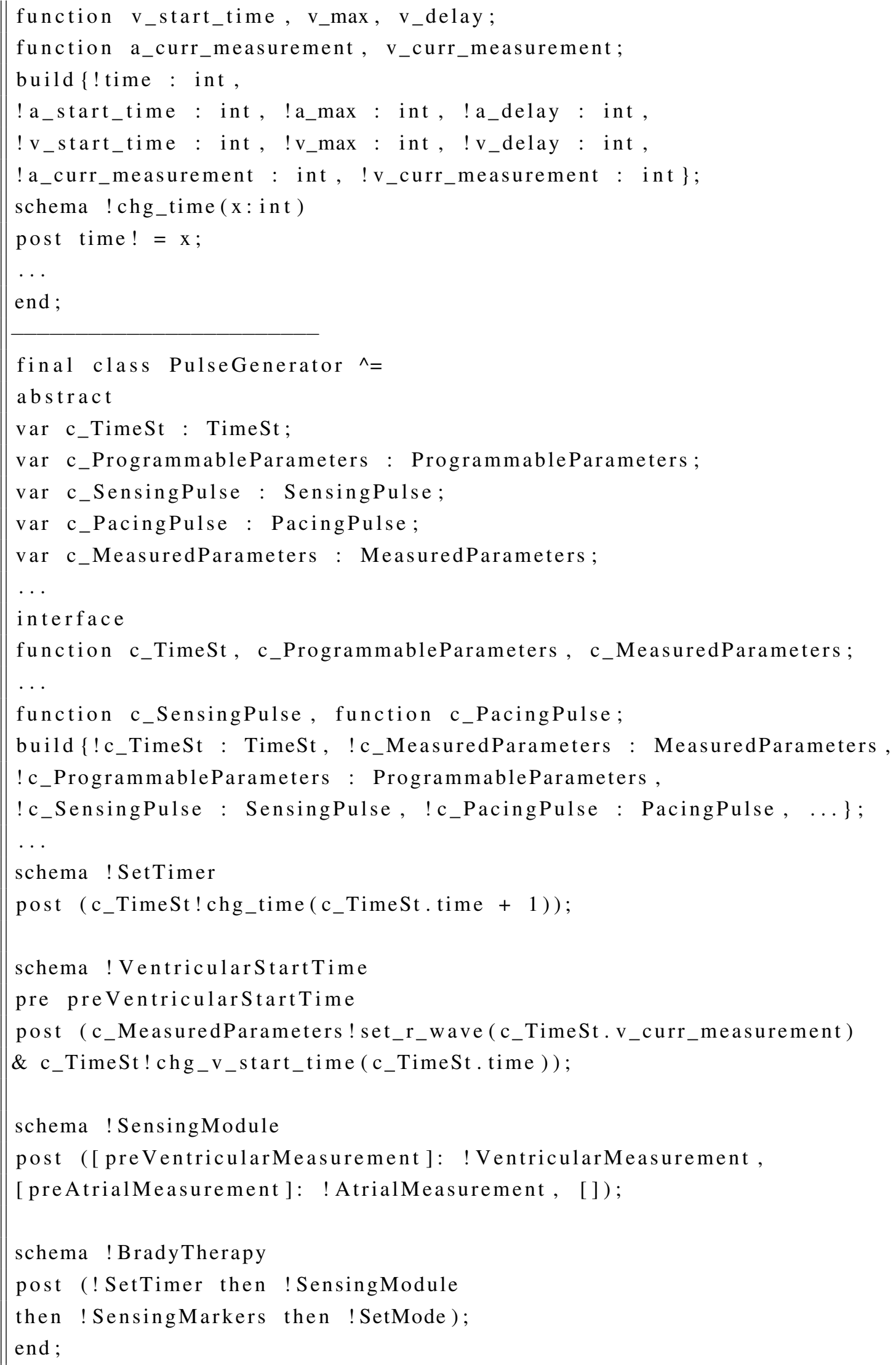

Para gerar o código do marca-passo, é necessário definir uma plataforma de hardware. Existe uma plataforma de referência do desafio de métodos formais para marca-passo (LABO- 
RATORY, ), que é definida como um Microchip 8-bit PIC18F4520 microcontrolador (PIC18 MCU) com $40 \mathrm{MHz}$ de clock.

Até este ponto é possível mapear os requisitos que estão relacionados com featue de estimulação ventricular até chegar ao código fonte, que deve ser configurado em uma ferramenta com base em templates, como JET ou acceleo.

Na segunda iteração, ainda deve-se continuar implementando features obrigatórias, pois restam ainda os marca-passos VVT, AAT e outros. Pode-se escolher um deles ao acaso e refazer o ciclo de desenvolvimento. Esse ciclo persiste, até que todas as variabilidades tenham sido implementadas.

\subsection{Discussão}

A literatura comprova que as linhas de produto representam uma abordagem bem sucedida para o desenvolvimento em larga escala (NORTHROP et al., 2009). Mesmo sendo reconhecidamente bem sucedida, essa abordagem enfrenta barreiras quanto ao desenvolvimento de sistemas embarcados críticos. Essas barreiras podem ser superadas por meio de uma abordagem sistemática que utilize técnicas de desenvolvimento já consagradas neste domínio, tal como a engenharia orientada a modelos.

Nesta tese foi definida uma abordagem que combina as duas técnicas de desenvolvimento para o desenvolvimento de SCES. Embora essas duas abordagens sejam robustas, quando combinadas, não geram muitas atividades extras como se espera, pelo contrário. A sua sinergia é grande, pois compartilham diversas atividades comuns e ao mesmo tempo, as atividades diferentes são complementares. Desse modo, o desenvolvimento de uma linha de produtos obtém grandes vantagens com técnicas orientadas a modelo e o desenvolvimento orientado a modelo oferece seus melhores benefícios combinado com uma estratégia de linha de produtos.

Conforme apresentado no Capítulo 2, os desenvolvedores da área necessitam principalmente de abordagem completas, que lidem com os requisitos e aumentem a produtividade, mas que ao mesmo tempo sejam de fácil adoção. A migração do desenvolvimento de sistemas únicos para o desenvolvimento de linhas de produtos requer uma adaptação e pessoal qualificado. Mesmo assim, o estudo de caso fornece indícios de que é possível adotar a abordagem proposta.

É claro que, idealmente, seria importante verificar se alguém diferente do autor da tese conseguiria elaborar algum exemplo de linha de produtos seguindo os passos dessa abordagem. Entretanto, restrições de tempo para a conclusão deste projeto não permitiram este tipo de validação. 


\subsection{Considerações Finais}

Neste Capítulo foi apresentado um estudo de caso que aplicou a abordagem proposta ao domínio de sistemas de marca-passo. Foi possível notar que as técnicas de linha de produtos em combinação com técnicas orientadas a modelos introduzidas pela abordagem proposta nesta tese, introduziram pouca carga extra ao desenvolvimento, quando comparado com outras abordagens de linha de produtos.

Além disso, a combinação dessas técnicas permite que o domínio de sistemas embarcados críticos possa se beneficiar de um reúso sistemático e desenvolvimento em larga escala, ao mesmo tempo que continua a se beneficiar do aumento do nível de abstração, possibilidade de validação e verificação desde os estágios iniciais do desenvolvimento, co-desing e co-simulação, além de reduzir a atividade de codificação manual que é tão sucetível a erros. 


\section{Conclusões}

Reutilização de software e desenvolvimento em larga escala é um objetivo constantemente procurado por pesquisadores e profissionais envolvidos com desenvolvimento de software em diferentes domínios. A crescente imersão dos sistemas críticos em nossas atividades cotidianas aumentou a demanda por esse tipo de sistema, e consequentemente, são necessárias novas técnicas para aumentar a produtividade.

Embora a idéia de reutilização possa parecer simples de se colocar em prática, e obter benefícios com suas promessas, na prática, a sua aplicação efetiva requer abordagens sistemáticas, demanda um maior custo inicial e exige profissionais qualificados. Para alcançar os benefícios da Engenharia de linhas de produto no domínio de sistemas embarcados críticos, optou-se por combinar técnicas de engenharia orientada a modelos dentro do ciclo de vida de desenvolvimento de linha de produtos, visto que o MDE já tem comprovados benefícios no domínio de SCES, tais como aumento do nível de abstração, co-desing, co-simulação, geração automática de código, entre outros.

Entretanto, ao combinar duas técnicas robustas de desenvolvimento, pode-se imaginar, em um primeiro momento, que a abordagem de desenvolvimento pode ficar demasiadamente grande e de difícil adoção. No entanto, esta tese apresentou indícios contrários a esse pensamento, pois essas técnicas já possuem uma grande sinergia e muitas atividades em comum. Portanto, o domínio de SCES pode sim, se beneficiar de uma abordagem sistemática de reúso, como linha de produtos e continuar se beneficiando dos avanços obtidos com o desenvolvimento orientado a modelos.

\subsection{Principais Contribuições}

Nesta tese foram discutidas idéias para resolver parte do problema de desenvolvimento em larga escala para o domínio de sistemas embarcados críticos, por meio do desenvolvimento de linha de produtos, sem perder os benefícios que a orientação a modelos já oferece há algum tempo, neste domínio.

Após estudos e pesquisas nas áreas relacionadas, foi definida uma abordagem de linha de produtos com técnicas orientadas a modelos para o desenvolvimento de famílias de sistemas embarcados críticos, visando guiar o engenheiro de sistemas, de software e hardware desde as atividades iniciais de definição dos requisitos até a configuração de um gerador de aplicações para o domínio, utilizando o desenvolvimento orientado a modelos para fornecer aumento do nível de abstração e possibilidade de validação desde os estágios iniciais de desenvolvimento. 
Neste sentido, as seguintes contribuições foram feitas nesta área:

- Uma abordagem sistemática, contendo atividades, com suas respectivas entradas e saídas que detalham as tarefas necessárias para a realização da engenharia de domínio, com integração de forma concreta das técnicas orientadas a modelo no desenvolvimento de sistemas embarcados críticos;

- Definição de um processo sistemático para Engenharia de requisitos de domínio orientada a modelos e com garantia de rastreabilidade de requisitos;

- Identificação de um conjunto de padrões específicos para garantia de segurança que podem ser combinados com padrões referentes a variabilidades para guiar a definição da arquitetura da linha;

- Definição de um perfil de variabilidade para oferecer rastreabilidade entre os artefatos de requisitos e projeto sem a necessidade de ferramentas específicas;

- Definição de um método para combinar SysML com a linguagem CVL para derivação de produtos da linha durante a Engenharia de Requisitos;

- Condução e apresentação de uma revisão sistemática sobre as técnicas de desenvolvimento de linha de produtos de sistemas críticos com uso de técnicas orientada a modelos.

\subsection{Publicações resultantes da tese}

Além das contribuições citadas na seção anterior, as seguintes publicações diretamente relacionadas à tese foram obtidas:

- Queiroz, P.G.G; Braga R.T.V. A critical embedded system product line model-based approach. In: Proceedings of the Twenty-Sixth International Conference on Software Engineering \& Knowledge Engineering (SEKE). Knowledge Systems Institute Graduate School, 2014. p. 71-75.

- Queiroz, P.G.G; Braga R.T.V. Development of critical embedded systems using modeldriven and product lines techniques: A systematic review. In: Proceedings of the 8th Brazilian Symposium on Software Components, Architectures and Reuse (SBCARS). Alagoas, Brasil, 2014.

- Queiroz, P.G.G; Braga R.T.V. Combining MARTE-UML, SysML and CVL to build unmanned aerial vehicles. In: Proceedings of the Ninth International Conference on Software Engineering Advances (ICSEA).IARIA, 2014.p. 334-340. 
- Queiroz, P.G.G; Braga R.T.V. Desenvolvimento de Sistemas Embarcados Críticos: Técnicas e Perspectivas. In: INCT-SEC Internal Workshop, 2011. p.1-9. São Paulo, Brasil.

Além destas, foram obtidas outras publicações durante o período do doutorado, mas não diretamente relacionadas ao assunto principal da tese. Estas também são importantes como parte da experiência de uma pesquisa em nível de doutorado.

- Queiroz, P.G.G; Braga R.T.V. Application engineering of service-based software product lines. In Proceedings of the 27th Annual ACM Symposium on Applied Computing (SAC '12). ACM, New York, NY, USA, 2012.

- Queiroz, P.G.G.; Braga, R.T.V., Domain Engineering of Software Product Lines with Service-Oriented Architecture,In: Proceedings of the Fourth Brazilian Symposium on Software Components, Architectures and Reuse, 2010 pp.80,89, Sept. 2010

Para finalizar, Durante o período do doutorado ainda surgiram trabalhos que não estão ligados ao assunto da tese, mas que foram fruto de orientação de alunos, portanto fazem parte da experiência de uma pós-graduação em nível de doutorado.

- MORENO, N. C. G. ; QUEIROZ, P. G. G. . Refatoração por meio da aplicação de padrões de projeto em um software de clínica de oftalmologia. In: Anais da VI Escola Potiguar de Computação e suas Aplicações (EPOCA), 2013, Mossoró. v. VI. p. 139-144.

- OliveIRA, M. M. A. ; Castro ; QUEIROZ, P. G. G. . Um Estudo Comparativo de Desempenho entre Técnicas de Persistência de Dados, no Contexto de uma Aplicação Web. In: Anais da VI Escola Potiguar de Computação e suas Aplicações (EPOCA), Mossoró., 2013. v. VI. p. 186-191.

\subsection{Lições aprendidas}

As contribuições citadas são de caráter científico e acadêmico, pois apresentaram melhorias em conceitos que estão sendo explorados ou preencheram lacunas em assuntos ainda pouco explorados na literatura. Entretanto, com o desenvolvimento deste trabalho, diversas lições importantes, que valem a pena compartilhar, foram aprendidas.

Foi importante observar a grande variedade de trabalhos similares existentes na literatura. É de praxe encontrar trabalhos parecidos com os temas investigados nesta tese, entretanto, com uma grande diversidade no foco. Cada trabalho é direcionado a uma determinada linha de pesquisa bem específica. Não existem muitos trabalhos que tenham o objetivo de englobar e unificar os diversos aspectos do problema, como foi proposto nesta tese. 
No período desta pesquisa, foram estudadas diferentes tecnologias relacionadas ao MDE. Pôde-se perceber a evolução do estado-da-arte e da prática nesta área, em termos de quantidade. A proposta inicial deste trabalho previa ainda o desenvolvimento de alguma ferramenta de apoio, entretanto a gama de ferramentas existentes é muito grande, o que mostra indícios do crescimento do MDE. O que ainda falta é diversidade em relação às ferramentas.

Outra lição aprendida é em relação ao uso do MDE. Muitos autores advogam que essa técnica traz muitos benefícios ao desenvolvimento, pois um dos seus objetivos é a geração automática de código. Entretanto, durante esta pesquisa ficou claro que o "fardo" da codificação ainda está longe de ser abolido, ele apenas mudou de nível e nome, com o MDE existe o "fardo" da definição de transformações, que em muitos casos são mais complexas do que a codificação manual. Portanto, uma das lições mais importantes é a convicção de que o MDE não é a solução mais indicada para todos os casos. Ele deve ser usado quando o domínio é maduro, com DSLs e geradores desenvolvidos, ou quando o objetivo é o desenvolvimento em larga escala, assim como linha de produtos. Utilizar técnicas de MDE para domínios incipientes ou para desenvolver apenas uma aplicação, com foco em geração automática, ainda não é vantajoso. Essa situação pode mudar quando surgirem ferramentas que simplifiquem o processo de definição de transformações.

Ainda em relação ao MDE, foi importante perceber que a possibilidade de geração automática de código é a menor de suas vantagens. Na verdade, sua vantagem é o aumento do nível de abstração, que possibilita validações e verificações em estágios iniciais de desenvolvimento, além de favorecer as técnicas de simulação em diversos níveis de abstração, por meio da simplificação das plataformas de operação dos sistemas.

\subsection{Trabalhos futuros}

Além das contribuições da pesquisa e das lições aprendidas, foram identificadas oportunidades para trabalhos futuros, quer seja para complementar esta pesquisa explorando aspectos que não puderam ser abordados em profundidade nesta tese, ou para iniciar novas investigações em áreas que apresentam lacunas em seu estado da arte. Dessa forma, foram identificados os seguintes pontos para investigações futuras:

- Realização de estudos empíricos: embora a realização de um estudo de caso possa fornecer indícios sobre a validade da pesquisa, a realização de estudos empíricos com rigor estatístico é de grande importância para apoiar a pesquisa realizada. Além disso, pode ser muito enriquecedor para a área, pois são raros os trabalhos que realizam estudos empíricos rigorosos.

- Replicação do estudo de caso: pelo mesmo motivo citado anteriormente e pela existência de possíveis ameaças à validade do estudo de caso apresentado nesta tese, como a participação 
do autor da tese durante os estudos. Uma meta de pesquisa é encontrar voluntários para adotarem a abordagem proposta e confirmarem os indícios apresentados no estudo de caso, de que a abordagem é viável e adiciona grandes benefícios ao desenvolvimento. Além disso, é de grande importância para o amadurecimento como pesquisar, avaliar suas próprias pesquisas e propor melhorias constantes ao método, assim, visando melhorar a validade das conclusões.

- Outro interesse de trabalho futuro é investigar formas de reduzir a complexidade das transformações do MDE. Como comentado nas lições aprendidas, da forma que as técnicas de geração automática de MDE são utilizadas, só se move o problema de lugar, mas em algum momento, ele deve ser abordado.

\subsection{Considerações finais}

Neste trabalho apresentou-se a tese de que é possível obter as vantagens do desenvolvimento em larga escala no domínio de sistemas embarcados críticos e continuar se beneficiando dos avanços advindos da utilização de técnicas orientadas a modelo. Para defender esta tese, foi definida uma abordagem de linha de produtos com técnicas de MDE para o domínio de SEC que foi avaliada por meio de estudo de caso.

A abordagem combina elementos de processo, como atividades, tarefas, entradas e saídas, com diretrizes e métodos para auxiliar os desenvolvedores durante a engenharia de domínio orientada a modelos. Além disso, a utilização da abordagem, simplifica sobremaneira a engenharia de aplicações.

O trabalho apresentado nesta tese é um exemplo de pesquisa aplicada, que busca unificar diferentes técnicas, tais como Engenharia de linhas de produtos, desenvolvimento orientado a modelos e técnicas de desenvolvimento de sistemas confiáveis e seguros de uma forma original, oferecendo um apoio combinado que é melhor do que a aplicação das técnicas de forma isolada. Os resultados foram promissores, pois as técnicas combinadas são semelhantes, pois exigem algumas atividades em comum e ao mesmo tempo, são complementares, pois suas diferenças parecem se ajudar. 



\section{Referências}

AGX Tecnologia Ltda. 2014. Disponível em: <www.agx.com.br>. C Citado na página 33.

ALFÉREZ, M. et al. Evaluating scenario-based spl requirements approaches: The case for modularity, stability and expressiveness. Requirements Engineering, v. 19, n. 4, p. 355-376, 2014. Citado na página 142.

ALFÉREZ, M. et al. A model-driven approach for software product lines requirements engineering. In: SEKE. [S.1.]: Knowledge Systems Institute Graduate School, 2008. p. 779-784. ISBN 1-891706-22-5. Citado na página 89.

ALI, S. et al. A product line modeling and configuration methodology to support model-based testing: An industrial case study. In: FRANCE, R. et al. (Ed.). Model Driven Engineering Languages and Systems. Springer Berlin Heidelberg, 2012, (Lecture Notes in Computer Science, v. 7590). p. 726-742. ISBN 978-3-642-33665-2. Disponível em: <http://dx.doi.org/10.1007/978-3-642-33666-9\_46>. Citado 2 vezes nas páginas 91 e 104.

ALMEIDA, E. S. de et al. A systematic approach to design domain-specific software architectures. $J S W$, v. 2, n. 2, p. 38-51, 2007. Citado 2 vezes nas páginas 165 e 170.

ALMEIDA, E. S. de et al. The domain analysis concept revisited: A practical approach. In: MORISIO, M. (Ed.). ICSR. [S.1.]: Springer, 2006. (Lecture Notes in Computer Science, v. 4039), p. 43-57. ISBN 3-540-34606-6. Citado na página 116.

ALMENDROS-JIMÉNEZ, J. M.; IRIBARNE, L. Describing use cases with activity charts. In: Proceedings of the 2004 International Conference on Metainformatics. Berlin, Heidelberg: Springer-Verlag, 2005. (MIS'04), p. 141-159. ISBN 3-540-27328-X, 978-3-540-27328-8. Disponível em: <http://dx.doi.org/10.1007/11518358_12>. Citado na página 143.

ALMENDROS-JIMÉNEZ, J. M.; IRIBARNE, L. Describing use-case relationships with sequence diagrams. Comput. J., Oxford University Press, Oxford, UK, v. 50, n. 1, p. 116-128, jan. 2007. ISSN 0010-4620. Disponível em: <http://dx.doi.org/10.1093/comjnl/bxl053>. Citado na página 143.

AMELLER, D. SAD: Systematic Architecture Design, A Semi-Automatic Method. Dissertação (Mestrado) - Universitat Politécnica de Catalunya, Barcelona, 2010. Citado na página 53.

ARDIS, M. A.; WEISS, D. M. Defining families: the commonality analysis (tutorial). In: Proceedings of the 19th International Conference on Software Engineering (ICSE '97). New York, NY, USA: ACM, 1997. p. 649-650. ISBN 0-89791-914-9. Citado 2 vezes nas páginas 77 e 78 .

ARLOW, J.; NEUSTADT, I. Uml and the Unified Process: Practical Object-Oriented Analysis and Design. 1st. ed. Boston, MA, USA: Addison-Wesley Longman Publishing Co., Inc., 2002. ISBN 0201770601. Citado na página 154.

ARMOUR, F.; MILlER, G. Advanced Use Case Modeling: Software Systems. Addison-Wesley, 2001. Disponível em: <http://www.amazon.com/ Advanced-Use-Case-Modeling-Addison-Wesley/dp/0201615924>. Citado na página 143. 
ARMOUSH, A. Design Patterns for Safety-Critical Embedded Systems. Tese (Doutorado), Aachen,Germany, 2010. Director-Stefan Kowalewski. Citado 5 vezes nas páginas 165, 166, 167, 169 e 175.

ASIRELLI, P. et al. Design and Validation of Variability in Product Lines. In: Proceedings of the \{2Nd\} International Workshop on Product Line Approaches in Software Engineering. ACM, 2011. (\{PLEASE\} '11), p. 25-30. ISBN 978-1-4503-0584-6. Disponível em: $<$ http://doi.acm.org/10.1145/1985484.1985492>. Citado na página 92.

ATKINSON, C. et al. Component-based product line engineering with UML. [S.1.]: Addison-Wesley, 2002. 464 p. Citado 3 vezes nas páginas 30, 78 e 177.

ATKINSON, C.; KüHNE, T. Model-driven development: a metamodeling foundation. Software, IEEE, v. 20, n. 5, p. 36-41, 2003. Disponível em: <http://dx.doi.org/10.1109/MS.2003.1231149>. Citado na página 28.

AURUM, A.; WOHLIN, C. Engineering and Managing Software Requirements. Secaucus, NJ, USA: Springer-Verlag New York, Inc., 2005. ISBN 3540250433. Citado na página 119.

BALMELLI, L. The systems modeling language for products and systems development. Journal of Object Technology, v. 6, n. 6, p. 149-177, 2007. Citado na página 64.

BASS, L.; CLEMENTS, P.; KAZMAN, R. Software Architecture in Practice. 2. ed. Boston, MA, USA: Addison-Wesley Longman Publishing Co., Inc., 2003. ISBN 0321154959. Citado 7 vezes nas páginas 155, 156, 159, 160, 164, 165 e 173.

BAUMGARTL, J. et al. Towards easy robot programming: Using \{DSLs \}, code generators and software product lines. In: \{ICSOFT\} 2013 - Proceedings of the 8th International Joint Conference on Software Technologies. [S.1.: s.n.], 2013. p. 548-554. ISBN 9789898565686. Citado na página 93.

BAYER, J.; FLEGE, O.; GACEK, C. Creating Product Line Architectures. In: Proceedings of the International Workshop on Software Architectures for Product Families (IW-SAPF-3). London, UK: Springer-Verlag, 2000. p. 210-216. ISBN 3-540-41480-0. Citado na página 78.

BAYER, J. et al. PuLSE: a methodology to develop software product lines. In: Proceedings of the 1999 Symposium on Software Reusability (SSR '99). New York, NY, USA: ACM, 1999. p. 122-131. ISBN 1-58113-101-1. Citado 3 vezes nas páginas 77, 78 e 135.

BAYER, J.; MUTHIG, D.; WIDEN, T. Customizable domain analysis. In: CZARNECKI, K.; EISENECKER, U. W. (Ed.). GCSE. [S.1.]: Springer, 1999. (Lecture Notes in Computer Science, v. 1799), p. 178-194. ISBN 3-540-41172-0. Citado na página 88.

BEHRMANN, G.; DAVID, R.; LARSEN, K. G. A tutorial on uppaal. In: . [S.1.]: Springer, 2004. p. 200-236. Citado na página 146.

BERNSTEIN et al. The revised naspe/bpeg generic code for antibradycardia, adaptive-rate, and multisite pacing. Journal of Pacing and Clinical Electrophysiology, Elsevier, Inc., v. 25, p. 260-264, 2002. Citado na página 190.

BERNSTEIN, P. A.; LEVY, A. Y.; POTTINGER, R. A. A Vision for Management of Complex Models. [S.1.], 2000. 18 p. Disponível em: <http://research.microsoft.com/apps/pubs/default. aspx ?id=69782>. Citado na página 55. 
BESSLING, S.; HUHN, M. Formal safety analysis and verification in the model driven development of a pacemaker product line. In: Tagungsband - Dagstuhl-Workshop \{MBEES:\} Modellbasierte Entwicklung eingebetteter Systeme \{VIII\}, \{MBEES\} 2012. [S.1.: s.n.], 2012. p. 133-143. Citado 3 vezes nas páginas 93, 135 e 147.

BEUCHER, O. MATLAB und Simulink (Scientific Computing). [S.1.]: Pearson Studium, 2006. ISBN 3827372062. Citado 2 vezes nas páginas 28 e 98.

BEYDEDA, S.; BOOK, M.; GRUHN, V. Model-Driven Software Development. Berlin/Heidelberg: Springer-Verlag, 2005. ISBN 354025613X. Disponível em: <http: //www.springer.com/978-3-540-25613-7>. Citado na página 53.

BéZIVIN, J. In search of a basic principle for model driven engineering. Novatica Journal, Special Issue, v. 5, n. 2, p. 21-24, 2004. Disponível em: <http://www.dei.isep.ipp.pt/ \{\}\}alex/ publico/mde/up5-2Bezivin.p>. Citado na página 56.

BÉZIVIN, J. Model driven engineering: An emerging technical space. In: Proceedings of the 2005 International Conference on Generative and Transformational Techniques in Software Engineering. Berlin, Heidelberg: Springer-Verlag, 2006. (GTTSE'05), p. 36-64. ISBN 3-540-45778-X, 978-3-540-45778-7. Disponível em: <http://dx.doi.org/10.1007/11877028_2>. Citado 7 vezes nas páginas 28, 53, 54, 55, 56, 59 e 60 .

BÉZIVIN, J. et al. Model transformations? transformation models! In: Proceedings of the 9th International Conference on Model Driven Engineering Languages and Systems. Berlin, Heidelberg: Springer-Verlag, 2006. (MoDELS'06), p. 440-453. ISBN 3-540-45772-0, 978-3-540-45772-5. Disponível em: <http://dx.doi.org/10.1007/11880240_31>. Citado 2 vezes nas páginas 146 e 179.

BIOLCHINI, J. C. d. A. et al. Scientific research ontology to support systematic review in software engineering. Adv. Eng. Inform., Elsevier Science Publishers B. V., Amsterdam, The Netherlands, The Netherlands, v. 21, n. 2, p. 133-151, abr. 2007. ISSN 1474-0346. Disponível em: <http://dx.doi.org/10.1016/j.aei.2006.11.006>. Citado na página 33.

BORNIA, G. S. Estruturação de Descrições de Casos de Uso através de Mecanismos de Extensibilidade da UML. Dissertação (Mestrado) — UNIVERSIDADE FEDERAL DO RIO GRANDE DO SUL, Porto Alegre, RS, 2005. Citado 2 vezes nas páginas 143 e 145.

BORRIELLO, G.; CHOU, P.; ORTEGA, R. Embedded system co-design. In: MICHELI, G. D.; SAMI, M. (Ed.). Hardware/Software Co-Design. Springer Netherlands, 1996, (NATO ASI Series, v. 310). p. 243-264. ISBN 978-0-7923-3883-3. Disponível em: $<$ http://dx.doi.org/10.1007/978-94-009-0187-2_10>. Citado na página 45.

BOSCH, J. On the Development of Software Product-Family Components. In: International Conference on Software Product Line (SPLC 2004). [S.1.: s.n.], 2004. p. 146-164. Citado na página 77.

BOSCH, J. et al. Domain Analysis: Consortium Wide Deliverable on Scoping. [S.1.], 2001. Citado na página 115.

BOTTERWECK, G.; KOWALEWSKI, S.; POLZER, A. Variability and evolution in model-based engineering of embedded systems. In: Tagungsband - Dagstuhl-Workshop \{MBEES:\} Modellbasierte Entwicklung eingebetteter Systeme \{VI\}, \{MBEES\} 2010. [S.1.: s.n.], 2010. p. 87-96. Citado na página 93. 
BOTTERWECK, G.; O'BRIEN, L.; THIEL, S. Model-driven derivation of product architectures. In: STIREWALT, R. E. K.; EGYED, A.; 0002, B. F. (Ed.). ASE. [S.1.]: ACM, 2007. p. 469-472. ISBN 978-1-59593-882-4. Citado na página 88.

BOTTERWECK, G.; POLZER, A.; KOWALEWSKI, S. Interactive configuration of embedded systems product lines. In: \{CEUR\} Workshop Proceedings. [S.1.: s.n.], 2009. v. 557, p. 29-35. Citado 2 vezes nas páginas 31 e 93.

BOWEN, J. P.; BOWEN, J.; STAVRIDOU, V. Safety-critical systems, formal methods and standards. Software Engineering Journal, v. 8, p. 189-209, 1993. Citado 2 vezes nas páginas 27 e 45 .

BRAGA, C.; HæUSLER, E. Lightweight analysis of access control models with description logic. Innovations in Systems and Software Engineering, Springer-Verlag, v. 6, n. 1-2, p. 115-123, 2010. ISSN 1614-5046. Disponível em: <http://dx.doi.org/10.1007/s11334-009-0107-2>. Citado na página 146.

BRAGA, C. de O. et al. Transformation contracts in practice. IET Software, v. 6, n. 1, p. 16-32, 2012. Citado na página 146.

BRAGA, R. et al. Safe-crites: Developing safety-critical embedded systems supported by reuse techniques. In: Proceedings of IRI - International Conference on Reuse and Integration. [S.1.: s.n.], 2011. p. 1-6. Citado na página 94.

BRAGA, R. et al. Prolices: An approach to develop product lines for safety-critical embedded systems. In: artigo submetido, em análise. [S.1.: s.n.], 2011. Citado na página 94.

BRAGA, R. T. V. et al. The prolices approach to develop product lines for safety-critical embedded systems and its application to the unmanned aerial vehicles domain. CLEI Electron. J., v. 15, n. 2, 2012. Citado 2 vezes nas páginas 93 e 163.

BRAGANçA, A.; MACHADO, R. J. Transformation Patterns for Multi-staged Model Driven Software Development. Software Product Line Conference, International, IEEE Computer Society, Los Alamitos, CA, USA, v. 0, p. 329-338, 2008. Disponível em: $<$ http://dx.doi.org/10.1109/splc.2008.41>. Citado na página 58.

BRAGANçA, A. M. T. Methodological approaches and techniques for model driven development of software product lines. Tese (Doutorado) - Universidade do Minho, Braga, PT, 2008. Disponível em: <http://hdl.handle.net/1822/8137>. Citado 2 vezes nas páginas 88 e 160 .

BROY, M. The 'grand challenge' in informatics: Engineering software-intensive systems. IEEE Computer Society, Los Alamitos, CA, USA, v. 39, n. 10, p. 72-80, 2006. ISSN 0018-9162. Citado na página 44.

BUHNE, S.; LAUENROTH, K.; POHL, K. Modelling requirements variability across product lines. In: Proceedings of the 13th IEEE International Conference on Requirements Engineering. Washington, DC, USA: IEEE Computer Society, 2005. (RE '05), p. 41-52. ISBN 0-7695-2425-7. Disponível em: <http://dx.doi.org/10.1109/RE.2005.45>. Citado na página 120.

BUNSE, C.; GROß, H.-G.; PEPER, C. Applying a model-based approach for embedded system development. In: EUROMICRO-SEAA. [S.1.]: IEEE Computer Society, 2007. p. 121-128.

Citado na página 31. 
BURCH, J. R.; PASSERONE, R.; SANGIOVANNI-VINCENTELLI, A. L. Using multiple levels of abstractions in embedded software design. In: HENZINGER, T. A.; KIRSCH, C. M. (Ed.). EMSOFT. [S.1.]: Springer, 2001. (Lecture Notes in Computer Science, v. 2211), p. 324-343. ISBN 3-540-42673-6. Citado na página 27.

BUSCHMANN, F. et al. Pattern-oriented Software Architecture: A System of Patterns. New York, NY, USA: John Wiley \& Sons, Inc., 1996. ISBN 0-471-95869-7. Citado 2 vezes nas páginas 164 e 165.

BüSSOW, R.; GEISLER, R.; KLAR, M. Specifying safety-critical embedded systems with statecharts and z: A case study. In: . [S.1.]: Springer, 1998. p. 71-87. Citado na página 27.

CHEDDAR, T. M. to. MARTE TO CHEDDAR. [S.1.], 2007. Citado na página 195.

CHITFOROUSH, F.; YAZDANDOOST, M.; RAMSIN, R. Methodology support for the model driven architecture. In: APSEC. [S.1.]: IEEE Computer Society, 2007. p. 454-461. Citado na página 70.

CHRISSIS, M. B.; KONRAD, M.; SHRUM, S. CMMI: Guidelines for Process Integration and Product Improvement. 2. ed. Harlow, England: Addison-Wesley, 2007. ISBN 978-0-321-27967-5. Citado na página 120.

CLARKE JR., E. M.; GRUMBERG, O.; PELED, D. A. Model Checking. Cambridge, MA, USA: MIT Press, 1999. ISBN 0-262-03270-8. Citado na página 146.

CLEAVELAND, J. C. Building application generators. IEEE Softw., IEEE Computer Society Press, Los Alamitos, CA, USA, v. 5, n. 4, p. 25-33, jul. 1988. ISSN 0740-7459. Disponível em: $<$ http://dx.doi.org/10.1109/52.17799>. Citado na página 67.

CLEMENTS, P.; KAZMAN, R.; KLEIN, M. Evaluating software architectures: methods and case studies. Boston, San Francisco, Paris: Addison-Wesley, 2002. (SEI series in software engineering). ISBN 0-201-70482-X. Disponível em: <http://opac.inria.fr/record=b1097663>. Citado 3 vezes nas páginas 160, 164 e 176.

CLEMENTS, P.; NORTHROP, L. Software Product Lines: Practices and Patterns. Boston, MA, USA: Addison-Wesley Longman, 2002. 60 p. Hardcover. ISBN 0201703327. Citado 4 vezes nas páginas 76, 113, 116 e 117.

CLEMENTS, P. C.; MCGREGOR, J. D.; COHEN, S. G. The Structured Intuitive Model for Product Line Economics (SIMPLE). [S.1.], 2006. Citado 2 vezes nas páginas 113 e 115.

COCKBURN, A. Writing Effective Use Cases. 1st. ed. Boston, MA, USA: Addison-Wesley Longman Publishing Co., Inc., 2000. ISBN 0201702258. Citado na página 143.

COELHO, F. A. A. MODELAGEM, CONTROLE E SIMULAÇÃO HARDWARE-IN-THE-LOOP DE UM MÍSSIL COM VOO RASANTE A SUPERFÍCIE DO MAR. Dissertação (Mestrado) Universidade Federal do Rio de Janeiro, Rio de Janeiro, Brasil, 2007. Citado na página 183.

COHEN, S. Case Study: A Measurement Program for Product Lines. Carnegie Mellon University, Software Engineering Institute, 2004. (Technical note). Disponível em: $<$ http://books.google.com.br/books?id=Ag4nGwAACAAJ>. Citado na página 113.

COMMISSION, I. E. IEC 60812: Analysis Techniques for System Reliability. [S.1.], 2006.

Citado 2 vezes nas páginas 146 e 147. 
COOK, S. Domain-Specific Modeling and Model Driven Architecture. MDA Journal, January, p. 2-10, 2004. Citado 2 vezes nas páginas 70 e 88 .

COPLIEN, J.; HOFFMAN, D.; WEISS, D. Commonality and variability in software engineering. IEEE Softw., IEEE Computer Society Press, Los Alamitos, CA, USA, v. 15, n. 6, p. 37-45, nov. 1998. ISSN 0740-7459. Disponível em: <http://dx.doi.org/10.1109/52.730836>. Citado na página 116.

CRANE, M.; DINGEL, J. Towards a formal account of a foundational subset for executable uml models. In: . [s.n.], 2008. p. 675-689. Disponível em: <http://dx.doi.org/10.1007/ 978-3-540-87875-9\_47>. Citado na página 30.

CRUICKSHANK, K. J. A VALIDATION METRICS FRAMEWORK FOR SAFETY-CRITICAL SOFTWARE-INTENSIVE SYSTEMS. Tese (Doutorado) - NAVAL POSTGRADUATE SCHOOL, MONTEREY, CALIFORNIA, 2009. Citado 2 vezes nas páginas 40 e 41.

CSERTáN, G. et al. Viatra "visual automated transformations for formal verification and validation of uml models. In: Proceedings of the 17th IEEE International Conference on Automated Software Engineering. Washington, DC, USA: IEEE Computer Society, 2002. (ASE '02), p. 267-. ISBN 0-7695-1736-6. Disponível em: $<$ http://dl.acm.org/citation.cfm?id=786769.787011>. Citado na página 69.

CUENOT, P. et al. The \{EAST-ADL $\}$ A.rchitecture Description Language for Automotive Embedded Software. In: GIESE, H. et al. (Ed.). Model-Based Engineering of Embedded Real-Time Systems. [S.1.]: Springer-Verlag Berlin, 2010. v. 6100, p. 297-307. ISBN 978-3-642-16276-3. Citado na página 94.

CYBULSKI, J. et al. Reuse of early life-;cycle artifacts: workproducts, methods and tools. Annals of Software Engineering, Kluwer Academic Publishers, v. 5, n. 1, p. 227-251, 1998. ISSN 1022-7091. Citado na página 29.

CZARNECKI, K. et al. Model-driven software product lines. In: Companion to the 20th Annual ACM SIGPLAN Conference on Object-oriented Programming, Systems, Languages, and Applications. New York, NY, USA: ACM, 2005. (OOPSLA '05), p. 126-127. ISBN 1-59593-193-7. Disponível em: <http://doi.acm.org/10.1145/1094855.1094896>. Citado 5 vezes nas páginas 89, 155, 179, 180 e 187.

CZARNECKI, K.; EISENECKER, U. W. Generative Programming: Methods, Tools, and Applications. New York, NY, USA: ACM Press/Addison-Wesley Publishing Co., 2000. ISBN 0-201-30977-7. Citado 4 vezes nas páginas 30, 79, 177 e 180.

CZARNECKI, K.; HELSEN, S. Classification of model transformation approaches. In: OOPSLA'03 Workshop on Generative Techniques in the Context of Model-Driven Architecture. [S.1.: s.n.], 2003. Citado 2 vezes nas páginas 68 e 69.

CZARNECKI, K.; HELSEN, S. Feature-based survey of model transformation approaches. IBM Syst. J., IBM Corp., Riverton, NJ, USA, v. 45, n. 3, p. 621-645, jul. 2006. ISSN 0018-8670. Disponível em: <http://dx.doi.org/10.1147/sj.453.0621>. Citado na página 172.

CZARNECKI, K.; ØSTERBYE, K.; VöLTER, M. Generative programming. In: NúñEZ, J. H.; MOREIRA, A. M. D. (Ed.). ECOOP Workshops. [S.1.]: Springer, 2002. (Lecture Notes in Computer Science, v. 2548), p. 15-29. ISBN 3-540-00233-2. Citado na página 67. 
DALGARNO, A. M. Product line scoping in practice. Software Product Line Conference, International, IEEE Computer Society, Los Alamitos, CA, USA, v. 0, p. 363, 2008. Citado 2 vezes nas páginas 115 e 120.

DASKAYA, I.; HUHN, M.; MILIUS, S. Formal safety analysis in industrial practice. In: SALAüN, G.; SCHäTZ, B. (Ed.). FMICS. [S.1.]: Springer, 2011. (Lecture Notes in Computer Science, v. 6959), p. 68-84. ISBN 978-3-642-24430-8. Citado na página 147.

DE, G. G.; SAMI, M. (Ed.). Hardware/Software Co-Design. Norwell, MA, USA: Kluwer Academic Publishers, 1996. ISBN 0792338820. Citado 2 vezes nas páginas 45 e 187.

DEBAUD, J.-M.; FLEGE, O.; KNAUBER, P. Pulse-dssa\&mdash;a method for the development of software reference architectures. In: Proceedings of the Third International Workshop on Software Architecture. New York, NY, USA: ACM, 1998. (ISAW '98), p. 25-28. ISBN 1-58113-081-3. Disponível em: <http://doi.acm.org/10.1145/288408.288415>. Citado na página 176.

DEDRICK, J.; GURBAXANI, V.; KRAEMER, K. L. Information technology and economic performance: A critical review of the empirical evidence. ACM Comput. Surv., ACM, New York, NY, USA, v. 35, n. 1, p. 1-28, mar. 2003. ISSN 0360-0300. Disponível em: $<$ http://doi.acm.org/10.1145/641865.641866>. Citado na página 40.

DEELSTRA, S. et al. Model driven architecture as approach to manage variability in software product families. In: In Proceedings of the Workshop on Model Driven Architectures: Foundations and Applications. [S.1.]: Springer, 2003. p. 109-114. Citado na página 89.

DEMIR, A. Comparison of model-driven architecture and software factories in the context of model-driven development. In: MACHADO, R. J. et al. (Ed.). MDB/MOMPES. [S.1.]: IEEE Computer Society, 2006. p. 75-83. ISBN 0-7695-2538-5. Citado na página 61.

DERAKHSHANMANESH, M.; FOX, J.; EBERT, J. Requirements-driven incremental adoption of variability management techniques and tools: An industrial experience report. Requir. Eng., Springer-Verlag New York, Inc., Secaucus, NJ, USA, v. 19, n. 4, p. 333-354, November 2014. ISSN 0947-3602. Disponível em: <http://dx.doi.org/10.1007/s00766-013-0185-4>. Citado 5 vezes nas páginas 31, 32, 130, 131 e 183.

DEURSEN, A. van; KLINT, P.; VISSER, J. Domain-specific languages: An annotated bibliography. SIGPLAN Not., ACM, New York, NY, USA, v. 35, n. 6, p. 26-36, jun. 2000. ISSN 0362-1340. Disponível em: <http://doi.acm.org/10.1145/352029.352035>. Citado na página 29.

DIRCKZE, R. Java Metadata Interface (JMI) Specification. [S.1.], 2002. Citado na página 69.

DO-178B. DO-178B: Software Considerations in Airborne Systems and Equipment Certification. 1982. Citado na página 50.

DORI, D. Object-process methodology - a holistic systems paradigm. [S.1.]: Springer, 2002. I-XXV, 1-453 p. ISBN 978-3-540-65471-1. Citado na página 30.

DORNELAS, J. Análise de Mercado. 2014. Disponível em: <http://www.josedornelas.com.br/ wp-content/uploads/2014/02/Artigos-de-PN-Como-Fazer-An\%C3\%A1lise-de-Mercado.pdf>. Citado 2 vezes nas páginas 114 e 115. 
DOUGLASS, B. P. Real-Time Design Patterns: Robust Scalable Architecture for Real-Time Systems. Boston, MA, USA: Addison-Wesley Longman Publishing Co., Inc., 2002. ISBN 0201699567. Citado na página 164.

DOWSON, M. The ariane 5 software failure. SIGSOFT Softw. Eng. Notes, ACM, New York, NY, USA, v. 22, n. 2, p. 84-, mar 1997. ISSN 0163-5948. Disponível em: $<$ http://doi.acm.org/10.1145/251880.251992>. Citado 2 vezes nas páginas 29 e 41.

DUMAS, M.; HOFSTEDE, A. H. M. t. Uml activity diagrams as a workflow specification language. In: Proceedings of the 4th International Conference on The Unified Modeling Language, Modeling Languages, Concepts, and Tools. London, UK, UK: SpringerVerlag, 2001. (\&171;UML\&187; '01), p. 76-90. ISBN 3-540-42667-1. Disponível em: $<$ http://dl.acm.org/citation.cfm?id=647245.719456>. Citado na página 145.

DUNN, W. R. Designing safety-critical computer systems. Computer, IEEE Computer Society Press, Los Alamitos, CA, USA, v. 36, n. 11, p. 40-46, nov. 2003. ISSN 0018-9162. Disponível em: <http://dx.doi.org/10.1109/MC.2003.1244533>. Citado 2 vezes nas páginas 41 e 42.

ERIKSSON, M.; BöRSTLER, J.; BORG, K. The pluss approach: Domain modeling with features, use cases and use case realizations. In: OBBINK, H.; POHL, K. (Ed.). Software Product Lines. Springer Berlin Heidelberg, 2005, (Lecture Notes in Computer Science, v. 3714). p. 33-44. ISBN 978-3-540-28936-4. Disponível em: <http://dx.doi.org/10.1007/11554844_5>. Citado 3 vezes nas páginas 121, 135 e 142.

ESHUIS, R.; WIERINGA, R. A Formal Semantics for UML Activity Diagrams - Formalising Workflow Models. [S.1.], 2001. Citado na página 144.

ESHUIS, R.; WIERINGA, R. Tool support for verifying uml activity diagrams. IEEE Transactions on Software Engineering, v. 30, p. 2004, 2004. Citado na página 144.

EUROCONTROL. Manual for Airspace Planning Volume 2. 2003. Citado na página 110.

FAULK, S. R. Product-line requirements specification (prs): an approach and case study. In: Fifth IEEE International Symposium on Requirements Engineering. [s.n.], 2001. p. 48-55. Disponível em: $<$ http://ieeexplore.ieee.org/xpls/abs_all.jsp?arnumber=948543>. Citado 2 vezes nas páginas 126 e 145 .

FELIX, B.; PAUL, C. Variability in Software Product Lines. [S.1.], 2005. Disponível em: $<$ http://resources.sei.cmu.edu/library/asset-view.cfm?AssetID=7675>. Citado na página 120.

FENELON, P. et al. Towards integrated safety analysis and design. SIGAPP Appl. Comput. Rev., ACM, New York, NY, USA, v. 2, n. 1, p. 21-32, mar. 1994. ISSN 1559-6915. Disponível em: $<$ http://doi.acm.org/10.1145/381766.381770>. Citado na página 120.

FENG, Q.; LUTZ, R. R. Bi-directional safety analysis of product lines. Journal of Systems and Software, v. 78, n. 2, p. 111-127, 2005. Citado na página 147.

FERREIRA, A. B. d. H. et al. Aurélio Século XXI: O Dicionário da Língua Portuguesa. 3. ed. [S.l.]: Nova Fronteira, 1999. Citado na página 39.

FIRESMITH, D. Engineering safety requirements, safety constraints, and safety-critical requirements. Journal of Object Technology, v. 3, n. 3, p. 27-42, 2004. Citado na página 40. 
FONDEMENT, F; SILAGHI, R. Defining model driven engineering processes. In: in Proceedings of WISME. [S.1.: s.n.], 2004. Citado na página 121.

FOWLER, M. Language workbenches: The killer-app for domain specific languages? 2005. Disponível em: <http://www.martinfowler.com/articles/languageWorkbench.html>. Citado na página 180.

FOWLER, M.; SCOTT, K. UML Distilled: A Brief Guide to the Standard Object Modeling Language. 2. ed. [S.1.]: Addison-Wesley Professional, 1999. 185 p. Paperback. ISBN 020165783X. Citado 2 vezes nas páginas 141 e 142.

FRAGAL, V. H. et al. Application engineering for embedded systems :transforming sysml specification to simulink within a product-line based approach. In: \{ICEIS\} 2013 - Proceedings of the 15th International Conference on Enterprise Information Systems. [S.1.: s.n.], 2013. v. 2, p. 94-101. ISBN 9789898565600. Citado na página 94.

FRAKES, W. B.; DíAZ, R. P.; FOX, C. J. Dare: Domain analysis and reuse environment. Ann. Software Eng., v. 5, p. 125-141, 1998. Citado na página 88.

FRAKES, W. B.; ISODA, S. Success factors of systematic reuse. IEEE Softw., IEEE Computer Society Press, Los Alamitos, CA, USA, v. 11, n. 5, p. 14-19, set. 1994. ISSN 0740-7459. Disponível em: <http://dx.doi.org/10.1109/52.311045>. Citado na página 29.

FRANCE, R.; RUMPE, B. Model-driven development of complex software: A research roadmap. In: FOSE '07: 2007 Future of Software Engineering. Washington, DC, USA: IEEE Computer Society, 2007. p. 37-54. ISBN 0769528295. Disponível em: <http://dx.doi.org/10.1109/FOSE.2007.14>. Citado na página 52.

GACEK, C.; ANASTASOPOULES, M. Implementing product line variabilities. In: Proceedings of the 2001 Symposium on Software Reusability: Putting Software Reuse in Context. New York, NY, USA: ACM, 2001. (SSR '01), p. 109-117. ISBN 1-58113-358-8. Disponível em: <http://doi.acm.org/10.1145/375212.375269>. Citado 2 vezes nas páginas 136 e 177.

GAMMA, E. et al. Design Patterns: Elements of Reusable Object-oriented Software. Boston, MA, USA: Addison-Wesley Longman Publishing Co., Inc., 1995. ISBN 0-201-63361-2. Citado 4 vezes nas páginas 29, 165, 170 e 171.

GHOSH, D. DSLs in Action. 1st. ed. Greenwich, CT, USA: Manning Publications Co., 2010. ISBN 9781935182450. Citado na página 179.

GIMENES, I. M. S.; TRAVASSOS, G. H. O enfoque de linha de produto para desenvolvimento de software. 2002. Minicurso da XXI Jornada de Atualização em Informática (JAI 2002), evento Integrante do XXII Congresso da SBC (SBC 2002). Citado na página 78.

GLINZ, M. On non-functional requirements. In: Requirements Engineering Conference, 2007. RE '07. 15th IEEE International. [S.1.: s.n.], 2007. p. 21-26. ISSN 1090-705X. Citado na página 45.

GOMAA, H. Designing Software Product Lines with UML: From Use Cases to Pattern-Based Software Architectures. Redwood City, CA, USA: Addison Wesley Longman, 2004. 736 p. ISBN 0201775956. Citado 11 vezes nas páginas 14, 30, 78, 79, 80, 94, 103, 121, 135, 152 e 153.

GOMAA, H.; SALEH, M. Software product line engineering for web services and uml. In: AICCSA. [S.1.]: IEEE Computer Society, 2005. p. 110. Citado na página 57. 
GOMES, A.; OLIVEIRA, M. Formal development of a cardiac pacemaker: From specification to code. In: DAVIES, J.; SILVA, L.; SIMAO, A. (Ed.). Formal Methods: Foundations and Applications. Springer Berlin Heidelberg, 2011, (Lecture Notes in Computer Science, v. 6527). p. 210-225. ISBN 978-3-642-19828-1. Disponível em: <http://dx.doi.org/10.1007/978-3-642-19829-8_14>. Citado na página 197.

GOTEL, O. C. Z.; FINKELSTEIN, C. W. An analysis of the requirements traceability problem. In: International Conference on Requirements Engineering. [s.n.], 1994. p. 94-101. Disponível em: <http://ieeexplore.ieee.org/xpls/abs_all.jsp?arnumber=292398>. Citado na página 134.

GREENFIELD, J.; SHORT, K. Software factories: assembling applications with patterns, models, frameworks and tools. In: 18th annual ACM SIGPLAN conference on object-oriented programming, systems, languages, and applications (OOPSLA '03). New York, NY, USA: ACM, 2003. p. 16-27. ISBN 1-58113-751-6. Citado na página 77.

GRISS, M. L. Implementing product-line features with component reuse. In: ICSR-6: Proceedings of the 6th International Conerence on Software Reuse. London, UK: SpringerVerlag, 2000. p. 137-152. ISBN 3-540-67696-1. Citado 3 vezes nas páginas 28, 76 e 78 .

GRONBACK, R. C. Eclipse Modeling Project: A Domain-Specific Language (DSL) Toolkit. [S.1.]: Addison-Wesley Professional, 2009. ISBN 0321534077. Citado na página 75.

GROUP, O. M. Common Warehouse Metamodel 1.1 Specification. [S.1.], 2003. Disponível em: $<$ http://www.omg.org/docs/formal/03-03-02.pdf>. Citado na página 69.

GROUP, O. M. OMG Unified Modeling Language (OMG UML), Infrastructure, V2.1.2. [S.1.], 2007. Disponível em: <http://www.omg.org/spec/UML/2.1.2/Infrastructure/PDF>. Citado na página 122.

GÜDEMANN, M.; ORTMEIER, F.; REIF, W. Using Deductive Cause Consequence Analysis (DCCA) with SCADE. In: Proceedings of SAFECOMP 2007. [S.1.]: Springer LNCS 4680, 2007. Citado na página 28.

GUIZZARDI, G.; PIRES, L. F.; SINDEREN, M. J. V. On the role of domain ontologies in the design of domain-specific visual modeling languages. In: Proceedings of the 2 nd Workshop on Domain-Specific Visual Languages, 17th ACM Conference on Object-Oriented Programming, Systems, Languages and Applications (OOPSLA 2002). [S.1.]: Citeseer, 2002. Citado na página 179.

GURP, J. V.; BOSCH, J.; SVAHNBERG, M. On the Notion of Variability in Software Product Lines. In: Proceedings of the Working IEEE/IFIP Conference on Software Architecture (WICSA '01). Washington, DC, USA: IEEE Computer Society, 2001. p. 45. ISBN 0-7695-1360-3. Citado na página 78 .

GüDEMANN, M.; ORTMEIER, F.; REIF, W. Using deductive cause-consequence analysis (dcca) with scade. In: SAGLIETTI, F.; OSTER, N. (Ed.). Computer Safety, Reliability, and Security. Springer Berlin Heidelberg, 2007, (Lecture Notes in Computer Science, v. 4680). p. 465-478. ISBN 978-3-540-75100-7. Disponível em: <http://dx.doi.org/10.1007/978-3-540-75101-4_44>. Citado na página 147.

HABLI, I. M. Model-Based Assurance of Safety-Critical Product Lines. Tese (Doutorado), York, UK, 2009. Citado 5 vezes nas páginas 28, 29, 43, 96 e 103. 
HADDAD, H.; TESSER, H. Reusable subsystems: Domain-based approach. In: Proceedings of the 2002 ACM Symposium on Applied Computing. New York, NY, USA: ACM, 2002. (SAC '02), p. 971-975. ISBN 1-58113-445-2. Disponível em: <http://doi.acm.org/10.1145/508791.508981>. Citado 3 vezes nas páginas 123, 148 e 149.

HAILPERN, B.; TARR, P. Model-driven development: The good, the bad, and the ugly. IBM Syst. J., IBM Corp., Riverton, NJ, USA, v. 45, n. 3, p. 451-461, jul. 2006. ISSN 0018-8670. Disponível em: <http://dx.doi.org/10.1147/sj.453.0451>. Citado 2 vezes nas páginas 53 e 58.

HARBOUR, M. G. et al. Mast: Modeling and analysis suite for real time applications. In: In 13th Euromicro Conference on Real-Time Systems. [S.1.: s.n.], 2001. p. 125. Citado na página 195.

HAUGEN, O.; WaSOWSKI, A.; CZARNECKI, K. Cvl: Common variability language. In: Proceedings of the 16th International Software Product Line Conference - Volume 2. New York, NY, USA: ACM, 2012. (SPLC '12), p. 266-267. ISBN 978-1-4503-1095-6. Disponível em: $<$ http://doi.acm.org/10.1145/2364412.2364462>. Citado 7 vezes nas páginas 13, 34, 80, 83, 122,134 e 136.

HEIMDAHL, M. P. E. Safety and software intensive systems: Challenges old and new. In: BRIAND, L. C.; WOLF, A. L. (Ed.). FOSE. [S.1.: s.n.], 2007. p. 137-152. Citado 5 vezes nas páginas 48, 49, 50, 51 e 104.

HENKEL, J.; HU, X.; BHATTACHARYYA, S. S. Guest editors' introduction: Taking on the embedded system design challenge. IEEE Computer, v. 36, p. 35-37, 2003. Citado 3 vezes nas páginas 28, 47 e 187.

HENZINGER, T. A.; SIFAKIS, J. The discipline of embedded systems design. Computer, IEEE Computer Society Press, Los Alamitos, CA, USA, v. 40, n. 10, p. 32-40, out. 2007. ISSN 0018-9162. Disponível em: <http://dx.doi.org/10.1109/MC.2007.364>. Citado 4 vezes nas páginas 97, 154, 155 e 156.

HERRMANN, D. S. Software Safety and Reliability : Techniques, Approaches, and Standards of Key Industrial Sectors (Practitioners). Wiley-IEEE Computer Society Pr, 2000. Paperback. ISBN 0769502997. Disponível em: <http://www.amazon.com/exec/obidos/redirect?tag= citeulike07-20\&path=ASIN/0769502997>. Citado na página 50.

HESSELLUND, A.; CZARNECKI, K.; WASOWSKI, A. Guided development with multiple domain-specific languages. In: ENGELS, G. et al. (Ed.). MoDELS. [S.1.]: Springer, 2007. (Lecture Notes in Computer Science, v. 4735), p. 46-60. ISBN 978-3-540-75208-0. Citado na página 163.

HINCHEY, M. et al. Software engineering and formal methods. Commun. ACM, ACM, New York, NY, USA, v. 51, n. 9, p. 54-59, set. 2008. ISSN 0001-0782. Disponível em: $<$ http://doi.acm.org/10.1145/1378727.1378742>. Citado na página 40.

HLAVATY, T.; PREUCIL, L.; STEPAN, P. Formal Methods in Development and Testing of Safety-Critical Systems: Railway Interlocking System. 2002. Citado na página 27.

HOFFMAN, A.; KOGEL, T.; MEYR, H. A framework for fast hardware-software co-simulation. In: Proceedings of the Conference on Design, Automation and Test in Europe. Piscataway, NJ, USA: IEEE Press, 2001. (DATE '01), p. 760-765. ISBN 0-7695-0993-2. Disponível em: <http://dl.acm.org/citation.cfm?id=367072.367949>. Citado 3 vezes nas páginas 46, 47 e 187 . 
HOLZMANN, G. Spin Model Checker, the: Primer and Reference Manual. First. [S.1.]: Addison-Wesley Professional, 2003. ISBN 0-321-22862-6. Citado na página 146.

HOYOS, H.; CASALLAS, R.; JIMENEZ, F. Model-based framework for embedded system product line. In: \{IECON\} 2012 - 38th Annual Conference on \{IEEE\} Industrial Electronics Society. [S.1.: s.n.], 2012. p. 3101-3106. Citado na página 94.

HUHN, M.; BESSLING, S. Enhancing product line development by safety requirements and verification. In: WEBER, J.; PERSEIL, I. (Ed.). Foundations of Health Information Engineering and Systems. Springer Berlin Heidelberg, 2013, (Lecture Notes in Computer Science, v. 7789). p. 37-54. ISBN 978-3-642-39087-6. Disponível em: <http://dx.doi.org/10.1007/978-3-642-39088-3\_3>. Citado na página 93.

HUTCHESSON, S.; MCDERMID, J. In: SCHOITSCH, E. (Ed.). Computer Safety, Reliability, and Security. [S.1.: s.n.], 2010. p. 389-401. ISBN 978-3-642-15650-2. Citado na página 95.

IEEE. IEEE Std 610.12-1990(R2002). IEEE Standard Glossary of Software Engineering Terminology, 1990. Citado na página 43.

IEEE. Ieee recommended practice for architectural description of software-intensive systems. IEEE Std 1471-2000, p. i-23, 2000. Citado na página 42.

INCT-SEC. Sistemas Embarcados Críticos: aplicações em segurança e agricultura. CNPq, 2008. Disponível em: <http://www.inct-sec.org>. Citado na página 33.

INOKI, M.; KITAGAWA, T.; HONIDEN, S. Application of requirements prioritization decision rules in software product line evolution. In: Requirements Prioritization and Communication (RePriCo), 2014 IEEE 5th International Workshop on. [S.1.: s.n.], 2014. p. 1-10. Citado na página 138.

JACOBSON, I.; BOOCH, G.; RUMBAUGH, J. The Unified Software Development Process. Boston, MA, USA: Addison-Wesley Longman, 1999. 512 p. ISBN 0-201-57169-2. Citado na página 78.

JAMDA. The Java Model Driven Architecture 0.2. 2003. Misc. Disponível em: $<$ http://sourceforge.net/projects/jamda/>. Citado na página 69.

JARZABEK, S. Modeling multiple domains in software reuse. SIGSOFT Softw. Eng. Notes, ACM, New York, NY, USA, v. 22, n. 3, p. 65-74, maio 1997. ISSN 0163-5948. Disponível em: <http://doi.acm.org/10.1145/258368.258387>. Citado 3 vezes nas páginas 123, 148 e 149.

JEE, E.; LEE, I.; SOKOLSKY, O. Assurance cases in model-driven development of the pacemaker software. In: MARGARIA, T.; STEFFEN, B. (Ed.). ISoLA (2). [S.1.]: Springer, 2010. (Lecture Notes in Computer Science, v. 6416), p. 343-356. ISBN 978-3-642-16560-3. Citado na página 189.

JOHNSON, C. W. Failure in Safety-Critical Systems: A Handbook of Accident and Incident Reporting. Glasgow, Scotland: University of Glasgow Press, 2003. Disponível em: $<$ http://www.dcs.gla.ac.uk/ \{\}johnson/boo>. Citado na página 44.

JOHNSON, R. E. Frameworks = (components + patterns). Commun. ACM, ACM, New York, NY, USA, v. 40, n. 10, p. 39-42, out. 1997. ISSN 0001-0782. Disponível em: <http://doi.acm.org/10.1145/262793.262799>. Citado na página 29. 
JOHNSON, W. L.; HARRIS, D. R. Sharing and reuse of requirements knowledge. In: KBSE. [S.1.: s.n.], 1991. p. 57-66. Citado na página 29.

JOUAULT, F.; KURTEV, I. On the architectural alignment of atl and qvt. In: Proceedings of the 2006 ACM Symposium on Applied Computing. New York, NY, USA: ACM, 2006. (SAC '06), p. 1188-1195. ISBN 1-59593-108-2. Disponível em: <http://doi.acm.org/10.1145/1141277. 1141561>. Citado 2 vezes nas páginas 74 e 75 .

JSSSC. Software System Safety Handbook. A Technical \& Managerial Team Approach. [S.1.], 1999. Disponível em: <http://www.system-safety.org/Documents/Softwarel_System\_Safetyl _Handbook.pdf>. Citado na página 40.

JUNIOR, E. A. O.; GIMENES, I. M. S.; MALDONADO, J. C. Systematic management of variability in uml-based software product lines. j-jucs, v. 16, n. 17, p. 2374-2393, sep 2010. <l>http://www.jucs.org/jucs_16_17/systematic_management_of_variabilityl. Citado na página 152 .

JøRGENSEN, J. B.; TJELL, S.; FERNANDES, J. M. Formal requirements modelling with executable use cases and coloured petri nets. ISSE, v. 5, n. 1, p. 13-25, 2009. Disponível em: $<$ http://dblp.uni-trier.de/db/journals/isse/isse5.html\#JorgensenTF09>. Citado na página 121.

KALAVADE, A.; LEE, E. A. Hardware/Software Co-design Using Ptolemy: A Case Study. In: Proceedings of the IFIP International Workshop on Hardware/Software Co-Design. [s.n.], 1992. Disponível em: <http://ptolemy.eecs.berkeley.edu/publications/papers/92/codesign/>. Citado 2 vezes nas páginas 46 e 187.

KANG, K. C. et al. Feature-Oriented Domain Analysis (FODA) Feasibility Study. [S.1.], 1990. Disponível em: <http://www.sei.cmu.edu/library/abstracts/reports/90tr021.cfm>. Citado na página 79.

KANG, K. C. et al. A Reuse-Based Software Development Methodology. [S.1.], 1992. Citado na página 29.

KANG, K. C. et al. Form: A feature-oriented reuse method with domain-specific reference architectures. Ann. Softw. Eng., J. C. Baltzer AG, Science Publishers, Red Bank, NJ, USA, v. 5, p. 143-168, jan. 1998. ISSN 1022-7091. Disponível em: $<$ http://dl.acm.org/citation.cfm?id=590631.590645>. Citado 3 vezes nas páginas 30, 32 e 79.

KANG, K. C.; LEE, J.; DONOHOE, P. Feature-Oriented Product Line Engineering. IEEE Software, IEEE Computer Society, Los Alamitos, CA, USA, v. 19, n. 4, p. 58-65, Aug. 2002. ISSN 0740-7459. Citado 2 vezes nas páginas 79 e 122.

KEEPENCE, B.; MANNION, M. Using patterns to model variability in product families. IEEE Software, v. 16, n. 4, p. 102-108, 1999. Citado na página 165.

KENT, S. Model driven engineering. In: Proceedings of the Third International Conference on Integrated Formal Methods. London, UK, UK: Springer-Verlag, 2002. (IFM '02), p. 286-298. ISBN 3-540-43703-7. Disponível em: <http://dl.acm.org/citation.cfm?id=647983.743552>. Citado 2 vezes nas páginas 58 e 69.

KICZALES, G. et al. Aspect-oriented programming. In: AKşIT, M.; MATSUOKA, S. (Ed.). ECOOP'97 - Object-Oriented Programming. Springer Berlin Heidelberg, 1997, (Lecture Notes in Computer Science, v. 1241). p. 220-242. ISBN 978-3-540-63089-0. Disponível em: $<$ http://dx.doi.org/10.1007/BFb0053381>. Citado na página 177. 
KIENHUIS, B. et al. A methodology to design programmable embedded systems - the y-chart approach. In: Embedded Processor Design Challenges: Systems, Architectures, Modeling, and Simulation - SAMOS. London, UK, UK: Springer-Verlag, 2002. p. 18-37. ISBN 3-540-43322-8. Disponível em: $<$ http://dl.acm.org/citation.cfm?id=646466.691571>. Citado 3 vezes nas páginas 28,47 e 48 .

KIM, M. et al. An ethnographic study of copy and paste programming practices in oopl. In: Proceedings of the 2004 International Symposium on Empirical Software Engineering. Washington, DC, USA: IEEE Computer Society, 2004. (ISESE '04), p. 83-92. ISBN 0-7695-2165-7. Disponível em: <http://dx.doi.org/10.1109/ISESE.2004.10>. Citado na página 29.

KIM, M.; YANG, H.; PARK, S. A domain analysis method for software product lines based on scenarios, goals and features. In: APSEC. [S.1.]: IEEE Computer Society, 2003. p. 126-135. ISBN 0-7695-2011-1. Citado na página 88.

KIM, T. et al. Extending atam to assess product line architecture. In: Computer and Information Technology, 2008. CIT 2008. 8th IEEE International Conference on. [S.1.: s.n.], 2008. p. 790-797. Citado na página 176.

KIRCHER, M.; JAIN, P. Pattern-Oriented Software Architecture, Volume 3: Patterns for Resource Management. Chichester, UK: Wiley, 2004. ISBN 978-0-470-84525-7. Citado na página 165.

KITCHENHAM, B. Procedures for Performing Systematic Reviews. 2004. Citado 3 vezes nas páginas 33, 90 e 91.

Kleppe, A. G. A language description is more than a metamodel. In: Fourth International Workshop on Software Language Engineering, Nashville, USA. Grenoble, France: megaplanet.org, 2007. ISBN not assigned. Citado 2 vezes nas páginas 180 e 181 .

KNIGHT, J. C. Safety critical systems: challenges and directions. In: Proceedings of the 24th International Conference on Software Engineering. New York, NY, USA: ACM, 2002. (ICSE '02), p. 547-550. ISBN 1-58113-472-X. Disponível em: <http://doi.acm.org/10.1145/581339.581406>. Citado 5 vezes nas páginas 27, 40, 41, 104 e 120.

KNODEL, J. et al. An efficient migration to model-driven development (mdd). Electr. Notes Theor. Comput. Sci., v. 137, n. 3, p. 17-27, 2005. Citado 2 vezes nas páginas 89 e 150.

KOPETZ, H. Real-Time Systems: Design Principles for Distributed Embedded Applications. 1st. ed. Norwell, MA, USA: Kluwer Academic Publishers, 1997. ISBN 0792398947. Citado 2 vezes nas páginas 155 e 156.

KOZACZYNSKI, W.; BOOCH, G. Guest editors' introduction: Component-based software engineering. IEEE Software, v. 15, n. 5, p. 34-36, 1998. Citado na página 29.

KRUEGER, C. W. Software reuse. ACM Comput. Surv., ACM, New York, NY, USA, v. 24, n. 2, p. 131-183, jun. 1992. ISSN 0360-0300. Disponível em: <http: //doi.acm.org/10.1145/130844.130856>. Citado na página 57.

KRUEGER, C. W. Variation management for software production lines. In: Proceedings of the Second International Conference on Software Product Lines. London, UK, UK: Springer-Verlag, 2002. (SPLC 2), p. 37-48. ISBN 3-540-43985-4. Disponível em: $<$ http://dl.acm.org/citation.cfm?id=645882.672255>. Citado na página 105. 
LABORATORY, S. Q. R. Pacemaker formal methods challenge. Disponível em: $<$ http://sqrl.mcmaster.ca/pacemaker.htm>. Citado na página 199.

LAPRIE, J.-C. Dependability: A unifying concept for reliable, safe, secure computing. In: IFIP Congress (1). [S.1.: s.n.], 1992. p. 585-593. Citado na página 43.

LEE, K.; KANG, K. C. Feature dependency analysis for product line component design. In: ICSR. [S.1.]: Springer, 2004. (Lecture Notes in Computer Science, v. 3107), p. 69-85. ISBN 3-540-22335-5. Citado na página 165.

LEE, K.; KANG, K. C.; LEE, J. Concepts and guidelines of feature modeling for product line software engineering. In: Software Reuse: Methods, Techniques, and Tools: Proceedings of the Seventh Reuse Conference (ICSR7. [S.1.]: Springer-Verlag, 2002. p. 62-77. Citado 4 vezes nas páginas 124, 132, 133 e 149.

LENDIN, J. A. Development of advanced driver assistance systems with vehicle hardware-in-the-loop simulations. 1999. Citado na página 183.

LEVESON, N. G. Software safety: Why, what, and how. ACM Comput. Surv., ACM, New York, NY, USA, v. 18, n. 2, p. 125-163, jun. 1986. ISSN 0360-0300. Disponível em: $<$ http://doi.acm.org/10.1145/7474.7528>. Citado na página 40.

LEVESON, N. G. Software safety in embedded computer systems. Commun. ACM, ACM, New York, NY, USA, v. 34, n. 2, p. 34-46, fev. 1991. ISSN 0001-0782. Disponível em: $<$ http://doi.acm.org/10.1145/102792.102799>. Citado na página 52.

LEVESON, N. G. Safeware: System Safety and Computers. New York, NY, USA: ACM, 1995. ISBN 0-201-11972-2. Citado 3 vezes nas páginas 29, 43 e 50.

LINZHANG, W. et al. Generating test cases from uml activity diagram based on gray-box method. In: Proceedings of the 11th Asia-Pacific Software Engineering Conference. Washington, DC, USA: IEEE Computer Society, 2004. (APSEC '04), p. 284-291. ISBN 0-7695-2245-9. Disponível em: <http://dx.doi.org/10.1109/APSEC.2004.55>. Citado na página 144.

LONCHAMP, J. A structured conceptual and terminological framework for software process engineering. In: In Proceedings of the Second International Conference on the Software Process. [S.1.]: IEEE Computer Society Press, 1993. p. 41-53. Citado 2 vezes nas páginas 105 e 106.

LUCRÉDIO, D. Uma abordagem orientada a modelos para reutilização de software. Tese (Doutorado) - Universidade de São Paulo, São Carlos, SP, 2009. Citado 39 vezes nas páginas $54,55,57,58,60,61,88,89,105,106,116,121,125,135,140,142,148,149,151,152,153$, $155,157,158,159,160,162,163,164,166,171,172,173,174,178,179,180,181$ e 182.

LUTZ, R. R. Software engineering for safety: A roadmap. In: Proceedings of the Conference on The Future of Software Engineering. New York, NY, USA: ACM, 2000. (ICSE '00), p. 213-226. ISBN 1-58113-253-0. Disponível em: <http://doi.acm.org/10.1145/336512.336556>. Citado 4 vezes nas páginas 44, 49, 51 e 52 .

LUTZ, R. R.; WONG, J. S. Detecting unsafe error recovery schedules. IEEE Trans. Software Eng., v. 18, n. 8, p. 749-760, 1992. Citado na página 52.

M2T. JET (Java Emitter Templates). 2007. C Citado na página 69. 
MAIDEN, N.; ALEXANDER, I. Scenarios, stories, use cases : through the systems development life-cycle. Chichester: J. Wiley and sons, 2004. ISBN 0-470-86194-0. Disponível em: $<$ http://opac.inria.fr/record=b1105823>. Citado na página 142.

MATHWORKS. MATRIXx tech note. [S.1.]. Disponível em: <http://www.mathworks.com/ support/tech-notes/2200/2201.html>. Citado na página 174.

MATSUMOTO, Y. Some experiences in promoting reusabel software: Presentation in higher abstract levels. IEEE Trans. Software Eng., v. 10, n. 5, p. 502-513, 1984. Citado na página 29.

MAUW, S.; WIERSMA, W. T.; WILLEMSE, T. A. C. Language-driven system design. International Journal of Software Engineering and Knowledge Engineering, v. 14, n. 6, p. 625-663, 2004. Disponível em: <http://dx.doi.org/10.1142/S0218194004001828>. Citado na página 180.

MCDERMID, J. A. Software safety: Where's the evidence? In: Proceedings of the Sixth Australian Workshop on Safety Critical Systems and Software - Volume 3. Darlinghurst, Australia, Australia: Australian Computer Society, Inc., 2001. (SCS '01), p. 1-6. ISBN 0-909-92581-X. Disponível em: <http://dl.acm.org/citation.cfm?id=563780.563781>. Citado na página 50.

MCGREGOR, J. Agile software product lines, deconstructed. Journal of Object Technology, v. 7, n. 8, p. 7-19, 2008. Disponível em: <http://dblp.uni-trier.de/db/journals/jot/jot7.html\# McGregor08e>. Citado na página 118.

MCILROY, M. D. Mass-produced software components. Proc. NATO Conf. on Software Engineering, Garmisch, Germany, Springer-Verlag, 1968. Citado na página 29.

MELLOR, S. J.; BALCER, M. Executable UML: A Foundation for Model-Driven Architectures. Boston, MA, USA: Addison-Wesley Longman Publishing Co., Inc., 2002. ISBN 0201748045. Citado na página 175.

MELLOR, S. J.; CLARK, A. N.; FUTAGAMI, T. Guest editors' introduction: Model-driven development. IEEE Software, v. 20, n. 5, p. 14-18, 2003. Citado 4 vezes nas páginas 53, 54, 55 e 72 .

MENS, T.; GORP, P. V. A taxonomy of model transformation. Electron. Notes Theor. Comput. Sci., Elsevier Science Publishers B. V., Amsterdam, The Netherlands, The Netherlands, v. 152, p. 125-142, mar. 2006. ISSN 1571-0661. Disponível em: $<$ http://dx.doi.org/10.1016/j.entcs.2005.10.021>. Citado 2 vezes nas páginas 55 e 68.

METZGER, A.; POHL, K. Variability management in software product line engineering. In: Companion to the Proceedings of the 29th International Conference on Software Engineering. Washington, DC, USA: IEEE Computer Society, 2007. (ICSE COMPANION '07), p. 186-187. ISBN 0-7695-2892-9. Disponível em: <http://dx.doi.org/10.1109/ICSECOMPANION.2007.83>. Citado na página 28.

MICHELL, G. D.; GUPTA, R. Hardware/software co-design. Proceedings of the IEEE, v. 85, n. 3, p. 349-365, Mar 1997. ISSN 0018-9219. Citado 2 vezes nas páginas 46 e 187.

MIL-STD-882B. System Safety Program Requirements (30 March). U.S. Dept. of Defense, U.S. Govt. Printing Office, Washington, D.C. 1984. Citado 2 vezes nas páginas 39 e 43.

MILLER, J.; MUKERJI, J. MDA Guide Version 1.0.1. [S.1.], 2003. Citado 5 vezes nas páginas 30, 57, 69, 70 e 72. 
MIT. Survey Guidelines. Massachusetts Institute of Technology, 2011. Disponível em: $<$ http://web.mit.edu/surveys/survey-guidelines.pdf>. Citado na página 114.

MITSCHING, R.; WEISE, C.; KOWALEWSKI, S. Design Patterns for Integrating Variability in Timed Automata. In: 2010 Fourth International Conference on Secure Software Integration and Reliability Improvement Companion (\{SSIRI-C)\}. [S.1.: s.n.], 2010. p. 38-45. Citado na página 95.

MODELING, O. source tool for U. Open source tool for UML modeling. 2011. Disponível em: $<$ http://www.papyrusuml.org/>. Citado 2 vezes nas páginas 111 e 188.

MOIR, I. Civil Avionics Systems. [S.1.]: John Wiley \& Sons Ltd, 2006. (Aerospace Series (PEP)). ISBN 0470029293. Citado na página 27.

MOON, M.; YEOM, K.; CHAE, H. S. An approach to developing domain requirements as a core asset based on commonality and variability analysis in a product line. IEEE Trans. Softw. Eng., IEEE Press, Piscataway, NJ, USA, v. 31, n. 7, p. 551-569, jul. 2005. ISSN 0098-5589. Disponível em: <http://dx.doi.org/10.1109/TSE.2005.76>. Citado na página 88.

MORAES, M. B. S. de. RiPLE-SC: An Agile Scoping Process for Software Product Lines. Dissertação (Mestrado) - Universidade Federal de Pernambuco, Recife, PE, 2010. Citado 2 vezes nas páginas 115 e 130.

MULLER, G. Opportunities And Challenges In Embedded Systems. 2008. Citado 2 vezes nas páginas 27 e 31 .

NORTHROP, L. M. et al. A Framework for Software Product Line Practice, Version 5.0. 2009. Disponível em: <http://www.sei.cmu.edu/productlines/framework.html>. Citado 7 vezes nas páginas 28, 29, 78, 112, 116, 155 e 199.

Object Management Group. OMG Systems Modeling Language (OMG SysML), V1.3. [S.1.], 2012. Citado 8 vezes nas páginas 34, 61, 62, 63, 64, 122, 128 e 142.

OLIVEIRA, A. L. de et al. A model-based approach to support the automatic safety analysis of multiple product line products. In: Proceedings of the IV Simpósio Brasileiro de Engenharia de Sistemas Computacionais. [s.n.], 2014. p. to apear. Disponível em: $<$ http://sbesc.lisha.ufsc.br/sbesc2014/dl175>. Citado 2 vezes nas páginas 146 e 147.

OMG. Meta Object Facility (MOF) 2.0 Core Final Adopted Specification. [S.1.], 2004. Disponível em: <http://www.omg.org/cgi-bin/doc?ptc/03-10-04>. Citado 2 vezes nas páginas 59 e 61.

omg. Meta Object Facility (MOF) Core Specification Version 2.0. [S.1.], 2006. (OMG Available Specification). Disponível em: <http://www.omg.org/cgi-bin/doc?formal/2006-01-01>. Citado na página 70.

OMG. XML Metadata Interchange (XMI). [S.1.], 2007. Citado na página 71.

OMG. UML Profile for MARTE: Modeling and Analysis of Real-Time Embedded Systems. 2009. Citado 3 vezes nas páginas 64, 65 e 66.

OMG. Meta Object Facility (MOF) 2.0 Query/View/Transformation Specification, Version 1.1. [S.1.], 2011. Disponível em: <http://www.omg.org/spec/QVT/1.1/>. Citado 2 vezes nas páginas 69 e 71. 
OMG. OMG Unified Modeling Language (OMG UML), Infrastructure, Version 2.4.1. [S.1.], 2011. Disponível em: <http://www.omg.org/spec/UML/2.4.1>. Citado 4 vezes nas páginas 71, 78,129 e 130.

OMG. OMG Unified Modeling Language (OMG UML), Superstructure, Version 2.4.1. 2011. Disponível em: <http://www.omg.org/spec/UML/2.4.1>. Citado na página 145.

OMG. OMG Object Constraint Language (OCL), Version 2.3.1. [S.1.], 2012. Disponível em: $<\mathrm{http}$ ///www.omg.org/spec/OCL/2.3.1/>. Citado na página 71.

OPTIMALJ. Using OptimalJ OptimalJ 3.1. 2002. Disponível em: <http://www.uio.no/studier/ emner/matnat/ifi/INF5120/v04/verktoy/UsingOptimalJ3.1.pdf>. Citado na página 69.

OQUENDO, F. Formally modeling software architectures with the uml 2.0 profile for $\pi$-ADL. ACM SIGSOFT Software Engineering Notes, p. 1-13, 2006. Citado na página 42.

ORTMEIER, F.; REIF, W.; SCHELLHORN, G. Deductive Cause-Consequence Analysis (DCCA). In: Proceedings of the 16th IFAC World Congress. [S.1.]: Elsevier, 2005. ISBN 978-3-902661-75-3. Citado na página 147.

OSTROFF, J. S. Formal methods for the specification and design of real-time safety critical systems. J. Syst. Softw., Elsevier Science Inc., New York, NY, USA, v. 18, p. 33-60, April 1992. ISSN 0164-1212. Disponível em: <http://portal.acm.org/citation.cfm?id=145180.145184>. Citado na página 27.

POLZER, A.; KOWALEWSKI, S.; BOTTERWECK, G. Applying software product line techniques in model-based embedded systems engineering. In: $\{$ ICSE $\}$ Workshop on Model-Based Methodologies for Pervasive and Embedded Software, 2009. \{MOMPES\} '09. [S.1.: s.n.], 2009. p. 2-10. Citado na página 95.

POLZER, A. et al. Managing complexity and variability of a model-based embedded software product line. v. 8, n. 1, p. 35-49, 2012. ISSN 1614-5046. Citado na página 95.

PORTER, J. et al. Models in software engineering. In: CHAUDRON, M. R. (Ed.). Berlin, Heidelberg: Springer-Verlag, 2009. cap. Towards Model-Based Integration of Tools and Techniques for Embedded Control System Design, Verification, and Implementation, p. 20-34. ISBN 978-3-642-01647-9. Disponível em: <http://dx.doi.org/10.1007/978-3-642-01648-6_3>. Citado 2 vezes nas páginas 28 e 104.

PRESSMAN, R. Engenharia de Software. McGraw Hill Brasil, 2011. ISBN 9788580550443. Disponível em: <http://books.google.com.br/books?id=y0rH9wuXe68C>. Citado na página 100.

PRIETO-DIAZ, R.; FREEMAN, P. Classifying software for reusability. IEEE Software, v. 18, n. 1, January 1987. Citado na página 29.

PUCCI, G. On the modelling and testing of recovery block structures. In: FTCS. IEEE Computer Society, 1990. p. 356-363. ISBN 0-8186-2051-X. Disponível em: <http://dblp.uni-trier.de/db/conf/ftcs/ftcs1990.html\#Pucci90>. Citado na página 170.

Pure Systems. pure::variants. 2012. Citado 3 vezes nas páginas 98, 123 e 153. 
QUADRI, I. R.; SADOVYKH, A.; INDRUSIAK, L. S. MADES: A SysML/MARTE high level methodology for real-time and embedded systems. In: ERTS2 2012: Embedded Real Time Software and Systems. [S.1.: s.n.], 2012. Citado 2 vezes nas páginas 27 e 156.

QUEIROZ, P. G. G. Uma abordagem de desenvolvimento de linha de produtos com uma arquitetura orientada a serviços. Dissertação (Mestrado) - ICMC-USP, 2009. Citado 3 vezes nas páginas 67,152 e 178 .

QUEIROZ, P. G. G.; BRAGA, R. T. V. Desenvolvimento de sistemas embarcados críticos: Técnicas e perspectivas. In: Proceedings of INCT-SEC internal workshop. [S.1.: s.n.], 2011. Citado na página 87.

QUEIROZ, P. G. G.; BRAGA, R. T. V. Combining marte-uml, sysml and cvl to build unmanned aerial vehicles. In: Proceedings of the Ninth International Conference on Software Engineering Advances. IARIA, 2014. p. 334-340. ISBN 978-1-61208-367-4. Disponível em: <http://www.ksi.edu/seke/Proceedings/seke/SEKE2014_Proceedings.pdf>. Citado 2 vezes nas páginas 103 e 104.

QUEIROZ, P. G. G.; BRAGA, R. T. V. A critical embedded system product line model-based approach. In: Proceedings of the Twenty-Sixth International Conference on Software Engineering \& Knowledge Engineering. Knowledge Systems Institute Graduate School, 2014. p. 71-75. ISBN 1-891706-35-7. Disponível em: <http: //www.ksi.edu/seke/Proceedings/seke/SEKE2014_Proceedings.pdf $>$. Citado 4 vezes nas páginas 27, 103, 104 e 109.

QUEIROZ, P. G. G.; BRAGA, R. T. V. Development of critical embedded systems using model-driven and product lines techniques: A systematic review. In: Proceedings of the 8th Brazilian Symposium on Software Components, Architectures, and Reuse. [S.1.]: IEEE, 2014. p. to appear. Citado 5 vezes nas páginas 87, 90, 97, 98 e 99 .

RA, Ø.; STRØM, T. Trends and Challenges in Embedded Systems - CoDeVer and HiBu Experiences. 2004. Citado 3 vezes nas páginas 27, 31 e 42.

RAHEJA, D. G.; ALLOCCO, M. Assurance Technologies Principles and Practices: A Product, Process, and System Safety Perspective. New Jersey, USA: Wiley, 2006. 449 p. ISBN 978-0471744917. Citado na página 49.

RAVI, S. et al. Security in embedded systems: Design challenges. ACM Trans. Embed. Comput. Syst., ACM, New York, NY, USA, v. 3, p. 461-491, August 2004. ISSN 1539-9087. Disponível em: <http://doi.acm.org/10.1145/1015047.1015049>. Citado na página 31.

REDMILL, F.; ANDERSON, T. Lessons in system safety: proceedings of the eighth Safety-Critical Systems Symposium, Southampton, UK, 2000. Springer, 2000. ISBN 9781852332495. Disponível em: <http://books.google.com.br/books?id=HsceAQAAIAAJ>. Citado na página 29.

ROBBES, R.; LANZA, M. Example-based program transformation. In: CZARNECKI, K. et al. (Ed.). MoDELS. [S.1.]: Springer, 2008. (Lecture Notes in Computer Science, v. 5301), p. 174-188. ISBN 978-3-540-87874-2. Citado na página 181.

ROBERTSON, S.; ROBERTSON, J. Mastering the Requirements Process (2Nd Edition). [S.1.]: Addison-Wesley Professional, 2006. ISBN 0321419499. Citado na página 126. 
RTCA. Software Considerations in Airborne Systems and Equipment Certification. Radio Technical Commission for Aeronautics (RTCA), European Organization for Civil Aviation Electronics (EUROCAE), DO178-B, 1992. Citado na página 43.

RUMBAUGH, J.; JACOBSON, I.; BOOCH, G. Unified Modeling Language Reference Manual. 2. ed. [S.1.]: Addison-Wesley Professional, 2004. 576 p. Hardcover. ISBN 0321245628. Citado na página 141.

RUSHBY, J. A comparison of bus architectures for safety-critical embedded systems. In: . [S.1.]: Springer-Verlag, 2001. p. 306-323. Citado 3 vezes nas páginas 28, 42 e 44.

SAHRAOUI, A.-E.-K. Requirements traceability issues: Generic model, methodology and formal basis. International Journal of Information Technology and Decision Making, v. 4, n. 1, p. 59-80, 2005. Citado na página 134.

SANGIOVANNI-VINCENTELLI, A. et al. Metamodeling: An emerging representation paradigm for system-level design. Design Test of Computers, IEEE, v. 26, n. 3, p. 54-69, May 2009. ISSN 0740-7475. Citado 2 vezes nas páginas 156 e 157.

SCHMID, K. Scoping software product lines: An analysis of an emerging technology. In: Proceedings of the First Conference on Software Product Lines : Experience and Research Directions: Experience and Research Directions. Norwell, MA, USA: Kluwer Academic Publishers, 2000. p. 513-532. ISBN 0-79237-940-3. Disponível em: $<$ http://dl.acm.org/citation.cfm?id=355461.357568>. Citado na página 115.

SCHMID, K.; VERLAGE, M. The economic impact of product line adoption and evolution. IEEE Softw., IEEE Computer Society Press, Los Alamitos, CA, USA, v. 19, n. 4, p. 50-57, jul. 2002. ISSN 0740-7459. Disponível em: <http://dx.doi.org/10.1109/MS.2002.1020287>. Citado 2 vezes nas páginas 113 e 118 .

SCHMIDT, D. C. Model-driven engineering. IEEE Computer, v. 39, n. 2, February 2006. Disponível em: <http://www.truststc.org/pubs/30.html>. Citado 3 vezes nas páginas 53, 61 e 187.

SCIENTIFIC, B. Pacemaker system specification. 2007. Disponível em: <http://sqrl.mcmaster. ca/_SQRLDocuments/PACEMAKER.pdf>. Citado na página 190.

SENDALL, S.; KOZACZYNSKI, W. Model transformation: The heart and soul of model-driven software development. IEEE Softw., IEEE Computer Society Press, Los Alamitos, CA, USA, v. 20, n. 5, p. 42-45, set. 2003. ISSN 0740-7459. Disponível em: $<$ http://dx.doi.org/10.1109/MS.2003.1231150>. Citado na página 68.

Shimabukuro Junior, E. K. Um gerador de aplicações configurável. Dissertação (Mestrado) Universidade de São Paulo, São Carlos, SP, 2006. Citado 3 vezes nas páginas 68, 69 e 77.

SHOOMAN, M. Avionics software problem occurrence rates. 2013 IEEE 24th International Symposium on Software Reliability Engineering (ISSRE), IEEE Computer Society, Los Alamitos, CA, USA, v. 0, p. 55, 1996. ISSN 1071-9458. Citado na página 50.

SIFAKIS, J. Modeling real-time systems - challenges and work directions. In: In Proceedings of the 1st International Workshop on Embedded Software (EMSOFT), Lecture Notes in Computer Science. [S.1.]: Springer Verlag, 2001. p. 373-389. Citado na página 27. 
SIFAKIS, J. Embedded systems - challenges and work directions. In: OPODIS. [S.1.: s.n.], 2005. p. 184-185. Citado 3 vezes nas páginas 27,39 e 41.

SINGHOFF, F. et al. Cheddar: A flexible real time scheduling framework. In: Proceedings of the 2004 Annual ACM SIGAda International Conference on Ada: The Engineering of Correct and Reliable Software for Real-time \&Amp; Distributed Systems Using Ada and Related Technologies. New York, NY, USA: ACM, 2004. (SIGAda '04), p. 1-8. ISBN 1-58113-906-3. Disponível em: <http://doi.acm.org/10.1145/1032297.1032298>. Citado na página 195.

SIQUEIRA, F. L.; SILVA, P. S. M. An essential textual use case meta-model based on an analysis of existing proposals. In: LENCASTRE, M.; ESTRADA-ESQUIVEL, H.; FIGUEIREDO, E. (Ed.). WER. [S.1.: s.n.], 2011. ISBN 978-85-8006-032-4. Citado na página 144.

SMARAGDAKIS, Y.; BATORY, D. Application generators. In: in Software Engineering volume of the Encyclopedia of Electrical and Electronics Engineering. [S.1.]: John Wiley and Sons, 2000. p. 200-0. Citado na página 67.

SOARES, M. dos S. Architecture-Driven Integration of Modeling Languages for the Design of Software-Intensive Systems. Tese (Doutorado) - Universidade Técnica de Delft, Delft, Holanda, 2010. Citado na página 40.

SOARES, M. dos S.; VRANCKEN, J. Requirements specification and modeling through sysml. In: Systems, Man and Cybernetics, 2007. ISIC. IEEE International Conference on. [S.1.: s.n.], 2007. p. 1735-1740. Citado 5 vezes nas páginas 62, 63, 119, 128 e 134.

SOARES, M. dos S.; VRANCKEN, J. L. M. Model-driven user requirements specification using sysml. $J S W$, v. 3, n. 6, p. 57-68, 2008. Citado 6 vezes nas páginas 121, 126, 129, 130, 143 e 158.

STAHL, T.; VOELTER, M.; CZARNECKI, K. Model-Driven Software Development: Technology, Engineering, Management. [S.1.]: John Wiley \& Sons, 2006. ISBN 0470025700. Citado na página 56.

STANDARDIZATION, I.-I. O. for. 26262-6:2011(E) Annex D: road vehicles-functional safety. [S.1.], 2011. Citado na página 120.

STANDISH. Chaos: A Recipe for Success. Standish Group International, 1999. Citado 2 vezes nas páginas 119 e 120.

STEINBERG, D. et al. EMF: Eclipse Modeling Framework 2.0. 2nd. ed. [S.1.]: Addison-Wesley Professional, 2009. ISBN 0321331885. Citado na página 28.

STOREY, N. R. Safety Critical Computer Systems. Boston, MA, USA: Addison-Wesley Longman Publishing Co., Inc., 1996. ISBN 0201427877. C Citado 2 vezes nas páginas 49 e 169.

SVENDSEN, A. et al. Cvl tool - modeling variability in spls. In: BOTTERWECK, G. et al. (Ed.). SPLC Workshops. Lancaster University, 2010. p. 299. ISBN 978-1-86220-274-0. Disponível em: $<$ http://dblp.uni-trier.de/db/conf/splc/splc2010w.html\#SvendsenZFHOM10>. Citado 2 vezes nas páginas 111 e 188.

Svendsen, A. et al. Developing a software product line for train control: A case study of cvl. In: BOSCH, J.; LEE, J. (Ed.). SPLC. [S.1.]: Springer, Sep. 2010. (Lecture Notes in Computer Science, v. 6287), p. 106-120. ISBN 978-3-642-15578-9. Citado 2 vezes nas páginas 135 e 136. 
SZYPERSKI, C. Component Software: Beyond Object-Oriented Programming. 2nd. ed. Boston, MA, USA: Addison-Wesley Longman Publishing Co., Inc., 2002. ISBN 0201745720. Citado na página 29.

TAYLOR, R. N.; MEDVIDOVIC, N.; DASHOFY, E. M. Software Architecture: Foundations, Theory, and Practice. [S.1.]: Wiley Publishing, 2009. ISBN 0470167742, 9780470167748. Citado na página 155.

THÜM, T. et al. Featureide: An extensible framework for feature-oriented software development. Sci. Comput. Program., Elsevier North-Holland, Inc., Amsterdam, The Netherlands, The Netherlands, v. 79, p. 70-85, jan. 2014. ISSN 0167-6423. Disponível em: <http://dx.doi.org/10.1016/j.scico.2012.06.002>. Citado 4 vezes nas páginas 79, 112, 131 e 188.

THÜM, T. et al. Abstract features in feature modeling. In: Proceedings of the 2011 15th International Software Product Line Conference. Washington, DC, USA: IEEE Computer Society, 2011. (SPLC '11), p. 191-200. ISBN 978-0-7695-4487-8. Disponível em: $<$ http://dx.doi.org/10.1109/SPLC.2011.53>. Citado na página 79.

TIAKO, P. Designing Software-intensive Systems: Methods and Principles. Information Science Reference, 2009. (IT Pro). ISBN 9781599047010. Disponível em: <http: //books.google.com.br/books?id=YTPF08oDb0UC>. Citado na página 40.

TOKUMOTO, S. Product line development using multiple domain specific languages in embedded systems. In: \{CEUR\} Workshop Proceedings. [S.1.: s.n.], 2010. v. 644, p. 125-129. Citado na página 96.

TOLVANEN, J.-P. Making model-based code generation work. 2004. 36 - 38 p. Citado 2 vezes nas páginas 60 e 66.

TOLVANEN, J.-P.; KELLY, S. Defining domain-specific modeling languages to automate product derivation: Collected experiences. In: Proceedings of the 9th International Conference on Software Product Lines. Berlin, Heidelberg: Springer-Verlag, 2005. (SPLC'05), p. 198-209. ISBN 3-540-28936-4, 978-3-540-28936-4. Disponível em: <http://dx.doi.org/10.1007/11554844_22>. Citado 3 vezes nas páginas 88, 150 e 180.

TRUJILLO, S. et al. Feature-oriented refinement of models, metamodels and model transformations. In: \{ACM\} International Conference Proceeding Series. [S.1.: s.n.], 2009. p. 87-94. ISBN 9781605585673. Citado na página 96.

UNMANNED DYNAMICS LLC. The AeroSim Blockset User's Guide. [S.1.]. Citado na página 183.

VANDERPERREN, Y.; DEHAENE, W. From uml/sysml to matlab/simulink: Current state and future perspectives. In: Proceedings of the Conference on Design, Automation and Test in Europe: Proceedings. 3001 Leuven, Belgium, Belgium: European Design and Automation Association, 2006. (DATE '06), p. 93-93. ISBN 3-9810801-0-6. Disponível em: $<$ http://dl.acm.org/citation.cfm?id=1131481.1131512>. Citado na página 174 .

VARRó, D. Model transformation by example. In: NIERSTRASZ, O. et al. (Ed.). MoDELS. [S.1.]: Springer, 2006. (Lecture Notes in Computer Science, v. 4199), p. 410-424. ISBN 3-540-45772-0. Citado na página 181. 
VISSER, E. Generative and transformational techniques in software engineering ii. In: LäMMEL, R.; VISSER, J.; SARAIVA, J. a. (Ed.). Berlin, Heidelberg: Springer-Verlag, 2008. cap. WebDSL: A Case Study in Domain-Specific Language Engineering, p. 291-373. ISBN 978-3-540-88642-6. Disponível em: <http://dx.doi.org/10.1007/978-3-540-88643-3_7>. Citado na página 180.

VISSER, P. S.; KROSNICK, J. A.; LAVRAKAS, P. J. Survey research. NY, USA: Cambridge University Press, 2000. Citado na página 34.

VOELTER, M. Implementing feature variability for models and code with projectional language workbenches. In: Proceedings of the 2nd International Workshop on Feature-Oriented Software Development, \{FOSD'10\}. [S.1.: s.n.], 2010. p. 41-48. ISBN 9781450302081. Citado na página 96.

VOELTER, M.; GROHER, I. Product line implementation using aspect-oriented and model-driven software development. In: Software Product Line Conference, 2007. SPLC 2007. 11th International. [S.1.: s.n.], 2007. p. 233-242. Citado 2 vezes nas páginas 88 e 89.

VöLTER, M. A catalog of patterns for program generation. In: HENNEY, K.; SCHüTZ, D. (Ed.). EuroPLoP. [S.1.]: UVK - Universitaetsverlag Konstanz, 2003. p. 285-320. ISBN 978-3-87940-788-0. Citado na página 182.

WARMER, J.; KLEPPE, A. The Object Constraint Language: Getting Your Models Ready for MDA. 2. ed. Boston, MA, USA: Addison-Wesley Longman Publishing Co., Inc., 2003. ISBN 0321179366. Citado na página 146.

WEHRMEISTER, M. A. An aspect-oriented model-driven engineering approach for distributed embedded real-time systems. Tese (Doutorado), Porto Alegre, Brasil, 2009. Citado na página 65.

WEISS, D. M.; LAI, C. T. R. Software product-line engineering: a family-based software development process. Boston, MA, USA: Addison-Wesley Longman, 2004. 448 p. ISBN 0-201-69438-7. Citado 3 vezes nas páginas 30, 77 e 113.

WEISS, D. M. et al. Decision-model-based code generation for sple. In: SPLC. [S.1.]: IEEE Computer Society, 2008. p. 129-138. ISBN 978-0-7695-3303-2. Citado na página 88.

WHITTLE, J.; HUTCHINSON, J.; ROUNCEFIELD, M. The state of practice in model-driven engineering. IEEE Software, IEEE Computer Society, Los Alamitos, CA, USA, v. 31, n. 3, p. 79-85, 2014. ISSN 0740-7459. Citado na página 53.

WIMMER, M. et al. Towards model transformation generation by-example. In: Proceedings of the 40th Annual Hawaii International Conference on System Sciences. Washington, DC, USA: IEEE Computer Society, 2007. (HICSS '07), p. 285b-. ISBN 0-7695-2755-8. Disponível em: <http://dx.doi.org/10.1109/HICSS.2007.572>. Citado 2 vezes nas páginas 178 e 181.

WIRSING, M.; HöLZL, M. Software Intensive Systems. In: PLEXOUSAKIS, D. (Ed.). Anticipating Future and Emerging Information Society Technologies, ERCIM EEIG. [s.n.], 2006. Disponível em: <http://www.pst.ifi.lmu.de/veroeffentlichungen/2006/wirsing_hoelzl-software_ intensive_systems-2006.pdf>. Citado 2 vezes nas páginas 40 e 44.

WOLF, W. Computers As Components, Second Edition: Principles of Embedded Computing System Design. 2nd. ed. San Francisco, CA, USA: Morgan Kaufmann Publishers Inc., 2008. ISBN 0123743974, 9780123743978. Citado na página 45. 
XU, D.; MIAO, H.; PHILBERT, N. Model checking uml activity diagrams in fdr. In: Computer and Information Science, 2009. ICIS 2009. Eighth IEEE/ACIS International Conference on. [S.1.: s.n.], 2009. p. 1035-1040. Citado na página 146.

YGLESIAS, K. P. Information reuse parallels software reuse. IBM Systems Journal, v. 32, n. 4, p. 615-620, 1993. Citado na página 29. 